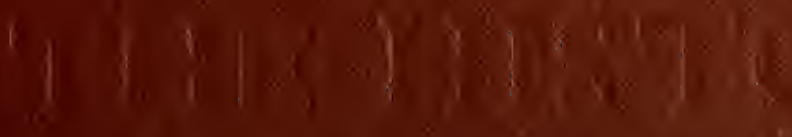

$\int x^{2}\left|y^{2}\right|$

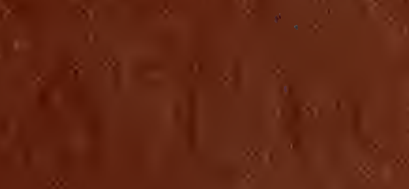





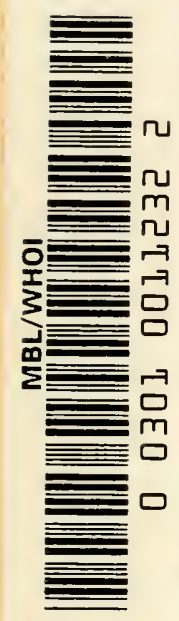



The History of Civilization

The Earth before History 


\section{The History of Civilization}

In the Section of this Series devoted to PRE-HisToRY AND ANTIOUITY are included the following volumes:-

\section{Introduction and Pre-History}

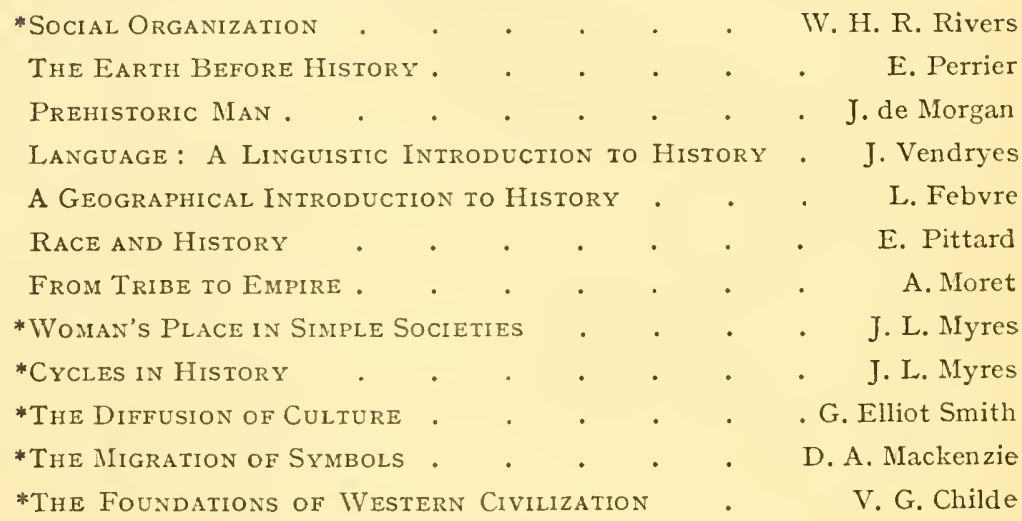

\section{The Early Empires}

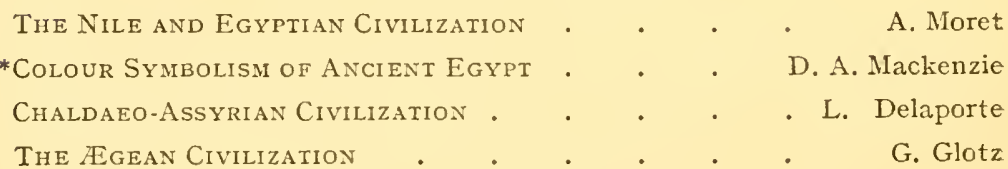

* An asterisk indicates that the volume does not form part of the French collection " L'Évolution de l'Humanite" (of which the present work is No. I of the First Section), published under the direction of M. Henri Perr, Editar of the "Revue de Synthèse Historique ".

A full list of the SERIES will be formd at the end of this volume. 


\title{
The
}

\section{Earth before History}

Man's Origin and the Origin of Life

\author{
By \\ EDMOND PERRIER
}

Late Professor of Comparatize Anatomy at the Muséum d'Histoire Naturelle, Alembre de I'Acadímie des Scionces et de I'Acadénie de Mtedécine.

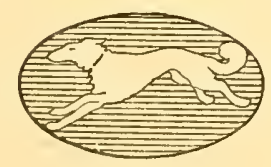

NEW YORK

ALFRED A. KNOPF 
Translated by

PAUL RADIN, Ph.D.

Late Associate Professor of Anthropology in the University of California, and

V. C. C. COLlum 


\section{GENERAL INTRODUCTION}

TWO circumstances, quite different in nature, make the present time particularly' favourable for the writing of a Universal History: on the one hand, the development of historical studies, and, on the other, the growth of world-conditions in which all countries share.

For almost a century now an ever increasing number of students-anthropologists, historians, archaologists-have been extending, with commendable patience, their researches along all lines and into the most remote corners of man's past. The tremendous mass of detailed knowledge thus accumulated was bound eventually to force upon scholars the necessity for some kind of synthesis, and this need has made itself felt most imperatively in a desire for some co-ordinating point of view from which it would be possible to dominate Time.

$Y$ et the work of the historians, no matter how impartial it may appear, does not merely respond to interagl law's but is also subject to external influences to a certain extent. If, for instance, any particular trait may be regarded as characteristic of our present epoch it is the human solidarity encountered all over the earth. Our planet seems to have shritnk in size through the rapidity of communication and civilized nations have developed such intimate relations either between one another or through intensive colonization, with less developed peoples, that, as in an organism, everything seems to be inter-connected. To-day we have a world-politics, a world-cconomics, a worldcivilization. This visible spatial and temporal unity in human groups invites us to reflect upon the rôle which the universal factor has played from the beginnings of time.

Thus, apart from the works devoted to facts and individuals, to countries, peoples, and successive epochs, we have the Earth and Humanity left as objects that must be studied.

In Germany, during the years preceding the war, the study of universal history flourished-under the name of "Weltge- 
schichte". In that home of erudition and adventurous synthesis, where a balance between "micrography" and metaphysics is seldom achieved, the arduous labour of historians and a preoccupation with world affairs have resulted in the appearance of mmerous works, unequal in importance and interest, which endeavoured to satisfy, and at the same time have stimulated, the demand for universal history. Some of these volumes are merely collections of chapters, compilations without unity, others are systematized to an excessive degree; some are co-operative, and are the result of more or less definite collaboration, others represent the enterprise, rash though it may have been, of one man. Yet all possess merits, whatever be the criticism to which they lend themselves. But there is room for a new synthesis, for a vast enterprise, on new foundations, which shall include Humanity, from its origins, and the Earth as a whole.

The work which this introductory volume is to inaugurate will have the following special features:

It will have a real unity: not merely the unity of its subjecthistory in its entirety-but unity of plan, firmly binding together all the various parts; and also unity of the activating ideas. The problem with which we are faced is how to prevent incoherence and yet to avoid the opposite error of over-systematization. In the present state of our knowledge, a single individual cannot accomplish this task alone, and even to organize it he must exercise very great discretion. Certain ideas will run through the whole enterprise, but they will not be dominating theories thrust upon the collaborators, and, throngh them, upon the facts; rather will they be experimental ideas, hypotheses pervading the whole work, and subjected to the control of actual facts by unfettered investigation, allowing complete autonomy to the collaborators. Onr undertaking is thus something in the nature of a vast experiment, to be gradually undertaken under the eyes of the public to the great profit, as we hope, of historical science; and the ideas put forward will emerge from the test either confirmed or rectified.

Within this unity of the whole each part will have its own unity. The series has not been planned in terms of large collective volumes, grouping together more or less unconnected chapters written by various collaborators, but as independent volumes of moderate size. The number of these will, therefore, be considerable, 
since they will correspond to the great problems and the organic divisions of history; and each, as far as this is possible, will be entrusted to a single scholar of recognized authority. Each will be an independent work, will carry the imprint of one personality, and will be the more interesting in that it will have bcen written with greater freedom and pleasure. Each volume will have its own life; so too will a given group of volumes, and they will thus, from different view-points, form a whole within a whole, partial syntheses within a total synthesis. Our task, in short, is to combine the advantages of an historical encyclopedia with those of a continuous history of human evolution.

Having thus indicated the general characteristics of our enterprise, let us proceed to the principles which will govern the undertaking as a whole, and to the general character of the volumes themselves.

To unite Science and Life: such is the formula which expresses the ideal we desire to attain.

This series is to be essentially a work of scholarship. Not only will it offer the most authoritative knowledge, but this knowledge will be amply documented-as we shall shortly explain. Any learned synthesis, which gives results without indicating the sources, presupposes an act of faith, since it does not facilitate verification and must in a way appear to lead to stagnation in research, since it does not provide the impetus to proceed further. But if we set forth an inventory of the work accomplished we can not only indicate all that remains to be done but procure the means for accomplishing it. From the standpoint of scholarship, then, our undertaking vill at once mark achievement and provide a point of departure for work still to be done.

But the aim of the series is not merely to be erudite: it is also to be scientific in the full sense of that term. Scholarship may enable us to prepare and assemble materials : it is science alone, however, that brings order into them. Indeed, one of the most subtle problems confronting the human mind is that concerned with the scientific nature of history. To arrange facts in series, in traditional comparments, to recount the lives of individuals or of peoples, this has nothing to do with science-for its proper work is to generalize and to elicit principles of explanation.

Without claiming that the method of scientific synthesis can 
actually be fixed for history in any definite fashion, it may be assumed-at least, as a tentative hypothesis-that the facts of which human evolution is woven, can be grouped in three quite distinct orders. The first are the contingent, the second the necessary, and the third those that relate to some imner logic. We shall try to make use of and to harnonize the very diverse explanations that have been attempted, by endeavouring to show that the whole content of human evolution falls into these general divisions of contingency, necessity, and logic. It seems to us that by this tripartite division, history receives both its natural articulation and its whole explanation. Indeed, this classification opens up a deeper view of causality. It invites us to probe into the mass of historical facts and to attempt to disentangle three kinds of cansal relations: mere succession, where the facts are simply determined by others: velations that are constant, where the facts are linked to others by necessity: and internal linkage, where the facts are rationally connected with others. On this view of the nature of the causes operating in history, a synthesis may not appear easy, but it is at least conceivable. We have developed this methodological hypothesis ${ }^{1}$ at length elserehere; here we would merely summarize briefly its general bearings.

For societies to take form and to endure they must submit to certain special and necessary conditions which we call institutions. Wherever a society exists there are institutions-at any rate, in outline. We encounter the same fundamental institutions everywhere, although under different forms; but this diversity is not unlimited in its characteristics, a fact that is to be explained, in part, by the differences existing in the very structure of societies-that is to say, in the number of social units and their concentration or density. "Sociology," when it is conscious and scientific looks upon socicties merely as such. The proper work of the sociologist is the study of social organization from the comparative point of view. In order the better to define its essential functions as translated into institutions, and in order to determine the connexions of these functions with the social structure and their reciprocal inter-relationships, it isolates the social element. This is one of the aspects of historical synthesis, yet only one. A complete historical synthesis brings this element, these necessities or social lare's, into renewed contact 
with the other elements of history, clements neglected and, indeed, often denied by the pure sociologist.

It is also desirable in any attempt to differentiate between various explanatory elements to make the following distinction. Even if institutions are always a social construction, so to speak, and bear the stamp of society, it does not follow from this that they aliway's express the specific necessities of society or respond to actual functions. Not everything which, in the course of the life of society, takes on an institutional form is essentially social.

The juridico-political function is an essential characteristic of society and it differentiates itself into political, juridical, and moral elements; its only reason for existence is in, and for, society, of which in fact it forms the chief support. Just as economic institutions correspond to the personal necessities of the individual-the necessities of subsistence, of enjoyment, and of luxury-so we may speak of an economic function of society; theoretically it might even be considered as primary, for society can only be organized by giving to these needs of the individual a more secure and complete satisfaction by appropriate means and by substituting, to a great extent, co-operation and division of labour for individual effort. But we camot accurately speak of a mental or asthetic function of society, although institutions have been built up with art and science in view. Society does not think. Mental development as well as esthetic-from the most rudimentary technique to the efflorescence of philosophy, science, and art-rests essentially' on the faculties of the individual: it is human not social. Of course, this human development is only possible within socicty. Between the human and the social there is constant action and reaction, and with the very beginnings of thought we are confronted by the problem of the nature of this interrelation between the individual-as a thinking beingand society. It develops particularly with that very complex group of phenomena which we call religious. But in spite of appearances we believe it to be as impossible to speak of a religious function of society as of a mental or cesthetic one. Religion consists fundamentally of a comnected system of beliefs and practices related to a given milien and to forces surrounding and transcending those of man: in other words, it is an interpretation of the objects by which hmman activity tends to be regulated. It gives expression to the most profound anxieties of developing thought and amalgamates them with the most varied 
psychical elements. It is human in essence-but strongly socialized. The possession of specific institutions does not suffice for religion; it must also enter into the various functions of social life. In short it consolidates into one unified whole the social bond and simple primitive mentality-consolidating the one by means of the other. In thus strengthening thought, however, it at the same time confines and tends to constrain it; and, moreover, the individual endeavours either to transform the religious institutions or, to a certain extent, to free himself from them; it is io this effort that art, philosophy and science specifically owe their development.

If, then, the study of the social factor is at the basis of historical synthesis, since society is man's necessary milieu and a constant and regular element in history, it is just as clear that the evolution of society, as such, as well as its complications, only become intelligible when considered in the light of other factors. It is therefore necessary to introduce that "logical" factor which has already been so much abused, under the terms "finality" and "Idea", by philosophic historians, and the factor of contingency, of rohich purely descriptive historians have made too exchisive and complacent a use; the latter being also known as the principle of change as such, fortuitous or directed.

Contingencies modify the structure of human society; they either react on them or influence them directly. Their number in history is infinite, but they can be brought together under cerain genera! categories: accidental happenings, the rôle of the individual as individual, temporary collective arrangements, and ethnic and geographical conditions. Neither the categories themselves nor the contingencies within each category are of equal interest to the historian who is concerned with explanation. Their importance is determined by the extent and the duration of their action: surroundings races, and epochs can be grouped from the point of view of human evolution; individuals and events can be selected from the same standpoint; some are insignificant, others important. Our mind can only dominate and systematize the past by resorting to elimination-just as chance has unfortunately done with remote epochs. But we must consign again to oblivion something of what has been selected.

It is when we thus reject negligible events that tile rôle of 
"logic" in the life of societies is best realized. The logical factor is explanatory in the deepest sense of the roord. It is what gives to evolution its real continnity, its inner law; it is from their connexion with it and exactly to the degree in which they either serve or contradict logic that contingent happenings derive their actual value. They lead to others : but it is the logical factor which alone produces new events: it alone is creative. The principle from which all logic proceeds, the real motive force of history-as of life-can only be discovered, it seems to us, in the tendency of a human being to maintain and expand his personality. Life is not a passive and empty thing. It is tendency and memory. When successful it retains the means that led to its success. Logic, strictly speaking, is the profitable use of mind; in the broader sense, however, it is that activity which conforms to the fundamental tendencies of the being who employs appropriate means. Springing from the inner core of life the logical activity ends by both in co-operation and in struggle, but expands more in the form of social instinct than as egotism; in short it creates society itself.

Once society has been formed and endowed with specific laws, the principle that gave it birth continues to aid in its development. The same logic that laid the foundation for the social organism produces in large measure the inner phenomena of crisis and reform, of political, juridico-moral and economic evolution. It manifests itself in the external activity of social groups and in inter-social connexions by means of various phenomena, all of vital historical interest. There is, for instance, the phenomenon of " migration", to explain which it is not enough to give an account of the pressure of geographical surroundings, but which through a "Will to Change", gives expression to that restlessness which craves for a better existence, to the desire for a habitat favourable to life, and, undoubtedly also, to an ambition to enlarge the sphere of the known and to secure a larger possession of the earth. There is the phenomenon of "Imperialism"which tends, by a "Will to Growth", to seize possession, for divers purposes, of a larger or smaller part of humanity. It has, moreover, various types, some more violent, others of a more assimilative nature. There are finally the phenomena of "receptivity", of "renaissance", of international "co-operation"-which, by a "Will to Culture", tend to unite societies, across space and time, in order that they may conquer nature and 
adapt it to human needs, and to render them more and nore at one through the creation and multiplication of "values" of all kinds.

In connexion with the manifestations of this social logic which concerns either the inner life or the external activity of societies-there arises a very important and subtle question and one which has already presented itself in regard to mental evolution, namely the rôle of the individual and his relation to society. We have seen that mental development introduced into social organization elements that were human in originthat is to say, individual-and remodelled the "Institutional" form without, however, entively depriving the individual of his specific faculty of thinking. Indeed, in addition to being the agent of mental logic, the individual is also, it seems, the agent of social logic. These institutions which appear as something objective and with a large measure of constraining force, these actions of the group which spring apparently from a collective will, do not entively escape the consciousness of the individual. In fact, what is the "social conscionsness" - if we would not be duped by words-except the representation of society in the conscionsness of individuals? Even the most striking phenomena of social life, those that arise from what might be called " herd conditions", admit of an active participation of the individual, however effaced this may seem to be. In these states-which are essentially affective-although the individual representations are sharpened and have become harmonized through a common emotion, and although, to a certain degree, a unity of conscionsness can be temporarily realized, individuals are always found who unquestionably respond in a high degree to the needs of the group as regards canalizing and directing the manifestation : they are, in consequence, not simple elements of society but true social agents. But apart from these "herd" manifestationswhich for mumerous reasons have become less and less frequent in the course of history-can it be said that the representation of society has been especially unequal in intensity or in precision in the minds of different individuals? Sociely, let me repeat, does not think: it is the individual who thinks. He can, however, also be more than a social agent: an initiator, a social inventor. Mental and social logic have the same profound source and here they meet. Born of the success of activity, thought in the individual concerns itself with serving action and perfecting social life. 
It is difficult to deny the practical efficacy of ideas : we should rather endeavour to determine it.

In fine, to unravel the complicated skein of causality: to distinguish the "accidental" or the "crude facts" of history, the institutions or the social necessities, the needs or the fundamental causes that flower in the form of ideas within reflective thought: to study the play of these diverse elements-contingent, necessary, and logical-their reciprocal action and what may be called the rearrangement of causes: this should constitute the essential object of this synthesis. We must take care not to promise too much. Universal history-because of its extent, its complication, its lacunce, and the necessity for co-operation-does not permit a complete solution of these problems. Studies more limited in scope and at the same time more intensive alone can furnish decisive demonstrations. But for special studies to be suitably directed it is useful to have before us the general tendency of history as a whole. That is why we shall try, in the main at any rate, to make our work the opposite of milateral, to neglect none of the explanatory elements, but yet, by careful arrangement, to give to each its proper part. In distributing the subject-matter and in deciding upon the volumes to be included, certain hypotheses, dictated by the whole scope of the work, were, indeed, paramount. They have been indicated at the outset and will appear at different places in the introductions, but they will serve merely as a bondand that only discreetly. It would not be wise to rely on it unduly. Let it be remembered that the collaborators are free and that their liberty of action alone can give full value to this enterprise. This is no pre-arranged experiment-merely a simple experiment "to see", as Claude Bernard said. It is not a question of solving problems at all costs but rather of stating them and of introducing into universal history the leaven of true science.

$$
\text { * * * }
$$

Although profoundly scientific in intention this series will not, for that reason, be any the less alive. It has been supposed, quite erroneously, that the introduction of science into history is opposed to life, that the resurrection of the past is the privilege of art. It is analysis which reduces the past to a dust-heap of facts; what erudition collects is saved not from death but from oblivion. Synthesis resurrects the past, otherwise than does intuition, and better. Its task as defined by Michelet, "the 
resurrection of the whole of life not merely in its surface aspects but in its inner and deeper organisms", cannot be fulfilled by genius; but science can accomplish it by deepening its theory of causality and endeavouring, through its synthesis, to reconstitute the interplay of causes.

It is this purpose, then, that animates our work: to render intelligible by the study of its causes, and to enable us to follow that progressive movement-not contimuously and absolutely progressive, but as a whole and from certain points of viewwhich gives meaning to the life of humanity. Facts of every category-isolated by special historical acconnts and forming in general histories a mosaic of juxtaposed chapters-will all be considered in relation to the permanent needs and individual character of different societies. These societies, on the other hand, will be considered not for themselves but in their relation to the great transformations of humanity. We would not make of them entities or idols. But it is the way in which life changes and develops in human societies that constitutes the specific object of historical science. This is all that is meant, in short, by "civilization" or "culture", both handy and rather vague words. We shall not deprive ourselves of the use of the word "civilization": and since we cannot begin with a precise definition we shall in these volumes give it its broad meaningthe increasing complexity of life-relying upon the work itself to indicate what is essential in this complex whole and how the true line of progress is to be determined.

From the point of view of an ideal presentation, a practical difficulty presents itself. The publications will follow as far as possible the order of the general plan. It would have been easier, after the plan of the work had once been decided upon, to publish the volumes as soon as they were completed without reference to any order: but we should then have produced not a real work; we should only have formed a collection. On the principle adopted, however, the authors and the public will take a more lively interest in the enterprise. Each author will be in a position to adjust his work to those volumes nearest in scope, no matter how strong the personal element, and thus make his contribution fit into the whole. There are undoubtedly subjects whose position is not strictly determined: but apart from a very limited number of cases, the volumes will appear in the order arranged, and, in particular, that one series will not overlap another. 
By a series, we understand a group of volumes composed from different points of view, and on this a few words of explanation are necessary.

The divisions of universal history in their time relations, represent a very delicate problem which the Germans call "Periodisierung der Weltgeschichte", and here many kinds of mistakes and prejudices must be avoided. Chronological divisions are handy and even necessary compartments; but pushed too far, a pre-occupation with chronology tends, on the one hand, to split up the study of regions and peoples and, on the other hand, to bring on to the same plane phenomena of unequal importance from the cultural point of view (Lavisse and Rambaud). If chronology is subordinated to geographical and ethnical interests the thread is broken: we simply get a collection of histories for different regions of the world (Helmolt), or for different peoples (Duruy, Oncken, Heeren, Uckert, von Giesebrecht, and Lamprecht), and not a universal history. If, on the other hand, chronology is subordinated to logic the woof is knit too tight, and we get a metaphysical synthesis and not a science of history. The purely logical divisions-whether through the choice of centres of civilization or of preponderating races, they ascribe to humanity a succession of periods enclosed as it were the one within the other (the Philosophy of history, Hegel), or give all peoples a succession of identical periods (Lamprecht); whether they terminate in a continuous progress (German philosophers) or in an eternal recurrence (Vico) with or without progress-are all arbitrary, undesirable and condemned: but they are always reappearing, doubtless because they correspond to some element of historical reality.

We, for our part, shall attempt to reconcile these various interests. We shall have four large chronological sections: Introduction (pre-history and proto-history) and antiquity; Christian origins and the Middle Ages; the Modern era; and the Contemporary era. Each of these sections will comprise almost the same number of volumes although they will embrace shorter and shorter periods. This economy can be easily justified owing to the inequality of the resources at our disposal for the investigation of these periods and the practical utility afforded respectively by their study.

In these sections, the secondary divisions and, in turn, their units, will be so arranged as to satisfy, as far as this is possible, 
the interests of geography, ethnography-or the psychology of peoples-and logic. The pre-occupation with the whole as such, with human evolution, will no doubt be constantly in evidence: and from the very nature of things this will become increasingly prominent since, as we remarked before, human solidarity becomes more and more manifest as we proceed: but light will be thrown, in the course of our work, at the opportune moment and in the measure desired, upon those portions of the earth and upon those peoples whose infunce makes itself felt, and becomes preponderant. As to logic, if our conception of causality occupies too large a place it will yet be admitted that it has been entirely freed from its metaphysical and à priori nature: it has become merely one of the positive elements of history whose rôle is to be determined. Moreover, is not the fundamental principle of division here of an internal nature? Is it not derived from the complex nature of historical causality? As we have already indicated, our principal care will be to lay particular stress on the effect of great events, the pressure of social necessities, the profound influence of psychic factors, of needs and ideas, and thus to bring into relief not the continuity of progress but the three-fold play of the permanent causes and the results of their continuous operation. ${ }^{1}$

Our work, although it will have all the utility of an Encyclopedia, will, as we shall see, be something quite different. If it is true that a little science sterilizes history, a good deal of science ought to endow it with life. The pre-occupation with general and permanent causes, which enhances the worth of even the most modest research, will give our synthesis not only its full dignity but its full interest, and an element of dramatic attraction. We are concerned, in other words, with reconstructing the road along which humanity has travelled; the path which a blind instinct, obscure infuences, and a variety of circumstances have forced it to take; and in so doing we are attempting to understand why this path has been pursued. Along the ages, through the

1 After the main outlines of the plan had been sketched, I submitted it to the judgment of friends, and I have also sought the advice of specialists in assigning the various volumes. Although firmly adhering to the initial lines laid down, I have profited by the experience of numerous scholars and the suggestions of the most diverse types of men. I would like to mention among those who have been most intimately associated in the work of elaboration my friends Paul Lorquet, L. Barrau-Dihigo, Lucien Febvre, and Abel Rey. To these and others the plan owes some of its merits: for its defects I alone assume full responsibility. 
efforts, ambitions, struggles, and the diverse fates of groups, in spite of stumblings, detours, and setbacks-Humanity progresses. Its horizon, as we advance, becomes higher: it endeavours with the aid of the historian to adjust itself in time and space, to take cognizance of itself, to know more in order to do more. An enterprise like ours is consequently a living thing. And though it is the duty of the historian as a scholar to collect facts and to study their causes objectively and dispassionately, yet he has the right as a man to develop an cnthusiasm for his work and impart to it an inner fire.

Since our work must possess this living character a final problem confronts us. Shall we content ourselves with the text alone and absolutely reject the picture or shall we utilize illustrations and thus give the text an additional vital interest?

Illustration has its dangers. A few pictures scattered through a volume give it a more attractive, perhaps a more unacademic aspect but do not necessarily heighten its value. Numerous illustrations, on the other hand, generally end by dominating the volume, impose upon it a definite size and definite proportions so that we run the risk of reducing the text to a mere commentary. Nevertheless, we admit that illustrations have their merits. The resurrection of the inner and deeper life of the past calls in some measure for a visualization of individuals and their surroundings. Michelet is the "visualizer" not merely of souls but also of forms. If, then, it is opportune to replace a dangerous psychological intuition by methodical research into causes, it is perhaps equally opportune to replace or help a dangerous imaginative vision by forcing it to look upon authentic pictures.

Whenever, therefore, the text would seem to be obscure and incomplete without this aid, useful illustrations will be found in the proper place. In certain volumes which demand a larger number, plates can be added in an appendix. In the main, however, the rôle of the illustration will always remain an accessory one.

\section{II}

Each volume, as roe have said, is to have its oron interest and its oren unity.

Each will constitute, for a given period or for a given historical problem, an inventory of what has been and what still remains to be accomplished. 
Each volume will contain a Bibliography: not exhaustive, of course, but sufficiently complete to furnish students with the necessary data for obtaining additional information. The works mentioned in this Bibliography will be numbered; and in the notes references will be made as far as possible by means of numbers-one for the bibliographical item, one for the volume of the work, and, if necessary, a number for the page. Placed one after another, and separated simply by commas, these references can be multiplied without encroaching upon or encumbering the book itself.

By this means we shall be able to realize our double purpose of satisfying the demands of science and helping the student, and of addressing ourselves, at the same time, to the large cultivated public interested in human destinies. The presentation of the results attained in language as clear and as vivid as possible will occupy the bulk of the pages. The amateur in history will find an advantage in this: he will even escape the involuntary distraction produced by notes which are immediate $y$ intelligible. In order to be useful our numbered references will necessitate a study of the Bibliography; but the author will thus be able, in an economical manner, to justify the essential parts of his text, and the historically minded reader, if "he so desires, to consult the sources with a minimum of effort, whether in order to verify the contents or to extend the work beyond the point where the author has left it.

Works without references, syntheses where, at the best, the Bibliography is found at the beginning or at the end of the chapters, without running notes, are quite popular to-day, in Germany and elsewhere, and represent a reaction against the abuse of erudite annotation. But this opposite excess appears to us also dangerous. Under such anti-scientific conditions we are forced to take the author at his word. But no matter how scrupulous he may be, an author will often allow himself to group facts artificially, to present hypotheses as certitudes. As far as facts or the explanation of facts are concerned, the certain, the probable, the possible ought, of course, to be carefully graded and be so offered for criticism.

The bearings of each work and what still remains to be done will be touched on in the last chapter of every volume in an arresting manner. The object aimed at will be to show the lacunce still existing, the questions which arise in the various fields in 
connexion with the different periods of history, the publications that are urgent and the researches, explorations, and excavations which, by furnishing new facts, might possibly clear up obscure points. These conchuding chapters will thus offer many advantages. Not only will they fumish specialists with useful hints, but they will, at the same time, offer numerous subjects for treatment and give many individuals with indefinite but praiserworthy desires, ample opportunity for effectively employing themselves. It is to be hoped that this general survey of the historical field may lead to a better organization of effort, to a more advantageous division of labour, and direct some of the surplus workers with which certain subjects are encumbered toward the neglected regions of science.

Our inventory will even be of profit to the merely curious public: it will provide a sane notion of the present and future conditions of historical studies. No one, of course, is to imagine that in this synthesis history has been completed. History is in the making: it exists as a knowledge of the past obtained through learned research, as an explanation of the past through the study of causes. Our knowledge of the past, quite incomplete to-day, will, in fact, always remain so in spite of constant progress; what has existed, what has lived, what has been created and then destroyed by time, of all this only an infinitesimal part can possibly be evoked. But the scientific problems raised by the past will gradually become more definite and in the course of investigations still to be determined may eventually be solved. That is how the public, no less than the historians, ought to conceive scientific history or synthesis-as the determination and gradual solution of limited problens relating to a subject that is itself without limitations and in part unknowable.

\section{III}

Our enterprise may thus be of great value to further decisive progress in the study of human evolution. Its object is the proper arrangement of labour and the elaboration of a true scientific method with the purpose of initiating the public into the more serious and engrossing aspects of history as a whole. In the natural sciences, laboratory research, however technical and ungrateful it may be, always results in theories or in a practical outcome to which the public cannot remain indifferent: and, for 
that reason, there is abundance of encouragement for those who cultivate these fields. On the other hand, because of its overerudite and insufficiently scientific character, history as presented by learned historians has become an arid speciality, in which the public manifests no interest-accepting in their place anecdotal and romantic works put together by clever popularizers in the guise of true history.

Thanks to the eminent collaborators who have co-operated in this undertaking, things may perhaps be changed for the better. Our programme is vast and our ambition must appear to many over-sanguine. But we must take the risk. It is obvious that a desire for action, a confidence in the spontaneous forces of life have been revived anongst us. There would be a disquieting side to this if, as some tell us, it has taken an antiintellectualistic turn. It is essential that this need for action, this revival, should also manifest itself in intellectual courage. Life expands with knowledge. And an historic science understood in a living manner - the consciousness of humanity springing from reflection is necessary to direct the tumultuons powers of instinct.

Henri Berr. 


\section{FOREIVORD TO THE FIRST SERIES}

$T^{T}$ is not our purpose to justify the plan of our first Section taken as a whole; it arose of itself. We shall preface each Series with such explanations as seem useful.

With regard to the first volume, we may observe that its object is not merely to give a résumé of all we know concerning human origins carried back as far as possible into the past. It is as much an introduction to history itself as to the problems of History.

The justification for its inclusion is that it connects History in the strict and accepted sense of the word with History as understood in its broader sense of linking the evolution of Humanity with the evolution of Life on the Earth and with the evolution of our planet in the Universe. It enables us to find a proper "place" for humanity so that its destiny does not seem like a mere adventure or an unrelated episode. To attain this it was above all essential to exhibit the great natural forces and the permanent factors, which in explaining the Earth and Life will explain, at the same time, the evolution of Man and of Society.

We shall thus see how the "milieu" of our history was formed in the stellar system: in this milieu, detached from the Sun though still dependent on it, we shall perceive life arisingapparently through the action of the Sun itself. We shall see its first tentative advances in all directions and its experiments with the most diverse forms. We shall see it subjected to the complex infuences of different habitats, of inmumerable vicissitudes and of its own inner properties: to heredity, that conservative principle which may also become an agent of change, and to tendency, an active principle expressing itself in the faculty of assimilation and of association more efficiently than in struggle: and realizing every sort of improvement, until finally, with the human form, we reach that decisive advance-the development of the brain. 
It is an immense subject demanding a richness and an exceptional variety of knowledge, together with a rare power of synthesis such as perhaps only the author of this volume possesses. The man who in IS8I wrote "Les Colonies animales et la formation des organismes", who occupied the professorial Chair of Lamarck, and always "followed with the deepest interest the attempts of the transformist doctrine to provide an explanation of the living world ", that man, at the summit of his great career was well qualified to establish, in this vigorous epitome, a biological bond of union between the physical sciences and history.

We need not be surprised that this volume does not entirely conform to the type we have outlined, that its Bibliography is so restricted, and finally that the concluding chapter does not indicate the gaps in our knowledge. The Bibliography and the list of the problems to be solved would be infinite were they not strictly limited in the case of a subject covering, as it does, millions of years.

In a general way, in the volumes of this first Series, the subjects, on account of their extent and complexity, do not lend themselves to quite the same treatment as that of the more properly historical volumes which follow.

HENRI BERR. 


\section{CONTENTS}

General Introduction (by Henri Berr). • vage

Foreword to the First Series (by Henri Berr) xxi

PART I. THE FORMATION OF THE EARTH . I

Chap.

I. The Birth of the World . . . . 3

II. Transformations of Land OR Water a I5

III. The Sun and Climatic Variation • . 38

PART II. THE PRIMITIVE FORMS OF IIFE . 57 CHAP.

I. The Appearance of Life • • • 59

II. The Genealogical Basis of Organic Differentiation · • • • • 74

III. The Genesis of the Typical Forms of the Plant Kingdom • • • • • $\quad 96$

IV. Primitive Animal Forms • . . . II2

V. Attitudinal Changes and Structural Modifications . . . . . . 126

VI. The Peopling of the Open Sea, the Ocean Depths, and the Land Masses • • I46 
I. Life in the Prinary Period • • . 199

II. Life in Secondary Times . . . . 243

IiI. Life in Tertiary Times. . . . . $28 \mathrm{I}$

IV. The Human Form . . . . . 317

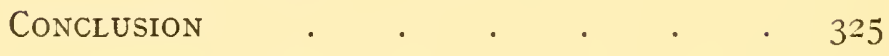

MAPS • • . $\quad . \quad$ • $\quad$ • 333

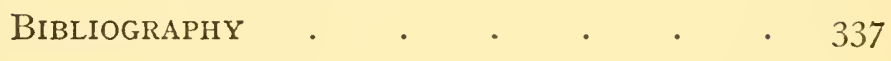

INDEX $\quad . \quad$. $\quad . \quad$. $34 \mathrm{I}$

\section{MAPS}

I. The Conformation of Land and Sea in the Northern Hemisphere at the Beginning of the Primary Period. . . . 333

II. The Continents of the Cambrian Epoch . 334

III. The Earth of the Jurassic Period. . • 335

IV. The Earth of the Nummulitic Period . $\quad 336$ 


\section{PART I}

THE FORMATION OF THE EARTH 



\section{CHAPTER I}

\section{The Birth of Our IVorld}

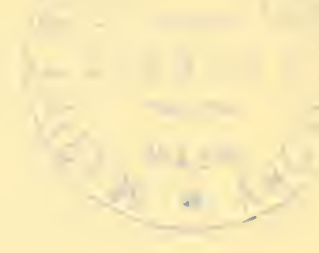

$A$ LL that we know of the extent of the universe has been I86,000 miles a second the light of the nearest of these stars takes about two years to reach us. We do not know how far removed the furthest of them is; we cannot even affirm that their distance is inversely proportional to their brilliance, nor can we say how many figures would be necessary to express this distance in miles. Whatever the nature of light may be we are at all events certain that it cannot reach us from those stars unless it is borne by that " unknown something " which fills space. It was once believed that this unknown medium was the substance of light itself. To-day, however, there are strong reasons for assuming that this medium exists in its own right. It has been named the ether, and has been pictured as composed of particles so small that in comparison with them an atom is enormous. These particles are capable of oscillating around a fixed point from which they can deviate only very slightly, and these regular oscillations, propagated in the ether as ripples are propagated in water when a stone is dropped into it, constitute light. The light of the sun and of the various stars maintain vibrations in the ether, which cross each other in every direction without mingling, but they are not alone in traversing it, for the ether is the scene of tremendous agitations. Through its medium the stars attract each other and the sunspots influence our magnetic needles, and there is even a question whether it is not actually the substratum of matter. Contrary to a belief that seemed at one time to be final, the study of radium has demonstrated that matter is neither eternal nor immutable. Atoms of radium destroy themselves spontaneously and give rise to helium and hydrogen. This destruction liberates a sufficient quantity of energy to act at a distance, through the ether, upon other atoms. 
Lord Rayleigh believed that in the series of elements drawn up by Mendeleef those having the greatest atomic weight are broken up in this way and that the atoms of the lighter metals are their residues. Silver, in this way, can be transformed into lead, lead into carbon, thorium into bismuth, and gold, perhaps, into copper. Thus atoms can be transformed and broken up and made to disappear.

Since matter can be transformed, and even be made to disappear, we have the right to ask how it was able to appear. The phenomena produced in a Crookes' tube, through the walls of which X-rays are able to escape, had practically demonstrated that atoms of matter were far from being simple entities. Among the various hypotheses as to their constitution we may at least accept this-that they are formed of infinitely small masses of matter charged with positive electricity, ${ }^{1}$ around which, like satellites round a planet, revolve a very large number of corpuscles, infinitely more minute, whose mass is 1,000 to 2,000 times less than that of an atom of hydrogen, the smallest known quantity of matter. ${ }^{2}$ These corpuscles, called electrons, are charged with negative electricity. What, however, do we mean when we say that a thing is charged with such and such a kind of electricity? Simply that these electrified bodies are centres of attraction or repulsion for other bodies; that is to say, that they are capable of determining movement; which they could not do if they were not themselves the theatre of movement. To pass from this to the admission that the electrons and the positive corpuscles are nothing but limited areas of ether and the centre of an active eddying movement, and that electricity is nothing but a manifestation of this vortical motion, is but a step. The nature of electricity then depends simply upon the direction of this movement. Molecular attraction, gravity, attraction of any kind, in brief, are also the consequences of this same movement.

If the stars are subject to this attraction, it is because its action, like light, is propagated through the medium of the ether, a medium which also transmits the Roentgen rays, the invisible rays of the infra-red and ultra-violet regions of the

1I, 21S. [In these notes the black Roman numerals refer to the Bibliography ; the Arabic numerals to the pages of the works quoted.]

${ }^{2}$ I, 15. 
spectrum, the Hertzian waves-the agents of wireless telegraphy-and the vibrations due to the destruction of radium and of analogous bodies; so that the substance which fills space is uninterruptedly traversed by waves of all descriptions of which actually we know only a part. These spread out in every direction, and in impinging on one another ought, strictly speaking, to give birth to vortical movements analogous to those of which atoms are the theatre, and thus originate matter.

But what we so far positively know of this movement is that it did not develop out of nothing. Every movement is the product of some former movement and the result of the transformation of that movement.

We do not know, and probably we never shall know, what was the nature of the initial motion from which came the electrons, with their negative charges of electricity, and the elements charged with positive electricity around which they revolve, thus forming the first elements of matter. Not long ago it was believed that motion, like matter, was eternal ; that it could change its modality; be transmitted from one body to another according to certain laws; affect the whole mass of a body, or merely disturb its molecules, producing, in this case, heat; and the demonstration of an equivalence between the mechanical work done and heat produced, foreshadowed by Carnot and determined by Joule, Mayer, Hirn, and Tyndall, apparently gave a very solid scientific foundation to this idea. Therefore, it would be useless to demand what may have been the origin of force. An ether completely permeated with motion and identical with it would thus originate all the forces which eventually would return to it and be lost in it, after having animated matter. To-day, however, we are not quite so certain of this eternity of motion.

Let us now return to intelligible things. We can see vaguely that a large number of elements, capable of becoming matter, were able to come together in certain regions of space and there form a kind of tight network ${ }^{1}$ across the path of infinitely small particles which the repulsive force of already existent stars projects constantly into space. These particles travel at a tremendous speed, and, according to Svante Arrhenius, are 
charged with negative electricity. They are arrested at the surface of the network, where their tension increases till they finally launch across the whole extent of its surface electric discharges which would illuminate it, just as such discharges illuminate a Crookes' tube. This would have been the origin of the nebulæ whose temperature, in spite of their phosphorescent condition, would be more than 200 degrees below zero. The spectrum of these nebulæ shows bands of helium, hydrogen, and certain apparently special elements. When a particle of matter, however small, penetrates such a nebula, a fragment of a broken star, for example, like those which form meteorites, it at once becomes a centre of attraction towards which the particles of the nebula hurl themselves and eddy round it, developing at the same time a terrifically high pressure and a very intense heat. The cold and phosphorescent nebulæ thus become transformed into a gaseous and incandescent mass, a kind of vast flame convulsed by movements of incredible violence, at first entirely disordered. Gradually, however, out of this very disorder, out of the collisions and partings which ensue, a kind of harmony is born. These internal movements become, so to speak, classified; some are reduced to simple vibrations propagated in the form of different radiations across the ether far removed from the nebula; others are fused in a single rapid rotatory movement, dragging along with them the entire mass of the nebula, compelling it to revolve at a prodigious speed around a single ideal axis. It must be admitted that, strictly speaking, the original diversity of the movements divides the nebular mass into several unequal parts, each whirling around on its own account, with a translatory movement which is transformed into a rotatory movement of the small masses around the larger ones by which they will be attracted. It is thus that a system of luminaries such as the multiple stars might have arisen directly. For our solar system, however, Laplace was led to another hypothesis, grandiose in its simplicity.

The incandescent nebula would, in his view, consist only of a spheroidal mass revolving in its entirety, at an inconceivable speed, round an axis. In conformity with the laws of centrifugal force this mass, by reason of its speed, would assume an ellipsoidal form such as that of the earth. The region corresponding to the equatorial zone would then, at the successive 
epochs of its cooling, break away and form a series of rings comparable to those of Saturn. On account of their more rapid cooling these rings would become condensed, the different substances of which they consisted separating from one another on account of their coefficient of specific heat and the difference between their melting and solidification points, and eacli ring having thus become distinct would break off. Since, however, the larger masses attract the smaller, the whole process would end in the formation of a globe revolving around the principal mass with a speed equal to that of the molecules of the ring after its isolation, but with an orbit of the same form and dimensions as that of the original ring. Thus the solar system would arise, and its stars scattered in the sky would all represent a more or less faithful repetition of the same process with the exception of the multiple stars which consist of many suns moving round one another in complex orbits.

These stars are not distributed in a haphazard order. Alongside of the nebulæ which possess such a vaporous consistency as to be considered simple stars in process of formation, there are others that only present a nebulous aspect when examined by a slightly magnifying telescope. The more powerful instruments show them to be formed of an infinite number of brilliant points which are manifestly stars. In these nebulæ thousands, perhaps millions, of stars comparable to our solar system are assembled; and they are probably the furthest away of all. Now these nebulæ frequently have the regular form of rings. We live in the midst of one of these rings, the Milky Way, and the beautiful stars of our firmament are merely those scattered through the nebular region nearest the sun.

At this point it may be asked whether beyond what we are able to see, there is really nothing else; whether there are not other universes separated from us by an absolute unbridgeable void, for could it, indeed, be bridged, it would not be a void; and also whether these universes are not made of an ether different from our own where our physical laws would have to be replaced by entirely different ones. This, however, we shall never know ; we shall never obtain even a hint of the answer and we must therefore be content to remain enclosed within our own universe, which is already of vast dimensions. It is the only one which we have any chance of knowing.

Had we announced only half a century ago that we should 
some day know of what the stars and the sun were made and whether the atmosphere of the planets was or was not charged with aqueous vapour, so daring a prophecy would have been regarded as the product of a deranged imagination. Yet such knowledge has been attained, and it is light itself which has furnished us with this information. Everyone knows that if a very narrow ray of white light is allowed to impinge on a triangular crystal prism, perpendicularly to one of its faces, it changes its direction in traversing the prism and, in emerging, spreads out fanwise, the rays as they shade insensibly into one another being of different colours, and the same colours always following on in the same order. Beginning with that part of the fan furthest from the original direction we have the following : Violet, indigo, blue, green, yellow, orange, red. We arrange them in this order instead of the reverse, because the names of the colours then form a word series easily remembered. Violet is the colour with the greatest refractability, red with the least.

This fan, whose colours seem to form a magnificent brilliant band when a white screen is placed in its path, is called the solar spectrum. If the ray is sufficiently fine and the prism thick enough for the opening of the fan to be of considerable size, black lines and dark bands are seen in the spectrum. These are the Frauenhofer lines, which justly bear the name of the German physicist who discovered them. On the other hand, the French physicist, Foucault, had pointed out that the spectrum of metals at white heat was not continuous ; that it was composed of lines and of brilliant patches. A little later in Germany, Kirchoff and Bunsen showed that if a beam of continuous white light is made to pass across a dark metallic vapour such as incandescent carbon emits, its spectrum shows dark lines exactly corresponding to the brilliant lines which would be found in the spectrum of the metal emitting the vapour. In other words, from the point of view of luminous intensity, a reversed spectrum of this metal is obtained. Now, on comparing the Frauenhofer lines with the brilliant lines of the spectra of various metals, they were found to be exactly superimposable, thus indicating the presence of these metals in the solar atmosphere. The study of this atmosphere charged with metallic vapours has been carried very far by the work of the French astronomer, Jannsen, and has demonstrated that all the elements therein contained are found also on the earth. 
But for some time it was supposed that one element was to be excepted which appeared to exist only in the sun and had for that reason been called helinm. Helium, however, has now been discovered on the earth as one of the products of the disintegration of radium, and, since the discovery of its origin, it has played a considerable rôle in the speculations of physicists. The study of the spectra of stars has not revealed any special bodies. Those of the nebulæ have given us only two, nebulium and archonium; so we reach the conclusion that our whole universe is made up of the same substances, which is, so to speak, quite natural if atoms are merely ether animated by certain vortical movements.

It is still more natural that the substance of the different planets should be identical, on the hypothesis that they have come from the sun, as Buffon already believed, and as has been accepted by all astronomers since Laplace. The origin of these stars is not due to chance; it occurred at definite periods which seem to correspond to successive phases of the contraction and cooling of the sun. During the period in which they were formed the elements composing the sun were already arranged in the order of their increasing density and in what might be called that of their viscosity. The most distant planets, the first in all probability to be formed, are very large and very light, and since they remained in a molten state for a very long time they themselves gave birth to a large number of satellites, that is, to numerous moons. ${ }^{1}$ These planets are Neptune, Uranus, Saturn, and Jupiter. Then, suddenly, come the denser and smaller planets, with only a small number of satellites: Mars, the Earth, Venus, and Mercury. Between these two groups and within the same orbit, revolve a great number-almost a thousand-of small stars, the asteroids. It may be conjectured that between Jupiter and Mars there once was a planet containing so large a proportion of light matter similar to that of the larger planets, or of heavy matter similar to that of the planets analogous to the earth, that since all these substances contracted unequally in cooling, the planet broke up like a piece of glass of heterogeneous origin in the fire; and that these fragments were then scattered along the whole length of its orbit. This hypothesis 
seems to be confirmed by the position occupied by the ring of asteroids. In fact, the distance of the different planets from the sun is controlled by a law formulated by the astronomer Bode, of Berlin, which may be set forth as follows, if we take as the point of departure not the sun but the last of the planets to be formed, Mercury :-

The distances of the planets from Mercury form a geometrical progression whose first term is 3 and ratio 2.

That is to say, the distances are to one another as the following numbers :-

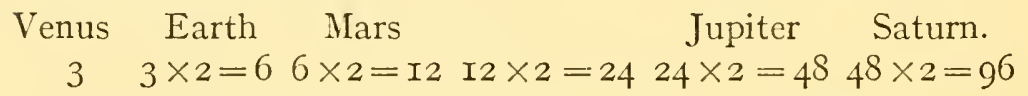

This law, first established by observation, was rediscovered in I867 through computation. As the astronomer Heinrichs has shown, it is due to the progressive condensation, regular and proportional to time, of the solar nebula, and is of such a nature that it also links together both the distances of the planets from the sun and the epochs of their formation. Now, in this series the planet corresponding to the number 24 is represented by the ring of asteroids. This ring therefore corresponds to a planet. It is also possible that the asteroids are not the result of the rupture of a planet but of a ring which once encircled the sun as Saturn is encircled to-day.

Although the various planets are only formed of substances found on the earth, it does not necessarily follow that each one contains all of them, still less that it contains them all in the same proportions. Their differences in density even force us to assume. that this could not be the case. If, for instance, we take water as the unit of density, we find that of Neptune to be $I^{\prime} 7$, that of Uranus $I^{\prime} 5$, and that of Jupiter $I^{*} 3$. These densities are only slightly higher than that of water, scarcely equal to that of sugar, and much lower than that of glass. Saturn, indeed, is so light that if there were a basin large enough to hold it, it would float on the water. The density of Mars on the other hand is 3.9 , that of the Earth 5.5 , Venus $4^{\circ} 4$, and Mercury 6.5 . These four planets may contain more or less of the heavy metals, and may have a more or less extensive atmosphere; but their densities approximate too closely for us not to assume that the same simple elements would be found there. The lightness of the planets outside the ring implies a 
predominance of metalloids and of alkaline or earthy metals the compounds of which are the lightest of all. The compounds of the alkaline metals are almost soluble; we may, therefore, assume that the seas of these planets are far more saline than ours, a fact which, as we shall see later on, is not without its consequences.

The present incandescent state of the sun's surface, and the immense hydrogen flames that dart out from it, imply that its entire mass has an extremely high temperature; it is even probable that it is in a molten state, and that its brilliancy is due to solid scoria floating on the surface of the molten mass. At the time when these planets were formed the temperature of the sun could not have been lower than it is to-day; it is therefore certain that the sun was in a liquid, if not a gaseous statc, when the planets were detached. Their distinctly spherical form and even their flattening at the poles confirm this hypothesis. It is only much later, when the atmospheric gases were freed, that their surface consolidated. Such, at least, is what happened on the earth. Water then formed a part of the atmosphere, the earth's surface being still too hot for it to exist in a liquid state; and as the surface cooled the water gradually became precipitated, and the vaporous atmosphere covering it became clearer. Venus, which is younger than the Earth, nearer to the Sun, and for these reasons hotter, is still in a phase where clouds absolutely conceal its surface ; it therefore reflects toward us the bright light which wins such admiration for the evening star, and shines even in a sky illuminated by the rays of the sun-although the firmament is masked for its own inluabitants who, according to the pertinent observation of Henri Poincaré, are perhaps still unaware of the existence of the stars. Mars, on the contrary, being smaller and twice our age, while Venus is only half, has acquired an atmosphere of extreme limpidity.

Jupiter, which is enormous in comparison with the Earth, being I,279 times larger, has cooled less rapidly, but it is further away from the sun, and eight times older than our Earth; it is possible that water is being precipitated on its surface, and that it has long since formed oceans like ours whence rise clouds which seem to be distributed in bands parallel to the equator by winds comparable to our trade- 
winds and counter trade-winds. It is possible that a ring like that of Saturn is beginning to be outlined on its surface. The existence of Saturn's ring is unquestionably connected with the extreme lightness of the substances which constitute it and which have yielded without resistance to the centrifugal action arising from its rotation. The peculiar nature of these distant planets and the fact that their birth goes back to so distant a past that we can form no idea of it, prevents us from being able to draw any very great profit from their study, in reconstituting the history of our globe.

The gradual cooling of the Earth did not merely bring about the separation of water from the atmosphere and its condensation upon the surface. It led in course of time to a whole series of modifications in the relations of the waters and the solid crust. Undoubtedly the Earth at first was absolutely spherical and was covered with a layer of water of probably uniform depth. Air, water, and earth formed three concentric spheres; the solid terrestrial crust itself covering the central mass, which remained burning and molten. The cooling gradually disturbed the regularity of this geometrical arrangement. Being homogeneous and contracting rapidly like all liquids, the central mass would soon have separated itself from the solid crust, and have left a void below, if the crust had not been distorted so as to limit its capacity.

The contraction of a cooling solid is, in fact, much slower than that of a liquid, and the solid covering, for that reason, would be unable to follow as quickly in its own contraction that of the liquid mass which it covers; it would collapse if it were not distorted. Perhaps such a collapse occurred more than once before distortion; possibly both had taken place together. This we shall probably never know, but it is of little importance. Whatever really happened it can be shown by a very simple geometrical calculation that, given equal surfaces, the solic with the greatest volume is a sphere, while that whose volume is smallest is a tetrahedron; and therefore the crust, merely through the process of cooling, must have tended to change from a spherical form to that of a triangular pyramid with four sides, whose four apices and the edges nearest to them must have projected above the water. From that moment continents and deep oceans must have existed. The sea, as the Bible says, was separated from the dry land. At first sight it looks 
as though the present disposition of the continents and seas confirms this calculation: ${ }^{1}$ the North Pole is occupied by a sea covering the base of the pyramid; at the South Pole a continent indicates the apex opposite the base ; the Eurafrician continent represents one of the lateral levellings; the two Americas correspond to the second, and the Australasian continent separated from Europe by the Aralo-Caspian depressic (the bed of an ancient sea) represents the third. These three continental masses widen towards the north, and duly become narrower towards the south. And, further, while the earth revolves on its axis, each of its meridians revolves in a given period, through an equal angle. But in order to revolve through an equal angle the points nearest the equator have to traverse an arc much greater than those near the poles, and they therefore move much more rapidly in a tangential direction. If, however, one part of this meridian sinks, the sunken points will move faster than they should, and will be in advance of the projecting points with their markedly retarded movement. The continents would thus have to twist their apices toward the east; and this torsion, evident as regards America, would lead to a rupture in the central portions. This would explain the existence of the Mediterranean and Caribbean Seas; and also the separation of the Australian continent from Asia. All this, unfortunately, must necessarily have taken place not in our days, but at the very beginning of the contraction of the earth's crust. It is always possible that the initial arrangement of the continents and seas began by conforming to this irreproachable calculation; but since then other causes have supervened which have modified the course of events. The oldest geographies extant yield no trace of tetrahedral arrangement, and the present disposition of land and water, which scems to conform to the calculation, is of relatively recent date. This conformity is a sort of anachronism. We have therefore had to abandon with regret, and only after many efforts to save it, that mathematical explanation, so seductive at first sight, known as the tetrahedral theory. The contours of the continents, their extent, and their altitude have changed many times. Areas long continuous have been cut up into many smaller ones; isolated 
islands, on the other hand, have become united to one another, and then attached to the continents nearest to them; and the vast regions thus formed have again been divided up by the invading waters. Plants and animal organisms which once lived together have become isolated from one another as a result; species enclosed in regions separated by seas have been able to spread from one to the other as soon as a land-bridge appeared, and to pass from one sea to another as soon as they were connected by straits. The evolution of life is intimately bound up with these slow and peaceful terrestrial " revolutions ", which, in fact, have been merely an evolution which we shall have to study before we can examine the evolution of life. 


\section{CHAPTER II}

\section{TRANSFORMATIONS OF LAND AND WATER}

JOWHERE have we been able to reach the primary solidified 1 crust of the earth. For a long time it was believed that this crust was represented by rocks which, in part, date back to a very great antiquity, such, for instance, as the granitoid and the gneisses, forming, almost of themselves, enormous areas such as the central plateau of France. It has, however, been shown that, in spite of appearances to the contrary, we have here, too, simply rocks deposited by water, and not all of the same age. Though some of then are to be classed with the oldest rocks known, others, identical in their mineralogical constitution and structure, are more recent and are discovered at different levels in analogous conditions. When the rocks laid down horizontally as sediment were folded by lateral pressure, it was near the bottom of these concave folds that granitoid rocks belonging to the same age as the sedimentary beds were found. From this we may infer that they were the result of a transformation of sedimentary rocks in a partly molten state violently compressed, and more or less altered either by gaseous or liquid infiltrations, and, through this two-fold action, crystallized. We call these rocks metamorphosed; and metamorphosis is of very general occurrence. It caused the formation of gneiss and granite whenever sedimentary rocks were compressed and folded, so that rocks once called primitive are seen to have lost that quality. ${ }^{1}$

It is none the less true that the oldest portions of the globe now emergent consist essentially of these rocks, whose thickness in certain places is more than fifteen thousand metres. This fact alone enables us to gauge the time required for such deposits to be laid down, especially if we consider that these deposits, by no means compact at first, have achieved the homogeneity which we find in gneiss. 
The oldest gneiss and granite is always found in the concavities of stratified layers folded by terrific lateral compression, and these folds are usually alternately concave and convex, constituting what geologists call synclines and anticlines.

The anticlines are naturally highly elevated, and correspond to the summits of the mountain chains formed by this crumpling. These chains were not formed by a single action. The solid crust of the earth, being compelled to follow the contour of the molten sphere, which, owing to the gradual cooling of the globe, contracted more swiftly, became folded in such a way as to preserve its surface intact while at the same time it shrank and diminished in volume. Contrary, however, to geometrical conjecture, from that epoch at which the earth becomes accessible to our observation, the continents did not form prominences directed towards the meridians, as the tetrahedral theory would have us believe, but rather rings or bands oriented parallel with the equator. This is either because the centrifugal force resulting from the rotation of the earth has contributed to their formation or because the cooling, always more intense at the poles, has caused the formation of powerful barriers that could resist a thrust in the direction of the poles, tangentially to the meridians. The first of these bands was formed near the North Pole; we do not know whether there was another corresponding to it at the South Pole, the southern hemisphere being to-day largely concealed beneath the ocean. It was in the course of its formation that the Circum-polar gneisses were folded; the direction of these folds indicates the position of the oldest of the mountain chains, the Huronian, so-called because the traces it has left of its existence are particularly visible in the neighbourhood of Lake Huron in the American continent; but it once extended from thence to Greenland, northern Scandinavia, and Siberia. Later it was surrounded by a second chain, situated more to the south, called the Caledonian because it is definitely recognizable in the Grampian Hills of Scotland; it extends into Scandinavia, and appears again in the Green mountains of Vermont, in the State of Maine and in the Appalachians. Still later, and always further to the south, rose the Hercynian chains, whose name recalls the vast Hercynian forest, which in the time of Cæsar covered the mountains of the Black Forest, the Harz, the Erzgebirge, and the Riesengebirge, and extended 
also across the Vosges from Lorraine to the central plateau and Brittany. These mountain chains sent branches into Spain as far as Seville and the Meseta in one direction; and, striking across Bohemia, reached as far as the Urals below the Carpathians and the Balkans, radiating into Asia from the Altai Mountains to the Gulf of Petchili, Tonkin, Annam, and Cambodia, and reappearing again in Australia, in Brazil, and the neighbourhood of Canada. Finally, we have a fourth, more southerly series of folds of still later origin, corresponding to the Balkans, the Alps, the Jura, the Carpathians, the Pyrenees, the Apennines, the Atlas mountains, the Caucasus, the Himalaya, the warped massif of southern and eastern China, and the mountains which skirt Indo-China on both sides, and, stretching out in a median chain in the Malay peninsula, betray their presence by the numerous volcanic islands of the Pacific. These folds then extend to the western coast of America, and, following the ocean, to North America and Alaska, which they reach as far as Terra del Fuego in a southerly direction.

The Alpine-Himalayan chains are the highest in the world, and attain in the Himalaya a height of 8,840 metres ; eternal snows accumulate on their summits, while vast glaciers move slowly down the entire length of their high valleys. In their vicinity, too, there are volcanoes, distributed so thickly along the coasts of the Pacific as to surround this ocean with what has been called its girdle of fire ; and it is either at the foot or the side of these mountains that earthquakes most frequently occur. All this is evidence of recent origin. The older mountains have been worn down, corroded and levelled by atmospheric agencies. It requires all the ingenuity of the geologist to reconstruct them by a study of the strata folded when they formed, and which to-day are like the buried foundations of a ruined city. A geographer limiting himself to a study of the earth's surface would hardly suspect their existence. They, too, once possessed glaciers, traces of which are found even on the oldest gneiss, but the actual remains of the original Hercynian ridges have been reduced by the wear and tear of time to hills of too modest a height for snow to remain long in temperate regions. The volcanoes indicate that quite recent fractures still persist along the flanks of recently formed folds, leaving a free passage for the molten matter within the earth. 
Similar fissures rent the Hercynian and Caledonian folds, and lava beds and streams, remains of ancient molten lava, are found in many places; but these have solidified so that all the openings from which these fiery torrents issued are now permanently closed. Stratified deposits at first horizontal, which were raised to form the flanks of ancient mountain chains, have either slid over one another or been completely inverted; the enormous masses thus dislocated have gradually reached considerable distances at times from the place of their origin, carrying along with them debris from the projecting folds encountered. Elsewhere the stratified rock has been broken vertically along the line of fissure whose two edges had changed their relative levels, constituting a fault. All this gargantuan task was not, of course, accomplished without sudden shocks causing earthquakes. To-day, however, all is consolidated, and in equilibrium, and only in the vicinity of relatively young mountain chains are seismic shocks still felt.

Theoretically the order of the superposition of the layers horizontally deposited by the waters should indicate their relative age. When these layers have been forced up vertically, folded, reversed, compressed, or carried away by cataclysms, this determination becomes more difficult ; but it is the business of stratigraphers to overcome these difficulties. They are almost always successful, and have developed, in conjunction with stratigraphy, a new science, that of tectonics, the special object of which is the study of the different agencies operating in the laying down of strata in different localities. When these layers have been pushed up vertically or folded, then raised above the water and once more submerged, the waters flowing back over their old domain cover it with horizontal strata oriented in a direction different from that of the tilted strata. 'This discordance indicates clearly that there were ground movements before the new layer was deposited, and if these are also in their turn folded, the discordancy persists, thus showing that the terrain was lifted up on two different occasions. It was by starting from these principles, so very simple in theory but often difficult of application, laid down in former days by Elie de Beaumont, that geologists succeeded in determining the relative age of mountains and arrived at the conclusion that there had been four series of folds whose distribution we have briefly indicated. 
This work of orogenesis, or mountain building, characterizes the great geological epochs, and the formation of one series of folds generally required an entire epoch for its consummation. The era in which the Huronian chain was formed is generally known as the pre-Cambrian; while the era extending from the origination of the Caledonian folding to the completion of the Hercynian, is known as the Primary. A long period of relative calm - the Secondary - followed. Orogenic disturbances continued in Tertiary times, and resulted in the formation of the Alpine and Alpine-Himalayan folds. Strictly speaking, one might concede that this third period has not yet come to an end, since the orogenic movement characteristic of it still continues. We can, indeed, point to movements indicative of the rising up of the land on many of our coasts, as on the Saintonge coast; ${ }^{1}$ or of its sinking, as in the Bay of Douarnenez. Earthquakes frequently occur at those points of the globe clearly connected with the intersection of mountain chains; volcanic craters are numerous, active and quite evidently associated, in regions where levelling is still proceeding. But the present, or Quaternary Epoch, was marked by an event to which we naturally attach the greatest importance, namely Man's effective appearance as the master of the earth; the beginning of this dominance coincides with a climatic condition which is regarded as closing the tertiary epoch-a lowering of the temperature which over and over again permitted a prodigious extension of glaciers. This glacial period was unquestionably the consequence of tertiary orogenic phenomena, which, by raising high peaks on the surfaces levelled during Secondary times, and by modifying the distribution of continents and oceans, favoured the accumulation of great masses of snow, augmented every winter on the summits of the vast chains of newly formed mountains. From a geological view-point, no new factor was involved, except perhaps at the beginning of the period of erosion of the Alpine chains. But we naturally attach particular importance to phenomena so intimately linked with our own history, and all geologists, for that reason, regard the era in which the human species began to assume an important

1 The movements found in such regions, it is true, are rather equilibratory, and belong to the category of epirogenetic movements, thanks to which the sea covers zones of subsidence which it abandons and re-occupies alternately. 
place among living beings as a distinct period in the earth's history.

Each of the eras just defined has been divided into many periods corresponding alike to the formation of certain parts of the great folds briefly described above, to a certain phase in the evolution of life, or to specific characteristics of the deposits then formed. We shall confine ourselves to enumerating these in the order of their formation, beginning with the oldest. Their names will be so many landmarks to which we can relate the various developments to be recorded in connexion with the evolution of life on our planet.

The oldest known deposits have been completely transformed into crystalline rocks or mica schists in which traces only of fossils have been discovered. They belong to a preCambrian era, in which two periods are recognized: the Archæan and the Algonkian. It is followed by the primary epoch, comprising five periods : I, the Cambrian whose deposits contain the earliest well-characterized remains of living beings ; 2, the Silurian ; 3, the Devonian ; 4, the Carboniferous, whose rich vegetation produced the most important coal deposits of our country ; 5 , the Permian, which immediately precedes the secondary period.

The secondary period, in its turn, is divided into three great periods: I, the Triassic, the period of transition; 2, the Jurassic, during which enormous coral reefs such as those encountered to-day in tropical regions were formed along our coasts ; 3 , the Cretaceous, in which the oceans were deepened and a fine calcareous ooze formed on their floor which later became chalk.

Finally, the Tertiary era, which witnessed the appearance and multiplication of animals more and more similar to those of our own times, has been subdivided into two great periods according to the proportion of animals with representatives still existing encountered in their fauna: the Eogene or Nummulitic, during which the sea was full of very simple organisms, which formed disc-shaped shells-nummulites-and the Neogene period, rich in animals of our present fauna. These periods have been again divided into two subdivisions: the Eogene, into the Eocene and Oligocene, and the Neogene into the Miocene and Pliocene. Sometimes another, the Pleistocene, corresponding to the quaternary, is added. 
The mountain chains whose main outlines we have just traced, did not attain their high altitudes without producing vast modifications in the level of the adjacent regions. In fact, they rest upon enormous continental bases ; as a rule, they are on the border line marking the separation of the continents of one epoch from those of a preceding one, so that where the continental barriers are missing, as along the American littoral of the Pacific, we are led to think there once existed a continent which has since disappeared.

We shall now endeavour to reconstruct, on the basis of the above principles, the distribution of the continents and oceans at the various geological epochs. The first continents to emerge from the seas, as has already been indicated, were arranged in the Northern Hemisphere in two principal semi-circles, of which the larger part has since then been submerged; the first constituting the Palearctic continent was not very far from the South Pole and the second near the Equator.

The Circumpolar coronet ${ }^{\mathbf{1}}$ broke up into four massifs or barriers arranged around the Pole like the petals of a flower : I, the Canadian barrier in North America; 2, Greenland; 3 , the Finno-Scandinavian barrier, including Scandinavia and Finland; 4, the Siberian massif. They formed at first, no doubt, a continuous half-moon, divided up by the sinking of certain portions in a meridianal direction. Their present distribution does not date back far beyond our own epoch. These four massifs had already been subjected to folding before any additional strata had been deposited upon them. They may have been temporarily submerged, but they have remained constant ever since the folding they underwent precedent to the subsequent geological periods, so that all the later deposits formed on their levelled surface have remained horizontal. Their folding shows that they underwent a process of corrugation at a very early period, resulting in the formation of mountain chains which quickly lost all traces of relief. It was these mountains, the oldest raised up on the earth's surface, which formed the Huronian chain.

Another continent extended from about $\mathrm{IOO}^{\circ} \mathrm{W}$. long. to I $65^{\circ} \mathrm{E}$. long., roughly resembling a huge spitted bird with folded wings (see Map II), with the equator representing the spit, the head towards the East, and with a huge wattle

${ }^{1}$ IX, 486, Map I. 
depending from it. The back of the bird rouglly corresponds to $30^{\circ} \mathrm{N}$. lat., its breast to $40^{\circ} \mathrm{S}$. lat., and the top of its head to $90^{\circ} \mathrm{N}$. lat. The end of its beak was placed $125^{\circ} \mathrm{E}$. long. by $55^{\circ} \mathrm{N}$. lat. An arm of the sea, comparable to a vast river, separated this continent from the Palæarctic and united the two sides of an immense ocean, occupying and generally exceeding in size the site of the present Pacific Ocean, which seems to have persisted, at least in the form of a girdle round the hypothetical Pacific Continent, through all the geological epochs. The equator cut the body of the bird into two almost equal parts, and the bird covered the whole of the Isthmus of Panama, spreading westwards over Venezuela, Colombia, Ecuador, Peru, and Brazil, and connecting this American portion with Africa, which, together with Arabia, it completely enveloped. It stretched eastwards beyond Madagascar, and to the mouth of the Indus. Spain, the north of Italy, France, the British Isles, nearly all Germany, Finland, and Scandinavia were submerged beneath the waters of the arm of the transversal sea behind the neck of the bird which ran along the north coast of Africa and the frontiers of Turkey and Austria, while the head covered the whole of Russia and nearly all China, the forehead and the beak extending obliquely from the Gulf of Obi to the north of Korea. The wattle, contained naturally between the two gulfs, covered India and Indo-China, and united all the islands of the Indian Archipelago, linking one part with the Asiatic coast and the other with northern Australia. At that time there was neither Atlantic (except for the transversal channel separating the two large continental belts) nor Mediterranean, North Sea, Red Sea, nor Persian Gulf. Chile, Argentina, Patagonia, and all eastern Siberia, including Japan, were submerged.

The geography just sketched corresponds to what geologists call the Cambrian period; it succeeded the pre-Cambrian, in which the rocks, afterwards becoming the northern granites and gneisses, were laid down. These granites and gneisses, during this period, formed a primary system of rocks-the Archæan, covered again by the mica-schists and sedimentary sandstone which constitute the Algonkian system. It is in these Algonkian deposits that the first traces of living organisms have been discovered. They are rare, and it is difficult to determine to what forms of life the traces or remains belong; 
but in the Cambrian deposits there appears a very complete fauna which the famous geologist Joachim de Barrande regarded as the oldest of all, and to which he gave the name of primordial fauna.

The sea at that time occupied an area almost equal to that which it occupies to-day; the diminution of the earth's diameter has since then perhaps increased its depth to a certain extent, but it was probably very little different then from what it is to-day. The transversal inter-continental channel was a kind of English Channel, and not very deep, its coasts rose in a very gentle slope, for we still find on the surface of the sandstone traces known as ripple-marks, left on the sand by the action of the waves. The west coast of America was, so to speak, staked out by three islands running parallel to its future coast, and practically occupying the site of the Rocky Mountains of Canada, the Sierra Nevada, and the Chilean Andes. In the same way a southern peninsula of the Palæarctic continent outlined the future Appalachians up to the neck of the isthmus connecting the persisting area of emersion called by Suess the Canadian barrier, with the continental mass of which it formed the western and southern extremity. The sea had abandoned the region of the Great Lakes situated between Canada and the United States (Map I).

Thenceforward these new lands were subjected to erosion; the crystalline rocks became decomposed by the action of the sea; and sands were deposited at the foot of the cliffs that were later to be transformed through the action of iron salts and iron oolitic carbonates ${ }^{1}$ into red sandstone, such as that of Saint-Rémy (Calvados), Segré (Maine-et-Loire), Nucic (Bohemia), the South of Spain, Saint-Léon (Sardinia), Krivorrog (Southern Russia), and those, somewhat later, ${ }^{2}$ of Clinton, in New York, and Lake Michigan, and which are accompanied by deposits formed in salt lagoons, such as gypsum and rock-salt, which reappear in all geological periods in places where the sea has receded. ${ }^{3}$

The oceans, however, had extended their domain in both hemispheres towards the equator; the inter-continental channel or inland sea extended over the north of Africawhich had risen above the water up to that point-as far as 
the Sahara, ${ }^{1}$ but had receded from Scandinavia and Finland, which remained united to Canada, and almost the whole of Russia; while the southern ocean invaded the south of Africa and a large part of Brazil. These changes were only temporary ; ${ }^{2}$ the sea reconquered Russia, the north of Scandinavia and Germany, almost all Europe, Siberia, China, and the greater part of the two Americas, except the east of Canada, which remained united to Scandinavia. Only Scandinavia, Central Africa, India, western Australia, and eastern China emerged from the sea.

It is also generally admitted that after this epoch a vast continent occupied the Pacific. After having worn down the coasts of the Palæarctic continent and washed away from them the portions which became the Old Red Devonian sandstone, the sea to the south of this continent dried up $;^{3}$ a zone of lagoons was formed there which laid down deposits of gypsum and salt, in which the bitumen of the White Sea, found in even greater abundance in the Appalachians, and between Hudson Bay and British Columbia, was produced, doubtless from decomposing animal remains.

The Hercynian folding coincides with the period during which the beds of coal, so useful to industry to-day, were successively laid down in the estuaries and lakes of these different regions. Their formation continued during the first part of the Secondary period. The uplifting of the land accompanying the gradual formation of the Hercynian chains drained the sea first from Scotland, ${ }^{4}$ then from the south of England, Belgium, and the north of France, ${ }^{5}$ and finally from the Central Plateau. ${ }^{6}$ At the beginning of this period there existed three large continental masses separated by as many seas; the transversal sea of the preceding epochs, which persisted in a more or less modified form, and two others of which one was oriented along the meridians. The Arctic continent still linked up Scandinavia, Greenland, and Canada, and formed the Canadian-Scandinavian plateau ${ }^{7}$ a second continent corresponded to modern Siberia and a part of modern China, constituting the Siberian plateau; a third extended

1 Coblentzian.

3 Frasnian.

5 Westphalian deposits.

7 Cf. Map V.
2 Eifelian.

4 Dinantian deposits.

6 Stephanian deposits. 
without a break from that part of Africa south of the Sahara to South America on the one hand, and to India and the north of Australia on the other ; this was the Equatorial or Gondwana continent. The transversal sea covered all Europe except Scandinavia and the north of Africa. In this vast channel called the Central Mediterranean by Neumayer, the Mesogean by M. Douvillé, and Tethys by Suess, a transversal island emerged consisting of Italy, the Balkan countries, and Southern Russia. This sea then became shallower and there emerged ${ }^{1}$ Wales, Holland, Normandy and the Ardennes region, Morvan, the southern part of the Central Plateau with the Vosges, Franconia united to Bohemia, Italy, the Balkan countries, the Caucasian region, comprising the south of Russia and the Urals-all forming as many islands separated by shallow channels. The straits between the Gallo-Dutch and the Ardenno-Norman islands were occupied by warm and limpid waters. Coral reefs ${ }^{1}$ bordered the coasts already established, though more to the west, during the Devonian period. These limpid waters created the Dinantian or "mountain limestones". To the south of the Gallo-Dutch island there was another strait separating it from Morvan and the Central Plateau. The southern border of this strait was the seat of great volcanic activity and was probably dominated by high mountains, whose erosion products, mixed with carboniferous substance, are found everywhere at their feet. Not long after, these newly emerged islands became covered by magnificent vegetation, the debris of which accumulated in the straits and drove out the corals. It was at this time that the coalbearing areas of Scotland, the rich coalbeds of Lothian and of Dalkeith, and those of northern France and Belgium were successively laid down. Whereas in Silesia, where four arms of the sea converged, a vast chain of mountains arose which was at once subjected to intense erosion, which filled the geosyncline situated at the base of the chain, and on the point of sinking at the time, with debris to a depth of I $_{4}, 000$ metres. A similar basin was formed in the neighbourhood of Moscow (Map III).

Mountains, however, continued to rise. The Hercynian chain extended across Spain, the Central Plateau, Brittany, the Vosges, the Black Forest, and Saxony. There were glaciers 
at certain points in the Alpine ${ }^{1}$ region. Two long parallel islands corresponded to the Rocky Mountains of California, and to the west coast of Mexico; a vast continent extended to the north, linking up the whole of the west of North America, the islands bordering the Arctic region, Greenland, Scandinavia, the British Isles, the west of France, Spain, Morocco, and Algeria; all this formed the Canadian-Scandinavian plateau separated by an arm of sea-the Fusulina Sea ${ }^{2}$-from the Siberian plateau. Italy constituted the nucleus of a large island.

The inland sea was thus pushed far southwards where it was bordered by the Afro-Brazilian plateau uniting Central America and the Equatorial Republics, the whole of Central Africa, Arabia, India, and the western part of Indo-China, including the Malay peninsula. To the north-east of this continent was attached a $\mathrm{T}$-shaped peninsula, of which the western arm, passing through north Italy and closing the inland sea on the west, was linked with Spain ; the other arm of the $\mathrm{T}$ corresponded to the Caucasus, and included the Black Sea and the entire central part of the Caspian Sea, terminating to the south of and slightly beyond it towards the east of the Sea of Aral. The other peninsula, situated in the south-east, united Indo-China to Australia, which had almost entirely emerged, and to the east of which a large island contained the north of Borneo and the whole Malay Archipelago. Finally, to the south of the Afro-Brazilian plateau there was another continent, separated from it by a second inland sea and uniting Patagonia to the African Cape region and to Madagascar, beyond which it extended considerably. The T-shaped peninsula was separated from the Scandinavian region of the Canadian-Scandinavian plateau by an arm of the sea, with parallel shores running from east to west and terminating in three divergent branches like the toes of a bird's foot. It was in these gulfs and along the coasts of this arm of the sea that the vegetable debris was accumulated which formed the coal beds of Scotland, the great coalfields of the south of England, Belgium, northern France, Bohemia, Upper Silesia, and Moravia (where the strata attain a thickness of $I_{54}$ metres),

1 Westphalian.

2 The Fusulinas are Protozoa in the shape of minute spindles, characteristic of carboniferous seas and belonging to the class of Foraminifera. 
and finally the Donetz coalfield in Russia, where this arm rejoined the ocean.

The secondary period opens with the Trias. It was an epoch of comparative calm during which the ocean probably experienced slow oscillations, the continents either increasing or shrinking in size; but there was no more crumpling on a scale that could raise long mountain chains thousands of metres high; on the contrary, it was the period in which the Hercynian chain was destroyed. The general configuration of the continents and the seas was but little different from that just 'described. During the Triassic epoch all the northern continents were united; only the north-west of Siberia, Alaska, and the western side of the United States and Mexico remaining submerged. A vast ocean, bounded on the south by the Pacific continent, occupied the site of the present North Pacific. The Gondwana continent was greatly extended; to the north, separating it from the North Atlantic, there was a large channel representing the inland sea or Tethys of the preceding age. Two arms of the sea flowing between the Pacific continent and the west coast of America on the one hand, and the east coast of Asia on the other, united the Tethys to an Arctic ocean, which continued its course southwards between the Pacific continent and the equatorial continent of Gondwana. These long channels alternately widened and narrowed in certain places, which was responsible for the three series of littoral deposits of the French Trias in the future Rhone valley, which gives the name Trias to the general deposits of this epoch.

This general arrangement lasted throughout the Jurassic period; the North Atlantic continent persisted throughout, although the sea nibbled at its coasts from time to time during the lower Oolic epoch. It was only from the Oxfordian epoch onwards that a depression in the Ural region separated it from the new Sino-Siberian continent to which it had been united during the Permian. This last remained above water throughout this period, except for the eroded coasts in the extreme north of Siberia and in Borneo during the Lias, the coast of Okutsk up to the Bajocian and the whole northern part of Siberia up to the Portlandian. The Gondwana continent was likewise cut in two by a depression in the region of 
Mozambique, the two halves becoming the Afro-Brazilian and the Australo-Indo-Madagascan continents. ${ }^{1}$ Between these two continents and the two northern ones the transversal sea, already alluded to as the Central Mediterranean or Tethys, grew larger. It occupied the exact site of the future Alpine folds. It is probable that the hypothetical Pacific continent still existed, and that the Tethys extended from the western to the eastern site of the present Atlantic, being prolonged towards the seas bordering it on the eastern coast.

We now come to the Cretaceous period. ${ }^{2}$ At its commencement the northern part of the North Atlantic continent (King Charles Land, Spitzbergen, east Greenland) was invaded by the ocean; an arm of the sea separated the SinoSiberian continent from the Scandinavian barrier ; in the AfroBrazilian continent the sea reached and submerged southern Abyssinia, the Somali coast, and the southern part of Cape Colony. Almost all the Australo-Indo-Madagascan continent, except the Kateh district and western Australia, was left intact. The arm of the sea which had united the Caribbean Sea to the Tethys in Triassic and Jurassic times still existed. This epoch might be called the Eocretaceous, and the following epochs the Mesocretaceous and Neocretaceous.

During the Mesocretaceous period the sea abandoned the Arctic regions just enumerated. The sea arm which had divided the Scandinavian barrier from the Sino-Siberian continent and the sea to the north of Siberia, and part of the ocean encircling the Pacific continent, dried up; but the waters invaded the western coast of the Canadian barrier, certain parts of Scotland, Ireland, Brittany, Bohemia, and Spanish and Moroccan Meseta, thus forming a communication between the Tethys and the Gulf of Guinea. The ocean entirely covered Syria, Arabia, the Sahara, the Sudan, the Africa coasts from the equator to the Cape, the north-east of Brazil, the north and south-east of the Indian peninsula, the plateau of Assam, Queensland, and the west coast of Madagascar. The Tethys continued to spread to the south of the North Atlantic and the Sino-Siberian continents, establishing a common marine fauna for the Asiatic and the present Mediterranean regions. One of its arms, passing between the 
North Atlantic and the Sino-Siberian continents, linked the Tethys with the Arctic Ocean, at least during the second part of this period; and it also communicated with the Antilles ${ }^{1}$ in such a way as to encircle an Atlantis. The Afro-Brazilian continent, from this epoch onwards, was divided into two by the immersion of a vast area corresponding to the South Atlantic. Madagascar and India still remained united. This disposition of land and water persisted throughout the Neocretacean period, when the sea advanced a little further in some regions, as in the Baffin Sea where a bay appeared, the north-east coast of Brazil and the neighbourhood of Pondicherry, and possibly isolated Madagascar for a short time (Map IV).

With the Tertiary period and the upraising of the AlpineHimalayan chains we rapidly approach present geographical conditions, so markedly different from those which we have just described. During a part at least of the Eogene or Nummulitic period, ${ }^{2}$ Europe and North America were still united in one vast continent, the rest of Europe remaining an archipelago whose principal islands, as during the Secondary era, were Scotland, Ireland and Wales, Brittany, the Central Plateau, and Spanish Meseta. These islands, separated by shallow branches of the sea, were intermittently reunited, and were even connected by a genuine Atlantis to North America. In any case a gulf of the Arctic ocean penetrated to the heart of Europe, covering what is now the North Sea, the Paris basin, and the south of England. The Afro-Brazilian continent still persisted. Madagascar was still united with India, but Australia from this time onwards was separated from it, and the Indo-Madagascan continent itself was separated by a strait from the AfroBrazilian. It is probable that the Pacific continent had already begun to collapse, but the sinuous marine ring surrounding it was momentarily raised and later transformed into a land of lagoons, or perhaps a shallow sea, communicating with the Tethys by a channel separating North from South America.

At the beginning of the Tertiary period the Southern sea still covered the site of the Pyrenees and Alps, as well as a part of Spain, all North Africa, Italy, Turkey, Greece, Asia Minor,

$$
1 \mathrm{X}, 134 \text {. }
$$$$
2 \text { Map IV. }
$$ 
Persia, the region now occupied by the Himalaya, and extended as far as China. This was the Nummulitic sea, so called because it contained enormous quantities of fossil nummulites, coinshaped, slightly bi-convex, and somewhat resembling the ancient liards. A gulf, which soon filled up, extended over the Paris basin. It was now that the Pyrenees began to emerge. between France and Spain. The sea spread further into the Paris basin, finally submerging Beauce, while certain reaches extended to the Central Plateau, and also covered the basin of the Gironde. England then stretched eastwards to Boulogne ; the Paris basin was inundated, and the English Channel, of which there were already signs, although narrower than at present, communicated with the North Sea. Soon, however, the level of the sea subsided and enormous freshwater lakes replaced it in the central parts of France, Spain, and Switzerland. This was the Oligocene period, which immediately followed the Miocene. The freshwater lakes occupying central France now filled up, and the Alps and the Himalaya attained their greatest altitudes. The sea finally abandoned the basin of the Seine, but, on the other hand, invaded those of the Loire, the Gironde, and the Rhone. Brittany became an island, was separated from the rest of France; England, on the other hand, was joined to the continent, from which it had been isolated in the preceding epocli. Throughout the rest of the Tertiary period England remained united at first to Artois, whose south-east coasts were washed by the lake that had occupied the basin of Paris. In the Miocene period this became free from water; the English Channel was driven back to the west of Cotentin, and England, to a large extent, was connected with what was to become Normandy and Artois. ${ }^{1}$ This large area was only an isthmus in the Pliocene period, and was cut during the Quaternary period, thus opening the Pas de Calais to the ocean which was to become the Atlantic and which already separated Europe from America and Africa from Brazil.

The general configuration of land and sea had already become stabilized somewhat earlier, during the Pliocene period. Some regions like Brittany were rather less hemmed in by the sea, which, on the other hand, advanced further along the entire west coast of the Atlantic from Brittany to Spain and 
along the littoral of the Gulf of Lions, where it invaded the whole valley of the Rhone as far as la Bresse, then occupied by a large lake. The straits of Gibraltar, the Dardanelles, and the Bosphorus were formed at this time.

The Earth thenceforth became what we know it to-day. No doubt modifications still continue. We know that at the present day certain coastlines are becoming submerged, while others are rising. Scandinavia has been regarded as subject to a sort of sea-saw movement, but this opinion is not strongly held to-day. ${ }^{1}$ The south coast of Brittany and the west coast of France are sinking beneath the Atlantic; the Channel Islands have become separated from the continent within historic times; the town of Ys has been engulfed by the waters of the Bay of Douarnenez; certain parts of the Italian coast have become raised, and numerous regions where earthquakes and volcanic eruptions still take place clearly indicate that the activity of the earth's crust has not yet ceased. All these changes, however, are so gradual and of such slight extent that geographers' maps are scarcely modified. Events moved just as leisurely in earlier times, and the greatness of the changes that have taken place is not to be explained by those tremendous cataclysms of which Cuvier has given us so grandiose a description at the beginning of his discourse on the Revolutions of the Earth, but rather by the extreme duration of the geological periods in which they occurred. This great duration, already invoked by astrologers in support of their cosmogonic conceptions-this stupendous length of time which Cuvier accused Lamarck of abusing in the interests of transformism, may be accepted as an established fact to-day. Attempts have been made to measure it in figures by taking various phenomena into consideration, but in spite of the hypotheses put forward to enable this to be done, and in spite of the objections of the last partisans of the chronology of Biblical commentators, to whom Cuvier lent the support of his remarkable erudition, the agreement between the results arrived at from very different starting-points, bearing no relation to one another, is such that it is impossible to escape from the evidence that the interval between two geological periods represents a stupifying succession of centuries. Time itself has been the great architect of the transformations of the earth. 
It is only since the discovery of radium that we have been able, by a simple calculation, to approach the question of the age of the earth, or, speaking more accurately, the age of some of the minerals constituting its solid crust. Strutt has drawn attention to the fact that some of these minerals contain at the same time uranium, itself radio-active, and a certain proportion of a substance resulting from the decomposition of uranium, viz. helium. He has calculated that II million years are necessary for a gramme of uranium-oxide to produce a cubic centimetre of helium. From the quantity of helium a mineral contains we can thus arrive at an estimate of the quantity of uranium it possessed at the time of its formation, and the time necessary for the transformation of this uranium into helium. The calculation yields 622 million years for the zirconium in the archæan rocks of Ontario; I 45 million years for certain Devonian hematites; 400 million years for some minerals, and only 40 million years for others. On the other hand, certain Swedish and American rocks yield figures of $\mathrm{I}, 300$ and $\mathrm{I}, 400$ million years, and specimens from Colombo, in Ceylon, reach I,6oo million years. These different figures enable us to determine the age of the terrain in which the buried minerals analysed are found, and thus to calculate the time that has elapsed between the geological periods corresponding with the laying down of the different strata. It may be, of course, that the differences are in part due to the fact that the minerals examined are not found in conditions equally favourable for the preservation of helium.

A further problem has been propounded, namely the date of the appearance of life on the earth, which must necessarily have been subsequent to that at which the temperature of the earth's surface fell below roo degrees. Lord Kelvin was the first to interest himself in this problem, and arrived at an approximate solution by treating the earth, for the purpose of calculation, as a homogeneous ball brought to a red heat and then allowed to cool. According to this hypothesis, which is very far removed, it is true, from the actual facts, Lord Kelvin, according to the secondary hypothesis favoured, found the answer to vary between 20 and Ioo million years. But the calculation can be made in another way by reckoning the time necessary for the different geological layers to be formed. We are assuming, of course, that during the geological periods which 
preceded our own, the rapidity with which sediments were laid down was the same as that of to-day. As we have only the vaguest notion of the reduction in thickness undergone by the oldest deposits during their transformation into gneiss, it is quite likely that estimates made by this procedure are too low and that the error due to this fact will compensate, in large measure, for possible exaggerations due to a difference in the rapidity with which certain deposits are formed. On the basis of the foregoing facts, Dana estimated the duration of the primary period as I5 million years; that of the secondary as 4 million, and that of the tertiary as $I_{2}^{\frac{1}{2}}$ million years, making the total of 20 millions at which Lord Kelvin had already previously arrived. The duration of our present period has been calculated from an entirely different startingpoint. The Niagara River, emerging from Lake Erie, originally fell, after a short course, into Lake Ontario. But gradually the cliff from whose height it falls has been eaten away; thus the Falls to-day are II kilometres distant from the lake. Taking as his basis the rate at which the cliff is retreating to-day, Lapparent estimated the duration of our present epoch as 40,000 years. This estimate is confirmed if we measure the present rate of increase of coral reefs and try to discover how long it has taken to unite to the peninsula of Florida the four coral reefs attached to its primitive coasts; this has required 35 to 40,000 years. The calculation of the time necessary for the formation of the present peat-bogs gives the same results. We may, therefore, regard it as exceedingly likely that about 40,000 years have elapsed since man began to spread over the earth.

From the agreement of all these facts we may at least conclude that the surface of the earth has been solidified for from I to 2,000 million years. Other calculations indicate that it is at least a trillion years since the earth was separated from the sun and that life is already an extremely ancient phenomenon.

The prodigious changes which have occurred in the course of ages in the configuration of the continents and the seas has necessarily influenced the mean temperature of any given region. According to whether the sea washing the coasts was in extensive communication with tropical or polar waters, its temperature rose or fell, and that of the adjacent continent 
became mild or rigorous and the climate humid or dry. The climate was in part also conditioned by the altitude of the mountains. The Caledonian and Hercynian chains were completely levelled during the primary and secondary periods; but from the inclination to one another of the layers constituting the two opposite faces, where the distance from one another is known, of an anticlinal fold, we can compute the height to which the summit of this fold was once raised, and we thus discover that the ridges of these chains rose to a height of many thousand metres as in the case of the present Himalaya. These high mountains were covered with an eternal garment of snow, as in our own time. Glaciers, of which traces can be seen even in the Archæan period, moved down their valleys and so cooled the air. At all epochs, therefore, there have been relatively cold and relatively hot regions, and, in consequence, winds and tempests, rain and snow. But all this is true even of tropical regions to-day, and we shall see that a. tropical climate dominated the world for a long time. It is tempting to attribute this to the fact, incontestable to-day, that the internal heat of the earth, still considerable no doubt, is more markedly felt through a solid crust where it is least thick. Since the appearance of life on the earth, however, this internal heat does not seem to have played any great rôle. As a matter of fact, we possess no means of calculating how much the earth's temperature rises at the centre. In the deep wells of mines, where the temperature has been studied, it has been found to increase steadily as one descends; but it does so in a surprisingly capricious manner. The term geothermic degree has been given to the number of metres corresponding to a rise of tenperature of I degree. In the mines of Sperenberg, which are among tlie deepest, the geothermic degree has been measured every 200 metres to a depth of 2,500 metres. It varies from I6 to I 40 metres. An attempt has been made to combine these observations by a formula of the second degree. The formula is as follows, $\mathrm{S}$ being the depth in metres and $\mathrm{T}$ the temperature (Réaumur).

$$
\mathrm{T}=7^{\circ} \mathrm{IS}+0,0,12983572 \mathrm{~S}-\mathrm{o}, 00000 \mathrm{I}_{2579 \mathrm{I} \mathrm{S}}^{2}
$$

This gives us the amazing result that freezing point would be reached at a depth of 3,420 metres if the temperature continued to obey it at this depth. But however variable laws may be, a 
continuous rise of temperature cannot change to a fall which eventually reaches freezing point. Assuming that the geothermic degree remains constant and equal at roo degrees, a figure not far from the observed mean, the temperature of the earth's centre situated at a depth of 6,350,000 metres would be found to be 63,500 degres - which is quite a different matter, but manifestly impossible, for this would be higher than the temperature attributed to the surface of the sun.

These contradictory data suffice to show how little we should know of the interior constitution of the earth if it were not for other facts which have recently come to light. The study of the lava from volcanic eruptions has led to the assumption that below the solid crust or lithosphere there exists a continuous molten mass, the pyrosphere, constituted by a magma containing iron and magnesium. This becomes increasingly homogeneous as the depth increases, tending to approach, in composition, that of silicate of iron and magnesium, which mineralogists call peridot. ${ }^{1}$ Peridot, deeply situated, is always associated with iron. This association is exactly reproduced in the meteorites studied by Daubrée and M. Stanislas Meunier, and has led them to consider these as the scattered debris of a star, or possibly a residual planet, approximately contemporaneous in origin with the earth, formed at the expense of the sun, and with an orbit crossing ours periodically. ${ }^{2}$ The composition of these meteorites may therefore be compared to that of the earth's core called the barysphere. This barysphere, in the main, would be formed by a metallic iron associated with nickel, a sort of steel. In this way the resemblance of its properties to those of a magnet and its power of directing a compass would be explained. Nickel-steel would thus be the essential metal and constitute the universal basis of the earth's crust.

The study of earthquakes has corroborated this conclusion in a manner as unexpected as it is exact. After numerous more or less clumsy attempts, an automatic registering apparatus has been constructed of such a degree of sensibility

1 The chemical formula of peridot is $(\mathrm{MgO} \cdot \mathrm{FeO})^{2} \mathrm{SiO}^{2}$.

2 It is difficult to assume that this star was a former satellite of the earth like the moon. The debris of such a satellite would have formed a ring round the earth or would have revolved round it like the moon, before falling to its surface as soon as its tangential acceleration had sufficiently slackened. This does not seem to be the case with meteorites which occur in "swarms" whose orbit rather resembles that of comets. 
as to record earthquakes produced in any part of the globe, however distant, and even when they take place in the greatest depths of the sea. A vertical pendulum, suitably constructed, describes the horizontal components, and a horizontal pendulum the vertical. The curves registered by the apparatus, undulatory like those described on a revolving cylinder coated with lampblack by a needle fixed to a freely vibrating scale, are remarkably uniform. For each shock they fall into three divisions, which differ solely in the length and amplitude of waves and are inscribed in succession. From the time taken for the registration of these vibrations and from what we know, through the experiments of Wertheim, of the mode of transmission of vibrations through solid bodies, Lord Rayleigh concluded that the first and second parts of the curve represent respectively transverse and longitudinal vibrations transmitted across the barysphere, the third series of vibrations and the last to arrive being transmitted across the earth's crust or lithosphere. Now the speed of the transmission of the first two series of undulations, 9, 6, and 5 kilometres per second, indicates that these latter have been transmitted across a medium more rigid than steel. The maximum density of this medium, as calculated by Roche, would be Io, 6, and, at most, a little greater than that of iron-7,7. These correspondences are somewhat disturbing in view of the diversity of the considerations involved, all bringing us back to the same assumption - that the earth's core may well be solid and consist essentially of iron. It must not be forgotten, however, that all the metals heavier than iron, especially those that combine with difficulty with metalloids, such as gold and platinum, are very probably at least as largely represented in the barysphere as in the lithosphere, and that, on the other hand, the mode of transmission of luminous vibrations across the interstellar ether equally leads us to assume a medium " more rigid than steel ", without implying, however, that it is solid in the sense in which we understand that term. The term " rigidity " simply means that the molecules of the body considered can be displaced only with difficulty and have an active tendency to return to the position from which they have been dislodged. As far as the barysphere is concerned, the rigidity of its substance appears to be due to the tremendous pressure to which it is subjected and which maintains the molecules in place 
without giving us any information as to their nature or their temperature. Under such colossal pressure probably the heat can no longer affect the mobility of the molecules: all bodies must appear rigid and solid. The distinctions made on the earth's surface between the various states of bodies no longer have any significance in these central regions.

However that may be, if the internal heat makes itself so little felt on the earth's surface to-day, we may perhaps also assume that it had very little influence during the epoch in which the first consolidated layer could support sediments more than 20,000 metres thick, as was already the case at the beginning of the primary period, not long before the first appearance of life. From that time onward climates have been determined by action from without the earth, and this action can only have been that of the sun-whose intervention we must now study. 


\title{
CHAPTER III
}

\section{The Sun and Climatic Variation}

\begin{abstract}
FTER giving birth to our planet the sun continued to be A so closely linked with it, as with the other planets also, that the more we increase our knowledge of those links the more they justify the worship it has inspired in diverse forms in so many of the peoples of antiquity. From the sun our earth, in addition to its material constitution, received and retains both its inner heat and the movements which cause it to revolve on its own axis and ceaselessly describe its vast elliptical orbit. From these movements night and day and the regular succession of the seasons take their existence, manifestations of the tutelage in which we are still held subject by the father of stars-held chained, indeed, by the mysterious bond of attraction within his resplendent mantle of gold and purple radiance.
\end{abstract}

Nothing takes place on our earth without the intervention of the sun. It penetrates the waters of the sea, scattering their molecules till they become invisible and then draws them up into the air, where they are left to unite and form clouds. It is the sun that, by heating unequally the different regions of the earth, generates the moisture-laden winds whence fall the fertilizing rains that permitted life to appear on the continents. And it is the sun that induces in the living web of the plant's texture the chlorophyll, the green substance which, when activated by its rays, combines water with carbonic acid and liberates the oxygen consumed by animals, thus performing the miracle of producing sugar and starch. These are called by the chemists carbo-hydrates, because they are composed entirely of water and carbon, and constitute the first and only source of all food, whether for animal or plant.

The sun alone, therefore, can maintain life on the earth. It determines the conditions of its development equally on land and sea. Innumerable green microscopic algæ float on the surface of the sea in calm and clear weather; and at the bidding 
of the sun they create the food which allows them to multiply rapidly. They themselves furnish the inexhaustible provender which attracts the countless infusoria and the minute, almost microscopic, larvæ of marine animals of every sort: worms, starfish, sea-urchins, and the small crustaceans which form the interminable army of Copepods-in a word, the whole minute world of life that swarms unceasingly near the surface of waters penetrated by light, and to which the Jena naturalist, Haeckel, gave the name of plankton, including thereby the algæ themselves. The herrings, sardines, and mackerel, in their search for the Copepods they delight in, are themselves pursued by the various tunnies and bonitos; and these in turn are hunted by porpoises, sharks, and even dolphins. When the weather is clear and the temperature favourable all this teeming life is clearly visible, fishing is fruitful and happiness and prosperity reign among the fishermen. But when the sky is overcast and the winds raise waves and trouble the waters, the débris so fatal to the transparency of the ocean is stirred up, and the plankton at once flees from the sullied surface, descending to calmer zones, attracting in its wake all those creatures that live at its expense. Herring, sardine, and mackerel become rare; the fisherfolk can no longer gain their livelihood; and the sound of their lamentations is heard even in Parliament itself.

All this is the work of the sun. Its activity does not, however, end here. By creating the winds that carry the clouds into the upper regions of the atmosphere, whence they fall in due course in the form of rain, the heat of the sun becomes changed into motion. The water which falls on the high mountain chains and streams down their slopes gradually wears them away; and this continuous action, however slight it be, produces a prodigious effect. The mountains of 7 or 8 thousand metres in height that formed the Huronian chain, and the younger Caledonian chain, have been completely levelled to the ground by this erosion, which may be said to be also the work of the sun. On the sun, too, depends the energy of watercourses, the energy developed by waves in their assault on the land, and the energy that lies hidden in the depths of the earth in the form of coal, for the sun is the principal builder of vegetable tissues. And as plants, children of the sun, directly or indirectly, are the only source from which animals derive the foods upon which they 
subsist, the animals owe to the sun their very power of movement. The rustling of the leaves as they are stirred by the wind, the devastations that follow in the wake of cyclones; the gentle ripples formed by light breezes on the surface of placid waters, like the colossal waves raised by tempests; the tranquil course of rivers, like the impetuous violence of torrents-all are the sun's work, just as is the clumsy progress of the earth-worm, the fleetness of the gazelle or the bold flight of the eagle. The song of the elves in The Midsummer Night's Dream, as they pray that "never harm, nor spell, nor charm" may disturb the slumbers of their queen is a prayer to the sun, which causes both thunder and the song of birds, and all the sounds to be heard on earth. In the opinion of meteorologists even the spots on the sun's surface influence our atmosphere; the dry and rainy periods being supposed to vary with the number of spots observed. These spots reach a maximum every eleven years, which thus corresponds exactly to our rainy cycles, and it has been even assumed, perhaps too rashly, that this maximum also coincides with a period of frequent earthquakes.

Night and day and the periodic recurrence of the seasons depend equally upon the sun, just as does the existence of diurnal and nocturnal animals, which pass the day or the night, as the case may be, in periods of alternating rest and activity. To the sun, finally, is due the increase of life throughout all Nature in the spring, and the tendency of all organisms to multiply, each according to its kind. The sun, then, governs all activity on our globe; and, in accordance with the distribution of its heat and light, all the movement that animates the atmosphere and the seas, all the phenomena of life, are regulated. We must, therefore, examine in detail the various relations that unite us to the sun, and the way in which these relations have been modified in the course of centuries, as well as the changes which the sun itself has undergone.

The earth exhibits numerous types of motion; it turns on its own axis, and the duration of that rotation is called by astronomers a day; the axis upon which it revolves is a straight line fixed with reference to the earth, and the stationary points on its surface which represent the extremities of this imaginary line are known as the Poles; the plane perpendicular to this axis, which passes through the centre of the earth and which 
cuts the surface along a great circle, is called the equator. The earth, morcover, moves round the sun and describes an ellipse, of which it occupies one of the foci; the time required for this journey constituting the unit of measurement is called a year. The ellipse described by the carth is called its orbit, and the plane of the orbit the ecliptic. If the earth's axis of rotation were perpendicular to the ecliptic the equator would be situated in this plane, and every part of the globe would then always be illuminated for exactly one half the time occupied by the rotation. The term day is usually limited in its application in ordinary language, and refers not to the astronomical day but to the fraction of that day during which a given place is illuminated. On the hypothesis of a coincidence of the plane of the equator with that of the ecliptic the days on the earth's surface would be equal to the nights. But this is not so. The two planes indicated actually form an angle of $23^{\circ} 27^{\prime} 2 I^{\prime \prime}$. Now it can easily be shown by simple geometrical methods, that on account of this inclination, those parts of the earth, which are situated on the equator are the only ones where the days and nights are of exactly the same length throughout the year. At either Pole, on the other hand, it is night for six months, and also day for six months, the day of one of the Poles coinciding with the night of the other, and conversely.

For all points of the earth situated on a small circle whose distance from the Pole can be measured by an arc $23^{\circ} 27^{\prime} 2 I^{\prime \prime}$, there is a consecutive day and night period of 24 hours at the moment when the plane of the terrestrial axis and the perpendicular which passes through the centre of the earth also passes through the centre of the sun. That moment is called the solstice. Polar circles is the name given to the small circles that fulfil these conditions for either Pole. For all points situated between these circles and the Poles, the duration of the day and the night is longer than that of an astronomical day and all these points are situated within the frigid zones. On each side of the equator, a small circle, also situated at a distance of $23^{\circ} 27^{\prime} 21^{\prime \prime}$ from the equator, marks off the region where every point sees the sun twice a year exactly vertical, i.e. at its zenith, that being the moment in which the days and nights in the arctic circles are equal to the astronomical day. This is the torrid zone, and the small circles 
limiting it on each side of the equator are the tropics, or as they are sometimes called, the inter-tropical zone. Between the tropics and the Polar circles extend the temperate zone, where the duration of light and darkness is always less than one terrestrial revolution and where the sun never reaches its zenith.

At the particular moment in which the plane of projection of the earth's axis to that of the ecliptic is perpendicular to the line joining the centre of the earth to the centre of the sun, the days and nights are equal at all points of the globe, and this is called the equinox. From this moment onwards, we have inequality between the duration of day and night in both hemispheres, the nights becoming longer in one and shorter in the other. In one case we are passing from autumn to winter, and in the other from spring to summer. The culminating point of the hot season, which we call summer, coincides with that particular instant, which lies half-way between the two equinoxes, that is to say, at the summer solstice, and the same holds for the winter solstice. In our hemisphere the hot season coincides with the period in which the earth is approaching the height of its orbit furthest from the sun. It is the duration of the day and not the proximity of the sun which raises the temperature. As the length of the day is the same in the two hemispheres, the summer of the southern hemisphere is a little hotter than in the northern, the earth then being nearer the sun than it is during our summer. The year is consequently divided into four seasons, spring, summer, autunin, and winter.

These facts are not as definitely fixed as might at first be supposed. The terrestrial axis does not remain parallel to itself. It describes a cone with a sinuous contour round a line perpendicular to the ecliptic, whilst the orbit itself is revolving in its own plane. These combined movements cause the line of equinoxes passing through the centre of the orbit to turn, in the plane of this orbit, 62 " per year, just as if it were going to meet the earth, thus gradually advancing the period of the equinoxes. The procession of the equinoxes requires $2 \mathrm{I}, 000$ years to make one complete rotation. The duration of the seasons itself varies periodically, and under conditions at present prevailing in our hemisphere the spring-summer period lasts eight days longer than the autumn-winter period. 
There is consequently a slight rise in temperature to the advantage of the former. The converse occurs every 10,500 years.

The eccentricity of the earth's orbit is also subject to very important rariations: to-day it is $\frac{l}{00}$. But it can increase to $\frac{1}{1+5}$; that is to say, the orbit may be extended by the earth going further from the sun than it does to-day, and also by coming nearer to it; and this would lead, of necessity, to a greater difference between the hot and the cold season than that prevailing to-day, especially if the line of the solstice coincided with the major axis of the orbit. Conversely, if the eccentricity were zero, that is to say, if the terrestrial orbit became circular, a possible contingency, and the earth remained the same distance from the sun throughout the year, the seasons would be less marked than they are to-day. Such alternations must actually have occurred in the course of the millions of years represented by geological periods. But we may go further and say that in the present phase of our planetary system, the angle formed by the plane of the equator and the ecliptic varies only within narrow limits, from about $21^{\circ} 59^{\prime}$ to $34^{\circ} 36^{\prime}$. These two planes cannot coincide, which would eliminate the seasons. But other astronomical conditions affect the position of the earth's axis ; every change in the shape of the earth, which is not rigid, and every modification in the distribution of the matter which composes its mass, may bring about a displacement of the axis of rotation in relation to the surface, or, to put it otherwise, a displacement of the line of the Poles, and may, in consequence, fundamentally alter the climates of different regions of the globe. It has even been supposed that a greater accumulation of ice at one of the Poles than at the other can produce such an effect.

Neither has the sun itself remained unchanged. After the earth was detached from it the sun continued to shrink both as a result of cooling and because it had thrown off two other planets, Venus and Mercury, which naturally led to a reduction in its size. It would be sufficient for the sun to have an apparent diameter of $47^{\circ}$ to cause the lighted area of the earth greatly to exceed that of the unlighted, ${ }^{1}$ instead of their being equal as is the case to-day. Under those conditions, however, the long solar nights would disappear and there would be no more 
seasons. In the twenty million years during which life has existed on the earth, such climatic changes must actually have occurred. ${ }^{1}$ The computations of Blandet have led us to assume that during these twenty million years the diameter of the sun has decreased by one-half. When life began on earth the sun was so large that there was hardly any night at all. The work of $\mathrm{J}$. Bosler ${ }^{2}$ suggests that through radiation alone the sun must have lost in thirty million years a mass equivalent to that of the earth. This diminution, together with modifications in the longitude of the earth, would bring about a slowing down of the earth's motion equivalent by the end of the same time to a retardation of 36 hours for the seasons. The temperature of the sun, therefore, must have correspondingly diminished since the commencement of life. Scientists are not agreed as to its temperature at the present moment. M. Violle reduces it to 2,500 degrees, Lord Kelvin places it at I4,000, and M. Le Chatelier stops at an intermediate figure, 7,500 degrees. 6,000 degrees is regarded as the most probable figure.

Whatever the facts may have been, the diminution of the solar temperature must have changed the nature of the light emitted. To-day the sun is, in fact, a yellow star. We know that there are white and blue stars in the firmament which are hotter. The sun must once have belonged to one of these categories. The light which it then sent the earth was richer in chemically active rays-in blue or violet, or invisible ultraviolet rays. The energy of such light was then much greater and quite different from the solar light of to-day. It must consequently have produced on the earth chemical phenomena now impossible. We shall have recourse to this important fact later on; for the present, however, we may conclude that at a period not far distant relatively to the duration of the geological epochs, the sun was of sufficiently great dimensions to render the climate of those regions of the earth, corresponding to those now above water, quite different from what it is to-day. As to that, however, there are reasons nearer at hand thanks to which frequent changes of climate must have occurred in the same place. What determines climatic characters to-day is the altitude above sea-level, the proximity of high mountain chains covered with eternal snow and glaciers, and the position relative to the sea of these mountain chains whence hot or cold 
winds blow according as the air reaching them and carried to lower levels is dry or moist; and, finally, the distance from the sea, and the variable temperature in its vicinity depending on whether it is in open communication with warm equatorial water or the cold oceans of polar regions.

We have seen how, in the course of geological periods, mighty mountain chains were formed and then gradually levelled; their gradual elevation to great heights little by little cools the climate at their base, whilst around them the reciprocal effects of continents on islands, and land masses on seas, change incessantly. So that not only have there everywhere been slow yet ceaseless modifications in the general nature of meteorological phenomena, but all that was accomplished by the agency of the sun's energy on the earth has also undergone consecutive changes of aspect.

The study of plant and animal fossils by palæontologists would seem to support all that has been said above as to climatic changes. To-day there are animals and plants peculiar to cold countries, and others to temperate and hot countries. Conifers, birches, and analogous trees constitute the stock type of vegetation found on high mountains and more or less polar regions; annuals and caducous trees abound in temperate regions ; tree-ferns, cycads, palms, monocotyledons with large flowers, spices, such as the cinnamon, the clove, etc., at once evoke the idea of tropical countries, just as coral reefs and the greater shell-fish immediately suggest tropical seas. It is generally held to-day that, in warm climates only, can such creatures flourish as crocodiles among the greater reptiles, birds such as parrots, and mammals such as the elephant, rhinoceros, hyena, panther, lion, tiger, and monkey. We judge the climate of a region by the presence among its fossils of the remains of plants or animals analogous to whose habitat is known to-day. The method is far from unimpeachable, and the misadventure which befell even Cuvier should be enough to warn us to proceed in this direction with the greatest caution. The elephant was regarded by Cuvier as belonging to a warm climate; so that the discovery of the bodies of mammoths with flesh and hair still preserved, in the Siberian ice, seemed to him to prove that this country once enjoyed a tropical climate. To explain the presence of elephants buried in the ice he did not hesitate to assume that, owing to some miraculous 
cataclysm, a tropical climate had been instantaneously transformed into a glacial one. Mammoths were simply hairy elephants adapted to life in arctic countries, where they lived together with the rhinoceros and other species of animals whose representatives to-day are found only in tropical climates.

In fact, living organisms are exceedingly untrustworthy guides to climate for two reasons:-

I. Since they were produced successively only, the first organisms achieved spread over the whole globe without difficulty, with the result that the flora and fauna then presented a homogeneity giving the impression of great similarity in the conditions of existence, because we are accustomed to see a close correlation between these conditions, when they are diverse, and the presence of certain animal and plant groups. This is the case, for instance, for the ferns, horse-tails, club-mosses, conifers, and cycads which throughout the Primary Period constituted the flora of continents that possessed no flowering plants at that time. The same holds true for the Trilobites, cartilaginous fish, and carapaced Batrachians then dominating the fauna.

2. The same fauna can both adapt itself to and resist climatic conditions of the most varied kind.

The tiger, for instance, is encountered in the high cold plateaux of Tibet. Father Armand David also found monkeys and parrots there, and M. Lefebvre, in his excellent book Chaleur animale et bioénergétique, has described how he succeeded in getting a Cercopithecus to live under snow. ${ }^{1}$ Finally our domestic animals prove the extent to which an animal organism can adapt itself to the most varied conditions of existence.

Moreover, glaciers have again and again left traces which give us more precise information on the regions invaded by extreme cold than living organisms have given about heat. It is thus that the presence of glaciers during the Algonkian epoch, at a time when the oldest gneisses had hardly been formed, has been traced in Ontario, in the region between Lake Superior and Temiscaming forest, and in Minnesota, Michigan, Spitzbergen, and the Cape of Good Hope. It was the period 
in which the Caledonian chain attained its greatest height. At that date there were not only polar glaciers, but glaciers comparable to those which, later on, marked the approach of the quaternary period subsequent to the formation of the Alpine-Himalayan chain. These glaciers were perpetuated at the base of the Cambrian formations in Norway, in the Yangtse district, in India, at Simla, and in the soutl of Australia. This, as we have already pointed out, is no reason why we should believe that the climate became cold at this epoch; for even to-day there are glaciers below the equator.

With these reservations we may here summarize the conclusions reached by geologists as to the climates of the different geological epochs.

The temperature of the seas seems to have been uniform during the Cambrian Period, and, in fact, there is no reason for assuming - at least, if at that time the orbit of the earth had not become markedly flattened-that this temperature was lower then than during the Silurian epoch that followed. The abundance of corals found at all latitudes in the Silurian seas does indicate warm waters, since the secretion of calcareous matter by marine organisms increases in activity as the temperature rises. No traces of Silurian glaciers have been discovered, but this may simply mean that erosion had levelled the Caledonian mountain chain to such an extent that its mountains no longer accumulated eternal snows upon their summits. There is nothing to suggest that conditions changed during the Devonian Period, though glaciers have been traced at the Cape of Good Hope. On the contrary, corals continued to flourish all round the North Atlantic continent in the region corresponding to the site of the later Hercynian chain in the Central Plateau, Bohemia, etc. In addition, the abundance of red sandstone, whose colour corresponds to that produced in our day in desert regions under the influence of powerful solar radiation, seems to indicate that in those regions. temperate to-day the sun's power was then far greater than it is now. The glaciers of the Cape of Good Hope have even suggested the possibility of the South Pole having become displaced by $60^{\circ}$, but if this were true the same ought to hold for the North Pole, and no indication of such a displacement exists. We must admit, then, that the glaciers of the Cape of Good Hope were the result of a local phenomenon, namely, 
the presence in this area of a high mountain chain during the Devonian epoch. These mountains, after a period of quiescence, seem to have extended to other parts of South Africa, India, and Australia. At any rate, during the second half of the Carboniferous Period in which the coal deposits were formed, enormous glaciers, uniting at certain points, developed on the slopes of the high mountains in the southern portion of the huge continent of Gondwana, which then comprised Brazil, Africa, Madagascar, India, New Guinea, and the western portion of Australia, and whose southern coast was washed by the southern ocean.

It was also at this time that the Hercynian chain arose on the North Atlantic continent, which was then washed by the tropical Tethys or Central Mediterranean Sea. Both in the North Atlantic and the Gondwana continents the land vegetation assumed, during the first part of the Carboniferous epoch, an importance it had not hitherto possessed. The uprising of the Hercynian range and the volcanic eruptions accompanying it troubled the ocean waters. The corals abandoned these shores and retired to the north, to the region of Dinant in Belgium, the Pennine chain in England, and even the neighbourhood of the Pole. The temperature of the sea in this area, therefore, did not fall below $20^{\circ}$, the temperature essential for the development of coral reefs to-day. The Hercynian chain soon attained its greatest altitude; its slopes became covered with a rapidly growing vegetation of the nonflowering plant families, whose only representatives to-day are modest herbaceous plants, such as club-moss, the selaginaceæ, and horse-tails, or those whose flowers are still in an undeveloped stage, such as conifers. The torrents rushing down these mountain slopes became powerful streams, which uprooted trees and carried them to lakes and wide estuaries where they collected and helped to form coalfields such as those in the south of England, the north of France, and Belgium. At the foot of these slopes, in vast marshes, there grew also plants with long underground stems, ferns, and cycads, whose leaves, dead branches, and trunks then accumulated where they were and led to the formation of coalfields of another type, such as those of the Central Plateau, for instance. The richness of these deposits is such that it was at one time believed, owing to an illusion comparable to that 
which the idea of cataclysms created in the mind of Cuvier, that an exceptionally high temperature and an especially humid atmosphere charged with carbonic acid were essential to their origin. Nothing of the kind, however, was required. It needed only slopes capable of supporting a dense vegetation, a uniform temperature, and a normally humid atmosphere, to permit the rapid and continuous growth of vegetation. And, in fact, there is not the slightest trace, in cross-sections of treetrunks of this period, of those concentric circles which in the cross-section of contemporaneous trees indicate yearly growth in obedience to the seasons. During the Carboniferous Period the earth enjoyed a perpetual spring, somewhat mitigated in high latitudes, recalling those regions which to-day are represented in Europe by the Alps with their perpetual snows and glaciers. All this accords with the hypothesis of a then greater solar diameter. The absence of flowering plants must have caused a greater uniformity in the vegetation than there is to-day, and the newness of the land flora also explains why there was as yet so little differentiation into species. The same plants, in fact, were distributed over the entire North Atlantic continent. A similar uniformity characterized the whole Gondwana continent; but their flora is entirely distinct. The relatively poor flora of the Gondwana, known as the Glossopteris flora, seems to suggest, especially in the south, a lower mean temperature than that of the North Atlantic continent, at least, if the vegetation of this continent was not of more recent origin. This flora later extended to other regions.

At the end of this epoch the beautiful flora of the North Atlantic continent began to become impoverished. The climate then no longer allowed an abundant vegetation. Over a large part of northern Germany, the southern Alps, eastern Russia, and the United States, heavy rains, sweeping along with them into the sands, now transformed into sandstone, chemical substances which they dissolved, alternated with long periods of drought and heat which gave to these sandstones the colour so characteristic of desert formations. The species that were typical of the North Atlantic continent could not protect themselves against the invasion of the more resistent species from the Gondwana continent which had not had to endure the test of a dry heat comparable to that of the present Sahara. This period of impoverishment in the northern flora coincides 
with the Permian Period. It probably then gave rise to phenomena analogous to those which have produced the Gobi desert at the foot of the Tibetan massif.

We now approach the beginning of the Secondary Period, the Trias, during which, it appears, the height of the Hercynian mountain chain had been considerably reduced, either through long-continued erosion or local subsidences. The mountains, which play so great a rôle in atmospheric condensation, having been markedly levelled, glaciers seem to have disappeared and the rains to have become less abundant. The dry and hot climate of certain regions during the Permian epoch appears to have become general, or, at least, more extended.

Although local differences in the mean temperature existed, nothing indicates that at this period there were climatic zones comparable to those existing now. Until positive proof is forthcoming that, at this epoch, the earth's axis approached a position normal to the ecliptic, with which periodic variations of position are inconsistent, and also that at that time its orbit approximated to that of a circle, we must assume, as has been pointed out, that the apparent diameter of the sun was very much greater than it is to-day. A very slight decrease in this diameter, without the axis of the earth changing its position, would be sufficient to cause the appearance of polar zones, separated by a torrid zone that was, in fact, very extensive, for there still existed at this period reefs and islands formed of madreporic coral in certain areas of Europe corresponding to Alsace, the north of France, and Wales. This torrid zone seems to have been characteristic of the climate of the Jurassic Period.

Throughout this quiescent Secondary Period, during which not a single chain of mountains was raised, and in which the slow action of erosion continued, nothing could have been produced suddenly-neither glaciers in the deep valleys nor violent atmospheric condensations; but a slow retreat of coral formations towards the south indicates a gradual restriction of the torrid zone and a compensating appearance of temperate zones towards the polar regions.

Corals long persisted in Alsace, in Switzerland, in the cantons of Argovie and Fribourg, and in the Jura, whilst in Lorraine they formed reefs twenty metres in thickness. The flora 
extending from lat. $50^{\circ}$ to lat. $7 \mathrm{I}^{\circ}$, however, was a temperate one, and annual alternations of temperature are indicated in the trunks of certain conifers, notably in those discovered in Graham's Land on the edge of the Vancouver Straits, and in the Araucaris by the concentric rings known in the conifers and dicotyledonous trees of our country, but which are absent in trees of the torrid zone. Thus there were evidently seasons in the polar regions, which, however, continued to enjoy a very mild climate throughout the Jurassic Period, whereas a tropical climate persisted in what are the present temperate regions. For if the corals disappeared suddenly in the north of the Central Plateau, doubtless as the result of a change in the direction of the currents, they appear again in the Tethys, beginning at Poitou, and also, somewhat later, in the Ardennes, and still later near Trouville, on the eastern frontier of Lorraine, to the north of Morvan, at Bourges, Sancerre, and even extend to Yorkshire; while in the Jura they lasted still later.

These conditions changed very quickly in the Cretaceous Period which followed. The corals were entirely replaced in the Mediterranean area by the Rudistæ, peculiar lamell:branch molluscs, which also congregated in immense reefs and came from warm waters, though they accommodated themselves to a lower temperature. Caducous dicotyledons made their appearance and developed more and more in the northern regions. The temperature, however, continued, if not very high, at least mild and fairly constant as it is to-day on the coasts of Brittany, for the bread-fruit tree and various cycads flourished side by side with small-flowered dicotyledons, such as Willows, Poplars, Birches, Oaks, Walnuts, Plane-trees, and Figs, and evergreens like Ivy and Oleander. Some gamopetalous forms-the Viburnum, and even monocotyledons were associated with them.

During the Nummulitic Period, which marks the beginning of the Tertiary epoch, Greenland and Spitzbergen still retained a very rich flora, and even kept it through the Neogene Period that followed, which clearly demonstrates that the polar regions had not as yet experienced any considerable decrease in temperature. The temperature indeed was almost that of the present Mediterranean lands. Grinnel Land, in lat. $82^{\circ}$, had the climate the Vosges have to-day; poplars, birches, 
silver-fir, and water-lilies flourished there. In Greenland, in lat. $70^{\circ}$, magnolias flourished. A little later, during the Oligocene Period, in the area corresponding to our present temperate regions, there was now a mixed flora, now a localization of temperate flora and tropical flora, indicating that the vegetation had come under the influence of the temperature of the coastal currents. On the other hand, the nature of the arctic flora in the Neogene Period points to a very definite increase of cold in these regions. It was in this period that the largest of our existing mountain chains was formed, and, as in the case of the formation of the Caledonian and Hercynian chains, glaciers soon made their appearance.

The plants of the warm climates gradually moved south and were replaced by trees with caducous foliage, bearing witness to an alternation of cold and warm seasons. The camphortree, however, still flourished at a latitude of $5 \mathrm{I}^{\circ}$, and palms at $50^{\circ}$; the flora was identical from lat. $38^{\circ}$ to lat. $54^{\circ}$-from Serbia to Finland.

By the time that the Alpine-Himalayan chain had attained a great altitude the Oligocene epoch was in full sway. The presence of these large massifs conduced to condensation, and the summer became rainy; but the winter still remained warm. Along the shores of Lake Constance there was a climate like that of Madeira and the south of Japan; the mean temperature of the shores of the Sea of Okhotsk was about I $9^{\circ}$. But a period of erosion and settling followed for the new mountain chains. Torrential rains, caused by their very height, ravaged their slopes, cutting deep valleys, and there was a tremendous extension of glaciers.

This brings us to the beginning of the Quaternary Period, which witnessed man's conquest of the soil. During this period, apart from the changes in land elevation due to the formation of mountain chains, it seems that extensive continental areas experienced aiternate elevation and settling movements constituting what are known as epirogenic movements. During the periods of upraising, the glaciers that had formed in the valleys of the high ranges extended very far, only to retreat again during the epochs of settling. The climate naturally became colder in the neighbourhood of the glaciers, but in regions distant from them it still remained mild. 
These periods of alternate invasion and retreat of the glaciers are called glacial and inter-glacial periods, and have helped to mark the stages of man's history. At that time the Egean communicated with the Black Sea. After an initial lowering of temperature in the Pliocene, the climate became less rigorous: the Hippopotamus, Rhinoceros, Elephant, Lion, and Hyena, all of them animals to-day confined to tropical areas, flourished in southern France. The glaciers, however, once more gained the ascendancy (the Munsterian age), and spread over oneseventh of the whole land area of the globe, a total of twenty to twenty-five million square kilometres. In the United States they reached $40^{\circ}$ lat., somewhere in the neighbourhood of New York; in Europe they extended as far as lat. 50 covered England, North Germany, Scandinavia, and Russia up to the Vorona. The prehistoric ${ }^{1}$ Mammoth and Rhinoceros, whose descendants to-day are practically hairless, were then provided with a coat of woolly hair. When the ice retreated Lemmings were to be found near the glaciers, and further southwards Reindeer, arctic Hare, and arctic Fox. In fact, the fauna of the Steppes reached as far as the Pyrenees. The temperature subsequently became somewhat warmer and the air drier (the climate of the tundras). This was the age of the reindeer, which in the period following was temporarily to be driven northwards, to reappear at the end of the Pleistocene and again to descend to lat. $43^{\circ}$.

To what are we to ascribe these variations of temperature that brought about four successive glacial invasions? Formerly, when it was generally assumed that there had been only one glacial period, the explanation of Croll and Geikie sufficed which postulated a gradual lengthening and flattening of the earth's orbit. But the existence of several glacial periods renders this hypothesis of little avail as an explanation. It is also contradicted by the fact that the glacial period would thus seem to have made its appearance simultaneously in both hemispheres. A periodicity connected with sun spots has been suggested, but the period of duration of such spots is far too short, and it is therefore probable that local phenomena were entirely responsible.

Local phenomena, however, have played but a secondary róle in the earth's history, and then only for short periods. 
They are dominated by two outstanding facts: First, that as far as our observation can be extended, that is to say during a period of nearly twenty million years, the polar caps retained a climate resembling that of the Mediterranean to-day; for this to be the case it would be essential that they should have been almost permanently illuminated by the sun. Secondly, the torrid zone, on the other hand, had remained constant in climate ever since the origin of life, but it had gradually decreased in extent, and there had been a very slow but continuous cooling of the polar regions, whose climate, having become rigorous and glacial, was preserved in regions corresponding to our present temperate zone. This we can explain only in one way, by admitting a progressive shrinking of the solar disc, and it is therefore to this dominating cause that those other and secondary conditions appertain that have given to the Pleistocene Period the variety of characters peculiar to it.

It is therefore the sun which has guided the evolution of the earth. The sun has shown himself to be the great artist who can repeat over and over again the forms of living creatures, and who is himself the creator of every variety of living form. The periodic alterations in the earth's orbit and the inclination of the axis to the ecliptic, mentioned at the beginning of this chapter, have undoubtedly played their part here, too, so that if geologists and astronomers could be induced to co-operate in their researches into these questions, it might be possible, by exhaustive discussion of the testimony gathered by each, to find some method of explaining the principal geological events and arriving at an accurate chronology. The calculations of astronomers themselves do not take into consideration all the facts of the problem, for they have specifically studied the consequences of those events that, on the supposition of stationary stars, relate to the influences they exercise upon one another. Everything relating to modifications in the form and constitution of the earth escapes their calculations, though these modifications must have been relatively greater than those acting on the sun, owing to the smaller size of the earth. These modifications may have intervened to increase the inclination of the earth's axis of rotation to the ecliptic, or to have rendered it perpendicular to the same without changing the geographical position of the 
Poles, and this would have sufficed to bring about a complete alteration in the seasons, or even to have caused their disappearance. They might equally well have altered the geographical position of the Poles without increasing the periodic modifications of the inclination of the earth's axis to the ecliptic. It is, however, only after the inadequacy of explanations based on astronomical calculations has been demonstrated that these new data can be studied to advantage. ${ }^{1}$

1 For questions relating to climate see Febrre's Geographical Introduction to History. 



\section{PART II}

THE PRIMITIVE FORMS OF LIFE 



\section{CHAPTER I}

\section{The Appearance of Life}

$\mathrm{O}^{\mathrm{F}}$ all the problems with which man's mind has wrestled the most perplexing is that concerned with the origin of life, embracing as it does the problems of humanity's own origin. Even before science came into being, the most daring tlinkers of every age attempted to find some explanation for it, as the forms of life, among which we ourselves occupy the most exalted position, confront us on all sides in a far more insistent manner than even the phenomena of wind and weather. Our ancestors had to move about in enormous forests where they encountered powerful adversaries, against which they had continually to measure their strength. Only from the other living creatures which surrounded them could they obtain all that was necessary for the maintenance of life, and only by a constant struggle could they wrest these necessities from their rivals and at the same time defend their own lives. So long as man imagined a Creator under human form he supposed the gods to be the creators of all living things - of plants or animals just as we see them around us, of germs destined to evolve according to the process which could be observed every day in the germination of seeds and the hatching of eggs. No further explanation was required. As time went on it was thought that natural forces were in themselves capable of causing germination, or even that certain substances in the course of fermentation, under the action of the sun's rays, either in the secret depths of the ocean or in the bosom of the earth-so often regarded as the great mother of all being-were capable of forming themselves into organisms. To this, the doctrine of spontaneous generation, Joly, Archimède, Pouchet and Musset attempted to give scientific form. It was the doctrine that Aristotle had already advanced; it had been accepted by Lamarck; defended against Pasteur by scientists such as Musset, Joly and Pouchet, faroured by the medical men, extolled by the most materialistic philosophers, it finally took on, in the nineteenth century, a quasi-scientific air. 
It must be admitted that though the remarkable experimental researches of Pasteur opened up unforeseen perspectives to medicine and surgery and provided curative art with a new kind of precision and new methods with inexhaustible possibilities, they were, at the same time, the source of endless difficulties for the scientific philosophy of the day. One unquestionably correct idea prevailed-that every phenomenon was preceded by causes which definitely and inevitably determined it. Claude Bernard had introduced into physiology the notion of determinism in living phenomena, and had thus destroyed the older doctrine of vitalism, which excluded such phenomena from the working of the ordinary laws of physical chemistry. Vitalism once discarded, the phenomena of life had perforce to be attributed to these normal natural forces. It was readily admitted that living matter, composed as it is of carbon, hydrogen, oxygen, nitrogen, and traces of various other simple elements might well have arisen and could be reconstructed in the same way as other simpler chemical compositions. Huxley, we know, even believed in the existence of one single substance, the physical basis of life, and to this he gave the name of protoplasm, a name which has managed to survive. The German dreamer, Oken, founder of a so-called Philosophy of Nature, which, in the early nineteenth century created quite a stir on the other side of the Rhine, had already postulated the existence of a primordial slime, in which all life had its origin. Huxley at one time thought that he had really discovered it in the slime of the oceanic depths; he called it Bathybius haeckeli, and, in spite of Huxley's subsequent abandonment of the notion, the impenitent naturalist of Jena continued to insist on the real existence of this spiritual god-child of his, ${ }^{1}$ though Huxley himself recognized it as being only a mineral precipitate of gelatinous appearance, which arises when distilled alcohol is poured into sea-water containing organic matter in suspension.

Thus the new thinkers argued that if protoplasm really existed, and if it was only an especially complex chemical compound possessing special properties by reason of its complexity, it might be obtained artificially by appropriate chemical processes. The ill-success of chemists in their attempts to reconstruct even a nitrogenous substance like 
albumen, the simple white of an egg, possessing no life, might be nothing more than a temporary check. Had not Berthelot, for instance, succeeded in combining carbon directly with hydrogen and nitrogen, had he not formed synthetic sugar; and had not chemists before, during and after his day succeeded in obtaining an infinite number of substances which had once been regarded as the exclusive and peculiar work of the life-force itself ? Directly the chemists could understand the constitution of nitrogenous substances such as albumenand the most skilful were at work upon it-was there not every likelihood that its reconstruction would be achieved? And, finally, if protoplasm was merely one of these substances, endowed with specific instability and a particular capacity for combination, was it indeed foolhardy to believe that this, too, would some day appear in the retorts and test-tubes of the chemists? It would unquestionably emerge as an indefinite and amorphous mass, but could it not be given the form and the perpetuating activity which would make a living organism? . . . All this beautiful dream the experiments of Pasteur threatened to destroy at one blow. If, indeed, the free play of forces and substances was incapable of producing living matter, if it was necessary in order to account for its formation to have recourse to a direct act of creation, why not then admit with Cuvier the direct creation of all living beings and consequently the fixity of species? To accept the foolish theory of spontaneous generation was to undermine that whole doctrine of evolution which had proved so satisfactory to man's reason and had, moreover, been substantiated by so many facts.

As the difficulties in the way of reconstructing living substances appeared to be invincible, the idea soon occurred to some to explain its advent as from another world. In IS2I de Montlivault decided that life-germs from other planets, perhaps those furthest removed from uts, had been brought thence to our earth-no one could tell how, for no winds existed in the interplanetary spaces to carry dust from one to another. These germs had developed on earth and given rise to the first living organisms. In I 853 the hypothesis of de Montlivault was taken up again and developed by Count Keyseriing. Life, he said, is eternal, like the world itself ; but in the course of ages changes its habitat. Germs travel unceasingly from one stellar system to another, quicken into being those stars ready to 
receive them, reanimate life in places where some premature catastrophe has destroyed it, and enrich it where it already exists by bringing with them greater variety. Thus, on our earth, a fauna extinct at the end of one geological period was replaced by a new one at the beginning of the following epoch, and this phenomenon was repeated over and over again. However, as we said before, the means by which these germs made the journey had still to be discovered. In I865 Count de SallesGuyon opined that they must come to us in meteorites or thunderbolts. But this presupposed a disintegrated planet endowed with a tremendous wealth of life. Richter and Cohn preferred the idea of cosmic dust or comets travelling through vast spaces and sowing life as they go. The great physicists Helmholtz and Lord Kelvin accepted this hypothesis, and also the master of the French botanical school, Philippe Van Tieghem. ${ }^{1}$ But the germs of life did not come from the planets alone ; they could come also from the stars ; and therefore they must be considered non-combustible. In I872, indeed, Preyer did not hesitate to attribute to them this marvellous property. He gives the name of Pyrozoa to creatures born of these germs and able to resist fire. Strange as it may seem, the great physicist, Arrhenius, likewise accepted the idea of insemination by the stars by means of spores analogous to the reproductive cells of algæ and mushrooms, which spores possessed tremendous power of resistance to the extreme cold of abyssmal space. These minute germs, he declared, were scattered through space by the centripetal force of the stars, which also threw out such a quantity of minute dust around the sun that it formed what we call its corona, a phenomenon easily visible during total eclipses. Germs of this degree of minuteness may conceivably exist, for there are many microbes that can pass through porcelain and are invisible to the ultramicroscope. However, Paul Becquerel has demonstrated ${ }^{2}$ that certain ultra-violet rays kill them; a low temperature certainly augments their power of resistance, but in the end they succumb. This demonstration completely destroys the hypothesis of an extra-planetary insemination, unless we assume that germs coming from other planets possess a constitution peculiar to themselves. However, in the very first place, this 
hypothesis was self-destructive. In actual fact it solved no problem at all. Wherever the germs of life may have come from, it remains to explain how they originated in another world; the difficulty has merely been relegated to a farther sphere.

All living organisms, moreover, consist of atoms of the same nature. Carbon, hydrogen, nitrogen, and oxygen must at least be present. These exist on the earth, as well as on other planets that have passed, are still passing, or will pass through the same stages of evolution. Why, it may be asked, should these elements have united outside our earth and yet have remained separate here? This would indeed be contrary to the fundamental principle of all science-that the same causes always produce the same effects. If at any particular phase in the evolution of the planets some sort of life has succeeded in manifesting itself, the earth should be no exception to the general rule. The task before us therefore is to investigate fearlessly how, at some particular moment in the past, life originated on this planet of ours, whereas now it can pass only from one living organism to its successors. But, before undertaking this task, we must first arrive at some agreement as to what it is that constitutes living matter.

It is not to be regarded as some special substance in which life resides and which constitutes its unique and necessary basis, something like an essentially unstable chemical compound in a condition of perpetual change. On the contrary, it consists of an assemblage of chemical compounds with sensitive reactions which allow us, even during their living state, clearly to differentiate and characterize them. Foremost among these compounds are those which bear so much resemblance in their constitution to the white of an egg that they have received the name of albuminoid compounds. They consist of carbon, hydrogen, nitrogen, oxygen, and a small quantity of some fifth body : sulphur, phosphorus, or another substance. With these so-called quaternary compounds are associated, in greater or less quantities, temary compounds consisting only of carbon, hydrogen, and oxygen. Some of them contain more hydrogen than is requisite for the formation of water in combination with oxygen, while others can be considered as the result of a union of carbon and water; these latter are called carbo-hydrates. To. the first belongs the group of fats: sugars, dextrine, starch, cellulose, etc., belong to the carbo-hydrates. None of these 
substances has a simple constitution. The molecule $\mathrm{CH}_{2} \mathrm{O}$, which represents the least complex of the carbo-hydrates, develops very high powers in organic carbo-hydrates, so that their formula is given by $\left(\mathrm{CH}_{2} \mathrm{O}\right)^{\mathrm{n}} \pm \mathrm{pH}_{2} \mathrm{O}$. Thus glucose has the formula $\mathrm{C}_{6} \mathrm{H}_{12} \mathrm{O}_{6}$; the starches and cellulose $\mathrm{C}_{5} \mathrm{H}_{11} \mathrm{O}_{5}$ and cane sugar $\mathrm{C}_{12} \mathrm{H}_{22} \mathrm{O}_{11}$.

The fats are more complex: tristearine, for example, has the formula :

$$
\mathrm{C}_{3} \mathrm{H}_{5}\left(\mathrm{C}_{18} \mathrm{H}_{35} \mathrm{O}_{2}\right)^{3}=\mathrm{C}_{57} \mathrm{H}_{110} \mathrm{O}_{6} \text {. }
$$

But the highest degree of complexity is obtained by the albuminoid substances. For instance, the constituent part of the blood corpuscles of the dog has the formula :-

$$
\mathrm{C}_{726} \mathrm{H}_{1171} \mathrm{O}_{214} \mathrm{~N}_{191} \mathrm{~S}_{3} \text {. }
$$

The exponential numbers in these formulæ indicate the number of atoms of carbon, hydrogen, oxygen, nitrogen, and sulphur that enter into the constitution of the bodies represented. For example,

A molecule of glucose contains 24 atoms.

A molecule of tristearine I53 atoms.

A molecule of albumen 2,305 atoms.

A molecule of albumen, then, is a structure almost a hundred times as large as a molecule of glucose, and more than thirteen times as complex as a molecule of fat. It might be compared with a house of cards, or, at least with one of those fragile towers which children build with dominoes, and which the slightest shock will overthrow. However small any mass of living matter may be, it, nevertheless, contains a certain number of these molecules, as well as sugars, starches, and fats, all of which may exist side by side without any alteration so long as they are not exposed to the influence of the oxygen in the air, a most powerful disintegrating agent, or mixed with certain other also exceedingly active substances called soluble ferments, diastases or enzymes.

Ferments are chemical compounds which can be dissolved, precipitated, and then dissolved again; they pass through fi'ters slowly, and, as they do not absorb nourishment, they cannot be described as living substances, although they !ose all their activity when subjected to heat above roo'. They then appear to perish. They possess the property of acting 
upon certain organic substances, the carbo-hydrates, fats, and the albuminoid substances in particular, causing fundamental changes, and themselves undergoing transformations so slight in character that some experimentalists have thought they are not modified at all by their activity. Certainly the influence they exert is entirely out of proportion to the amount of their own substance that is altered and the enormous mass of substance they transform. There is an exceedingly large number of these ferments acting respectively on the carbo-hydrates (diastases) on the fats (lipases) or on albumens. Each one possesses its own specific action-decomposition, hydration, dehydration, oxidation, reduction, coagulation, or dispersion, and though simple, they suffice to displace, transform or break up complex organic substances. Each ferment frequently has some counterferment which neutralizes what it has accomplished; some are only active when associated with others which assist them; frequently they possess a reversible activity, and are capable under certain circumstances of reconstituting the bodies they have destroyed. ${ }^{1}$ They are frequently poured into the body of the organism by glands outside of which their action takes place, but they also mix with other associated substances to form a vital element, and their very presence suffices to stimulate the activity of substances that would otherwise remain inert. Through their agency, associated organic substances undergo unceasing interchanges and reciprocal modifications in the presence of the oxygen of the air and the water impregnating them. The larger organic molecules break down, so to speak, upon the others; but it is the characteristic of life that in this disintegration the more complex substances split up the simpler and annex the broken-down fragments, so that the unceasing process of decomposition is yet balanced by a building-up and an actual increase of the substance brought into action. This increase is called mutrition, and its natural consequence is reproduction.

Life, thus understood, is not the work of a single substance, but rather a result of the reciprocal reactions of a certain number of definite substances. These, moreover, are not without individuality. They appear in a relatively small number of groups, which in all living organisms seem to possess the same fundamental chemical structure although they differ 
in detail. The fundamental substance of the blood corpuscles, the green colouring matter of plants, the chromatin that plays such an outstanding part in the nutrition of the anatomical elements, the pigments, etc., all have a composition which may vary sometimes in kind, as Armand Gautier has demonstrated in connexion with the vine and various kinds of catechu, or from one variety to the other, but all belong to the same chemical type.

Hence we no longer seek to solve the problem of life-creation by looking for a special substance that is to represent "the physical basis of life", as Huxley believed, but by studying synthetic processes by which substances that in themselves may be commonplace and inactive, such as carbo-hydrates, fats, albuminoids, and ferments may be grouped or altered in nature. The turn recently taken by organic chemistry in reproducing artificially all those substances formerly believed to be the exclusive work of life, and the achievement of Marcellin Berthelot in producing synthetic sugar from hydrogen, carbon, and oxygen, justifies us in believing that the problem is not insoluble, and that, if the albuminoids still resist our attempts, their resistance will not be of long duration. However, we have yet a more delicate problem to solve-how to compound the recipe of different substances that must be combined if life is to be produced and maintained. This is a task of particular difficulty, as we do not yet possess any precise data on the constitution of those combinations in which infinitesimal traces of certain bodies can bring about fundamental changes. Yet what we are unable to achieve was done spontaneously in the beginning. If we are to suppose that elements capable of producing life when they come into contact with each other were formed at a given moment under influences still to be determined, they must have met and combined in all sorts of proportions, and the most complex combinations must have taken place as well as the most simple. Those that fulfilled the particular condition under which the reciprocal reactions of substances, accidentally brought together, led to an increase in the quantity of the total, constituted the earliest forms of living matter; and we may admit that such masses of living matter were at first quite amorphous and of unlimited dimensions. Now there exists a certain albuminoid substance which, when mixed 
with other albuminoids, possesses the property of forming from the carbon dioxide of the air and from water-vapour the carbo-hydrates that represent the most important primary foods. This substance is chlorophyll, the green colouringmatter of plants. After the carbo-hydrates have once been formed, the albuminoids already existing and the ferments accompanying them utilize the carbo-hydrates in the manufacture of new quantitics of albuminoid substances, including chlorophyll. It is therefore through the agency of chlorophyll that life can be perpetuated, and this leads us to think that the first masses of living matter were green, and if they still existed would be classed in the vegetable kingdom.

Water-vapour and carbonic acid from the air are unable to penetrate any organic compound except through the surface. It is therefore very important that the latter should develop as far as possible. Under the most propitious conditions this result could be achieved by a pulverization of the initial mass into small globules and microscopic granules such as those formed on the moist trunk of trees by Protococcus viridis. After they have attained a certain size these granules multiply by fission. This is the origin of the cellular constitution of living creatures. A pulverulent form like that of Protococcus results no doubt from certain advantages it presents in respect of nutrition. This we may well believe on the grounds that certain organisms such as the tan mould (Fuligo septicum), which do not absorb nourishment through their surface, but introduce into their substance digestible food particles, are able to form gelatinous masses, two to three decimetres in diameter and two or three centimetres in thickness, and can move themselves about by crawling.

It is possible that the animal and vegetable kingdom might already have been differentiated in this fashion. The green colouring-matter of the plants, chlorophyll, cannot combine atmospheric carbon dioxide and water-vapour, and at the same time eliminate oxygen, except by the action of the sun's rays. This process can be accomplished by living matter only through a surface that is free and exposed to the light. Nothing, however, prevents the soluble carbo-hydrates from penetrating the entire living mass if they are present in sufficient quantity, or, consequently, prevents the nutrition of which they are the basis from taking place, at some part far removed from 
the surface and from the light. There we see the first signs of the method of nutrition adopted by animals. Oken's hypothesis of a primeval slime (Urschleim), out of which all animals and plants have developed, is not therefore untenable. Organisms in the form of a simple mass of slime are, indeed, so exceptional that in all probability it was only after the pulverulent form had been developed that the separation of the two kingdoms took place, by means of a process analogous to that which we have just described.

The multiplication in situ, by fission, of these green granules, each one enveloped in a membrane formed by the exudation of carbo-hydrates not utilized in nutrition, must have sufficed to form a thick layer of vegetable powder which the solar light was finally unable to penetrate. The multiplication of vegetable powder would be none the less continuous because the nutrition had not been interrupted. Chlorophyll is only produced under the influence of those invisible ${ }^{1}$ or luminous radiations which form the solar spectrum. These rays are excluded as soon as the powdery mass has become sufficiently thick, but this does not prevent excess soluble carbo-hydrates, washed down by the dew, for instance, from passing into the deeper layers. These deep-sunken granules, if sufficient in number, continue to envelop themselves in cellulose and to feed by absorbing dissolved substances, but they form no more chlorophyll. Plants of this kind, which have no chlorophyll, are known as fungi. Underneath these, in our hypothetical layer of living granules, the carbo-hydrates are scarcer and are completely absorbed during nutrition; the granules build no more cellulose exudate, and the living slime remains free and mobile, as in the case of tan mould. Since it translates the stimuli it receives into visible movements it must consequently be sensitive. Mobility and sensitivity are characteristics of the animal kingdom, which thus appear as a degraded condition of primitive plant-life, to which is linked such forms of mixed origin as the fungi. Mobility and sensibility, however, have enabled the animals to come into their own by other means, and to raise themselves to the highest manifestations of life.

1 It can be formed by the infra-red rays alone in various species of microscopic algæ (Chlovella, Dictyospharium, Hormococcus, Pleurococcus, etc.), ferns, certain conifers, bulbous plants like onions or parasites like the mistletoe. 
Thus we see how the mere process of nutrition has sufficed to decompose our hypothetical layer of living granules into three strata : a green one corresponding to the algæ, a colourless one containing granules enveloped in cellulose corresponding to the fungi, and one with free granules, corresponding to the animals.

The knowledge we possess to-day thus permits us to form a logical idea of the conditions necessary for the appearance of life, alike for the formation of the animal and vegetable kingdoms, without presupposing the interference of anything but ordinary chemical or physical phenomena, or appealing to any but the simplest considerations-which to some people may appear even too simple. Natural laws, however, are always simple. It is only our mind that loves to surround itself with mystery and complication.

It may naturally be asked why those cells which do not form chlorophyll when they are in the dark should not again develop the power to do so when they are brought into contact with light. But it is a general rule that a function which is not exercised disappears, and the faculty of making chlorophyll can disappear even in the higher parasitic plants like Monotropa, the broom-rapes, and orchids of the genus Neottia, just as in the underground roots of ordinary plants.

One particularly tantalizing problem remains. If life has developed on earth in the manner here indicated, why does living substance no longer continue to form ? The conditions under which life is being actually maintained on earth suggest the direction in which many look to find an answer to this question. Herbivorous animals obtain their food exclusively from plants; carnivora live on the flesh of the herbivora; thus they, too, in the final analysis, are nourished exclusively by plants. Fungi, too, are dependent upon plants, to which they are parasites, either directly or through the medium of animals. Green plants are thus the great purveyors of nutrition to all other living organisms. They themselves obtain their mineral and nitrogenous food from the earth, and the indispensable carbo-hydrates from the atmosphere, but they can do this only by means of the sun's rays. Hence it is the sun, and the sun alone, that ultimately supports life on earth. If this is true, and it is indeed incontestable, we are naturally led to ask whether it was not the sun likewise that originated 
life; whether certain of its rays are not capable or, above all, were not formerly capable of producing directly those combinations that enter into the constitution of all living matter. Then we see how Daniel Berthelot and Gaudechon obtained synthetic carbo-hydrates by the reciprocal action of carbon dioxide and water, in the absence of any chlorophyll and solely under the influence of ultra-violet rays emanating from a tube of mercury vapour. The same rays enabled them to obtain formamides through their action on a mixture of carbon dioxide and ammonia gas. Formamide is the simplest of the quaternary substances, of which the albuminoids are the most complicated, and a combination of which constitutes the protoplasm which uses the carbo-hydrates as a food. Here we are on the path that ought to lead us to the origin of life. At any rate, it has been demonstrated that if certain ultra-violet rays kill spores, others, on the contrary, are capable in themselves of producing combinations which were for a long time believed to be possible only if certain organic substances were already present; and it is these very rays that do in fact penetrate our atmosphere. ${ }^{1}$

After giving his results, Berthelot adds: "The fundamental reason for the efficacy of ultra-violet rays seems to be their extremely high temperature. The higher the temperature of the source rises, the richer it becomes in ultra-violet rays. And when the reflection of a mercury-arc is projected upon that of the solar disc we recognize by the physical phenomenon of the displacement of the lines in the spectrum that the temperature of this arc is greater than that of the sun." Now it is certain that the portion occupied by ultra-violet in the solar spectrum was at one time greater than it is to-day. The sun, in fact, belongs to the group of yellow stars-Arcturus, $a_{2}$ of Centaur, the Polar star, etc. It is now already colder than Procyon and Canopus, which also belong to the yellow stars. The sun was unquestionably, at some distant epoch, far hotter than it is to-day; we can even reconstruct the various stages through which it has passed by studying the white and bluish stars that are by far the hottest of all. Some of the white stars, such as the majority of those in Orion and the Pleiades, Regulus, the $\beta$ of Centaur, Deneb, etc., are evidently the seat of electrical discharges produced under very special conditions ; 
others, again, are distinguished by the abundance of helium and hydrogen present in their atmosphere, indications of tremendous radio-activity. The bluish-white stars are even hotter; the ultra-violet portion of their spectra is very extensive, and includes radiation of particular intensity and of unknown origin, and the presence of helium in their atmosphere implies that they are also the seat of important radio-active phenomena. ${ }^{1}$

During the period when the sun was passing through these various stages, the chemical activities taking place on earth under its influence must have been more numerous and emphatically more powerful than they are to-day. The ultraviolet radiation was of greater extent than in our mercury vapour lamps to-day, and the chemical combinations this radiation was capable of stimulating must have been far more varied than those which we can bring about to-day, and which would be a necessary condition for the appearance of life. Ultra-violet radiation emanating from the sun and capable of penetrating our atmosphere was then able to achieve results which the irradiation of the present epoch is no longer capable of accomplishing unaided. Thus it is that we can explain the lack of spontaneous generation in our own day. Moreover, the earth itself, during that far-off period, was at a different stage. It was possessed of greater radio-activity, and its atmosphere contained hydrogen, helium, and perhaps other elements developing from the disintegration of various simple substances, at that particular stage which chemists call the nascent state, during which their chemical affinities were higher; hence we have another reason why combinations impossible to-day could then have been produced. It must have been from quaternary substances, more complex than the formic amides, that the true albuminoid substances developed. After the simplest of these had been obtained, the formation of the others became a purely chemical phenomenon. The researches of P. Schützenberger, A. Kossel, E. Fischer, L. C. Maillard, and others, on the constitution of albuminoid substances, essential factors in chemical life, at any rate, have thrown considerable light on the constitution of the quaternary substances. A preponderating part in their constitution is played by the amino-acids, formed by an acid agent 
resulting from the union of oxygen with carbon ( $\mathrm{COOH})$, and a basic agent resulting from the union of hydrogen with nitrogen $\mathrm{NH}_{2}$. These two agents are united in a single molecule without, however, being neutralized in their respective functions. From this it follows that the acid agent of the molecule continues to " attract the basic substances that are within its range, and the basic agent to attract the acid substances". 1 When the basic substances are derived from another amino acid a new body is produced by the elimination of a molecule of water so constituted as to regenerate, at the expense of substances annexed, the acid function of the primitive body. The same holds true for the basic function when it is this which co-operates in the elimination of a molecule of water. As the result of this double interplay, compounds of any degree of complication whatsoever can be obtained, and thus we may entertain some hope of being able to construct the enormous, unstable molecules with reciprocal reactions which give rise to the chemical phenomenon of life. The school of Fischer has already obtained substances analogous to the peptones into which the albuminoid food substances are first resolved in the course of digestion. With the aid of these peptides we ought to be able to reconstruct the substances from which the peptones come, and obtain the peptides themselves by methods more akin to those employed by living beings. This is what a number of chemists have attempted : Balbiano, Trasciatti in Italy, and Maillard in France. By means of a suitably induced reaction from pure glycerine and amino acids, Maillard has succeeded in obtaining bodies with a strong resemblance to peptones, to caseine, and to keratin substances which are the albuminoid substances par excellence. It is probable that by substituting sugars and alcohols for glycerine we might obtain other results equally as important. It is true that a temperature of $170^{\circ}$ to $180^{\circ}$ would be required to accelerate the reactions, but these can be obtained at lower temperatures if other accelerators are employed. The diastases, which are simply albuminoids of a nature still inadequately determined, and which are known to act especially by hydration and dehydration, appear to be capable of doing this work. If, therefore, it is true that all these substances might have arisen

1 L. C. Maillard, "Recherche du mécanisme naturel des formations albuminoïdes", Presse médicale, 17. Fév. 1912. 
unaided through the mere action of diverse radiations emanating from the sun or from radio-active bodies, then we can understand how it was that certain of these combinations might have represented the first living substances.

The question of the first appearance of life returns, then, like the whole subject of physiology, to the domain of physical chemistry. Life arose during conditions which we can now mentally reconstruct, and which still unquestionably persist in some stellar systems, but which have disappeared from the solar system, never to return. The faculty of giving birth to living matter gradually became the province of living beings alone, as the solar radiations and the radio-activity of the earth became feebler, but it has not always been their exclusive privilege. Physical astronomy, disclosing to us the stages of this impoverishment in stars of different ages and of different size, has brought Pasteur's conclusions into harmony with reason, and discredited all those hypotheses-so daring but so contrary to the scientific spirit-of a semination of life on the earth by germs of unknown origin coming from the great Beyond.

Under what form, then, did the first living organisms manifest themselves? The earliest fossils we know date from a period so much later than the first appearance of life on earth, and so many forms have disappeared during the metamorphosis of archaic formations that palæontology cannot aid us in this respect. However, the ties that unite the actual living forms are such that one form can be deduced from the other, on the hypothesis that they are the outcome of a natural evolution, with laws which can be precisely stated. These laws, in turn, permit us to reconstruct with great verisimilitude the different stages through which their various predecessors have passed. After this primary period, palæontology can provide us with landmarks and the means of checking the inferences we draw from the study of the structure and the embryogenetic development of beings now living, and of the modifications to which they are susceptible. This matter will form the subject of the next chapter. 


\section{CHAPTER II}

\section{The Genealogical Basis of Organic Differentiation}

$\mathrm{N}$ spite of the many millions of years that have elapsed since 1 the first appearance of life on earth, and even since the arrival of organisms with definite forms transmitted from generation to generation, so many simple types still persist that we can obtain an impression of sequence in living beings, complete from the initial forms onwards. This is one of the most astonishing facts that confront naturalists. It is true that innumerable secondary series connected with the complete cycle have disappeared, but the chain itself has been left sufficiently intact to render its reconstruction comparatively easy. The unicellular organisms which seem to possess the simplest form next to the "primeval slime", in which life can manifest itself, still abound in both the animal and vegetable kingdoms. Among the very oldest fossils we find not only bacteria but Globigerince and Orbuline, similar to those which now float upon the surface of the seas far distant from the coasts. We can trace sponges closely related to the beautiful Hexactinellidæ, with their skeletons of elegant opalescent lacework, that are still dredged from the waters of the coasts of Japan and the Philippines, and from the deepest parts of our own seas; we also find polyps; segmented forms which have been conserved, in their general character at least, in the Limuli of the Moluccas, Japan, and the Antilles, as well as in the Estheridæ, Nebalidæ, and in the species of Cypris of our oceans or fresh waters ; and, finally, Lingula and other unsegmented Brachiopods, which are highly modified descendants of annelid worms. Echinoderms are also encountered-of very special types, it is true, and molluscs with shells, already differentiated into the three present classes of Cephalopods, Gasteropods, and Lamellibranchs, of which the Octopus, Snail, and Oyster are the best-known present day examples, so far removed from the primitive types that we 
only cite them here in order to give a clear idea of the nature of these classes.

The comparatively abrupt appearance of so many organic forms has sometimes been regarded as evidence against the evolutionary theory. Again and again it has been proved that a new flora and fauna have suddenly appeared in some geological stratum after the complete disappearance of older ones preserved in the strata immediately antecedent, and the most ardent disciples of Cuvier considered this an unanswerable argument in favour of the hypothesis of independent creations. Alcide d'Orbigny succeeded in computing twenty-seven catastrophic phenomena of such a kind. However, it has been possible to show that in many cases layers now directly superposed in certain localities were at one time separated by intermediate strata containing transitional forms, or else to establish the fact that the higher layer was laid down only after a long period of subsidence, during which the lower layer had been subjected to considerable erosion. Hence the argument is destroyed. On the other hand, we have been able to follow, through long periods of time, continuous successions of forms which are manifestly derived from one another, but which might have been regarded as distinct species had they been considered by themselves. This, for instance, is the case with the spiral Ammonites of the Secondary Period, so thoroughly studied by Neumayer, Mosjisowic, Douvillé, Haug, and others; with Planorbidæ of the Miocene lake at Steinheim in Würtember, of Paludinidæ of the great Pliocene lakes of Slavonia and many others. We are consequently justified in assuming that every apparently sudden displacement of one fauna and flora by another is really the result of some interference in the deposits, whether of short or long duration, often due to a sudden subsidence which occurred between two apparently consecutive periods, corresponding to the two faunas and floras which appear to succeed each other. In connexion with the differences we observe between them, we do not know what part may have been played by transformations in situ and wellauthenticated migrations of animals and plants from one region to another.

Palæontology teaches us as little about the origin of life as it does about the origin of organic types or the causes that have produced them. Its sadly defective data can be of use only in 
verifying the laws deduced from a strict comparison of living forms and from the careful study of the possible influence exerted upon them by exterior environment, either in their adult forms or in the course of embryonic development.

The laws thus formulated have as rigorous and as absolute a character as those which control physical and chemical phenomena. After they have once been established in a definitive manner, the past history of each one of the main groups of living organisms can be reconstructed and the various phases of this past linked to preceding causes. Thus we may eliminate the valueless hypotheses and illusory philosophical conceptions which have so long concealed the true explanation of facts under false principles purporting to be axioms. Such erroneous notions are to be found in Leibnitz's principle of continuity-the Natura non facit saltus of Linnæus-Geoffroy Saint-Hilaire's law of unity in the plan of organic form in the animal kingdom, Cuvier's theory of unity, even as limited to the main branches, Charles Bonnet's "ladder of being", Blainville's Degeneration of Types, etc. These premature conclusions based on limited observation, satisfied human reason only at a time when science could not pretend to explain the nature of living organisms, in the proper sense of the term.

Darwin ${ }^{1}$ made admirable use of instinct and of sexual selection to explain the preservation, diffusion and even perhaps the exaggeration of useful characters. He could offer an explanation of the adaptation of animals and plants to the conditions of their existence, an adaptation so close that it gave rise to the notion of their predestination for these. He could explain the splitting up of the zoological and botanical series into species separated by seemingly unbridgable gaps. But his theories did not go so far as to determine the causes that made the distinctive characters appear.

Darwin did not even broach the problem of the significance of structural types as they are now called, in either the vegetable or animal kingdom. Later on Weismann ${ }^{2}$ assigned a mysterious function, in the evolution of organisms, to the living substance which mainly constituted the reproductory cells for which he claimed a constitution different from that of the body-cells. This substance he called the germen, or germ 
plasm, and regarded it as the sole depository of the forces regulating the evolution of organisms. The other substance, the soma or body-plasm, although distributed throughout the whole body, he considered as a protection provided for the needs of the germ-plasm, to protect it against the action of the external environment, to whose influences alone it yields. It is quite evident that such a conception is the absolute negation of every scientific explanation of living organisms, and it is indeed strange that no one should have perceived how the facts upon which it rests, far from serving as a starting-point for a general theory of evolution, were actually the specific result of a modification of embryogenetic processes concerning which we shall shortly have more to say. We have more reason to dwell on the important modifications that organisms exhibit under the influence of numerous internal secretions and of certain substances introduced from outside, such as the secretions of a number of parasites ${ }^{1}$ or the poison injected by the sting of particular insects, ${ }^{2}$ which have led us to postulate the existence of special substances, the hormones, ${ }^{3}$ which stimulate the various organs to react upon one another at a distance, and thus maintain the necessary solidarity within the organism. The hormones and the parasitic secretions constitute the mechanism of this reciprocal adaptation of organisms, the importance and range of which I pointed out in I88I, in the following terms :-4

"The direct causes for division of labour and the modifications connected with it in the associated merids are found in large measure, as in the case of the plastids, in the social life itself. Whenever two or more organisms enter into constant relations with each other, modifications of a more or less important nature take place in each of them."

In making use of the term social life, we come to the question that dominates the entire evolution of living beings, nameiy, the nature of that mechanism regulating the constitution of the long series of organisms, which begins with the first minute living things and culminates in types that are so far removed from the original starting-point in size, form, complexity of structure,

1 The wasps of the Terebrantia series, for example, producing the galls of the corn blight, etc.

a Galls produced by Cynipidæ. XXIII and XXV. ' XXVIII, 710. 
variety of functions, and in intellectual manifestations. As usual, a number of a priori ideas at first obscured the meaning of the facts. Because our own personality has always been regarded as an indivisible unit, and as indeed this word "individual", so often used to designate ourselves, has come to mean just that-i.e. an indivisible personality-we experience some difficulty in recognizing that this individuality was not achieved at the first attempt, hence the resulting inevitable conclusions meet with some resistance, even from people of distinguished intelligence. Even if we admit that in the beginning things might have happened otherwise, practically all organisms that have passed the stage of the primitive living slime are to-day constructed along similar lines and have attained their definitive structure in the same way. We might add that the exceptional cases that have been discovered, such as the Algæ of the Siphoneæ family, the Fungi of the Myxomycetes group, the Infusoria of the genus Salinella of Semper, can all be easily referred to the same general principles.

The outstanding facts which we cannot possibly ignore may be reduced to these four propositions :-

I. Every organism, be it animal or vegetable, is formed by the assemblage of elements, generally microscopic in size, possessing a similar fundamental constitution, and known as cells, anatomical elements, or, more recently, plastids.

2. Some organisms exist that consist of but a single plastid, and in nature to-day a multitude of forms, constituted by an increasingly complex association of plastids, form a chain linking together these isolated plastids, and the most complex organisms.

3. Every living being starts from a single plastid, the egg, and only attains its final complexity through repeated division of the first plastid and those arising from it.

4. The plastids that live as independent units divide as soon as they have attained a certain size, in just the same way as those destined to constitute organisms; the only difference is that the plastids resulting from this subdivision separate from one another as soon as they are formed, whereas they remain contiguous when they form part of an organism.

This is equivalent to saying that the higher organisms are exclusively formed by the gradual association of an increasingly large number of plastids. Through this union they unquestionably lose a certain amount of their independence, 
but in spite of this they conserve a large measure of individuality. It has always been known that certain parts of a plant could be separated from the plant itself without dying, and that if placed in propitious conditions could subsequently give birth to a new plant. As early as I740-4 ${ }^{1}$ Trembley showed that the freshwater Hydra could be dismembered in a similar manner, and since then it has been discovered that sponges, polyps, and all ramiform organisms possess this property. Transplantation of tissues and grafting have even succeeded as completely with the higher animals as with plants, and within recent times Dr. Alexis Carrel has succeeded in maintaining life and promoting growth in pieces of connective tissue, even nerves, under proper artificial conditions, without the aid of any organism. ${ }^{2}$ This directly proves the independence of anatomical units as Claude Bernard had deduced from his physiological experiments.

This independence still appears in the course of embryogenetic development. The first phases of this development consist in division of the egg into two elements, then four, eight, etc., all of which are quite alike as long as the egg does not contain a large quantity of nutritive material and as long as they are not so numerous as to necessitate an arrangement in to superposed layers. These units are called blastomeres. They resemble the egg itself. Certain eggs, when violently shaken, divide into the two original blastomeres, and each one of them develops independently and produces an embryo differing from the normal one only in being half its size. ${ }^{3}$

Such a separation of blastomeres can take place spontaneously but accidentally, even in man. The egg then develops two exact counterparts, always of the same sex, and in the case of the mammals, possessing only one placenta. What is purely accidental in man is of normal occurrence among such mammals as the armadillos, the carapaced Edentata of South America. The egg of the nine-banded Armadillo always divides in such a manner as to produce four of a sex at the same time ; ${ }^{4}$ and that of the hybrid Armadillo

I XXVIII.

2 XXIX.

3 Driesch $(\mathbf{X X X})$ experimented thus on the eggs of the Sea-urchin and of Amphioxus, and Bataillon (XXXI) has done the same for the Lamprey.

${ }^{4}$ De Morgan, XXXII, for a highly specialized fish belonging to the Malacopterygii. 
to produce seven, eight, or nine ${ }^{1}$ at a time. To cite a more extreme instance, if the fertilized egg of the sea-urchin is placed in water deprived of calcium, as in Herbst's experiment, the first thirty-two blastomeres can separate and develop independently, and produce the beginnings of as many as thirty-two embryos. Such a division is produced naturally in the embryo of certain minute four-winged flies, akin to the wasps, and which might indeed be considered as lilliputian wasps. The larvæ of these insects, minute in size but already highly organized, develop either within other larvæ imprisoned in galls, the larvæ of certain mosquitoes, the Cecidomyia, or more frequently in very small common caterpillars, like those of the moths of the genus Hyponomeutia which live on the spindle-wood. The parasitical caterpillars always contain a multitude of larvæ. As many as three thousand have been counted, and for a long time naturalists were puzzled as to why there was no intermediate condition between the presence of vast numbers of parasites and complete immunity, since the fertilized fly itself contains not more than a hundred eggs. The problem was solved by Marchal. ${ }^{2}$ The embryos of the majority of insects are enclosed in a sac, the amnion, derived like them from a cellular membrane, the blastoderm, formed by the division of the nucleus of the egg. In the case of the minute parasites in question, the egg commences by dividing into two halves, one of which develops into the amnion and the other, generally, into a single embryo. In certain species, however, the elements that are destined to form the embryo separate and develop independently, so that ten, ${ }^{3}$ two hundred, ${ }^{4}$ or even three thousand larvæ, ${ }^{5}$ varying with the species, may be born from a single egg. The blastomeres, in this case, retain their likeness throughout a large number of fissions.

In those eggs containing reserve substances what happens is quite different; this has led to embryogenetic conceptions that are entirely erroneous, because the facts were generalized without reference to their causes.

1 Von Jehring had in 18S5-6 already concluded from this the disjunction of the egg, a fact that was later confirmed by Miguel Fernandez in 1909 (XXXIII).

2 XXXIV.

3 Polygnotus minutus, the parasite of the Cecidomyidæ (Marchal).

- Encyrtus (Ascidiaspis) fusicollis, the parasite of the caterpillar of Hyponomeutia of the spindle-wood (Marchal).

5 Litomastix, the parasite of the caterpillars of the nocturnal butterflies of the genus Plusia (Silvestris). 
After their first division, the blastomeres are often very unequal; the smaller, clearer, and more transparent being formed of almost undiluted living substance, the granular and larger opaque one contains practically all the alimentary reserve. This large blastomere continues to divide unequally, and forms new small, translucent blastomeres, but, at the same time, the original itself divides in a leisurely fashion into other blastomeres which remain granular and much larger than the clear ones. The embryo, consequently, is made up of two kinds of blastomeres, which are necessarily conjoint and mutually dependent on the larger for the supply of the nutritive substances which are needed for the increase and division of the smaller. From that time the embryo forms a unit, still susceptible of subdivision into cellular agglomerations possessing both elements and capable of developing into distinct individuals. The egg of certain Bryozoa, ${ }^{1}$ after segmentation, can still subdivide into any number of groups of blastomeres up to a hundred, each of which is capable of producing a larva. The embryos of some species of Lumbricus even divide regularly into halves before producing the succession of segments that constitute the worm. In exceptional cases this division may still be partially realized in the embryos of higher animals, and it is to this that many kinds of double monstrosities owe their origin. But, as a rule, after a very short time it becomes impossible to separate the different parts of the embryo from one another, and each blastomere, from the time it is formed, appears to have a particular destination. Some seem to be charged with the duty of forming the anterior portion of the body, others the middle portion, and still others the posterior; some belong to the left side, others to the right; some are utilized for the ventral side, others for the dorsal; each blastomere playing a distinct part in the building up of the tissues and organs of the different parts of the body. If one of these particular elements is suppressed, its place is not then taken by the others; the tissues and the organs that should develop from it do not appear ; they are suppressed with it ; ${ }^{\mathbf{1}}$ if displaced, it does its own work in the new place imposed on it. The embryo thus resembles a building made of stones, which have been prepared in advance to occupy one fixed place and no other. Potentially it contains all the different parts of the future adult individual,

1 Experiments of Wilson. 
and nothing else. Each part corresponds to a particular portion of the egg, and even the substance of the egg itself is subdivided in such a way that we can say it possesses an anterior and posterior end, a dorsal and ventral region, and a left and right side, corresponding exactly to the equivalent parts of the embryo. But, between this kind of egg and an egg capable of producing numerous embryos, there are all kinds of intermediate forms. This determination of the functions of the blastomeres, by virtue of which, as soon as each becomes an individual unit, it is destined to occupy a place in a definite portion of the body, which it cannot then leave and for which it must form tissues and organs, does not, of course, represent the initial condition of all embryogenetic development. It has been gradually evolved step by step, giving to embryogenetic phenomena a precision which leads in turn to a maximum rapidity in development. This is merely one particular aspect of the phenomena of embryogenetic acceleration or tachygenesis, which have played so great a part in the evolution of organisms, and which have been so long neglected, though it is impossible to understand anything about the history of living forms or the determination of their origin without taking these phenomena into consideration. It is quite evident that if, reversing the actual order of the facts, we consider the normal embryological type to be an egg in which everything is determined beforehand, nothing but a miracle could have created it, and we should not need to look further for explanation. This notion has frequently recurred with fatal results in the philosophic biology which either takes man as its point of departure or as the model for the entire animal kingdom. But just as there are some blastomeres in the egg which are destined for different functions according to the rank they occupy in the sequence of the egg's bipartitions and to the position this imposes, so there are others which are not of direct service in building up the body and are held in reserve, to develop later. The most important of these latent organic elements are those which, in many animals such as the Rotifers, Daphnia, and various small insects, enter into the formation of the reproductive elements. They may become isolated from the very first segmentation, and thus constitute true blastomeres. It is because his conclusions were based on these specialized examples, which he took as representative of the 
primordial conditions of generation-in other words because he reversed the entire order of facts-that Wcismann believed himself justified in considcring the plasma constituting the generative organs-the germen or germ-plasm-as distinct from the plasma constituting the organs of the body proper, the somatic plasm or soma. Upon this distinction he built up his whole system, a veritable pyramid resting on its apexbut we need not pursue the matter further.

The elements thus separated may evolve with varying rapidity, and produce others more or less specialized, such as those of the genital ducts and others that retain their primitive character of blastomeres. The latter are naturally capable of developing without impregnation into new individuals. This explains most cases of parthenogenesis occurring in minute insects such as plant-lice, the cochineal insects and Cynips, occasionally complicated by viviparity, and liable to occur even in larvæ, such as those of the Diptera of the genus Cecidomyia.

At the same time these reserve elements are not exclusively destined to produce the genital apparatus; they may belong to any part of the embryonic body, and thus as in embryos produced from predetermined blastomeres, represent that particular portion of the body and none other. Thus Künckel d'Herculais and Weismann have shown that in each of the segments of insect larvæ subject to complete metamorphosis there are gathered together in the form of folds of the skin certain neutral elements to which the first of these naturalists gave the name of histoblasts, and the second imaginal discs. They are destined either to replace outworn elements of the larvæ, or to produce those new tissues or organs which give the adult animal a form often very different from that of the larva, thus constituting an actual metamorphosis. The fact that these histoblasts represent only that particular segment of the body with which they are connected, tends, moreover, to establish the individuality of these segments. This idea has its importance in the explanation of organic evolution.

We may postulate that the ultimate cause of this evolution lies in the power acquired by the earliest microscopic organisms to unite and to form a body destined to acquire tremendous possibilities; if further we may conceive that each element in such an association retains a considerable degree of independence, yet modifies itself in a special way according to 
influences derived from external environment or from neighbours which pervade and penetrate it with their excretory products, continually modifying even their common medium to suit their nutritive needs; then nothing would be more natural than that considerable variety should therefore develop in the characters and properties of the elements associated in the same body. Furthermore, from this variety there would naturally arise among the inter-related elements a more or less notable degree of solidarity, since, though each organism lives for its own sake, the medium or ensemble in which they live is their common achievement, and can scarcely be reconstructed without them. But when a group of elements capable of living together and multiplying, or a single element, the egg, capable of absorbing nourishment and multiplying in an independent fashion, becomes detached from this association, how does it happen that the new elements become diversified, and in both cases, whatever the external conditions may be, are grouped in such a way as to form another organism similar in all its details to that from which they were separated originally?

With regard to this point, we are forced back upon hypotheses whose phenomena, however, may be submitted to close analysis, thus circumscribing the ground we have to cover. Every modification affecting any predetermined part of the body expresses itself in a change either in the constitution of its elements or of their mode of nutrition, activity or number. In every case the products excreted are themselves changed qualitatively or quantitatively. These products can be poured directly into the interior "environment", i.e. into the blood, or the liquid that takes its place in the lower animals, and this environment then experiences a modification correlative to that of the portion of the body modified. These products may also pass immediately into contiguous elements, which they modify, and which in their turn modify the parts with which they are in contact; and these modifications may then proceed, stage by stage, till they reach the reproductive cells, which in the first case are modified at the beginning because of their immersion in an interior medium itself having undergone modification. However, it is difficult to admit that so intimate a correlation exists between the interior medium and the various parts of the body, that the modifications of the latter should be reecloed in the reproductive cells through the agency of this 
medium and thus be reproduced exactly, each in its relative situation. The second hypothesis is more plausible, but it assumes that the reproductive cells succeed in evolving only when all the characters of the organism to which they belong are developed. It is true (except in rare cases) that it is at maturity that the reproductive cells of animals become ready to develop-and any exceptions to this rule are either apparent only or explicable by the phenomena of tachygenesis. Among the structural cells, the most active agents of transformation are those which direct the phenomena of nutrition and thus play the principal part in building up form ; these belong to the category of soluble ferments. If the very extensive action of these ferments is reversible, and they prove capable, under certain circumstances, of rebuilding what they have destroyed, and if the reproductive cells contain some ferments of this nature, they ought to be capable of building up again, according as the division of the blastomeres increases, the series of substances composing the elements through which they had originally passed in order to attain the egg-stage. Accordingly as the new elements appear, they will assume the form and the properties of the various parental elements.

Is there anything in the structure of the reproductive cells that would lend support to this hypothesis? In order to answer this question we must now show exactly how the structure of body-building cells and reproductive cells is common to both at the beginning of their existence.

Every structural cell, as we know, is made up of a mass of protoplasm (a mixture of various substances) protected by or innocent of a membrane; in the centre of this cell is a delicate vesicle isolated from other substances, which constitutes the nucleus. The most remarkable substance within the nucleus itself is that which has received the name of chromatin 1 because it possesses a special ability to fix colouring matter and particularly ammoniacal carmine. During the period of bipartition and multiplication of cells, the chromatin contained in the nucleus normally arranged in the form of a network, shrinks into a sinuous ribbon, the loops of which, constant in number-with rare exceptions -for all the cells of organisms of the same species, soon 
separate from one another forming as many distinct bodies, the chromosomes. The number of chromosomes is generally even. Throughout the entire animal and vegetable kingdoms the cells that are later to give rise to the ova and spermatozoa, as the case may be, divide twice in succession, in such a fashion that down to the last division in the case of animals, and to the penultimate division in the case of plants, the chromosomes, instead of splitting before the cell divides and then distributing themselves equally between the two resulting new cells, form two equal groups without preliminary fission. The number of the chromosomes in the germ cells is consequently less by half than that in the somatic cells. The penetration of the spermatozoon within the ovum reestablishes the proper number of chromosomes and makes the fecundated ovum the first complete, normal body-unit, which will produce others by bipartition.

From the above it appears that in order to make use of the reserve materials it has accumulated, which distinguish it from the male element, the ovum must possess a predetermined quantity of chromatin. Thus, chromatin must be the active substance which controls the digestion of the reserves in the structural cells. The experiments which Balbiani performed long ago on Infusoria, and which many investigators have since repeated, seem to confirm this view completely. The chromatin can only perform this digestive function with the aid of ferments no doubt associated with other secretions, affecting by their quantity and quality the nature of the elements formed later, and determining the separation previously described.

A proof of this influence exerted by chromatin is furnished by the observation of what occurs in the case of certain insects possessing spermatozoa of two kinds, where either half the spermatozoa contain one chromosome more than the others ${ }^{1}$ or where one half contains a chromosome much larger than the others. ${ }^{2}$ In both cases ova fecundated by the spermatozoa richest in chromatin produce females, the others males. This fact acquires even greater significance if it be recalled that the

1 Moths ; Cockroaches, Hemiptera of the genera Pyrrhocoris, Protenor, A nasa, Alydus, etc.

2 Hemiptera of the genera Lygaus, Conus, Euschistus; coleoptera of the genus Tenebrio; the domestic fly. 
eggs of bees which develop without fertilization always produce males.

It is not our purpose here to study the problem of sexdetermination; it must suffice if we have shown the importance of the part played by the chromatin and indicated the bearing it has upon a clear conception of the phenomena of heredity. Furthermore, if in certain cases, most frequent in connexion with insects, sex is determined from the time of the fecundation of the egg and is specifically connected with certain conditions in the formation of the spermatozoa, and even if this determination in other cases is precocious, that is no reason why we should assume that it is impossible to influence sexdetermination, or that we should abandon the problem forthwith.

Summing up, we may assert that the evolution of the ovum can be classed as a phenomenon of nutrition. The reappearance of the characters of parents in their offspring is called heredity. No true explanation of the matter has yet been given. All that has been asserted about it is either pure hypothesis or a begging of the question, and the best that we can do for the present is to attempt to narrow down the conditions in which heredity first could have arisen, and once established, those in which it functions. ${ }^{1}$

After what has been said of the theory of Weismann we need not stop here to discuss his rejection of the inheritance of acquired characters. This rejection is meaningless. It must be admitted that living organisms have been modified since the beginning of time; that they have only been modified by the acquisition of new characters, and that had these characters not been hereditary, their modifications would not have been preserved. The only problem with which we need concern ourselves is to find out how these new characters have been acquired. They have not arisen of their own accordunless we are face to face with a miracle-and yet, on the other hand, it is undeniable that drought, humidity, a stronger or weaker wind-action, heat, light, and even electricity can modify, either temporarily or permanently, the individual characters of living beings, be they animals or plants. The nature of the food consumed and its superabundance or scarcity have a still greater influence. If we cannot yet afford 
to claim as much for the use or disuse of every organ, at least it cannot be denied that exercise does expand the muscles and create new habits.

The organism possesses within itself the various causes for those chemical modifications which are so important. Every cell in the body, from the very fact that it feeds and is active, exudes around it substances which then become diffused throughout the entire body and consequently make their activity felt in varying degrees throughout the whole. Apart from the modifications that may arise from the mere mode of functioning, every organ, by the very act of functioning, tends to modify the whole organism in some particular manner. The substances by means of which it acts unquestionably possess certain elective affinities for some particular element, but, in the case of animals, they may have a general influence upon the organism either by direct diffusions or by way of the nervous system. For instance, they may augment or diminish its size, as in the case of acromegaly due to disturbance of the function of the pituitary body. They may act also upon a particular tissue or organ, or on some particular system or apparatus, thereby exercising a local influence changing the relative proportions of organs, thus modifying the external form of the body. Armand Gautier ${ }^{1}$ has shown that the morphological characters of different varieties of vines correspond to modifications in the chemical composition of their pigments, which, although all belonging to the same chemical type, differ in the number and the composition of the radicals constituting them. The reproductive organs are to be reckoned among those in which chemical action is most vigorous. We know, for instance, what extensive modifications they may bring about in reproductive leaves and the leaves which surround them-petals, sepals, bracts, and in Poinsetia, even in a certain number of its ordinary leaves. Analogous modifications have been observed on the reproductive rami of hydroid polyps, ${ }^{2}$ and the gay "bridal dress" which many Worms, Fish, Batrachians, Reptiles, and Birds put on at the breeding season has often been described. The coincidence between the formation

1 LXVI.

2 Corbullidæ of Aglaoahenia, phylactocarps of Lytocarpus, Medusæ of Campularia and gymnoblastic Hydras. 
or maturation of the scxual cells, and the appearance of this brilliant ornamentation is so general that there must be a correlation of cause and effect; and since the reproductive cells are here the active ones, it is quite probable that either they or the interstitial glands derived from them are to be considered as the exciting cause of the modifications that the organism presents during the period of reproduction. Pursuing this line of thought, we are perhaps justified in asking if the wings, new forms and brilliant colours characterizing adult insects at the moment of their sexual maturity were not originally their nuptial apparel. On the other hand, it might be urged that the mating plumage, which in the male of some birds, ruff, white heron, etc., only occurs in the courting season, becomes permanent in others (cocks, pheasants, peacocks, etc.) from the time when the males become adult and that there are numbers of species in which the brilliant adornments of the males are gradually taken on by the females, as in the case of the Kingfisher family and that of the small blue Butterflies of our own fields, Argus or Polyommatus. This gives us a sound reason for assuming that a character temporarily acquired under influences peculiar to one sex, can persist when the influences determining it have ceased and can subsequently, through heredity, become extended to the other sex.

Whatever be the cause or the aggregation of causes that has led to a modification of an organism, for that modification to be inherited it is necessary that the cause or the causes that have determined it should act directly or indirectly upon the germ cells. But it is also necessary that the modification the reproductive cells experience be of such a nature as to react in its turn upon those elements arising from them and thus, by means of a series of successive releases, succeed in establishing the new character. But how can this series of releases be initiated with the regularity familiar to us? If it be remembered that the toxins injected into an organism generally stimulate the formation of antitoxins with opposite properties, we may regard it as probable that the active substances contained within the ovum may be able to reconstitute gradually the substances whose successive modifications have caused their own formation, and thus the reappearance of the characters to which they correspond. 
Recent researches, moreover, have shown that the action of radiation on organic compounds is often reversible, and E. Bourquelot and Bridel have demonstrated that in the same way ferments are generally able, under certain conditions, to reconstruct what they have destroyed. ${ }^{1}$ It would seem that we may attribute heredity to a similar reversibility. This statement is not, of course, an explanation of the phenomena of heredity, but it does permit us to get a glimpse of how these phenomena arose; opens the way to accurate research, and allows us from the outset to eliminate as useless those hypotheses which demand almost supernatural, or, at least, intangible agencies. Yves Delage, in his book on Heredity, entered into a learned discussion of all these questions, which will probably be solved only by extremely minute investigations in the bio-chemical laboratory.

However that may be, if we consider heredity with regard to its effects and not its causes, we shall all agree in attributing to it the function of maintaining, in the lineage of organisms, the characters acquired under the influence of determined causes after these causes have themselves ceased to act. At first sight, consequently, it would appear to be an essentially conservative force, but for this very reason it creates the gravest difficulties for all investigations into the causes determining the characters of living beings, simply because heredity maintains these characters under conditions manifestly incapable of producing them, and with which they may even be completely out of harmony. But that is not all : even when these organisms continue to live under the conditions which have determined their characters, the characters appear when the causes are incapable of acting as, for instance, during embryonic life; or, if the characters are periodic, they may occur out of their appropriate season. Thus it happens that the correspondence between the journeys of migratory birds and variations in temperature is relative only. Accustomed as naturalists are to observe organic characters and embryonic phenomena generally without finding it possible to trace them back to definite external causes, and powerless as they are to give irrefutable proof of the existence of any causes they may suspect, they have ceased to be interested in the search for any explanation, and have declared this search to be vain, if

1 LXVII, 63. 
not positively unscientific. Or sometimes in place of explanations they have accepted certain a priori conceptions, stated in the form of general laws borrowed from some philosophical system or relegated to the sphere of Nature's unfathomable mysteries. It is, indeed, owing to the difficulties which heredity puts in the way of all explanations, that the doctrine of spccial creation has arisen and persisted, contrary to all reason.

However, the function of heredity is not limited to the mere conservation of characters, apart from the causes that have produced them. In the very act of conserving it must accumulate them. This it is that Etienne Geoffroy Saint-Hilaire so clearly perceived when he asserted that the embryos of the higher animals reproduce the permanent forms of lower animals, i.e. that they manifest, one after another, the characters acquired by their various ancestors, which they must have inheritedif, with Geoffroy Saint-Hilaire, we accept the theory of evolution. The same truth is expressed with less precision by the somewhat mystical formula of Antoine Serre, a disciple of Geoffroy Saint-Hilaire: "Transcendental anatomy is only a transitory comparative anatomy, just as comparative anatomy is only a transcendental permanent anatomy." What he called transcendental anatomy we now call embryogeny. As we can study comparative anatomy only by considering the series of forms, beginning with the simplest, that is to say the oldest, and working up to the most complex, which are the most recent, we come face to face with the formula of Haeckel, which differs from the preceding ones only in its adaptation to modern ideas: "The embryogeny of living organisms is merely an abbreviated recapitulation of their genealogy."

If we were to take this formula hiterally it would merely be necessary to take the final expression of each organic series and study it from the initial egg-stage to its full term of life, in order to obtain an exact recapitulation of the entire past history of the organisms now living on earth. True, we should still have to reconstruct subsidiary lines that have now become extinct, but we should be able to do this by means of the comparative study of fossils as they succeeded one another. An accurate knowledge of the laws determining the evolution of the series actually represented to-day would permit us to fill the gaps with extinct series, of which only a few fragments have been found. 
Unfortunately, it is not quite so simple as this, for within those apparently innocent words of Haeckel's formula" abbreviated recapitulation"-are concealed such insidious pitfalls that Haeckel himself could not avoid them, and could not even succeed in showing us where to look for them.

As we have already stated, the duration of life on earth is to be reckoned in millions of years, and a similar length of time must be assumed for existing species to have acquired their special characters. Now the maximum period required for the development of an individual animal, apart from size, does not exceed two years, and certain very complex insects complete their term of life, including their metamorphoses, in a few weeks. In the one case as in the other, the abbreviation of descent that takes place in embryogeny is simply stupendous. It is, moreover, exceedingly unequal, even in closely related species. There are instances in which a young animal is hatched with only a small portion of its body developed : the other parts are then successively formed without cessation of the normal life-activity. There is consequently always a possibility that the successive forms which the creature assumes will represent ancestral forms, or at least forms which suggest them. To the modes of development which fulfil this condition we give the name of patrogony. However, even here the abbreviation is so great, and the ancestral forms succeed one another so rapidly, that they are telescoped into one another, so to speak, and the successive shapes assumed by the embryo may be considered only as analogous to ancestral forms and not their exact reproduction. The general trend of evolution is here indicated, not its detail.

In some species related to those described above the young animal emerges, if not in possession of its final form, at all events provided with all the parts of its body. The development then takes place so quickly that the parts of the body which were formed successively in the preceding case, here appear to be formed simultaneously; thus the course of evolutionary development can be so modified, and the forms assumed by the embryo recall the ancestral forms so little that, if at any given moment we were to free it from its protecting envelope, the organism would be unable to lead an independent existence. This is the case with all vertebrates except Amphioxus. We call this greatly accelerated embryogenetic 
development tachygony. In the same series of organisms it is possible to find all the steps intermediate between tachygony and patrogony. This gradual embryogenetic acceleration we have already termed tachygenesis. ${ }^{1}$

Alike in the case of patrogony and tachygony the embryo is subjected to the influence of the actual conditions under which its development takes place. These tend to make it vary from the ancestral forms, and may impose upon it forms quite different from those of the embryos of species that have developed under other conditions. These adaptive modes of development, which may be recognized by the great variety of characters that the embryos of related species present, are distinguished under the name armogony, ${ }^{2}$ and the phenomenon of adaptation to the conditions of development that determine them can thus be called armogenesis. Armogenesis can both complicate and simplify patrogony. Thus, pelagic embryos living in the open sea often acquire organs which are not present in the littoral patrogonic embryos ; on the other hand, the larvæ of insects which live parasitically lose the legs and even the masticatory organs found in free larvæ. Moreover, the very simplified tachygonic embryos of mammals develop a special organ, the placenta, which has nothing to do with ancestral forms. ${ }^{3}$

It might perhaps be surprising that armogenesis, while modifying embryonic forms, should not lead to important modifications in the final form they are to assume. Giard has endeavoured to explain this paradox by resorting to comparison with mechanical laws. Comparisons, however, are not reasons. In reality it is the elements held in reserve in the interior of the body, the highest expression of which is found in the histoblasts of insects and Nemerteans, which mould the permanent form after the disappearance of armogonic organs, because these reserves have escaped from the influence of external actions and have preserved intact the

1 LXX VIII, 149.

2 From ápuós joint or $\dot{\alpha} \rho \mu \eta^{\prime}$ union and consequently adaptation and yóvos, generation. I have hitherto employed the word armozogony from the verb $\dot{\alpha} \rho \mu \delta \zeta \omega$ "I harmonize," but it does not express the facts any better, and is too long.

3 It should, of course, be remembered that the words patrogenesis, tachygenesis, and armogenesis by no means designate a special active cause found only in living beings, but the totality of the causes and mechanisms, still too little known, which give rise to the diverse modes of organic development. 
stored-up hereditary characters which they received from the ovum.

Armogenesis has consequently only a secondary importance in the evolution of organisms. Not so, however, tachygenesis. We have demonstrated elsewhere that it furnishes us with an explanation of the resemblance of the evolutionary development in the female and the male cells. ${ }^{1}$ Its influence on the morphology of living beings is just as great. By virtue of the independence of the structural cells giving rise to the tissues, the organs, and even the areas of the body, this influence affects the different parts in various ways, modifies their relationships and their proportions, and induces transpositions and fusions, to which Étienne Geoffroy Saint-Hilaire had already appealed when he tried to explain how unity in the plan of composition did not necessarily exclude variety in the details of organization. It thus becomes an instrument of modification, all the more powerful since in the course of embryonic development a veritable struggle for existence takes place, in a narrow field of battle, so to speak, between all the structural cells and all the tissues and organs which they constitute as well as between the various body areas themselves.

If armogenesis tends to bring embryos into intimate relation with the environment in which they develop, tachygenesis, on the contrary, tends to alter these relations more and more, and to accentuate the dissociation between causes and effects which heredity in its purely conservative aspect had already begun to accomplish. Fortunately, this dissociation is generally gradual. In each series the lower forms most frequently present a patrogonic form of development, in which essential characters are conserved in the tachygenetic forms. This permits us, on the one hand, to distinguish the links which connect characters and the causes capable of producing them, and, on the other hand, to eliminate, by explaining the facts upon which they might be based, any possible objections to the inferences suggested by the analysis of the modes of development most closely akin to patrogony. This work of weeding out and classifying embryogenetic phenomena had never been done in a methodical manner until I attempted it in the embryological section of my Traité de Zoologie. ${ }^{2}$ For this reason it has

1 XXX VIII, 330.

a XIII, 567, 624, 961, 1605, 2251, 2565. 
not hitherto been possible to extract from embryogeny all the data it affords on the subject of the origin of living forms; for this reason no light has been shed in particular on the perfectly commonplace causes which deternine the formation of the great organic types. Indeed, so accustomed have we become to regarding these facts as miraculous phenomena that the explanations we shall make are liable to the reproach of being over-simple. Mystical or purely verbal explanations have been treated with more respect, as if there were any causes operating around us other than commonplace causes. The world tends to forget that all the progress we have made in geology within the last few generations is due to the abandonment of old doctrines based on miraculous cataclysms, universal floods, and other "world revolutions", in favour of the careful investigation of actual cause and effect, to which Buffon and Lamarck had already devoted themselves before Sir Charles Lyell systematized them.

The oldest known geological period, the Archæan, was actually of longer duration than the whole Primary Period, and witnessed the formation of deposits which are still more than 20,000 metres thick, despite the levellings and metamorphic transformations they have undergone. Yet if we wish to reconstruct the forms of life which probably prevailed so long ago, the inadequacy or, indeed, the total absence of palæontological documents compels us to fall back upon the data supplied by existing forms. As we have already observed, the lowest of these are so simple that we can hardly conceive of any simpler. If there be any general theory which establishes a connexion between these simple beings and the most complicated organisms we know, and leaves no gaps in the chain, that theory will possess the best chance of being applicable to fossil as well as to living forms. Consequently it will add precision to our work in linking the first with the second, interpreting the inadequate remains left to us, and filling in the lacunæ between the forms that have persisted. It will also frequently guard us against judging by appearances in determining the date when these forms first appeared. Such a theory would be synonymous with an explanatory genealogy of living forms, which we are now about to outline. This question can only be broached, however, after the principles we have just expounded have been well established. 


\section{CHAPTER III}

The Genesis of the Typical Forms of the Plant Kingdom

IF the ingenuity of the naturalists has been tirelessly exercised on all matters relating to the problems of variability in living forms, it has turned aside from any explanation of factors which are fixed and stable. All variations of detail have been studied with the most painstaking care; botanists have been at the greatest pains to note the slightest modifications in the form and colour of flower-petals, in the contour of leaves, in the abundance or scarcity of hairs; they have made careful and sometimes ultra-minute distinctions in the case of Briars and Vines, for instance, between species and sub-species; between spontaneous, geographic or merely topographic, cultivated or wild races, varieties and sudden, heritable variations, fluctuations, etc. The zoologists have been hardly less energetic in studying the smallest variations. They have made violent onslaughts upon the old classification-striped, spotted and piebald animals, and have even subdivided the African Elephants, because their ears and tails are not exactly alike. Interesting as it may be to study the variability of details, all this is certainly not so important as the causes that have led to the development of animals and plants on the lines of those marvellously persistent types which Cuvier called embranchements (main divisions); or as the reasons for differentiation between plants and animals.

The latter question has been broached before. Plants take their special character from the fact that every one of their essential parts is enclosed in a rigid cellulose membrane, preventing any movement and consequently any external sign of sensibility. This membrane may temporarily be missing, as in the case of the zoospores and the antherozoids or reproductive cells of certain algæ and fungi. It may only be present for a time, and then only around the spores or reproductive cells, as in the case of slime-fungi or Myxomycetes, 
but its mere existence, however brief, authorizes us in classing the organism as a plant. Certain organisms throughout their whole lives may resemble either zoospores of Algæ or Fungi, or else myxomycetes, and differ only in the complete absence of the formation of a cellulose membrane. It is these forms which link up the regetable and animal kingdoms. Here the differentiation between the two is quite artificial, though it is legitimate to consider these ambiguous forms-devoid as they are of the positive characters that distinguish true plantsas members of the animal kingdom; the more so as the absence of cellulose, a negative feature, goes with that mobility which is a positive character of animal organisms. Because of that very immobility imposed on their cells by this rigid membrane of cellulose, the evolution of plants has been relatively simple. When isolated, these cells appear in the form of rounded granules, ${ }^{1}$ rods, ${ }^{2}$ spindles, ${ }^{3}$ crescents, ${ }^{4}$ spirals, ${ }^{5}$ etc. They can be juxtaposed so as to form chains, ${ }^{6}$ networks, ${ }^{7}$ small solid cubes, ${ }^{8}$ and fans supported on a stem, ${ }^{9}$ or even spherical masses capable of swimming ${ }^{10}$ whenever the cells of which they are built up are furnished, as in Volvox, with vibratile flagella. Generally they are placed end to end so as to form those interlacing green filaments called confervæ, which abound in fresh water. Analogous filaments, welded together in parallel lines and giving rise to lateral branches, form the body or thallus of Chara. Cells that are more or less polyhedral and dissimilar in shape arranged in several layers, can build up laminated or even massive structures of large dimensions such as those that form the varecs of our coasts, the great marine Laminaria many metres long, or those enormous floating Macrocystis found in southern waters, which can spread out their branches over more than a hundred metres. Plants thus formed entirely of cells almost alike in structure and juxtaposed are subdivided into two groups: Algæ, when they are coloured green by chlorophyll; and Fungi, when, devoid of chlorophyll, they live at the expense of other organisms-as animals, in their very different way, are also compelled to do.

In spite of their homogeneous structure, Algæ may exhibit

1 Micrococcus, Protococcus, etc.

3 Navicula.

5 Spirilla, spirochaetes.

7 Hydrodictyon.

9 Gomphonema.

2 Bacilli, bacteria.

4 Closterium.

6 Nostoc.

- Merista.

10 Voliox. 
a high degree of complexity. Certain forms attach themselves to submarine rocks by means of processes like the roots of higher plants; or the body of the plant may elongate into a cylindrical cord resembling a stem with lateral ramifications, sometimes flattened, which might therefore be called leaves. We would be tempted to assume that Algæ such as these having become terrestrial, were metamorphosed as a group into plants analogous to those that grow in our fields to-day, were it not that the mechanism of their origin is apparently more complicated.

Fungi, obviously later in origin than Algæe, but dominated in their evolution by the necessity to lead a parasitic life, have not attained such a high degree of complexity. Their most highly developed forms consist of elongated filaments variously intertwined, and wound in places, which become attached to one another and come up out of the ground, or erect themselves upon the surface of the plants in which they have developed, and finally spread out to form that cap-shaped fructifying organ which we know so well both as a delicious food and a deadly poison.

The terrestrial plants which form the group of the Mosses, always very modest in size, still bear a close resemblance to the Algæ as regards their structure. In the class of Muscineæ, to which they belong, we can even trace gradations between a flattened thallus in the form of a continuous lamina found in certain Hepaticæ, and the thallus of those Mosses which exhibit a small cylindrical stem bearing leaves laterally. Only the root is absent.

In the case of the Mosses, however, reproduction has taken a special line which tachygenesis will modify in the higher plants by making it pass through successive stages, each of which will be characteristic of some main branch. The lower Algæ generally reproduce themselves by means of corpuscles, which we call zoospores, provided with minute paddles, whip-like threads or waving cilia, enabling them to swim. In these Algx the zoospores are all alike, in others, however (Ulothrix, Tetraspora), they can, according to circumstances, either remain alike in character and give birth singly to new algæ, or take on two different forms: one largesized, which accumulates reserve substances in its protoplasm, the other small, and without these reserves. A large zoospore can then only develop into a new alga if it first unites with a 
small one. This is the beginning of sexual reproduction, and we call the large zoospore female, the small one male. The first is sometimes known as an oospleve, and the second as an antherozoid. In the seaweeds the oosphere is enormous and immobile; the antherozoid alone is active; there are no zoospores-reproduction is always sexual. Finally, in certain Algæ, the zoospores are replaced by immobile asexual cells called spores, formed in special organs known as sporangia. In the case of the Mosses these two kinds of reproduction are combined, and alternate with perfect regularity. In the early spring each small moss-stem expands at its extremity into a delicate rosette of leaves, among which two kinds of minute cups can be distinguished. The first, known as archegonia, contain the immobile oosphere, and the second, known as antheridia, are filled with very active antherozoids. Each oosphere is soon fecundated by an antherozoid. Without leaving its archegonium it develops into a small new plant made up exclusively of a filament ending in an ovoid capsule or sporangium, filled with spores. These spores, scattered over the humid soil, develop into filaments similar to those of the Confervæ; upon these grow the buds, which eventually become new Moss plants.

The method of reproduction found in the Mosses is retained in those plants, frequently large in size, which belong to the three classes of Ferns, Club-mosses, and Horse-tails, and together form the division of the vascular Cryptogams. Here the method of growth becomes complicated. The body of the plant generally consists of a stem which creeps along the surface or under the ground, at times almost indefinitely, and which is called a rhizome. On this rhizome two kinds of ramifications grow in opposite directions ; one sort moves upward towards thelight and forms leaves, and the other, pushing deeper into the ground, forms roots-which here make their first appearance. Through files of elongated cells, ranged end to end in a straight line, water charged with salts absorbed from the soil finds its way upward to the leaves, where it becomes charged with the sugar they have formed, and makes its way back again to the roots. This circulating water is the sap, and the long lines of cells which provide its paths represent the vascular system of the plant, an arrangement which is also here observed for the first time, and which has earned for the Ferns, Club-mosses, and 
Horse-tails their name of vascular Cryptogams. When a cluster of leaves develops at the same point on the rhizome, these leaves become adherent and form a secondary stem, which grows erect, as with the tropical tree-ferns, and probably also at first with the Horse-tails with verticillate leaves. In the case of the Mosses, it is the leafy stem which bears the organs of sexual reproduction, and also a kind of accessory plant fixed on this leafy stem which furnishes the sporangia and the spores. In the vascular Cryptogams we find a singular reversal of the dimensions of the sexual and the asexual plants that alternate regularly in the development of Mosses, and up till the present no intermediate condition has been found to fill the gap separating the latter from the Cryptogams. The sporangia are, indeed, borne on the large leaves of the Ferns and on the leaves of the accessory stems of the Club-moss and the Horsetails; the spores arising from these sporangia give birth only to a leaf-like shoot without roots, resembling the thallus of the Hepaticæ and known as the prothallus. This prothallus bears archegonia, each containing an oosphere, and antheridia which produce antherozoids. Every fecundated oosphere gives rise to a new leaf-bearing stem.

The same process takes place in the three classes of Ferns, Club-mosses, and Horse-tails: in all three there are parallel modifications of reproduction, due to tachygenesis and to the gradual transformation of the normal method of reproduction into another more accelerated method, characteristic of the gymnospermous Phanerogams. From this we can draw the inference that it is certainly tachygenesis which transformed the vascular Cryptogams into gymnospermous Phanerogams, though probably each class of Cryptogams has passed over separately to the gymnospermous condition, and given rise to special types of the latter. Indeed, the Cycads, with their large leaves, seem to be connected with the Ferns; the Conifers, with their small leaves arranged spirally, with the Club-mosses; and the Gnetaceæ, with their small whorled leaves, with the Horse-tails.

However that may be, the course of tachygenesis in the three classes of Cryptogams is the same.

I. The dimensions of the prothallus are reduced and instead of developing outside the spore, they develop inside it.

2. The sporangia, instead of being identical in form, are divided into two groups: the macrosporangia, which produce 
a small number of large spores, and the microsporangia, which produce a large number of small spores. The large spores only give rise to female prothalli bearing archegonia, and the small spores only to male prothalli bearing antheridia.

3. In the spore-producing tissue of the macrosporangia the spores cease to be individualized and invested with their protective membrane. This tissue remains neutral; the archegonia are directly formed there, and each one is itself reduced to an oosphere surmounted by four or eight cells representing the neck. In the microsporangia, on the contrary, the spores become individualized, but the prothallus which they contain consists simply of three cells of which one, the generative, can give rise by subdivision to eight or ten small cells (Microcycas colocoma of Cuba), each producing two antherozoids, or the generative cell can itself directly produce two antherozoids only (Cycas, Ginkgo).

4. Lastly the antherozoids cease forming their helicoid band of waving cilia and are reduced to a simple nucleus.

These modifications can already be produced without changing the form of the vegetative system, as Grand 'Eury has observed in certain fossil Ferns. They are characteristic of the reproductive system of gymnospermous Phanerogams, but the names of the various parts we have just enumerated must in this case be changed, because the reproductive system of Gymnosperms was at first compared with that of Angiosperms, for which botanists have created a special terminology. Thus, the macrosporangium becomes the ovule; the tissue corresponding to the prothallus, the endosperm, and the archegonia are the small bodies, each corresponding to an embryo sac. The microsporangia, in their turn, become the pollen sacs, and the microspores the pollen grains. At the same time the modified leaf that bears the macrosporangia becomes the carpel, and that which bears the microsporangia, the stamen.

The transformation of gymnospermous Phanerogams into Angiosperms is accomplished very simply by a renewed progress of tachygenesis. The carpels, instead of remaining spread open, and leaving the ovules unprotected, as in the Gymnosperms, ${ }^{1}$ which derive their name from this fact, are

1 From $\gamma u \mu \nu o ́ s$ naked and $\sigma \pi \epsilon ́ p \mu a$ grain. 
rolled up in a cone-shaped receptacle so as to conceal the ovules, and it is thus their name of Angiosperm arises. At the same time the prothallus is still further reduced in the ovule; the cell which gives rise to it, and which is called the embryo $\mathrm{sac}$, increases in size; the nucleus generally undergoes only three successive subdivisions, which give rise to eight nuclei; two of these nuclei fuse into a single one occupying the centre of the embryo sac, three others are arranged at its base, and the last three at the top, where they form the basis of an equal number of cells. Of these three cells. one only is transformed into an oosphere; the others remain sterile, and all traces of the archegonia are lost. The microspores or pollen grains do not themselves contain more than two nuclei, one of which is subdivided to form two others, the last relics of the antherozoids.

Anyone who has followed this evolution must realize that it is the characters produced by tachygenesis which distinguish the three large groups of Rhizophytes or plants possessed of roots and vessels: the Cryptogams, the Gymnosperms, and the Angiosperms. It is evident that these three classes successively developed their characters in the order we have just indicated, and could have appeared on our earth in no other order. Tachygenesis, however, goes still further in the Angiosperms. The reproductive leaves of the same sex are all grouped together in the Gymnosperms, and arranged in a tight spiral, forming what we know as a cone; there are both female and male cones, generally found on the same tree; hence the conifers are said to be monœcious. The Angiosperms, like the Gymnosperms from which they are directly derived, ought to have "flowers" reduced to the essential parts; those of the same sex ought to be grouped together, either on the same tree or on two separate trees. This actually occurs in the large family of the Amentaceæ, which group their flowers in unisexual catkins, or sometimes reduce them, as in the case of certain willows, to two stamens protected by a simple scale.

How was it possible for catkins to evolve into true flowers, as botanists understand the term? Flowers of the highest type consist of four whorls. Two are of sterile leaves: these are the calyx, whose leaves generally remain green, and the corolla, whose leaves are usually coloured. The two other whorls are 
fertile, and are always arranged in the same order, a whorl of male leaves or stamens, above the corolla, and a whorl of female leaves or carpels, formed at the end of the floral branch. At first sight the mechanism of this transformation is not apparent; however, in the light of what we already know of the nature of the sexes, it is possible to make a good guess. In the first place sex is not, as we might be tempted to judge from ordinary observation, something absolute. We have seen that the difference between the male and the female cells is essentially a difference of aptitude for nutrition. This difference can be aggravated by an increase or decrease of nutrition in the individuals producing these cells. A simple transplantation often suffices to change Thladianta dubia (Blavet), Tricenosperma ficifolia, Dioscorea canariensis, and Clematis hilarii (Spegazzini, I900), from the female to the male sex. The same result has been obtained by cutting off the head of a willow (Salix capraa, Haacke, $\mathrm{x} 896$ ). The contrary transformation has been obtained also in willows (Klein, r896): Edmond Bordage saw the same thing take place in a papaw on Reunion Island (rSgS); Hariot (I902) and Davaul (I9O3) announced that this phenomenon is habitually produced in the palms of the oases of Southern Algeria by longitudinally splitting from the centre to the sheath all the leaves of stems two or three years old. Moreover, in a series of the most exact and ingenious experiments, Blaringhem ${ }^{1}$ has obtained the most startling results. Dividing the young female stems of Mercucialis and of Spinach, he saw shoots arise each bearing male and female flowers, and thus he transformed a diœcious plant into a monœcious one. He was able to go even farther, and obtained hermaphrodite flowers by mutilating the stalks of the male hemp. His experiments on Maize also proved the influence of nutrition upon these phenomena. Maize-stalks, as we all know, terminate in a plume of male ears which becomes characterized at an early stage; later on female ears, enveloped in large bracts, appear at the flower-axil of the stalk, like lateral branches. It may be observed that the male tuft forms at the stage when the young maize-stalk is only growing small roots; consequently its nutrition is not very active and tachygenesis makes it develop too soon. The female ears, on the contrary, 
develop when the stalk is at its full activity. With this in mind, Blaringhem cut the Maize-stalks at different stages of growth, thus suppressing the first male ear and a large part of the stalk that had borne it at the exclusively male stage. This stalk was replaced by numerous lateral shoots, which can be considered as new stalks. If the section of the original stalk took place when the roots were only partially developed, that is to say, under the conditions which produce the male plume of this stalk, all the shoots likewise terminated in a plume exclusively male. If the section was delayed till the roots developed, an increasing number of female flowers appeared on the terminal crowns of certain shoots. If he waited till the approach of the period of maximum growth of the stalk, which was obviously the period in which the roots exhibited great nutritive activity, the terminal plumes of a certain number of shoots bore only female flowers. Finally, if the section was made during or after the blossoming period, all the shoots terminated in a head of female flowers. Blaringhem succeeded equally well in obtaining the transformation of female ears into male ones. All that was necessary was to twist the stalk below the terminal bud, thus arresting its development. The lateral buds benefited by the nourishment which the other would have absorbed, and grew actively. Instead of forming a short thick crown, with flowers exclusively female, they elongated at the expense of their width, tended to ramify like the male ear, and finally produced a certain number of male flowers. The same result can be obtained even more consistently by twisting either the peduncle of the female ear itself in the process of development, or the same ear at a certain point of its length. In the latter case the twisted portion, being less well nourished, produces male flowers.

The influence of nutrition on sex is thus quite evident. But these operations are not confined to sex determination in flowers; they also confer upon the seeds arising therefrom a special aptitude for getting nutriment. If we go on to plant the seeds obtained from a male ear, the terminal ear of the young stalks issuing from them would normally contain both male and female flowers; a new factor comes in in the development of these new growths-heredity.

It is even possible to make new organs appear in the flower, which, of course, also implies that they can be suppressed. 
Blaringhem succeeded, in the case of maize, in adding carpels to the male flowers in which the stamens remained intact, and thus obtained hermaphrodite flowers. This is probably what happens in the analogous transformations observed in the unisexual flowers of a certain number of other plants. ${ }^{1}$

Thus we have made our first point :-

The sex of flowers is clearly a function of their nutrition, and not determined in advance-at least, in a certain number of cases. The fundamental identity of the phenomena of reproduction in animals and plants is a no less incontestable fact, and we are consequently justified in appealing from what is obvious in the one kingdom to its application to the other. There are, as we shall see, groups of hermaphrodite animals, but while hermaphroditism is the rule in the higher plants, it is the exception in animals, which indicates that its appearance is of later origin, and explains why its causes can be more easily understood.

The conditions under which hermaphroditism has been observed in the Animal Kingdom agree in establishing the fact that it, too, is connected with some disturbance in nutrition, which leads to the disappearance of the males and the transformation of the females into hermaphrodites. This hermaphroditism is brought about in a particular way; the cells destined to produce germ-cells are formed early and make their first appearance during the period of growth; when they are competing with the somatic cells in the process of multiplication they evolve in the direction of masculinity; when maturity is attained, however, they are enabled to appropriate all the nutritive substances, and then evolution is towards the female sex. There is no simultaneity in the development of the two kinds of germ-cells, except, perhaps, for a short transitional period in certain animals such as the Oyster ${ }^{2}$ which begins as a male and then becomes a female. This process is called protandrous hermaphroditism. The converse may take place, but it is extremely rare. Among the Cirripedes and the Nematodes we often find supernumerary and useless males, which persist as though to serve as witnesses of the mechanism that produces hermaphroditism. We are thus justified in thinking that the same may hold true in the Vegetable Kingdom; that under new conditions of nutrition, as in the case of vegetation which had

1 Trianosperma, Dioscorea, Clematis.

2 XII. 
at first been possible only in very humid or even marshy soil, and which was transplanted to dry soil, the male catkins, always present in Gymnosperms and the Amentaceæ, have disappeared from the latter, and the female catkins alone have persisted and become hermaphrodite. From this fact alone, the explanation of the habitual form of flowers becomes easy. We may assume that the hasty and precipitate formation of fertile leaves, stamens, and carpels in a floral bud which is undergoing especially rapid development has caused the disappearance of the rudimentary infertile leaves which generally accompany them, and which in the cone of the Gymnosperms are mingled with them in various ways. These leaves, as a matter of fact, are represented by little scales in the Plane-tree catkin, and by little knobs in the case of the Willows and the Poplars; they are completely absent in the female catkins of the Birch, in all those of the Myricinacer, and in the Oaks, Hazels, Chestnuts, and the ordinary and white Beeches. Here the catkin is protected by other infertile leaves called bracts, grouped together by their bases and forming the cup for nuts like the acorn (that of the hazel-nut surmounted by long leaflike appendages), the bur of the chestnut, the beech-mast, and the envelope of the fruit of the horn-beam. In these plants, almost all of them large trees or bushes, the flowers still possess neither calyx nor corolla. Although they also demonstrate the contingent character of the accessory parts of the flower, we need not be concerned with those cases in which, as in many groups of Monocotyledons, Juncaceæ, Cyperaceæ, Gramineæ, Naiadaceæ, and Lemnaceæ, the perianth, normally developed in other plants, has become reduced and finally abortive. The instance of the Arums is particularly interesting, because it shows how the reduced perianths of flowers grouped in an ear can be replaced by a huge bract capable of taking on the aspect of the most brilliant perianth.

Let us imagine a female catkin composed entirely of fertile leaves, protected at its base by sterile bracts, which, under unaccustomed conditions of nutrition, such as must have frequently occurred when plants became more exclusively terrestrial, is subjected to an accelerated development. The first fertile leaves formed in the course of the elongation of the catkin, those that occupy its base, will compete for their nutrition with the catkin itself. As in the protandrous 
hermaphroditism of animals, these will become reduced to the state of male flowers, that is to say, stamens; only the fertile leaves at the top of the catkin, those that represent the final growth, preserve their female sex, and become carpels with their ovules. Thus we have the actual flower of the dicotyledons, as it is schematically represented and as it is described in all the classical works on botany, with its carpels in the centre forming the gyncecium or pistil; a ring of stamens forming the andrecium, and a ring of sterile leaves constituting the perianth. The latter is usually double, and comprises the coloured leaves of the corolla and the green leaves of the calyx. In order to explain this fact, we must turn to another order of considerations. The elaboration of the germ-cells does not take place without the resultant formation of special compounds, waste products evacuated by these cells and thus coming into contact with others contiguous to them, either by absorption or by way of a circulatory system. Zoologists and physicians have long been aware of the influence exerted upon the organism by these internal secretions, as they are called to-day, and we have already indicated to what degree they are capable of modifying the form, size, and the colour of the organs they penetrate, especially those which form part of the secondary sexual characters. So far as colour is concerned, this action may be spent entirely in modifying the corolla, but sometimes it is extended to the calyx, which then becomes petaloid, notably in many Monocotyledons (Colchiaceæ, Liliaceæ, Asparagoideæ, Orchidaceæ, etc.), and can even succeed in modifying the bracts (various Sages) or the leaves (Poinsetia). ${ }^{1}$

Naturally, if flowers have originated thus, the earliest of them ought to preserve some traces of the primitive elongation of the catkins and the indeterminate number of their constituent elements: sepals, petals, stamens, and carpels ought to have been numerous at the beginning, because of their common origin, and to have approximated to one another by gradual transitions.

1 It may happen, of course, that the cause for these phenomena is just the reverse, and that the coloured bracts, the petaloid calices, and the petals owe their particular development to the fact that they have arrested in their passage the foods which the fertile leaves have attracted toward themselves, and thus profited by additional nourishment; but if this were so we might well ask why these parts do not themselves become fertile. Experiment or chemical analysis must be left to decide this. 
These conditions are certainly fulfilled in a large number of flowers, at any rate in certain of their parts, the androcium or the gynceium, of which the multiple elements are arranged in spiral form like the scales of a pine-cone around its axis. The Magnolias, the white Water-lilies (Nymphea alba), the Camelias, and the Cactus also have such helicoidal flowers with numerous elements, in which we can trace the development of the sepals into petals (Camelia) or petals into stamens (Nymphea). In roses the leaves develop into sepals, and although the latter are only five in number, they are gradually modified. The number of petals is also five, all resembling each other. The stamens, arranged in three whorls, are always twenty in number, the carpels indeterminate, and arranged spirally inside a cup hollowed out in the extremity of the stem-axis. In the Strawberry, Raspberry, and Blackberry, on the contrary, the axis protrudes, but the carpels have the same arrangement. The calyx and the corolla are in whorl formation, and the parts are all equal in the case of the Buttercups, Anemones, Clematis, etc., but the stamens and carpels are many in number. The latter become reduced in number and fuse with one another, while the stamens remain numerous, in the Poppy. Finally, all is regularized, tachygenesis shortens the axis which supports the various parts of the flower; parts of the same nature then arise simultaneously, and their helicoidal arrangement disappears completely; sepals, petals, stamens, carpels, form so many whorls of which the parts, equal in number, alternate from one whorl to another. The flower is then said to be isomerous. The last reduction of all affects the gynœcium, which may be formed from carpels less in number than the corresponding parts of the other whorls.

Once the flower has been thus evolved, other causes can modify it; it can, for example, pass from the whorl form to one symmetrical about one plane, as in the Papilionaceæ; but, above all, under the influence of tachygenesis, the parts of the same whorls may be formed so quickly that they grow into one another, and the dialypetalous corolla becomes gamopetalous. This fundamental division of the Dicotyledons, which everyone recognizes, would thus appear to be the result of such a process of tachygenesis. It is tachygenesis, moreover, which in both these two series has 
led to the concrescence of all the carpels with the base of the other floral organs, and hence lias determined the achievement of the so-called inferior ovary. Thus, in each of the two subclasses of Dialypetalæ and Gamopetalie, two orders can be distinguished, one with superior ovaries and one with inferior. This makes it clear that the gamopetalous Dicotyledons could not have appeared until after the dialypetalous.

We have now reached a delicate point. The older botanists, having failed to take into consideration these facts, from which we have just drawn so many inferences, or, may be, having failed to realize them, were guilty of an error of judgment which certain present-day botanists are inclined to revive. There is a widespread opinion that the Monocotyledons are lower than the Dicotyledons, and must have appeared first, and many ingenious attempts have been made to establish this fact. But the moment we apply to the flowers of the Monocotyledons the incontrovertible principles that result from the study of the Dicotyledons, we are immediately convinced that far from being primitive flowers they are the most highly developed of all. In the first place, like the flowers of the highest Dicotyledons, with very few exceptions, ${ }^{1}$ they are almost all isomeric and constructed on type 3 , that is to say, they have three sepals, three petals, three or six stamens, and three carpels. They are among the most brilliant. Frequently the calyx is as magnificent, or even more so, than the corolla-a rare thing among Dicotyledons. Often, as in many of the Orchids, ${ }^{2}$ they are arranged symmetrically to the median plane in such a way as to resemble bees or butterflies. Sometimes the androcium undergoes a reduction that bears witness to an alteration of the general type, subsequent to the achievement thereof. The Monocotyledons with small flowers, such as the rushes, sedges, and grasses, are not more primitive than the others because their flower is small and green. They are isomeric like them, and the flower of the Gramineæ has undergone profound modifications of this isomeric type, which is recent in itself.

The relatively advanced character of the Monocotyledons

1 The Centrolepidex, indigenous in Australia, and the plants of the Lemnaceæ, and the Naiadaceæ families, all either floating or submerged, in which this very specialized manner of life goes along with an undeniable degeneration of the flower.

2 Fly Orchis, Bee Orchis, Hornet Orchis, etc. 
is therefore proved by the structure of their flowers; the contrary idea has arisen because the structure of their stalk resembles, in certain respects, that of the vascular Cryptogams. But the Monocotyledons are angiospermous plants which can only have acquired this character by passing through the Gymnosperm stage, and the stalk of the known Gymnosperms has developed far beyond the primitive stemstructure of the vascular Cryptogams. Consequently the explanation of this feature must be sought elsewhere. The Monocotyledons appear to have lived originally in humid or marshy soil, or even in the water, as is indicated by their smooth, simple, thick, parallel-veined leaves. Many are still in this condition. We have but to cite the Rush, Sedge, Rice, Iris, Arum Lily, Marsh Reeds, Bamboo, Eel-grass, Pond-weed, Duckweed, etc. Even Palms, contrary to the popular notion, are not found in the desert but in the wellwatered oases of the desert, which is not the same thing at all. The stems of the ancestors of monocotyledonous plants, being ill-supported in the soft soil, as we shall see, assumed a recumbent position in the ground and became transformed into rhizomes, like those of the vascular Cryptogams, and it is upon this rhizome that the aerial stems were formed again by a process analogous to that which forms the stalk of Mosses and Horse-tails-which they thus resemble quite naturally. These marshy plants are most favourably situated for fossilization. It is not surprising, therefore, that they should have been more easily preserved than the Dicotyledons, and that they should even be found in strata that have not as yet furnished any Dicotyledons. Lignier has actually described under the name of Propalmophylla the basal parts of Jurassic leaves that he believes to have belonged to the group of Monocotyledons.

It would be useless to attempt to systematize the forms, essentially variable according to their circumstances, of Fungi, Algæ, Hepaticæ, and even Mosses. Their organic unity is scarcely higher than that of the plastids; all the parts of the body, complicated as it appears, have the same value; none of them can be considered as having any particular individuality. It is very different when we come to analyse the vascular plants. If we look at the trunk of a Tree-fern, a Cycad, or a Palm, it would seem evident, at first view, that 
it is formed by the growing together of the petioles of the leaves, and there has been much discussion of this theory. Dicotyledonous plants are in a different case. Here the stem does not develop from the leaf, but seems, on the contrary, to have produced it. Hence the conclusion that the apparent formation of the trunk from concrescent petioles was illusory. Perhaps it would have been more logical to take as the starting-point the obvious indications furnished by Ferns, and then to find out how the initial method of trunk formation was able to give rise to a structure characteristic of the trunk of Gymnosperms and dicotyledonous Angiosperms. This indication provided by the Ferns, Cycads, and Palms carries us further still. We have only to examine the young branch of a Conifer to get on the track of it. Without entering deeply into the problem we may point out that the order of formation of the crgans is often altered by tachygenesis, and that where organs of independent origin are fused into one, as more than one example will prove, the new organ resulting from their fusion is formed, in the course of embryogenetic development, before those parts that have remained independent, thus appearing to be formed at their expense. This is notably the case with the primitive kidney or pronephros of Vertebrates. This observation gives its value to Goethe's theory. He believed that every plant is an association of leaves, and every leaf a kind of individual which by its own indefinite repetitions forms the whole plant, and by transforming itself gives rise to all the parts of the flower. What Goethe divined from the study of flowering plants alone has since then been demonstrated by the study of the vascular Cryptogams. There the leaves, all alike at first and equally capable of bearing sporangia, subsequently divide into two types with distinct forms, the sterile leaves and the fertile leaves. In the case of Club-mosses and Horse-tails, these leaves form in groups around the end of the branches or stems and hence presage the formation of the cones on the Conifers, which, in their turn, shadow forth the flower. 


\section{CHAPTER IV}

\section{Primitive Animal Forms}

\section{Branched and Segmented Animals}

\section{$\mathrm{O}$}

WING to their aptitude for changing their form and moving about, those members of the arimal kingdom reduced to a single structural element or plastid, acquired a variety of forms infinitely greater in number than that which we find at the corresponding stage in the Vegetable Kingdom. Furthermore, these plastids, having once become associated, modified each other reciprocally and became mutually dependent much more quickly than the vegetable plastids. Hence, we do not find in the Animal Kingdom, alongside of unicellular beings which constitute the large group of Protozoa corresponding to the simplest structural type, creatures of larger size possessing the homogeneous structure encountered in the Algæ and the higher Fungi. We pass suddenly from the Protozoa to organisms already complicated; the Protozoa, however, possess an infinite variety of forms and abound everywhere. They are divided into three large groups, the Rhizopoda, Infusoria, and Sporozoa.

The body substance of the first has a consistency so nearly akin to that of water that the surface of the mass responds to the least attraction; it is constantly being flocculated, fringed, or lobed, and the temporary amœbic protrusions that emerge from its mass are called psendopodia, that is, false feet. These pseudopodia, if they are extensively ramified, may have the delicate ramifications fused together. Thus, they become surrounded by a kind of living network. Two classes of these reticulated Rhizopoda have played a great part in all Geological Periods, and are still abundant in all our seas; these are the Radiolaria with a skeleton, which is often silicious, and the Foraminifera, with a shell that is generally calcareous. The first float on the water, and their skeletal débris is found as far back as the Algonkian deposits; the second group live nearer or actually 
at the bottom of the sea. They have formed, practically unaided, deposits of great thickness at different epochs. In the less important Rhizopods the pseudopodia do not fuse; in the Amœba they take the form of simple rounded lobes.

We come thus to the Infusoria, which alter their shape but little, and move with the aid of permanent processes known as vibratile flagella when they are long and few in number, and waving cilia when they are short, numerous, and arranged like a fleece or in fringes. The Infusoria have left no fossil traces. Some Flagellates, however, are interesting because certain bodies which resemble them in all respects, are charged with the duty of promoting the circulation of water in the internal canals of Sponges. This is the only case in which so marked a resemblance has been found between free Protozoa and cells forming an integral part of an organism.

The ciliated Infusoria, in spite of their small size-the largest hardly attain a length of more than a few tenths of a millimetre, present an interest of a different order; their forms already seem to obey the laws dominating the higher organisms. The thin cuticle is pierced by two orifices functioning like those found in the digestive tube of higher animals, one for the entry of food, and the other for the expulsion of the residuum of digestion. These orifices may be terminal, in which case the form of the animal is disposed symmetrically to the axis uniting them. The vibratile cilia form a continuous fleece (Holophrya) or are arranged in a series of transverse rings (Didinium). This is therefore essentially a swimming type, but most of the Infusoria are able to move over the surface of Confervæ, minute Algæ, or even directly over the ground. In this case they have a flattened ventral aspect, to which the mouth has been transferred. This latter is slightly eccentric. But for this fact, the symmetrical currents, stimulated by the cilia, would flow around it without directing any food to it. The eccentric position of the mouth and the way in which the larger lateral portion of that region of the body in front of it forces the currents with the food particles they carry against it, provides it with food. The vibratile cilia round about it are at first similar to the others (Paramecium), but, as though strengthened by the constant and intensive use the animal makes of them, they grow larger than the others and form an adoral fringe that can twist itself in a spiral around the pseudo- 
mouth (Spirostomum), or be simply oblique (Bursaria). Finally, when the Infusorian has become definitely ambulant, the cilia of the dorsal side are atrophied as though through disuse, and those of the ventral side take on special forms (hooks, probes, cirri, paddles, etc.), adequate to the function they fulfil. It is quite clear that we cannot assume for the Infusoria anything comparable to volition, determining the use or disuse of its organs, nor any sentiment of need. It is external stimulation which incites to movement certain cilia rather than others, and which determines the contraction or relaxing of this or that part of the body. But use or disuse, although determined by another cause, has had the same effect as in the case of animals endowed with sensibility and volition. This purely mechanical action is clearly exhibited in Stentor, a large Infusorian provided with an adoral fringe analogous to that of Spirostomum, and with a kind of posterior suction cup that permits it to fix itself temporarily. When the animal is free the cilia of the adoral fringe function like paddles and propel it forward. When it is fixed behind by its sucker they drag forward the body of the animal till it is stretched and elongated into a kind of bell or trumpet, of which the adoral fringe borders the base. This form becomes definitive in the Vorticellids, which are almost permanently fixed.

There is a very interesting difference between the free and the fixed Infusorians as regards multiplication. All the ciliated Infusorians multiply by division, and bipartition is the normal type of this mode of multiplication. In the free Infusorians it is produced transversely, and in the Vorticellids longitudinally, so that in the former case the two new Infusorians are placed one behind the other, and in the second case side by side. However, in certain species, this separation into new individuals is either retarded or does not occur at all. In the first instance we find a chain of individuals resembling the body of an annelid worm, with its division into rings (Anoplophrya, Hoplitophrya, Opalinopsis); in the second a kind of little bush (Zoothamnium, Carchesium. Epistylis). We shall find the same forms allied with the same conditions of life in the higher animals.

Geometrically an egg floating in a homogeneous environment, such as water, ought to produce, after segmentation, a hollow globe with walls formed of a single layer of blastomeres. 
Indeed, this is practically what happens when hereditary or other influences do not disturb the phenomenon. There are organisms that remain practically thus throughout their lives (Volvox, Protospongia, Magosphara, etc.) ; and a fairly large number of embryonic forms in the higher animals momentarily adopt this shape, to which the name blastula has been applied. As a rule this stage is soon passed. The blastulæ are usually covered with vibratile cilia, and it would, indeed, be remarkable if the strength and activity of these cilia were to act with strictly equal force on every side of the blastula. If this were really the case the blastula would be continually whirling around its centre. As a matter of fact, there is always one region in which the cilia are more active, and these draw the embryo in their own direction. Therefore, the blastula has an anterior and a posterior extremity. It elongates along its axis of locomotion and becomes ovoid. The active anterior end is the region devoted to the consumption of reserves contained within the constituent cells of the blastula, and these reserves are accumulated in the inactive posterior area; thus the constituent substances of the ovoid blastula are constantly attracted forwards. Hence, a current is established which induces the posterior half of the blastula to become invaginated into the anterior half. This explains one of the more common developments in embryogeny.

The blastula thus becomes a gastrula; its anterior hemisphere, formed of transparent cells, remains external and becomes the ectoderm: the posterior hemisphere, formed of granular cells on account of the reserve substances it contains, now becomes the interior layer and is known as the entoderm; the orifice, which is necessarily posterior owing to invagination, is the blastopore. Various floating bodies, generally detached from the entoderm, penetrate into the space separating the ectoderm from the entoderm. These may fill the whole space, or they may, in part, become attached to the inner, and in part the outer side of the ectoderm, so as to leave a cavity between them. This is the colom or general cavity, and the elements between the ectoderm and the entoderm constitute the mesoderm. The entoderm circumscribes the primitive digestive cavity which, wherever a cœlom exists, is generally brought into communication with the exterior by a second orifice opposite the blastopore, which becomes the mouth. 
Thus, we become acquainted with three simple organic types, and to these we shall give the name merids. These merids may remain fixed or become, in this condition, free. In the first case they become the respective startingpoints for the three great types of ramiferous organisms: the Sponges, with complete mesoderm, the Polyps, with no mesoderm, and the Bryozoa, with a mesoderm hollowed out by a cœlom. ${ }^{1}$ These three types must have been simultaneously formed from the earliest times when life existed on earth.

The modern Sponges have the property of forming in their tissues small mineral concretions, of a sharply determined form, known as their spicules. These spicules may be siliceous, or calcareous, or they may be replaced by fibres of a substance analogous to silk, and known as spongin. The earliest Sponges seem to have been provided with siliceous spicules bearing six rectangular branches. Our seas still contain them, and they constitute the family of Hexactinellidæ. The Polyps and the Bryozoa can also deposit mineral substance in their tissues, but this is always calcareous. It was they that built the calcareous deposits of former ages. The Bryozoa have had but a humble destiny, while the Polyps, on the contrary, have at all times played an important part; thus, it becomes necessary to detail with precision the relations they bear to one another.

One of the simplest forms in which they can be studied is the freshwater Hydra, rendered so famous by the researches of Trembley. It is, indeed, very difficult to imagine a more primitive animal. It is a trumpet-shaped organism, six or seven millimetres long, and attaches itself by its pointed end to submerged leaves; its orifice, serving at once as mouth and anus, is surrounded by tentacles capable of seizing minute prey, such as small crustaceans, worms, etc. After it has attained a certain size the hydra ceases to grow along constant lines, but produces laterally and in succession small protuberances or buds, each of which develops in order to form a new hydra

1 We may designate these principal merids as spongomerids, hydromerids, and bryomerids. These latter differ from the merids that have given rise to the Artiozoa, or, at least, to the Annelid Worms and their derivatives, only in the fact that they have become fixed. This is one reason why the Bryozoa, Bracliopods, and a part of the Gephyreans have been united in an artificial group of Vermes, containing at the same time primitive and degenerate forms. 
exactly like the parent. The new hydra detaches itsclf and leads an independent life such as a slip taken from a plant would do. At a mean temperature of some twenty degrees, a wellnourished hydra buds with great activity; the hydra born of these buds detach themselves very slowly, and only after having produced buds themselves. In this way Trembley obtained a hydra which bore nineteen others in three different generations. What is exceptional in the case of the ordinary Hydra becomes the normal condition in the majority of the innumerable marine species which, together with this creature, form the main group of Hydroids. Their bodies are generally supported by a thin covering of horny consistency forming the polyp capsule. One of these Hydroids, Cordylophora lacustris, has succeeded in acclimatizing itself to freshwater, and can be obtained in the Seine. The Hydroids, fixed like plants, develop like them by budding laterally, and ramifying; they take on the appearance of small shrubs whose branches consist of single hydroid Polyps, just as the primitive plant was formed of leaves. The polyps, by remaining associated, have constituted a new organism, which is to each of them what a rose-bush is to its leaves, and what the polyp itself is to the plastids of which it is composed. It is formed by the same mechanism-an association of like parts, each capable of leading an independent existence, but which lose part of this independence by reason of their association.

Let us state at once that the mechanism we have seen at work in the Vegetable Kingdom is also usual in the Animal Kingdom. Thus, we ought to give a name to the organic forms corresponding to the successive stages of this complication. We have called plastids the simplest of these living elements, which for a long time were called cells owing to incomplete observations by the early histologists. We have described as merids the organisms resulting from the association of plastids. Hydras are consequently merids. An association of merids we shall call zoids, and, as we shall also meet with associations of zoids, we shall particularize them as demes. These terms suffice to express all the stages of organic evolution. Their brevity allows us to use them as suffixes in compounds ; for example: spongomerid, hydromerid, bryomeridspongozoid, hydrozoid, bryozoid-spongodeme, hydrodeme, etc. It sometimes happens that groups are formed within a deme 
capable of liberating themselves and of leading an independent life (Siphonopliora); these we shall call demules.

In these associations the component parts at first enjoy almost complete independence, which has led to their having been considered as constituting a special kind of body, to which the name of colony has been given in order to distinguish it from ordinary organisms. It is assumed-on a purely arbitrary basis - that the merid of each zoid and the zoid of each deme preserves its own individuality, although the zoid and the deme are themselves deprived of it. However, as in the associations of plastids, the diversification of form and function in the merids brings about an increasing solidarity in the zoid, which, through every possible transition has led us to transfer to them the idea of indivisibility and unity that we have produced from our own consciousness, and which we have transferred to the higher animals and plants themselves.

In actual fact all the hydromerids forming a hydrozoid preserve enough independence to invest them with the various forms, each corresponding more or less to a particular function (without that form, however, becoming indispensable) which their position, the conditions of their nutrition, and the stimuli to which they are exposed, determine. Contrary to the opinion generally expressed in the meaningless phrase "the function creates the organ", which is often applied incorrectly and misguidedly, just because it has no significance, the hydromerids among the Hydroids become modified quite independently of any function. They then perform such actions as their form and position allow, and this activity then becomes a function of which each pseudo-individual is naturally the organ. Thus, along with the normal merids, which preserve their mouth, eat and digest, and which may be called gastromerids, others are found which, since they are nourished by the former, dispense altogether with a mouth. They are able, however, to seize and palpate objects. These dactylomerids, functioning like fishing-tentacles, take on a large variety of forms. Others of the community, the acanthomerids, transform themselves into defensive spikes, thanks to their horny covering. Others, again, find themselves placed in such conditions that the buds they produce rapidly develop germ cells; these are the gonomerids, the carriers of the gamomerids, some of which are male and others female. A. de Quatrefages 
was the first to describe the whole of the small and varied world in Hydractinia that encrusts the shells inhabited by the Hermit-crab. This variety of associated forms, which often corresponds to that presented by the leaves of a plant, is widely spread among the Hydroids, and has led to the same results. When a gamomerid, or sexual merid, develops, at any particular part of the hydrozoid, it brings about the transformation of the neighbouring merids into dactylomerids. All of these form a single whorl, which admits four merids, for the simple reason that any circumference offers about three times as much room as its diameter, and very little more. These dactylomerids cannot coil about the gamomerid they surround without drawing towards them the periphery of the peduncle upon which they grow, and they thus necessarily form a bell-shaped web membrane of which the gamomerid constitutes the clapper. The walls contain muscles which permit it to contract and instantly drive out the water which fills it, and the recoil produced by this sudden expulsion of water has the effect of tugging at the support which at its summit unites it to the Hydrozoid. The peduncle finally breaks and the bell is set free. It consists of a gamomerid provided with a mouth and capable of digestion, an umbrella, which serves as an organ for swimming, and four fishing-tentacles-all that is necessary for maintaining an independent existence. It is free henceforth to live in its own way. A new type of organism, a veritable flower-animal, has come into being; this floweranimal is known as a medusa. The medusæ may remain attached to the hydrozoid that produced them, which then becomes a hydrodeme, since the creatures are themselves all hydrozoids. Their formation is frequently influenced by tachygenesis; hence they sometimes remain incomplete.

Instead of attaching themselves to some solid body, certain hydromerids, drawn by their lightness to the surface of the water, find a way of imprisoning an air-bubble which thenceforward buoys them up. The hydrodemes resulting from their development remain floating and act together, like a fish pursuing and capturing prey. Gastromerids, dactylomerids, and medusæ then take on the most diverse forms. A certain number of contiguous medusæ are employed like a crew of oarsmen for locomotion, and by a phenomenon of tachygenesis these medusæ, which have an indispensable function, even 
develop before the gastromerids. Nothing equals the brilliant coloration and the richness and variety of form manifested by these swimming hydrodemes, constituting the order of Siphonophora. They are real autonomous organisms, and furnish definite proof that what used to be called a colony is nothing but the first phase in the formation of higher organisms.

The advance made by the medusæ in the development of Siphonophora can take place to an equal extent in the fixed hydrodemes. By their help we can construct the stages right up to that moment when the development of the egg ends, not as in a hydrozoid which itself produces a hydrodeme, but directly in a medusa. The gradual suppression of the hydrodeme is here equivalent to the gradual suppression of the prothallus in the Vascular Cryptogams. These medusæ, independent of any hydrodeme, but whose formation was prepared, and could not have been produced but for a lengthy elaboration by a series of hydrodemes, themselves undergo important modifications, becoming complicated in a variety of ways till they finally attain many decimetres in diameter. They form the class of Acalephæ, comprising many orders, ${ }^{1}$ the first culmination of the Hydroid series.

There is a second condition more important still, attained by the Coral polyp via the Madreporaria, those very wonderful reef-builders. Certain Hydroids akin to Hydractinia had already been able to secrete lime. This property is general among the hydrocorallines-so well studied by Moseley in the course of the Challenger Expedition. In the case of the hydrocorallines we can trace from the Echinopora, still closely akin to Hydractinia, to Millepora, Allopora, Stylaster and Cryptohelia, all the phases in the grouping of a certain number of dactylomerids around a gastromerid, analogous to that which has given rise to the medusæ. But here the gastromerid, instead of remaining independent in the centre of its ring of dactylomerids attaches itself to them throughout its whole length and communicates with them by means of corresponding longitudinal slits. It loses its tentacles, which are replaced by dactylomerids. The whole forms a coralozooid achieved by a mechanism analogous to that which produced the dialypetalous flowers with inferior ovaries. 
The Sea-anemones of our coasts are coralozooids that have lost the faculty of producing lime, a property that permitted the other coral-building organisms to play a tremendous part during the Geological Periods, and which still makes them important agents in modifying tropical coasts. In the present state of almost all coralozoids, the dactylomerids associated with the gastromerid number either six or a multiple of six. This number may remain fixed or may augment during the animal's life. The phenomena of embryogenetic acceleration which I have discussed elsewhere, ${ }^{1}$ show how the Madrepore corals constructed on the sextuple type were able to give rise to the Coral and to animals which form with them the order Alcyonaria. These animals appear at a first glance to be Madrepora constructed on the eightfold type, but in reality they are quite different.

From the point of view of the history of the development of life on earth, we will draw from the foregoing these few conclusions only: alongside of the Sponges and the Bryozoa, which appear to have but little plasticity, the Polyps were very rapidly evolved; obviously their primitive forms can only have been Hydromedusæ, but from these arose simultaneously the parallel forms Acalephæe and Corals. Although actually free, the Acalephæ must have appeared originally in sedentary forms, which developed by branching. They acquired their liberty secondarily, and only, as we have seen, through the agency of tachygenesis.

While these organisms were evolving from the fixed merids others were developing from the free merids. These last appear to have belonged exclusively to the type provided with a general cavity, which when they attached themselves to some object, gave rise to the Bryozoa. There was no reason why the preservation of their liberty should have deprived them of their faculty of budding. Locomotion, however, is a factor which has completely modified the conditions of evolution. In fact, when the initial merid remained free and moved about, its weight, locomotion, and the conditions of its search for food, compelled it to abandon a form symmetrical upon one axis, such as it could have retained if it had always swum suspended in the water, and take on a form symmetrical to a single plane. 
In order to succeed in remaining without too much effort between two layers of water, it was obliged to possess the same weight as the water it displaced; and its constituent substances had to be carefully distributed so as to give it this quality, as some of them were heavier than water, and others, such as the fats, were lighter. But this could only happen in exceptional cases. If it were lighter than water, it would be drawn towards the surface and exposed to all sorts of accidents. Hence the heavier forms which were naturally drawn towards the bottom of the sea had the richest potentialities for the future. Under these conditions the merid continued to elongate in the direction of its trajectory. The end which went first and which had to explore the ground to which the rest of the body had to be committed, became differentiated from the posterior. Its constituent parts acquired a greater and greater sensibility, and a fair number were transformed into nervous elements, distributed along the exploratory tentacles or grouped together to form eyes. A little behind the latter came the mouth, naturally preceded by the exploratory region. The animal, probably by virtue of a tactile sense, without which it would have been unable to live, forced this mouth toward the ground on which it crawled in its search for food. Thus, the mouth became a feature of the ventral side, which was, moreover, flattened by its own pressure against the ground, light as this must have been. As the ventral side and the whole periphery of the mouth were thus constantly stimulated by contact with the earth, the development of numerous sensitive cells within this area finally produced around the latter a ring of nerve tissue, and on the ventral side a similar strand. Little by little-in certain embryos, indeed, all the stages of this phenomenon can be followed-the nerve cells became isolated from the epidermis of which they had at first formed part, and eventually came to constitute in the adult creature, the pharyngeal collar, and the nerve-chain, which is found in a more or less modified form in all Arthropods, Annelid Worms, Echinoderms, and Molluscs.

Locomotion has had even more influence on the final evolution of the mobile protomerids than on their forms. The same reason that determined the evolution of the fixed merids by budding, holds good throughout for the free merids, except that in the latter the buds would not be arranged in the same way. 
It is evident that a branched organism would be greatly hampered in its attempts to move backwards, all its branches bcing brushed back in front of its head. Forward movement would result in bending back these branches against the body, and thus prepare for their fusion. There is no reason why these appendages pressed against the body should have been raised from its surface, or spread out laterally, unless they could have been used in locomotion, like the appendages of the Arthropods. In this case they were only necessary because a rigid covering of chitin around the animal's body prevents it from swimming or crawling by means of undulatory movements. The budding therefore is localized at the posterior part of the body, relatively inactive and younger, and formed of non-specialized cells. The new buds are arranged in a straight line behind the old ones, all together forming a body made up in this way of segments placed end to end. The posterior end of the body of the embryo is always completely formed at an early stage by a special segment, constituting a veritable rearguard of sensitive tissue adapted to protect the young animal from contacts to which it may be subjected.

This last segment or telson is always the second one to form ; the others develop immediately in relation to it, so that the youngest segment of the body is always the one before the last. This short description suffices to give us the basis of the embryogeny of all animals with segmented bodies: Arthropods, Annelid Worms, and even Vertebrates. In the latter the body segments, whose bounds are marked by the vertebræ, are also formed one by one at the back of the body, progressing from a terminal region corresponding to the telson.

The essential characters of the evolution of segmented animals are thus outlined. At the beginning of their existence they consisted of a single segment, which, from its constitution, has been capable of budding at the posterior extremity, so that the formation of segmented animals has been very precocious and rapid. It is possible that the merids that gave rise to them were originally similar, and that their integument was formed externally of a layer of cells with vibratile cilia; but this initial type was soon resolved into two others. In one, the superficial cells produced a solid coat, ${ }^{1}$ thick enough to glue the

1 Composed of a special substance of a horny consistency, called chitin, derived from cellulose by the substitution, for one or more atoms of hydrogen, of a nitrogen radical. 
vibratile cilia together, and cause them to disappear; in the other, the vibratile cilia, arranged like fleece or in a ring, persisted, and formed the primitive organs of locomotion. Failing them, the merids of the first type were obliged to propel themselves by means of lateral buds moved by muscles and provided with rigid filaments, which developed into feet. From this type arose the long series of Arthropod forms. The ciliated type produced the series of Annelid Worms, which share with the Arthropods all these characters of organization resulting from their powers of locomotion; Cuvier had already united the two in order to form his group of Articulata. However, the two series differ entirely in all those qualities entailed by the absence of vibratile cilia; they have evolved separately on parallel lines, with no bond of relationship between them.

Embryogeny gives us some idea of what these primitive merids may have been. All the Crustaceans of the large sub-class Entomostraca, however complicated they may be, are born in the form of small organisms, called nauplii, with only three or even two pairs of appendages surrounding the mouth. These serve, primarily, as swimming organs, but at the same time they hold prey by means of hooks borne by their proximal joint. These appendages, after having been employed simultancously as legs at their free end, and as jaws at their base, develop into the two pairs of antennæ and the mandibules of the adult. Various species of higher Crustaceans have continued to hatch out at the nauplius stage, notably the large edible prawns ${ }^{1}$ found along the Mediterranean coast. The embryogeny of certain fossil Trilobites of the Primary Epoch has also been reconstructed. The species of Sao, for instance, were born with only three segments, the others being formed successively in front of the telson.

At birth the free marine Annelid Worms whose bodies are not divided into distinct regions, and which have been called Annelida Errantia, appear with a still simpler form, which, strictly speaking, represents only the first segment of the adult animal and the telson; this is the trochosphere, an ovid body, barred with two rings of vibratile cilia between which lies the mouth.

Starting from these initial stages we can follow, in the two series of Arthropods and Vermes, every step by which an 1 Penaeus scaramota. 
increasing embryogenetic acceleration, favoured by the accumulation within the eggs of a larger and larger amount of reserve nutritive material, leads to the higher forms that develop entirely within the egg. These creatures hatch out with all the segments they will ever have, and often in their permanent form. This is the necessary preliminary condition which alone has permitted the realization of organisms capable of living in fresh water, or on the earth, and hence of breathing air.

The two series of free and segmented animals have evolved naturally at the same time as the Algæ, the Sponges, the Polyps and the Bryozoa. We may assume that from the beginning the waters were peopled with the most diverse formis, which could vary in many ways, according to circumstances, because they were not under the domination of heredity and because, on the other hand, the struggle for existence was not very intense and the mere ability to keep alive sufficed to perpetuate their stock. All that was possible was attained. It is due to this easy stage in the struggle for existence that certain deformations, apparently disadvantageous, of primitive types have occurred and given rise to forms which appear almost monstrous, but which, nevertheless, have managed to occupy a most important place in nature. As from the point of view of locomotion, there are only two kinds of existence, immobility, which means attachment to some foreign body, and mobility we might suppose that there should be only two types of structure for animals, the branched type, linked with immobility, and the segmented, linked with locomotion. There are, however, four others: (I) the Echinoderms, radiate without being fixed; (2) the Molluscs, non-segmented, and often found in spiral or helicoidal form; (3) the Tunicates, fixed or swimming, but unsegmented and non-radiate. This last is a regressive type, due to degeneration following upon fixation to the earth of already highly organized animals, and which were nothing less than the precursors of the Vertebrates. Of these precursors Amphioxus is the last representative ; (4) Finally we have the Vertebrates, truly segmented, but with an internal structure apparently quite different from the expected and theoretical structure of segmented animals. Our task now is to find out how such organisms were enabled to develop. 


\section{CHAPTER V}

\section{Attitudinal Changes and Structural Modifications}

\section{$W^{1}$}

HEN in my book, Les Colonies animales et la formation des organismes, I attempted to explain how the different types of the Animal Kingdom had been evolved, it was not difficult for me after having given a history of the branched and segmented animals, to show, as other authors had pointed out for each group in particular, that the Annelid Worms, in all probability, were the progenitors of the Echinoderms, Molluscs, Vertebrates, and, in consequence, of the degenerate derivatives of the latter, the Tunicates. But although I had at that time already pointed out the importance of tachygenesis, I had not as yet realized the full consequences of this mode of hereditary action, nor had I perceived one particularly powerful cause for the modification of organisms, namely, the changes of posture that have taken place in each species in the course of ages.

To convince ourselves of the reality of these changes, we need but cast our eye over the existing series of living forms. Among the Crustaceans, Apus and other Branchiopods swim with their ventral side uppermost and their dorsal side downwards; the same is true of Notonectes among the Insects, and its name indicates this position; among the Cirripedes, Lepas and its allies suspend themselves from floating objects by their head, which is drawn out into a long peduncle; while forms like Badanus, closely related to them, obliterate, so to speak, this same extremity against the rocks to which they closely adhere. In the subdivisions of the Tunicates we observe the same contrast between Boltenia and the other Ascidiacea, while the Tunicates that have reverted to swimming retain the normal position. Among the Echinoderms the common sea-urchin has its mouth below and the anus above, so that the five radial areas, bearing their organs of locomotion, are erected vertically like the petals of a flower, all five arising from the mouth and capable of reaching the orifice opposite. But there are some species which dig cease- 
lessly in the sand, and in these the lower region of the body becomes flattened to form a ventral side, while the mouth advances gradually towards the edge of this surface that the animal keeps habitually in front. Above this, one of the ambulacral areas, which has become the anterior one, moves up to the top of the body, round which the other four ambulacral areas, now become lateral, continue to converge; the anus leaves the top for a definitely posterior position, and finally reaches the region of the edge of the flattened lower surface, which thus forms a ventral side situated between the two lateral ambulacral areas that are furthest away from the anterior one. The Holothurians, or sea-cucumbers are Echinoderms closely akin to the Sea-urchins, but the body is elongated like a sausage instead of being globular. They often live in the crevices of rocks ; they can only maintain themselves on the ground in a recumbent posture, the openings of the digestive tube each occupying one end of the body. A certain number of littoral species, however, crawl on the sea-bottom ; they then acquire a flattened ventral side always divided by one of the radial locomotor areas into two symmetrical halves and bounded by two lateral ones. Exactly the reverse condition is found among the Sea-urchins, where the ventral side has no median radial area while the dorsal side has. The mechanism of the formation of the ventral side, however, is quite different in both cases. The Holothurians with ventral sides behave in two ways. Those inhabiting great depths live on mud; they direct the mouth towards the earth by sharply bending the anterior extremity of the body. At first temporary, this bending becomes later permanent, and subsequently disappeared, the mouth finally. becoming definitely ventral. Those attached to rocks, on the contrary, draw their nourishment from the surrounding water, and their mouth becomes dorsal (Psolus). Moreover, certain Holothurians always live buried in sand; some remain elongated vertically, ${ }^{1}$ while others curve their body into a $\mathrm{U}$ so as to bring their anus to the surface and evacuate their excrement without soiling the sand. This attitude, at first temporary, ${ }^{2}$ also becomes fixed, ${ }^{3}$ so that the two ends of the body 
approach one another more and more, and eventually fuse in a single tube pierced above by two openings. The Holothurian thus takes on the shape of a bottle, whose neck carries the two digestive openings that have now become contiguous. ${ }^{1}$

The Mollusca are at least as accommodating so far as posture is concerned. The molluscs with spiral or helicoidal shells crawl on their ventral surface; but all those capable of swimming, even if only temporarily, swim upside down, the abdomen uppermost and the back below. Some molluscs, indeed, are exclusively swimmers $;^{2}$ others exclusively crawlers, and others swim or crawl, according to circumstances.

The molluscs with bivalve shells have aptitudes even more varied. Mussels, and those molluscs akin to them, suspend themselves by filaments which constitute the byssus; the Oysters, Pecten, Spondylus, etc., live resting on their sides; Tridacnæ live on their backs on the polypary; Vems, Razor-shells, Pholades, and a host of others, bury themselves in the sand or penetrate into holes which they hollow out even in rock, and live immobile, the head, or what takes its place, being furthest in. A special form of body corresponds to each of these attitudes, which is easily accounted for by the continuous action of weight upon the various internal parts of the immobile creatures. The body of the mussel enlarges in the region turned downwards, and becomes pointed in the neighbourhood of attachment of the byssus; the lower valve of oysters and other bivalves that lie on their sides, originally symmetrical with the upper valve, swells so as to form a sort of chamber, of which the upper valve, flattened to concavity, is nothing more than a cover; the heavier organs of Tridacna sink below the lighter, and reach almost to the hinge of the shell, so that the mollusc appears doubled up inside it. In the species that immobilize themselves in holes, the thick lime-secreting mantle becomes elongated into two long siphons, one for the entrance of the water which brings the animal air and food, and the other for evacuation. These modifications, with the exception of the last, have been brought about by the persistent action of a most ordinary cause, namely weight pressure, which

1 Rhopalodina (LIV, 280).

2 Nautilus, Pteropods, Ianthina, and the larvæ of all the marine Gasteropod Molluscs. 
is also responsible for forming the ventral surface of the bilateral Echinoids and the deep-sea Holothurians.

Neither have the Vertebrates escaped attitudinal changes. Amphioxus, the soles, turbots, dabs, and other flat-fish classed as Pleuronectids, remain on their sides. They therefore bcconie dis-symmetrical (much like the molluscs that live under the same conditions), and carry their two eyes on the same side of their body. The Echeneididæattach themselves to sharks, pressing against the body of their hosts their dorsal surface, which thus functions as the ventral surface of other animals with respect to light and the soil. The dorsal surface becomes discoloured and flattened, while the ventral side takes on the characteristic of the ordinary dorsal surface. The influence of external conditions on form and colour is thus clcarly shown.

This influence is secn to operate unceasingly directly we make any attempt to correlate animal characteristics with the conditions in which they live, rather than considering them apart from all the causes which, with any degree of plausibility, can be invoked to explain their existence-as if they were the result of some miracle. Let me give some examples. The links which unite the main divisions of the Fishes ${ }^{1}$ can be summed up in this one proposition: The branchial region, situated between the head, to which the water offers resistance when the fish swims, and the body, which is pushed forward by the sudden propulsions of the tail, is progressively shortened till it finally becomes atrophied in the Batrachians, their descendants. Among the terrestrial vertebrates a neck, which may be enormously elongated, takes the place of the branchial region that has disappeared; but when these vertebrates again become aquatic and swim after the manner of fishes, their neck, placed in the same mechanical conditions, undergoes the same reduction, whether we take Reptiles like Ichthyosaums of the Secondary Epoch; the Herbivora that have become aquatic, like the Sea-cows and Dugongs; Seals that have become divers like the Zeuglodonts, or Cetaceans which are probably descended from another stock. This repetition of like phenomena, under like conditions, among different Vertebrates, which, moreover, have preserved the characteristic organization of their group, illustrates well how these phenomena have been due to external actions modifying 
the parts of the body directly subjected to their influence and not affecting other parts; which is equivalent to saying that these external actions are the causes of the modifications which are correlated with them. This correlation is found in an infinite number of cases. The legs of the swimming Arthropods, for instance, which move them about only by thrusting against the water, are flattened and acquire a fringe of long hairs; a web appears between the toes of the foot in all walking Vertebrates, that return to the water, whatever the type to which they belong: tailless batrachians, crocodiles, pond and marsh tortoises, web-footed birds, Ornithorhynchus, desman, musk-rat, beaver, mink, otters, seals, etc. In all the groups of climbing vertebrates which press their abdomen against the trunks of trees, we likewise find species that have lateral skin-folds running down on to their limbs in such a way as to reach as far as the digits. This condition is reproduced in Petaums, among the Marsupials, in the lemur Microcebes, in the insectivorous Galiopithicus, Pteromys sibericus, and in the squirrel Anomaturus; and in reptiles that lead up to the flying dragons, such as Stychozoon and Uroplatus. This condition prepared the way for the wings of the Pterodactyles or Flying Reptiles of the Secondary Epoch, and for mammals like the bats.

Certainly the kind of life led does not suffice to bring about this transformation. Otherwise all climbing animals, for example, would have acquired parachutes. Certain organic conditions are also required which we as yet cannot define, or perhaps a minimum degree of frequency in the repetition of the same acts permiting the modifying forces to assert themselves with especial intensity, or the regular co-operation maybe of many of these forces acting simultaneously. At all events, the correlation is too frequent for us to believe that it is independent of a causal factor.

An explanation of this correlation has been attempted by appealing to what have been called pre-adaptations. New characters make their appearance without our being able to assign a reason; they would be cryptogerous, as geologists say of species that suddenly make their appearance in certain geological layers, without it being possible to discover for the moment whence they have come. Throw-backs due to heredity, unknown modifications of the internal environment, 
and various external actions whose influence it has not been possible to determine-all of these may give rise to new characters without their being of any immediate utility, but once present, the animal, which at first had only to exercise them, will make use of them as soon as it discovers how to do so.

Thanks only to these new characters, which appear to have resulted from the new conditions of its existence, the animal was able to profit by the changed conditions. These preadaptations are real, and it is due to them that natural selection, which results from the struggle for existence, was so efficacious, and it is they that have given Darwin's theory its whole value. We must not conclude from this that the conditions of existence or of development do not encourage the appearance of new characters in harmony with them, either directly or through their reactions on the animal. Often, on the contrary, preadaptations and adaptations overlap. This is what has happened to the Birds. Their feathers were not meant for flying, but were at first merely tegumentary overlapping excrescences, doubtless irregularly branched; these branches because of the deterioration resulting from the mode of superposition, ended by developing laterally only; thus those of the wings and the tail were utilizable for support in the air. The foot of the Bird, on the contrary, everywhere bears witness to its will to stand erect on its hind limbs, which it straightens by aid of its muscles to the point of using its toes only as supports. The great toe ends by no longer touching the ground ; it becomes atrophied, but is still represented by the spur of cocks. Those muscles which extend from the pelvis to the thigh and maintain the body erect, having extra work to accomplish, increase in size, and cause considerable growth of the pelvic bones, which invade more and more of the vertebral region both behind and in front of the hip-joint socket. Here we have an evident triumph of the Lamarckian principle of the influence of use and disuse of organs, a principle alien to the origin of the feathers, if not to the determination of their final form. None of these characters were developed with a view to flight; it was simply a matter of co-ordination of bones and muscles favourable to the biped posture and to hopping, as is proved by the Iguanodons and other herbivorous birdlegged Reptiles of the Secondary Period, or Compsognathus, 
another and carnivorous group of Reptiles of the same Period, called Theropods. Many of these animals had bones which were hollow or penetrated by the diverticula of the air-spaces which are now peculiar to Birds, so that the respiratory apparatus itself, so long considered as destined to obtain for the bird the energy required for flight, is seen to have had no original connexion with this special method of locomotion. None of the characters that class an organism as a bird were assembled for its present peculiar mode of life; the feathers arose from the multiplication of the cells of the epidermis and their faculty of producing abundantly a horny substance ; the conformation of their hind legs results from the advantage the beast found in standing erect upon them and in hopping, and the augmentation of activity it developed for this purpose reacted upon the respiratory apparatus. Thus far, it might seem that the animal was a kind of patchwork; but once these characters were all united, the Reptile, having become a hopping creature making use of its feathered front limbs as parachutes, was able to support itself in the air, as, by different methods, the Insects and the Pterodactyls had succeeded in doing, and as the Flying Fishes and the Bats succeeded in doing later. Thus, from the fortuitous reunion of a set of characters and organic arrangements, developed without any end in view, or, at least, with an end other than that of flight, the Bird subsequently perfected itself through the exercise of these characters. We must, then, guard against the belief that a single category of causal factors, a single process, or a single method has sufficed to create the diverse forms of living creatures, and that any one theory can account for their evolution. All these living forms that surround us are the result of a gargantuan conflict of forces and substances, greater even than what we call the struggle for existencea conflict compared with which the history of peoples and races, complex as it appears to us, is but a picture seen through a diminishing glass. Nor must we forget that even in the case of what are called pre-adaptations, the animal can only profit by the new characters it has acquired by using its muscles and its nervous system in a new way. It depends on itself whether it makes the best use of these various features of its organization. Adaptation to environment, initiated before its own volition comes into play, is finally achieved only by this volition, 
and obliges the organs to change their function. These changes of function are frequent in the animal kingdom. Anton Dohrn, the founder of the famous Aquarium at Naples, called attention to these in an admirable series of memoirs. ${ }^{1}$ Flying fishes make use in flight of anterior fins developed originally for swimming; the abdominal and anal fins of Gobius, Liparis and Lepadogaster are transformed into suckers to facilitate fixation; the anterior part of the dorsal fin becomes a fixed cephalic sucker among the Echeneididæ; Savigny has shown how largely the buccal appendages of Insects can be modified, according to the very varied food of these creatures; the anal terebra, serving as the ovipositor of Hymenoptera with phytophagous or entomophagous larvæ, becomes the defensive sting of Bees, Wasps, and Ants ; the mouth of the Vertebrates is a former branchial slit, etc. We might almost say that all comparative anatomy is but an account of similar changes of function-the very opposite of pre-adaptations. No more than pre-adaptations can these explain everything, and with them they merely furnish a basis, still too narrow, for a complete theory of organic transformations. But if we bear these facts in mind we shall be better able to recognize the determining causes of those persistent characters which are found in all animals of the same group, and lend to each group a special physiognomy. To go back to their original cause, it will suffice to call to our aid the fundamental principles of embryogeny described in an earlier chapter. Let us first see how the Echinoderm type was arrived at, whose larvæ are free, or are only fixed at a late stage, and which yet produce organisms definitely radiate, i.e. ramifie, a phenomenon that at first sight appears contrary to the laws that have determined the two main types of animal structure.

Doninating the almost infinite variety that armogenesis and tachygenesis together have imposed upon the embryonic forms of Star-fishes, Sea-urchins, Holothurians, and Crinoids forming the phylum of the Echinodermata, certain constant characters appear that are essentially patrogonic, that is to say, representing phases of the phylogenetic evolution of the ancestors of the present Echinoderms. Whatever be the external form taken by these embryos, they first present at their birth a distinct bilateral symmetry. Their dorsal convex 
surface is more rleveloped than their ventral concave surface, so that they might be regarded as curved like a $\mathrm{C}$. Bands of vibratile cilia, originally arranged round them in a girdle, as in the larvæ of the Synaptidæ and the Crinoids, but deformed by the excessive growth of certain parts of the embryo, particularly the dorsal surface, divide the body into five segments, whence the term pentatrochal applied to these larvæ. If the organism remained in this condition there would be no hesitation about including it among the Annelid Worms. Soon, however, calcareous spicules appear in its tissues, and at the same time the internal organs become dissymmetrical; those of the side which develops most rapidly present the characteristic feature of rolling up in a spiral. Shortly after the appearance of calcareous spicules in the tissues, the young organism, grown in weight, ceases to swim and falls to the seabottom, and there its posture is steadily modified, the left and right sides becoming respectively the ventral and dorsal aspect of the adult animal. If we take these constant developmental phases of the Echinoderms as patrogonic in originand to do otherwise is to deprive embryogeny of all significance - the phylogenetic history of these animals appears to be as follows. Their ancestral form was that of a short Annelid Worm, reduced to five segments, whose body, merely because of its muscular tonus, became curver into a $\mathrm{C}$ like the majority of segmented animals in their fixed state. ${ }^{1}$ This worm originally a swimmer, secreted lime, which was deposited in the form of spicules in its tissues, thus gradually increasing its weight. It finally fell to the bottom, and, having become rigid and incapable of recovering its position, owing to this development of spicules, so, because of its curvature, it remained lying on its side. Thenceforward it became dissymmetrical, like the larvæ of Amphioxus and the Tunicates, and the Pleuronectoid Fishes, which have changed similarly. But an animal lying on its side is unfavourably situated for securing nourishment, for it is particularly on the floor of the sea that the food it requires must be sought. It is therefore forced to bring its mouth to the floor, using for this purpose all the muscles at its disposal. Guided by what Iamarck called the sentiment of need or of

1 Woodlice and other Isopod or Amphipod crustaceans; the larvæ of Cockchafers among the Arthropods; Aphrodite and other crawling Annelid Worms with short bodies and ventral surfaces with strong muscles. 
well-being, which to-day we tend to replace by what we call tacticism, it disposes its anus as far as possible from its mouth ; it will thus reach that stage of coiling into a helix, with whose phases we are familiar in its embryogeny. Except that they are fixed, certain Crinoids of the Primary Period, e.g. Agelacrinus, seem to have been arrested at this stage of their development. The causes limiting budding to the posterior region of the body in mobile animals, and operative in the case of the Annelid Worms, are here absent. Any segment of the body can produce a series of buds that first share the linear arrangement of the parent, but subsequently can also become ramified (Astrophyton and other Ophiuroids that attach themselves to polyparies, also Pentacrinoids and Comatulides). It is in this manner that Starfish originated, which go back to the most remote antiquity, and it is easy to derive all the other Echinoderms from them by reference to simple embryogenetic considerations. I have shown ${ }^{1}$ that among the Starfish, Brisinga still has its arms regularly segmented; that the new segments form directly in front of the oldest segment, represented by the radial disc plate of the embryo as in the case of Annelid Worms, and that all the transitions between this type that therefore appears primitive and the pentagonal Starfish, so far removed from it, such as the Culcites and Pentagonaster, can be followed. After the metamorphosis resulting from their pleuronectean attitude, all the Echinoderms pass through a common embryonic phase. What was formerly the right side, and has become the dorsal surface, takes on a radiate structure characterized by the presence of a central calcareous plate, surrounded by five similar plates called basals, followed by five others alternating with them, called radials. The former left side, now the ventral surface, is rayed in the same way, but each ray is essentially composed of a double series of plates, called ambulacral plates, connected with tentacles or tube-feet. According to the special fashion in which the calcareous plates multiply, starting from this common embryonic form, all the various classes of the Echinoderniata have been derived. This multiplication is almost non-existent in the Blastoids which have to-day disappeared. Among the Starfish and the Ophiuroids new plates are formed between all the dorsal plates, particularly between the basal and radial ones. They 
are thus constantly being forced outwards, and five arms are formed behind them, the ventral surface following step by step the growth of the dorsal surface. Among the Sea-urchins new plates are not formed between the dorsal ones, which remain united around the anus, but the ventral surface undergoes a rapid growth, so that the animal swells like a soapbubble suspended from the pipe by which it is blown. The Holothurians are scarcely more than Sea-urchins whose skeleton has become reduced to spicules. Among the Crinoids the primitive plates remain united as in the case of the Seaurchins, but between the centro-dorsal and the basal plates there is formed a layer of plates in the shape of a long peduncle, by means of which the animal fixes itself. The ventral face is not developed, but outside the radials, which remain united to the basals, under the stimulus of the genital organs there occurs an active budding which gives rise to five arms that may remain simple (Hyocrimus, Rhizocrinus, Democrimus, Eudiocrimus), may bifurcate (Antedon), or, ramify in various ways. Finally, the Cystidis are fixed like Crinoids, and it appears that, contrary to what occurs in Sea-urchins, only their dorsal surface is developed. We may once again enunciate the proposition: all that it is possible to achieve is achieved.

The phylum of the Mollusca has developed by analogous changes of posture. All zoologists have been struck by their resemblances to the Worms, either at birth, when they take on a form very like the initial form of these last, or in various organic characters of the adult state. One class only, the Amphineura or Chitonidx, show actual segmentation of the body. Two others, the Cephalopoda and the Gastropoda, are characterized by the transformation of their dorsal surface into a large cone, which must have grown in opposition to gravity if the creature's posture had always been what it is to-day. This cone does not exist among the Lamellibranchiata ; but, as we shall soon see, it remains characteristic of the Molluscs. It was straight, among most of the older Molluscs, Cephalopods (Orthoceras) and Gasteropods (species of Tentaculites, Conularia, Hyolites, etc.); it has persisted in most of the present Cephalopods (squids and octopuses); it is rolled up in a plane spiral so as to retain the primitive symmetry in the majority of the shelled Cephalopods (Nautilidæ, Goniatitidæ, 
Clymenididæ, Ammonitidæ), and among some primitive Gasteropods (Bellerophon); among others it is wound not in a flat spiral but in a helix, thus becoming dissymmetrical, as has also happened in the case of some of the later Ammonites (Turrilites). What relation is there between all these facts?

It cannot be supposed, as we said above, that the dorsal cone of the Cephalopods and Gasteropods was able to grow upright on the creature's back in spite of its weight, which must then have flattened it. We may rather suppose that these organisms originally either floated or swam on their backs in the water, the ventral surface uppermost, and were able to maintain this position by some means or other of suspension and locomotion. In this case their dorsal surface would inevitably have yielded to the pressure of the viscera under the influence of gravitation and to the pull of the calcareous protective shield, when there was one on this side. A pendent dorsal cone must thus have been formed in the water, and it is only thus that the posture of the Cephalopods and the primitive straight-shelled Gasteropods can be conceived. On the other hand, it is impossible not to notice that all the present swimming Molluscs swim on their backs with their ventral side uppermost (species of Nautilidæ, Ianthinidæ, Carinaridæ, Pterotracheidæ, Pteropoda), and that all the marine larvæ of the Gasteropods provided with a shell swim in the same fashion. If, as we have explained, ancestral forms are recapitulated embryogenetically, here is a definite indication that the ancestors of the present Molluscs were swimming organisms, and swam in the inverted position still maintained in larvæ, and re-adopted by adults when they revert to life in the ocean.

The causes that have produced the coiling of the shell are not in the least mysterious; they were in part suggested long ago by Arnold Lang. The gills of the Cephalopods are situated in a cavity, within which the anus also opens, and which therefore corresponds to the posterior region of the body. The organism is able to respire freely only if the opening of this cavity is uncovered by a forward inclination of the point of the dorsal cone. This point is then pushed back and upward, as a result of the resistance of the water to the mollusc's weight, but the mollusc is propelled forward by suddenly expelling the water contained in the branchial cavity; the 
reaction of the water thus expelled pushes it forward, and the resistance of the sea-water again intervenes to force backwards the point of the cone, which is then pulled downwards by gravity. All these co-ordinated actions, added to the phenomena of yrowth, inevitably determine the coiling of the shell in a spiral form, the opening being directed backward and the coiled part forward, as is seen in Nautilus.

This is also the form of coiling found in the young shell of the oldest Gastropods (species of F issurella, Trochus, etc.), from which we may conclude that their gills were primitively posterior. These Gasteropods, like the Cephalopods (Bellerophon), were originally swimming organisms, and were also obliged to coil their shell forwards. The pressure of the water against the shell carried thus forwards and spirally wound sufficed then to keep the posterior branchial aperture open. Later, however, these molluscs become crawlers (species of Pleurotomariidæe, Fissurellidæ, Haliotidæ, Trochidæ, Turbo, etc.), and once more had to apply the ventral aspect to the ground surface. The forwarddirected shell then became directed backwards, as a result of crawling, and again masked the branchial aperture. Lang $^{1}$ has shown how the Gasteropods got out of the difficulty by contracting one half of the body, so as to turn the branchial cavity to the front, and Robert ${ }^{2}$ has been able to trace the phases of this rotation in the larvæ of Trochus. The almost permanent contraction of one half of the body has gradually induced a shortening and then a partial abortion of this half ; the spiral coiling of the cone thus became dissymmetrical, and was replaced by a corkscrew formation. The torsion into a figure 8 of the nerve cord, from which the visceral nerves are derived, is at once a result and a proof of the displacement of the branchial cavity.

How is it that the bivalve Mollusca, of which the Oysters are typical, escaped both the dorsal cone and the coiling which would be its natural sequel ? The method we have just followed will provide the explanation. Being without any embarrassing dorsal cone, those Molluscs, like the Oysters, which do not lie on their sides, are strictly symmetrical, but it is not difficult to discover the nature of their affinities with the other molluscs. The primitive Gasteropods, in fact, present some peculiar structural characters. The heart possesses two auricles, and 
its ventricle is traversed by the rectum, and they have two bipectinate gills. These special characters are found again in the Lamellibranchs, which ought, in consequence, to be regarded as related to the older Gasteropods called Diotocardiac, because of the two auricles with which their heart is provided. As a matter of fact, all the present Diotocardiacs are dissymmetrical; the most primitive of them all, the Pleurotomariidæ, the Fissurellidæ, Haliotidæ, and a few others have retained as a common character the most inanifest traces of bilateral symmetry; the anterior edge of the opening of their shell is either deeply divided or curved inwards, at any rate, in the young; the slit may persist (species of Plenrotomaria, Emarginula) and give rise to a series of holes arranged in a helicoid line (Haliotis), or to an opening situated at the apex of the shell, which is then in the form of an elliptical cone (Fissurella). However, this slit, which indicates a division of the mantle into two lohes, each connected with the two gills, is also found, arranged according to the symmetrical plane of the shell, in Bellerophon of the earliest Primary Period, now extinct. There can be no doubt that these organisms were diotocardiac Gasteropods, which, like the Cephalopods, all swimmers, had preserved a perfect bilateral symmetry. But for our purpose it is enough that organisms analogous to Bellerophon, in the course of their pelagic life, gradually re-absorbed their dorsal cone, and that the initial slit became extended along the whole length of the plane of synimetry in order that the shell should become bivalve. The play of the muscles in closing the two valves of the shell compressed the molluse, which, having lost its dorsal cone, was able to crawl, like the Solenmyidæ, without any alteration of its bilateral syminetry. The disappearance of the dorsal cone, moreover, is a frequent phenomenon ainong the crawling Gasteropods, and occurs in the most varied orders of this group; it is, for instance, complete in the Fissullidæ, which are diotocardiac, the Patellidæ, which are heterocardiac, the Valvatidæ, which are monocardiac, the Limacidæe and the Vaginulidæ, which are pulmonate, and among is large number of Opisthobranchs. To suppose that it had disappeared among Molluscs analogous to Bellerophon is therefore only to base our hypothesis on quite a common phenomenon.

Thus the three main classes of Molluscs are easily explained. 
It remains to be seen how the molluscan type originated from a transformation of a more easily explicable type. We have already pointed out the transitional characters of the Amphineura, of which the Chitons represent the common type, and whose back is protected by eight calcified plates essentially similar one to another, the shell-plates or "valves", revealing a segmentation of the body. It is the less possible to escape this interpretation in that the valves are not a simple covering, dead and calcareous like the shell, but are rather living differentiations of the integument of which they form an integral part, traversed by nerves, and the seat of sensitive organs which may become eyes and which are repeated regularly in the same place on all the valves. It is then quite clear that the integument of the Chitons is segmented like that of the Worms; incomplete partitions even separate these segments inside the body, where similar organs are encountered in all segments thus divided. It must therefore be admitted that the Oscabrians are closely akin to the Annelid Worms whose origin we have already described. Their nervous system has been studied in detail ; it is the nervous system of the Worm very little modified, and this confirms our conclusion. The nervous system of the Pleurotoma and the Fissurella has also been carefully studied and described by Bouvier and Fischer. ${ }^{1}$ With the exception of those portions correlated with the dorsal cone or superposed portion of the $k$ udy, their nervous system is identical with that of the Chitons. Cuvier has said: at bottom, the nervous system is the animal; the close relationship of the Chitons and the diotocardiac Gasteropods, which their external form does not suggest, is here quite patent. This, then, is the link showing how the Molluscs deviated from the Annelid Worms. The nervous system of Nautilus, studied by Gravier, brings further support to the assertion, for it is manifestly formed of two rings united in front, instead of two longitudinal cords. It could, however, hardly be otherwise, seeing that the ventral surface of the Cephalopods, which corresponds to the feet of the Gasteropods, is reduced to the space between the mouth and the anus, that is to say, the periphery of the mouth itself.

We come finally to the higher animals, to those in which 1 XL VIII, 117-272. 
organization has attained the greatest development, namely the Vertebrates, to which man himself belongs. The body remains symmetrical. The structure of the vertebral column, even the arrangement of the muscles in the body-ivallsespecially among Fishes and Batrachians-of the nerves, blood-vessels, and lateral sense-organs in the aquatic Vertebrates, of the renal ducts in those Vertebrates provided with gills at birth, and of the embryos of those where these organs are vestigial and disappear before birth-all this leaves no doubt about the relationship of the Vertebrates to segmented animals, to which Étienne Geoffroy Saint-Hilaire, ${ }^{1}$ Semper, ${ }^{2}$ and Balfour ${ }^{3}$ drew attention. Even in r869, however, de Lacaze Duthiers insisted that there was an unbridgeable gulf between the Invertebrates and the Vertebrates. It is, of course, true that the Vertebrates entirely lack the characteristic arrangement of the nervous system found in all Invertebrates in which a nervous system is differentiated, -the ganglionic ring surrounding the beginning of the œsophagus; furthermore, while the nerve-chain which, in Invertebrates, is usually a continuation of this ring, is ventral, the spinal cord, which seems to correspond to it among the Vertebrates, is dorsal. Conversely, the circulatory centre is dorsal in the segmented Invertebrates, and ventral in the Vertebrates. Étienne Geoffroy Saint-Hilaire had already pointed out, in ISo8, that this opposition was only apparent and that in order to make it disappear it was only necessary to place the segmented Invertebrates back downwards and belly upwards - that is, to reverse their attitude. But why this reversal? Geoffroy Saint-Hilaire limited himself to envisaging the matter from the point of view of unity of plan in the composition of the Animal Kingdom, and though the idea seemed to be ingenious and even drew an anonymous letter from the physicist Ampère raising certain difficulties, it was soon abandoned. Yet the reality of the inverted attitude suggested by Geoffroy can be both demonstrated and explained. In origin, the œsophageal ring of the segmented animals was simply the result of a sensitive differentiation of the epithelial cells surrounding the mouth, brought about by the stimulating action of the food seized and swallowed by the organism. We can follow, as we have seen (p. I22) in the 
case of the Annelid Worms, all the phases of this differentiation and of the migration of the nerve cells out of the epidermis, from which they only separate completely by slow degrees, in order to form an independent ring. This differentiation and separation, which early became independent of external excitation, and operative only through heredity, gradually became more and more precocious following the laws of tachygenesis, as the nervous system assumed greater importance. What fundamentally characterizes the Vertebrates is precisely the large volume of the nervous system in comparison with the rest of the body. The nervous system must accordingly be formed veryearly, and this is what we find, in fact, in Amphioxus and in the Tunicates which are degenerate forms of the same group. In these animal organisms - and the same is true of all the lower Vertebrates-the nervous system is formed by a modification followed by the invagination of one complete embryonic surface, and these phenomena long precede the formation of the mouth. At the time when the mouth can form, the place it ought to occupy is taken by the already far advanced general outline of the nervous system. But at this particular moment there is formed in Amphioxus, on one side of the body, the first branchial slit establishing communication between the exterior and the cavity of the future digestive tube. The young organism makes use of it as it would make use of the mouth it does not yet possess, but it is obliged for that reason to lie on its side, and, like the soles, to turn this side into a ventral surface; like them, also, it becomes dissymmetrical. This dissymmetry is revealed by the encroachment by the muscle segments of one side of the body across on to the other, so that each semi-segment of one side is in advance of the other by one half of its length; by the localization on the side of the body that has become dorsal, of the olfactory pit; and also by the formation on the same free side of the body, of two series of branchial slits arranged in a curve, and thus betraying the torsion that the body has had to undergo in order to bring over to its free side the branchial slits of the other, which the impurities of the soil would have blocked up. The young organism at this stage swims on its side like the Pleuronectid Fishes. Later it burrows vertically into the sand, and since everything around it is once more symmetrical, it proceeds to repair its dissymmetry. The series of branchial slits, 
displaced by the torsion of the body, regains its position on the side abandoned. The first branchial slit, which remained in its original place but enormously increased in size, is gradually masked by a fold of the integument which comes down over it like a shutter, and only leaves free a slit along the ventral edge. The false lateral mouth, constituted by the first branchial slit, becomes median, but is opposite to the nervous system instead of being situated on the same side. In order to utilize it, the organism is forced to turn itself towards the ground, where it must, after all, find its food. It thus converts its old dorsal surface into a ventral surface, and vice versa. The attitudinal reversal pointed out by Geoffroy Saint-Hilaire is thus. actually observed and explained in the most primitive of the Vertebrates, and, as we have seen, it takes place twice over.

The Vertebrates that are descended from the primitive types, of which Amphioxus is the last remaining example, have necessarily preserved their type, because their nervous system has merely gone on increasing in size, and because it is the rolume of the nervous system which determined it as a natural consequence of tachygenetic processes that have come in in its method of development. Dohrn has since demonstrated that in the Lampreys and Sharks also the mouth was only a modified branchial slit, and these animals have retained numerous traces of dissymmetry.

We must bear in mind from now on that the Vertebrates owe their origin to the importance assumed by the nervous system. It is by the subsequent development of this system that they rise above the other animals, and arrive at last at Man, whose evolution has thus been dominated by the rapid progress of the organs in which intelligence resides. Here is a theme for philosophers and above all for metaphysicians - a theme which could provide a field for the adjustment of doctrines hitherto regarded as irreconcilable. I have shown elsewhere how other characteristics of Vertebrates, such as the formation at the expense of the endoderm of a dorsal cord round which the vertebral column develops, follow from these premisses. ${ }^{1}$

I will not here lay stress on the phenomena of degeneration which produced the type of the Tunicates, nor the interest their history presents, together with certain inferences to be drawn from it. I have treated this important subject in another work 2 
in all possible detail. It is a subject ${ }^{1}$ that has given rise to much discussion, and has served as the basis of many and diverse theories, having such general descriptive titles as alternating generation, digenesis, geneagenesis, metagenesis, etc. It will be sufficient for me to indicate that these facts are explained by considerations analogous to those which have here permitted us to give the first scientific explanation ever attempted of the formation of the great organic types which Cuvier regarded as irreducible, and which he called "embranchements".

To sum up, the causes that have determined the formation of the four great branches of the Animal Kingdom, into which the primitive organization of the Worms has been modified, can be thus synthetized:--certain phenomena of a purely chemical nature, such as the secretion of lime or of fat, by weighing down or lightening the animal, or of a purely physiological order giving to the development of the nervous system certain advantages enabling it to advance more rapidly than the other organs, have determined a change of orientation in relation to the ground. Either through some reflex action, or more or less consciously, the animals that have undergone this change in orientation have utilized such means as they possessed within themselves, and especially their own muscles, to modify their structure and bring about the greatest possible adaptation of their organism such as it resulted from their former mode of life, and the new conditions of existence imposed upon them. In harmony with the general ideas of Lamarck's doctrine, these animals have been the active agents of their own transformation. For them this transformation was a period of crisis, analogous to that which becomes so acute in insects which undergo complete metamorphosis, and obliges them to shelter themselves so carefully throughout its duration. They would certainly have succumbed during this critical period if, at its outset, their rivals had been very numerous and the struggle for life very intense. It is therefore in an epoch when the competition between them was not fierce, that is to say, very early indeed, that these differentiations within the Animal Kingdom must have begun. The struggle for existence which, as Darwin showed in his celebrated books, played so important a rôle in the choice of the secondary modifications characteristic of the forms that have come down to us, and in the formation 
of the gapswhich divide them into species thenceforth incapable of intermingling, had nothing to do with it. On the contrary, it would have rendered this differentiation impossible.

The causes which determined the formation of the four great divisions resulting from these modifications, moreover, were independent of one another. Since all four sprang from the Worms, their formation must have been simultaneous, and this enables us to understand that, however far back we may go, these are always to be found in association: except perhaps for a slight delay in the appearance of the Vertebrates, which is explained by the fact that they are the result, not of purely chemical phenomena, but of the degree of perfection attained by the nervous system.

These embranchements have persisted because the causes to which they were due at first remained constant. Gradually, however, they became disengaged from these causes, and new causes, essentially intrinsic and constituting what we call heredity, were substituted for those that were primitively operative; and these hereditary determining factors are still sufficient to perpetuate the fundamental forms they created. Later modifying agencies have only been able to effect changes in detail.

It was then, as we have seen, in the water, and certainly not below the depth of four hundred metres reached by the really useful solar rays, and particularly along the shores of seas where all that is necessary for them in the way of food abounds, that living forms became diversified. We must now inquire how these forms descended to the depths of the sea and how they came to enrich the solid earth. 


\section{CHAPTER VI}

The Peopling of the Open Sea, the Ocean Depths, and the LANd MASSES

IF every living creature in the open sea, the ocean depths, and on the continents were to be destroyed, those organisins still inhabiting the shore would suffice for us to establish quite unmodified all these doctrines constituting what is now called the zoological philosophy. It is true that important culminating points would be missing; Botany, reduced to the history of the Algæ and a few of the lower Fungi, would have been greatly simplified. We should know nothing of Arachnids, Myriapods, or Insects, and the wonderful blossoming of lower forms into Reptiles, Birds, and Mammals would have remained unknown. But the existing littoral forms would none the less have furnished us with a continuous series in which each form would have been explicable in terms of the others, so that it would have been possible, through their comparative study, to reconstruct the conditions essential to the evolution of life. The fauna of the open sea and the ocean depths, and the fauna of the solid earth, on the other hand, is full of gaps. In the open sea, as well as along the coasts, there are, no doubt, numerous microscopic swimming creatures which belong to both kingdoms : the Diatoms and the minute Algæ which draw their nourishment from gases of the air and water combined by the sunlight, and the Protozoa which live on these microphytes. After these, however, comes a series of lacunæ, and whole classes are absent, or represented only by specially adapted types, occasionally developed from forms normally fixed to the ground. The Sponges are absent, and the order of Polyps is represented only by the Medusæ, in which tachygenesis has replaced the phase of fixation in the polyp type by a direct development; by Siphonophora which have found a means of attaching themselves to an air-bubble instead of to the ground; and by the floating Actiniæ, with 
their beautiful blue colour. Some of the Bryozoa also have learnt to swim. In the Tunicates, tachygenesis has accelerated the metamorphosis which must necessarily have followed fixation, until the egg directly reproduces the permanent form. A strange paradox thus appears. Three new independent types of swimming Tunicates, Pyrosoma, Doliohtm, and Salpa, are created, in a sense, by their very inımobility and resulting degeneration. The Arthropods are represented notably by small Copepods, which exist in countless shoals, by Schizopods, and Squilla. Contrary to what might be expected, the Annelid Worms, so agile when they squirm among the Algæ, furnish the pelagic fauna with few forms, which are generally transparent and of small dimensions: Tomopteris, Ophryotrocha, Palolo, etc. There are also some strange open sea Nemerteans. On the other hand, Sagitta, with its exceedingly simple organization, entirely isolated among the Worms, abounds at a distance from the coast. The heavy Echinoderms are represented only by some floating Holothurians. The Cephalopod Molluscs are essentially creatures of the open seas, and very varied, but they are also found along the coasts. Among the true Gasteropods on the other hand we can cite only the Ianthinidæ, the Atlantidæ, Carinarïßæ, and Pterotrachoididæ, which have such special characters that they form a group to themselves, the Heteropoda. The true Gasteropods are replaced by the Pteropods, closely related to the already aberrant Opisthobranchs among the Gasteropods, but removed from them structurally by the possession of swimming organs, which are very mobile and consist of two flexible paddles, developed from the "foot". Like the Copepods and Sagitta, they live together in shoals. All the pelagic Invertebrates have been more or less affected by a curious mimetism. Their bodies, which look as though they were inflated by water, are either transparent or coloured the same shade as the apparently deep blue water of the open sea.

The fish naturally form a long series, but certain groups, important from the geological view-point, are lacking. Among these are the Lampreys, in fact the lowest of all; and absent also are the most primitive Bony Fishes, with pectoral and abdominal fins far apart like those of the Sharks. Sardines, Herrings, and Anchovies really belong to this order, but they live too near the coasts to be considered truly pelagic. 
This fauna is completed by the turtles and the Cetaceans, representing a special adaptation of Mammals to marine life. It is obviously quite fragmentary, and the presence of turtles and Cetaceans indicates an immigration from the coasts.

The fauna of the ocean depths is no less incomplete. ${ }^{1}$ When it was discovered, an idea became prevalent that the depths of the ocean were particularly rich. Having had the opportunity of studying the excellent collections of Starfish gathered by Alexander Agassiz in the Caribbean Sea, and those obtained in the Atlantic by the Travailleur and Talisman expeditions, I had the curiosity to investigate how often the dredge would have to be let down to bring up a single organism of any kind, a species, or a genus, according as the depth increased. The figures mounted progressively for the three cases, which implies that the fauna of the depths diminishes and becomes impoverished as regards the number of species and genera as we go deeper. It is therefore evident that the depths of the sea are not, as was once believed, a reserve of living forms. On the contrary, life reaches these depths very slowly, and comes not from the surface, which, as we have seen, was peopled in a special way and possesses only a fragmentary fauna, but from the shore. In fact, all the species of Starfish found at great depths are represented along the shores by analogous species; but the littoral species, which can be regarded as the forbears of the deep sea species, are scattered along the coasts in such a way that all the coasts may claim to have supplied their contingent to the deep sea fauna.

These considerations almost dispense with the necessity of having to examine the nature of this fauna in order to establish its littoral origin. But it will furnish valuable evidence in support of our point of view. We must make an important preliminary distinction at the outset. Down to a depth of fifteen hundred to two thousand metres we do find an increase in species belonging to groups that flourished during the Secondary Period and have since then become rarer or have even completely disappeared along the coasts. Such, for instance, among the "Phytozoa", are the glassy Hexactinellid Sponges, the hydrocoralines, the solitary corals 
(Flabellum and others); the Polychelidx, a kind of flattened lobster akin to the Jurassic Eryon; among the Echinoderms the fixed Crinoids, flexible sea-urchins of the type of Calveria, and Pourtalesia, related to the Ananchytes of the Cretaceous Period, and among the Molluscs the Pleurotoma and Pholadomya. The fish also belong to types best represented in fresh water, which, as we know, are the oldest; they are akin to Salmon, Pike, Eels, or Cod, types with which are likewise connected a certain number of pelagic fish remarkable for the numerous eyes ${ }^{1}$ they have on the sides of their body, one pair on each segment, representing the remains of modified lateral sense organs.

These archaic types disappear by degrees as we go gradually deeper, and are replaced by organisms manifestly recent, although specifically adapted to life in deep waters. Among them the most remarkable are perhaps the Holothurians. They abound along every coast. There nearly all of them are shaped somewhat like a cucumber, and from this fact is derived the name of one of the commonest genera, Cucumaria. Their body is divided into five like parts by five rows of membranous tubes ending in suckers and serving as feet. Ten more or less spreading tentacles surround the mouth at one end of the "cucumber", while the anus is situated at the other. The tody thus possesses an absolutely perfect radial symmetry. The organisms live among the pebbles, under stones, or in the fissures of rocks, and under these conditions they utilize indifferently any set of feet when they move. Some, however, press constantly against the ground the same portion of their body which comprises three sets of ambulacral tentacles, one median and two lateral (Stichopus, Colochirus). This body area is distinctly flattened, and already constitutes the beginnings of a ventral sole. This attains its maximum differentiation in Psolus, which lives attached to the surface of rocks, and has a mouth, definitely dorsal, surrounded by long ramified tentacles. These tentacles are covered with minute vibratile cilia, whose incessant pulsations direct towards the animal's mouth the microscopic particles constituting its food. The ventral sole becomes the rule in the ocean depths, and we have already pointed out (p. I27) how it is formed, and for what cause. Here we can follow all the 
phases of a transformation whose point of departure is manifestly the position imposed upon the animal by the necessities of its search for food. The deep-water Holothurians have nothing to get from the clear water around them, in which none of the microscopic Algæ sufficing for the nourishment of Psolus are to be found. They feed on mud, and for this purpose the tentacles that surround their mouths are reduced to simple tubes spread out into the form of a button; the contrast between the dorsal and ventral surfaces is accentuated; 1 the suprabuccal bend of the Peniagone spreads out into a sort of banneret, with the anterior border elegantly pinked; the unused dorsal tube-feet elongate into purely ornamental cones in the case of the Deimatinæ; they are atrophied in Psychropotes, and the body terminates in a broad pointed and hollow tail; the lateral tube-feet of the ventral surface sufficing for locomotion, the median ones may disappear altogether through disuse.

Even in mean depths of four hundred to two thousand metres, where the light has ceased to penetrate, forms representative of the fauna of Secondary times are scarce, and none are related to those which characterized the Primary Epoch. From this we must conclude that the fauna of the deep sea is relatively recent, and since we have not discovered in the depths those archaic forms with which Agassiz credited it, not even a single one that might be considered the head of a series, but only much modified organisms adapted to a special type of life, we are forced to conclude that these forms have come down from the shores, and as they descended into the deep water, have gradually taken on special characters in harmony with their mode of life. These adaptations are especially remarkable in the Decapod Crustaceans. They are divided into two groups: the swimming Decapods, of which Shrimps are the common type, and those Decapods that walk on the ground, represented by such familiar forms as the Lobster, the Crayfish, the innumerable legion of Galatheidæ, and the familiar Crab. The first make but little use of the long, thin legs with which their thorax is provided; they swim either by means of large flattened appendages which replace the legs on the segments of the abdomen, commonly supposed to be the tail, or by sudden

1 Psychropotes, Oneirophanta, Deima, Peniagone, etc. 
flexing movements thereof. This last method of locomotion is not unknown among the crawling Decapods, but they employ it less often. Their abdominal appendages are not utilized in swimming, and the creature progresses by the aid of ten strong legs borne on its thorax. The swimming Decapods keep below the surface most of the time, and move with great agility; the crawlers, on the contrary, hardly leave the bottom, with which their feet are most generally in contact, and which they are perpetually feeling, so to speak. The deep-sea adaptations of these two types of Crustaceans takes place, consequently, along two opposite lines. The antennæ of the swimming Crustacean become fine and exceedingly elongated, so as to serve as tactile organs ${ }^{1}$ to warn the creature of the least obstacle, and their eyes become greatly enlarged. The antennæ of the walking Crustacean, on the contrary, remain relatively short, and their powerful thoracic appendages disappear, as also their eyes, now unnecessary owing to the creature's extreme caution in moving. ${ }^{2}$ The increase in size of the eyes of the swimming Crustaceans appears at first somewhat paradoxical. But the darkness of the great depths is not absolute. Many organisms become light-producing. Among these are the Gorgonid Polyps, Crustaceans like Gnathophausia and Euphausia, which bear luminous organs on their appendages, and numerous swimming Decapods; certain Squids are provided with veritable light-projectors; and many Fishes ${ }^{3}$ have luminous organs situated either on the head or in series on the sides of the body, like the organs of the lateral line. We are unable to say whether it was the darkness that caused the elongation of the appendages and stimulated the development of the luminous organs. Viré, however, has shown that the appendages of certain Crustaceans kept in obscurity become very much elongated; and this happens likewise in the case of certain Insects inhabiting dark caves. It is probable that the constant use these animals make of their appendages for palpating their surroundings has contributed to this elongation; and it is quite normal that where no stimulus occurs the eyes should disappear. As to the frequency of luminous organs among deep-sea organisms, one might say with the defenders of the

1 Nematocarcinus gracilipes, Pandalus, Benthesicymus, etc.

2 Pentacheles, Nephropsis, Galathrodes, etc.

3 Chauliodus, Stomias, Malacosteus, etc. 
theory of preadaptations, that naturally the animals that descended into the darkness of the ocean depths were those that could illuminate it. As, however, the coastal species which may be considered as ancestral are not luminous, we must admit that the illuminating apparatus only developed after their descent, and not dismiss too rashly the idea that the absence of solar light favoured their appearance. Whatever the reason may have been, this faculty of developing luminosity is possessed only by a certain number of the types constituting the deep-sea fauna.

The deep-sea forms are not directly related. We find numerous vitreous Hexactinellid Sponges, and very few members of the other groups; Alcyoniaran Cœlenterates of the coral type or the solitary Madreporaria (Flabellum); few Bryozoa, but quite frequently doubtful forms assigned to them like Rhabdopleura and Halilophus dodecalophus. The Crustaceans also abound, and orders that are generally of small size are sometimes represented here by gigantic forms, such as Bathynomus giganteus, a large Isopod two decimetres long, or Gnathophausia gigas and Goliath. Annelid Worms are seldom encountered. Molluscs are rare and small, and it is their absence that has led to the peculiar habits of the Hermit-crab, which occurs fairly often. The Crustaceans of this group have large soft abdomens, which they enclose, if they live along the coasts, in hollow shells easy enough to find. As they grow they change their shell in order always to have a house appropriate to their size in which they can be completely sheltered. Quite often a beautiful vivid red Sea-anemone, belonging to the genus Adamsia, instals itself on this shell, and a kind of symbiosis is established between the Crustacean and Colenterate. Certain hermitcrabs can lodge in a fragment of bamboo. ${ }^{1}$ Some even make out of earth their own mobile habitation, like a kind of caravan. $^{2}$ At great depths the Gasteropod shells are rare, and small. The hermit-crabs can get into these shells perfectly well when they are young, but as they grow larger they make no effort to replace them; then they keep them, merely from habit, in order to satisfy their instinct, although the shells have become useless, and we sometimes find splendid specimens of the hermit-crabs ${ }^{3}$ with abdomens the size of a large human thumb,

\footnotetext{
1 Xylopagurus.

2 Pylocheles.

3 Catapagurus.
} 
carrying at their extremity a shell hardly as large as a rosehip, and held by terminal appendages transformed into hooks.

Certain species ${ }^{1}$ have as allies epizoic Coelenterates which live upon their shell. When the Crustacean and the Colenterate are young everything happens in the same manner as in the case of the littoral hermit-crab; but the hermit does not change his shell as he grows, whereas the polyp can produce, by the budding process, other polyps similar to itself. The young family soon gets too large for the shell, and spreads directly over the unsheltered portion of the hermit-crab's body, which thus finds itself protected by a living cloak which always fits it. This living cloak adapts itself so closely to the Crustacean that it always retains the same shape, and it would be difficult indeed to insist, in this case, that the form is not the direct result of the conditions of development imposed upon the relatively passive family of the polyp by the action of the hermit-crab. Here we have a clear case of the influence of external circumstances in the determination of organic forms.

The fact that the deep sea hermit-crabs can do without a protective shell Ostraconotus, or content themselves with an illusory one, implies that they do not run any great dangers and that consequently the struggle for existence is not, in this region, very intense. Indeed, whatever be the group under consideration, the number of individuals found is apparently too small to lead to serious competition. This dissociation of species is not due to natural selection. It is possible that species of the same genus which are distinct in the abyssal fauna are descended from species which were already distinct, although belonging to the same genus in the littoral region. It is also possible, even if we adopt the rarely applicable test of their inability to unite among themselves, that their formation may be a question of the chemical conditions surrounding them, and that therefore the normal species may be formed in this way by dissociation of the same type at any particular depth. The chemical view-point is the best one we can adopt if we wish to explain the perfectly useless colour of animals living in complete obscurity. 
We have seen that the transparency and the blue colour of pelagic organisms may be considered as protective characters intended to render them invisible. Such colours are not encountered in deep-sea specimens, which are generally white (Polycheles, Deima), pink (Peniagone), red (Phormosoma and many swimming Decapod Crustaceans), violet (certain swimming Decapods and Echinoderms of the genera Pourtalesia, Psychropotes). The deep-sea fish are generally black and their luminous organs green. Although they belong to well-known groups-most commonly to the type of "abdominal" or physostomous Fish - they, none the less, present special characters. They are often provided with long tactile appendages placed sometimes on the head, as in Melanocetes johnsoni, sometimes under the jaw as in Eustomias obscurus, in front of the fins as in Bathypterois longipes, or in both these places (Echiostoma micripnus). Here we find the same facts as among the Decapod Crustaceans, which implies that they have been produced by the same causes. Often, moreover, the mouth takes on enormous proportions (Malacosteus niger, Eurypharynx pelecanoides). Only a few families are represented at great depths; the Scopelidæ, ${ }^{1}$ also pelagic, the Clupeidæ, of which the Herring is the commonest type, ${ }^{2}$ and the Stomiadæ, which resemble the pike in the arrangement of their unpaired fins. These all belong to the group of physostomous Fishes. The physostomous Fish are represented almost entirely by Malacopterygians, such as the Gadidœ, ${ }^{3}$ typical forms of which are Cod; Macruridæ, with the body terminating in a point, and Ophididæ, elongated like Eels. ${ }^{4}$ The Fish fauna, unrepresented by Amphioxus, Lampreys, Sharks, and almost all fish with spinous dorsal fins, i.e. the most agile swimmers, is therefore essentially an incomplete fauna like the others, in other words an immigrant fauna, and that of the freshwater Fish will prove to be similarly incomplete.

But in this case the conditions of existence are absolutely different from those of the deep sea. The pervading immobility and the even temperature and consistency of the water gives place here to agitation that is never ceasing in the streams,

1 Scopelus, Saurus, Malacocephalus, Alepocephalus, etc.

2 Halosaurus.

3 Mora, Bathygadus, Coryphonoides.

4 Bathynectes crassus. 
and frequent even in stagnant waters. The temperature and the composition of the water varies incessantly. The "Phytozoa" are hardly adaptable to this mobility. They have only a few freshwater types, such as siliceous Sponges with straight spicules (Spongilla, Parmula, etc.), a very small number of Hydroid polyps or medusæ (Hydra, Cordylophora, Limnocodium, Limnocnida), an Asiatic fluviatile Actina, Phylactolœmatous Bryozoa with gelatinous investment, and some Gymnolœmata (Arachnidium, Victorella). All these organisms seem to be recent immigrants. It is remarkable that the freshwater Sponges and Bryozoa should possess another method of reproduction besides the sexual; during critical times fragments of their bodysubstance are enclosed in a protective envelope, which enables them to withstand all the destructive agencies that might menace them, and to escape the vicissitudes, so frequent in fresh water. These fragments subsequently free themselves from the envelope and evolve into new organisms as soon as circumstances are again favourable. Examples are to be found in gemmae or amphidisc capsules of Spongilla and the statoblasts of the Bryozoa.

The Crustaceans are represented only by Phyllopoda, ${ }^{1}$ which go back to a very remote antiquity; by a small number of Cladocera, ${ }^{2}$ Ostracoda, ${ }^{3}$ Copepoda, ${ }^{4}$ Isopoda, ${ }^{5}$ Amphipoda, ${ }^{6}$ Schizopoda, ${ }^{7}$ and Decapoda. ${ }^{8}$ These are very few in proportion to the enormous number of Crustaceans extant. To them must be added certain Arachnidas and Insects that have become aquatic again after having led an aerial existence. With certain rare exceptions, to which Charles Gravier has called attention, the Annelid Worms present belong to the class Oligochæta, of which the Earthworm represents a giant form, and to the class of the Leeches, which have only a small number of marine forms, apparently imported by migratory Fish. Among the Flat Worns only a small number of Planarians and Nemerteans are encountered. The

Estheridæ, Apuscancriformis, Branchippus.

2 Daphnidæ, Polyphemidæ.

${ }^{3}$ Cypridæ.

${ }^{4}$ Cyclopes.

5 Asellidæ.

6 Idothea.

7 Mysis relicta.

${ }^{8}$ Caridina, Palamonetes, Alphoopsis, Niphargus, crayfish and other allied genera, and some related crabs of the genus Telphusa. 
Echinoderms are entirely absent. The Molluscs deserve special attention; the Cephalopods are completely lacking, but many successive migrations of marine Gastropods can be counted. The Diotocardiacs are represented by the Neritinidæ, the herbivorous Monotocardiacs by forms like Ampulla, Paludina, and Valvata. No carnivorous Monotocardiac, Opisthobranch, or Pteropod occurs in fresh water. On the other hand, the Pulmonata are fairly numerous, and we might well ask whether they are not descended from terrestrial Pulmonata. This fauna is thus very limited. The Lamellibranchs are represented only by forms with a large open mantle, therefore primitive forms, Unio, Anodonta, Cyclas, Iridina, etc.; and by a single siphoned form which merely indicates the order, Dreyssensia polymorpha which penetrates into the rivers and carries with it Cordylophora lacustris and an annelid worm remarkable for its bristles of complicated form, Psammoryctes umbellifer. This invasion seems to have begun only since the beginning of the century, starting in the Baltic, then reaching the Thames and finally the Seine.

The group of freshwater Fish is among the most instructive. The primitive Fish, fleeing from the struggle for existence that was too intense along the coasts, sought refuge at some distant period in the lakes and rivers, just as the sturgeons, salmon, and shad still take refuge to spawn and place their progeny in some place of shelter. The number of marine creatures able to live in water containing no sea-salt is actually quite small; those which possessed this pre-adaptation to life in fresh water, or have acquired it, could not be pursued by those not possessing it, and this is why the rivers and marshes which were at first deserted, were early invaded by fugitives which preferred the calm of the inland solitudes to the dangers lying in wait for them among the active and numerous population of the coasts. Thus, the same desire for security peopled the open sea, the abysses and the fresh waters. If Amphioxus, the most primitive of Vertebrates, found a hiding-place on sandy shores, the Lampreys, like Petromyzon marinus, became the temporary guests of the fresh waters, where they only penetrated to spawn, their young having to pass the first part of their life in the fluviatile sand in the form of Ammocates. Others like the Petromyzon fluviatilis are 
permanent inhabitants of rivers. Only one group of Sharks has become lacustrine, Carcharias gangeticus; but of the three types of Ganoids still persisting, the Sturgeons, Lepodisteus and Amia, only the first spawn in rivers, and the other two do not leave their streams. In the same way the Crossopterygians which, with the Ganoids, were the most common fishes, and the most highly organized at the time of the Carboniferous Formations, are represented to-day only in the rivers of Africa by two closely related genera, Polypterus and Calamoichthys. The Dipnoian Fishes, which were the first, nevertheless, to develop lungs, the organs of aerial respiration, now exist only in three freshwater genera: Protopterus of Africa, Lepidosiren of Mexico, and Neoceratodus of Australia. This geographical distribution indicates that the first invasion of the fresh waters took place almost simultaneously in various parts of the world during the Primary Period. However, as in the case of the Molluscs, this was not the only invasion that occurred. The Bony Fish, in their turn, invaded the rivers shortly afterwards. One of the oldest families of this group, the Siluridæ, although rather poorly represented in Europe by two or three species, the gigantic Silurus glanis of the Danube, and Silurus aristotelis of Macedonia, is yet possessed of an astonishing plasticity, and has invaded almost all the rivers of the world in varied forms which have subsequently been copied by all the other freshwater Fish, with abdominally placed pelvic fins, retaining none the less the fundamental characters of the skeleton of its operculum. Like the Rays, it produced a group of electric Fish, Malapterurus, of Africa. Then followed the whole series of Fish with ventral fins far removed from the pectoral, as in the primitive Fish, which Cuvier called "les malacoptérygiens abdominaux," in which the swimbladder opens into the œesophagus or stomach (the Physostomi of J. Müller); that is to say, Trout, Pike, the long series of Cyprinidæ, to which the majority of the Fish of our rivers and swamps belong, Gudgeon, Barbel, Dart, Carp, Bream, Roach, Tench, Loach, etc., which are represented elsewhere by the Cyprinodontidæ. The Herring, Sardine, and Anchovy, all related to this type, have continued to live in the sea; but the Shad, which belong to the same family, namely the Clupeidæ, come to the rivers to spawn, like the Salmon, relations of the Trout. These are Fish of the same group that have furnished, 
as we have seen, the main forms of the pelagic and the ichthyological fauna of the deep sea. These two invasions of the fresh waters were followed by a third. This time the newcomers had soft dorsal fins, pelvic fins near the pectoral, and a closed swim-bladder. This kind, however, is still scarce, and is only represented in European fresh waters by the Lote, which are related to the Cod. Certain others belong to the pelagic forms that have a partially spinous dorsal fin and include strong swimmers related to the Perch. Some of these, like Cottus and the Red Gurnard, had reverted to their littoral habitat, and were therefore predisposed to enter fresh water. The Chubs of our rivers belong to this group.

Many marine Fish spawn an innumerable quantity of small eggs and abandon them without bestowing the slightest care upon them. As a rule, however, the species that penetrated into fresh water and remained there belong to genera or families which produce but a few large eggs, and attach them to the under side of stones, to algæ, or inside empty shells, if they do not actually spawn in shelters prepared in advance. These eggs are large because they are filled with nutritive substances which save the embryo from seeking any other nourishment until the supply is exhausted. Under these conditions the embryo grows very rapidly, and when it leaves the egg still often carries a part of the reserves in a receptacle called the vitelline sac. Thus it acquires both the agility and the resistance that will enable it to escape many of the dangers besetting it. This enhancement in the size of the eggs can also be observed in the case of the Prawns, which penetrate fresh waters and are hatched in a form that is almost mature, while their congeners still have profound transformations to undergo. The same difference exists between the Sea Crayfish and the Lobster. The former have small eggs giving rise to transparent swimming embryos called Phyllosoma, which in no way resemble the adults; the others, on the contrary, spawn large eggs from which the young are hatched out in their permanent form except that they have still to grow, and it is probably this that has permitted kindred forms to penetrate into the fresh waters where they have engendered the diverse forms of Crayfish.

The instability of the conditions of existence in fresh water appears to have resulted among the invertebrates which sought 
security therein in a consequence at first sight most singular. Nany became hermaphrodite, for instance, the Oligochætes, the Leeches, ancestors of the flat worms (Trematodes, Cestoides, Turbellarians), and Pulmonate Gastcropods. Whatever may be the general belief, herniaphroditism is not a primary condition. The prinitive genital elements, the spores, were simple asexual cells and in the first place they multiplied directly without fecundation. This is still the case with many cellular Cryptogams and certain Protozoa, but even in these groups sexual differentiation of the cells has already appeared as well as fertilization in the ciliated Infusoria, for example, in the Sporozoa and Foraminifera. When certain genital cells develop without fertilization, as in Apus, Branchipus, Daphnia, the Aphides, Cochineal-insect, the Cynipidæ, Wasps, Bees, various I.epidoptcra of which Bombyx is an example, in certain free-living Nematode worms, Rotifers, and Gasterotricha, the faculty has been re-acquircd. 1 The male and female characteristics of the sexual cells stand out clearly from their comparison in the Animal and Plant Kingdoms. The male elements, as we have seen, are produced by cells that multiply rapidly by division, and are incapable of accumulating reserve material. Hence they remain small, and their activity which is mainly of a mechanical order, is spent in the rapid movements of vibratile cilia or flagella. These are the antherozoids of the vegetable Cryptogams and the spermatozoa of animals. The female elements, on the contrary, are produced by cells in which division is retarded, especially in the last stages of their evolution, and of which the activity is essentially of a chemical order directed chiefly towards the elaboration of the reserve substances which accumulate in their protoplasm and increase their volume, making the cell heavier and suppressing all possibility of movement.

These characters, with which even unicellular beings are invested in order to reproduce themselves, before becoming a part of an organism, are retained by all living forms, and in each animal species the same individuals are capable generally of producing only one of the two types of sexual cells. This is especially marked among species which stand at the beginning of a series and therefore live in the sea. It would

1 We are not speaking here of artificial parthenogenesis, which is a phenomenon requiring a special study. 
seem at first sight as though this rule did not apply to plants, as each flower is hermaphrodite, but it must not be forgotten that in plants the primordial individual element is the leaf, so that a vascular plant is best considered as a collection of leaves. In the flower, however, the fertile leaves are exclusively male (stamens) or female (carpels), and consequently unisexual. We should also remember that in the oldest flowering plants the male flowers generally grow on different branches from the female flowers. Both are made up of cones or catkins exclusively male or female, and the sexuality frequently extends to the whole plant, in which case it is said to be diœcious (p. ro3).

Throughout the Animal. Kingdom the males or females share distinctly the characteristics of the sexual elements they produce. The females of the species belonging to the same genealogical stock generally resemble each other considerably, and retain the forms and colours that are practically those of the young individuals of the species, which indicates both that they have a common origin and that they have evolved but little. They are larger than the males, very often somewhat inactive, and usually accumulate more reserve substances in their tissues. The males, on the contrary, use up the products of their alimentation in activity. They are vividly coloured. Ornaments of all kinds, horns, tusks, manes, plumes of feathers, and aigrettes embellish the primitive form conserved by the females. Sometimes they produce substances with special odours. Through heredity, these acquired characters are often passed on to the females. Thus the small blue butterflies of our fields, called Argus, have generally brown females with yellow spots; but in some species the blue colour of the male can extend to the female. Again, among the Kingfishers the females of the Halcyon are grey, while the males have those magnificent blue and tawny shades which in our ordinary species are common to both sexes.

The incapacity of the males to provide themselves with reserve nourishment has a fatal result for them in those groups of the Animal Kingdom which do not endow the organism with much power of resistance. Already among many Insects ${ }^{1}$ their span of life is short; they do not concern themselves at all to provide for the future of their young, and die as soon as they have fulfilled their sole function of fertilization. Others

1 Bees, Wasps, Ants, and many Flies with four wings or Hymenoptera. 
are entirely incapable of nourishing themselves. ${ }^{1}$ Among the marine Worms, such as Bonellia, the female is as large as a nut, while the males are so small that they were once taken for Infusorians living as parasites on the female oryan, where they are found to the number of seven or eight.

At first sight there seems to be a contrast between this diminution in size and the splendour which the males attain in other cases, and also a contradiction between this diminution in size and the abortive forms so noticeable among certain females. In the Glow-worm, ${ }^{2}$ many night-flying Lepidoptera, ${ }^{3}$ and Stylops, the females are without wings. In the last case they are reduced to egg-sacs, and only their almost formless heads protrude outside the body of the wasp, in which they live as parasites. But all these apparently paradoxical facts range themselves under one and the same principle. It is the development and the nutrition of the eggs, that is to say the accumulation of reserve substances in the cells still belonging to the mother, and perhaps also the organism's disuse of its wings when it has become too heavy for them, that has brought about the reduction and disappearance of these organs in the Glow-worm and various female Lepidoptera. The same causes have determined the parasitism of the females of Stylops, a parasitism that has brought with it, as usual, the complete decay of the locomotor apparatus. Here we have a phenomenon analogous to that which has been observed in the Chondracanthidæ, which are Copepod Crustaceans, and Bopyridæ, which are Isopods. The males, a hundred times smaller than the females, which are almost formless and parasitic, remain attached like minute lice to the abdomen of the latter. These female Bopyridie are frequently found under the carapace of Shrimps, which they raise into an irregular swelling on one side. In another family of Copepods, the Lernæidæ, the males and females, at first small and almost alike, are coupled together; the males then disappear and the females parasitically attach themselves to the gills or other organs of some Fish, where they become enormous, almost limbless, and so unrecognizable that Cuvier classed them among the Wornis.

From all this it follows that individuals of the male sex are

1 Mosquitoes.

2 Lampyris noctiluca.

s Orgyia antiqua, Psyche helix, Cheimatobia brumata, etc. 
clearly affected either by a nutritive incapacity or by the orientation of their organism towards a useless expenditure of energy which destroys their alimentary reserves; so that they are, in short, impoverished organisms whose poverty affects the reproductive elements themselves and imposes special characters upon them. A predominance of males in an animal population would therefore be a sign either of dearth or of superactivity.

This last remark leads us to consider whether the explanation of hermaphroditism is not to be sought in the conditions which render alimentation precarious. Among these conditions one is especially evident, namely the abandonment of a free life for the sedentary one, and notably for attachment to the ground, which places the animal at the mercy of all the variations in its environment, from which freedom in movement would permit it to withdraw. Outside the "Phytozoa", in which fixation is primitive, this attachment to the ground occurs as an accidental condition in the Cirripedes, which are Crustaceans, and the Tunicates which are related to Amphioxus, the most primitive of Vertebrates. In both cases it leads to a complete change in the conditions of existence after the animal has attained the form which should normally have been permanent, and results in a complete deformation of the body. The Cirripedes and the Tunicates are protandrous hermaphrodites, that is to say, each individual commences life as a male, becomes transitionally both female and male, and finally passes definitely into the female condition. What does this very general phenomenon signify? The Cirripedes give us the answer to the question. Most genera of Cirripedes have no males at all. Where they exist they are not fixed, remain very small, and have but a short life. As the other individuals, in their quality of protandrous hermaphrodites, are capable of reciprocally fertilizing each other, if not themselves, the exclusively male individuals are of no use at all. They are not even what we sometimes call complementary or supplementary males, but simply useless males, or, if we desire to give them some designation, supernumerary males. Their existence merely serves to qualify the other individuals; it demonstrates that among the Cirripedes, before fixation, the sexes were distinct as among other Crustaceans; that fixation, with all its hazards, has been fatal for the males, which have 
become so rudimentary that they cannot even acquire organs of fixation. The females, on the other hand, possessing reserve substances and a special nutritive aptitude, have resisted these dangers. Yet they have to pass through a very critical period after the metamorphoses which follow in the train of fixation. It is then that their reproductory cells evolve in the direction of the male sex and regain their original sex when the physiological equilibrium has been re-established. There are no supernumerary males among the Tunicates, although their evolution has gone inuch further, since tachygenesis has brought about a regeneration of the free forms; but their whole history is so much of a pattern with that of the Cirripedes that there can be no doubt as to the identical nature of their case.

The researches of Maupas ${ }^{1}$ on free-living Nematodes permitted him to report the existence of supernumerary males among certain of these species. I myself ${ }^{2}$ have given elsewhere the reasons which lead me to classify the Nematodes not as Worms, according to the usual procedure, but as Arthropods degenerating through inherent inertia into parasitism, like many of the sedentary larvæ of Insects. ${ }^{3}$ So long as they are parasites, these organisms live in superabundance. Their passage to a free life, which is almost fatal in those groups where the eggs are often hatched in the ground or in the water, leads them back to these precarious food-conditions just as surely as fixation, but by another road. Here, again, there has been a great disturbance in nutrition, and we find the same facts; males becoming uncommon and inert, then disappearing altogether; females hermaphroditic, and finally parthenogenetic, if the reproductory cells develop very early through the operation of tachygenesis.

The organisms which passed from the sea to freshwater streams, lakes, marshes, and damp localities were likewise exposed to distressing uncertainties in the food supply; and these must have had the same results as in the preceding instances. We have thus the explanation of hermaphroditism in freshwater Annelid Worms, ${ }^{4}$ numerous species of Earth-

1 LV, 463.

2 LIV, 1345.

3 Larvæ of Coleoptera living in fruit or digging into wood; larvæ of Hymenoptera enveloped and provisioned, or nourished, by their parents ; larvæ of Diptera living in organic substances. These are all described in popular language as IVorms.

${ }^{4}$ Dero, Nais, Stylaria, Tubifex, Euaxes. 
worms, and Leeches derived from them, contrasting with the differentiation of the sexes so general in marine Annelid Worms.

Exactly the same thing happened in the case of Gasteropod Pulmonate Molluscs, of which the Snail is the common type, and which are represented by countless species in the fresh waters and in all damp land areas. All are hermaphrodite, whereas the marine Gasteropods, with their helicoidal shells, and gills protected in a special cavity situated in front of the dorsal cone, ${ }^{1}$ are all unisexual.

The marine Lamellibranchs, which lead a sedentary life, are often hermaphrodite, like fixed organisms ; hermaphroditism is also definitely protandrous in the Oysters, which are fixed like the Tunicates. ${ }^{2}$ We have very little information as to the sexual conditions of the other Lamellibranchs.

Objections might be raised against the theory that hermaphroditism is due to a precarious source of food supply, particularly in fresh waters and on land, namely the existence of hermaphroditism in true parasites, such as the liver flukes ${ }^{3}$ of Sheep and similar animals ${ }^{4}$ and in the Turbellarians, which are free-living and form together with them the order of Flat Worms, from which, however, the Nemerteans are to be excluded; and it may also be contended that every order of marine Gasteropod Molluscs without an anterior branchial cavity consists of hermaphrodites. However, a very few words will suffice to deprive these objections of all validity.

In the first place, although the organization of the hermaphrodite Flat Worms is so degraded that it has been attempted on various occasions to describe them as primitive, their double genital apparatus has preserved a complicated structure of a very special, constant, and definite type; this is enough to show that we are here dealing with a group of degenerate organisms, sprung from a higher group. The only possible starting-point for this degeneration is the Leech, whose class manifestly derives from the Earthworm, whose organization is so similar that a man like Franz Vejdowsky, ${ }^{5}$

1 They are called Prosobranchatata.

LVI.

3 They form the two classes of Flat Worms, the Trematodes, and the Cestodes, or Tapeworms.

4 They are called Opisthobranchiata.

5 LVII, 38. 
particularly competent in all that appertains to the history of Worms, classed genuine Leeches, such as Branchiobdella among the Naïdids. The most salient leech characters appear in certain Central African Worms, the Polytoreutidæ, ${ }^{1}$ in which, as in Leeches, the reproductive orifices are placed in a median ventral line instead of according to the usual symmetrical arrangement. In becoming carnivorous or parasitic, Leeches have merely continued to inherit the hermaphroditism of their oligochæte ancestors, who acquired it when they took to life in marine or freshwater lakes. Subsequently they transmitted the character to the Trematodes, which, when they became free organisms, gave rise to the Turbellarians.

We have an even simpler explanation of the presence of Opisthobranchs, which are all hermaphrudites, in the seas. Like the Pulmonata, they lave lost their primitive gills. This loss suggests that the ancestral Opisthobranchs at one time left the water and lived in the open, or at least in a low-lying littoral zone washed by the tides, and thus often out of the water for long periods. In this state they still remain, except for their derivatives, the pelagic Pteropods. Had they remained aquatic they would have preserved their branchial apparatus. There is no reason why they should lose a respiratory system so eminently advantageous after having once acquired it. It must therefore have been during their change of habitat that they became hermaphrodite like the Pulmonata, which aiso lost their gills and present so many characters analogous to the Opisthobranchs that we may justly ask whether some phylogenetic relationship does not exist between these two orders, and whether they are not linked up by certain still existing non-aquatic forms. ${ }^{2}$ Having reverted to their earlier environment the re-developed gills around the anus, ${ }^{3}$ on the back, ${ }^{4}$ on one, ${ }^{5}$ or on both sides of the body. ${ }^{6}$

Access to dry land was not so easy as might be imagined. In the first place there had to be preparation, and this, which can be regarded if one so wishes as a pre-adaptation, had elsewhere always consisted in the disappearance of the external

1 LXXII.

2 Oncidium.

3 Doridæ.

4 Nudibranchs.

5 Umbrellidæ, Pleurobranchs, Aplysia.

6 Phyllidiz. 
apparatus of aquatic respiration, of which traces sometimes persist, a disappearance that has often been produced in immigrant marine organisms when they took up life in fresh waters. For this aquatic respiratory apparatus was substituted an internal one, which was thus protected against desiccation, a danger to which air-breathing animals would be constantly exposed, but which a marine animal need not fear as its respiratory organs are always submerged and have only to be protected against collision, or the predatory attacks of small carnivorous creatures. Occasionally the branchiæ, which constitute the pre-eminent aquatic respiratory apparatus, were not replaced, the surface of the body sufficing for æration. This is what happened in the case of the Earthworm, their close kin the freshwater Annelid Worms, and the Leeches. Among those organisms which live in fresh water or have returned to the sea, the branchiæ in certain conditions can be redeveloped, as in the Opisthobranch Gasteropods. Thus, those beautiful little Freshwater Worms, Dero (LVIII), have a sort of outgrowth at the posterior extremity of the body, supporting four retractile finger-like processes, the whole constituting a respiratory mechanism over whose surface the water is constantly renewed by the action of powerful waving cilia. In the same wayOzobranchus, a Leech which lives in the mouth of Crocodiles, marine Tortoises, and Pelicans, and the marine Leeches of the genus Branchellion, living on the Electric Eels, have recovered these branchiæ, in the first case in the form of tufts, and in the second in the form of trumpets.

The substitution of an internal for a branchial respiratory apparatus naturally consisted merely in a process of invagination of certain portions of the integument, or in the adaptation to a respiratory function of internal organs having communication with the exterior, as is the case with the digestive apparatus. By means of a new application of the principle " everything happens that can happen", the two types have been arrived at by methods sometimes a little unexpected, and, moreover, independently of the conditions of the habitat. The larvæ of Dragonflies, though they remain exclusively aquatic, have an internal respiratory apparatus contrived at the expense of the rectal region of the digestive tube. This same rectal region, provided with powerful vibratile cilia, constitutes in Freshwater Worms a supple- 
mentary respiratory apparatus. Balanoglossus, a peculiar marine Worm without locomotor bristles, has constructed a respiratory apparatus at its other extremity at the expense of the esophagus. This consists of a series of symmetrical lateral pockets, communicating both with the osophagus and with the exterior. This arrangement is found again among Fish such as Bdellostoma and young Lampreys, and is slightly modified in Myxine and the adult Lampreys. The pockets have been replaced by simple slits in all the Sharks and Rays. The separating walls of these slits are now only represented in Sturgeon and Bony Fish by arches covered with a double row of points, arranged like the teeth of a comb. These pockets in Lampreys were also unquestionably preceded by simple slits, since that is the form of the respiratory apparatus in Amphioxus, from which is derived the enormous branchial sac of the Tunicates, constituting a kind of œsophageal abyss.

In spite of their chitinous envelope, the internal respiratory apparatus of the Arthropods originates from a simple invagination of the integument. This is also the way in which the integumentary glands of these organisms arise, notably the highly important coxal glands, connected with the base of the appendages, which, according to circumstances, become either salivary glands, poison glands, annexes to the proboscis in the Mosquito, the sting in the Bee, or else kidneys, like the green gland of the Crayfish and the analogous gland in Lobsters, Crabs, and their congeners, and which opens at the base of their antennæ. This similarity in origin, entailing a certain similarity of organization, has led to the idea that the tegumentary glands, at least in certain cases, can be transformed into respiratory tubes. However this may be, it would seem that four groups of Arthropods, the Onychophora, Arachnida, Myriapoda, and Insecta, have acquired independently an internal respiratory apparatus, constructed in an analogous fashion, in its permanent form at least.

The species of Peripatus are peculiar organisms, living under stones, in rotten wood, worm-eaten trees, and in vegetable débris generally. They resemble Caterpillars with membranous feet, and bodies terminating in front in antennæ, but without a distinct head. Thus in body type Peripatus also resembles the Annelid Worms, but the body is protected by a chitinous 
envelope about as thick as that of the Arthropods. They are very archaic organisms, belonging unquestionably to the first land immigration of the segmented members of the animal kingdom, for they are found at widely separated localities which could only have been connected during the existence of the former Gondwana continent, e.g. the Cape of Good Hope, New Zealand, the Amazon Valley, etc. Their respiratory apparatus consists of numerousinvaginations of the thinner parts of the integument arising indifferently from the dorsal or the ventral surface of the body; they are even seen on the surface of the membranous feet, constituting as many internal tubes, which, after being expanded into an umbrella, give rise to a bunch of slender tubes spreading from the centre thereof and terminating in a cul-de-sac without any ramification. These structures are known as trachece, and this same term tracheæ is applied to all the internal respiratory tubes of the Arthropods, whatever their form and origin. No connexion is to be seen between these very numerous respiratory tubes without any fixed morphological position, and the so-called lungs of the Arachnida. MacLeod has propounded an interesting hypothesis for the origin of these last-named organs, which does not, however, destroy the validity of Marie Pereyaslawzeva's ${ }^{1}$ observations. For him, in short, the lungs of Scorpions are nothing but a slight modification of the branchial apparatus of Limulus. The abdomen of these creatures, the earliest known Arthropods, since they are found in the Silurian deposits, possess flattened feet in the form of large chitinous lamellæ, in the rear of which are sheltered a whole series of thin leaves, superposed like those of a book. If that portion of the integument which supports these leaves were to be invaginated interiorly to the body, drawing them with it, while the protective plate constituted by the foot became shorter, a pocket would necessarily be produced, having on its inner side a series of leaves or lamellæ and opening externally by a slit-that is to say, a lung of the Scorpion type with its respiratory orifice.

1 These objections are founded on a lack of agreement between the actual order of appearance of parts in the lungs of the embryo and the theoretical order that ought to occur in the formation of these parts according to the hypothesis of MacLeod. However, we know that such reversals are frequent in embryogenetic development, and are the result of tachygenesis. (LXXII, 247.) 
The lungs of Thelyphonidæ, Phrynus, and Spiders, differ in no way from those of the Scorpions, and MacLeod's ${ }^{1}$ explanation consequently extends to them also. Lamy, moreover, has followed step by step in the case of the Spiders, their metamorphosis into tracheal tubes. ${ }^{2}$ This metamorphosis. is complete for the second pair of lungs of the Dysderidæ and Segestriinæ, which are normal Spiders in all other respects. Two tracheæ co-exist with the lungs in all the other Spiders, but are carried back towards the posterior extremity of the body, and there is only a single median orifice placed in front of the spinnerets. In the Galeodidæ, Field Spiclers and PseudoScorpions, the metamorphosis affects the whole pulmonary apparatus, hence these Arachnida are known as trachean. Mites or Acarina, generally small in size and often parasites, likewise breathe through their tracheæ, and thus seem to be degenerate Arachnida. However, the position and the number of the respiratory orifices which vary according to the genus and which may disappear altogether, render the assimilation of their tracheæ to the respiratory organs of other Arachnida rather uncertain so far as present knowledge goes. That does not affect the fact that the Arachnida present a special mode of forming their internal respiratory organs, different from that met with in Peripatus, and that they represent a second group of land immigrants, likewise archaic, and dating back to the Silurian period. Scorpions, as a fact, have been found in Silurian deposits, particularly in the island of Gothland. The Arachnida, moreover, belong to a class of Arthropods in which the first appendages of the body, anterior to or near the mouth, are still at least partially utilized for functions other than the retention or mastication of food, and which with creatures like Pterygotus, Eurypterus, Limulus, and the Trilobites, constitute the sub-class Merostomata.

With centipedes or Myriapods we come to a class manifestly derived from the true Crustaceans, in which the first five pairs of appendages are specialized for tactile or masticatory functions. Here, however, the segments carrying these appendages, more or less distinct in the Crustaceans-are combined in a single mass, whose limits we are unable to distinguish, and which we call the head. All the other segments 
are alike, and as they are variable in number we have no alternative but to connect the Myriapods with the lower Crustaceans or Entomostraca, a type which, though aquatic, is quite distinct from that of the Merostomata, which came later. In these, however, a tracheal apparatus develops, very much like that of the Arachnida, in which the respiratory orifices are also close to the limbs, one pair for each segment, except in the Scutigeridx, in which there are only seven orifices, placed on the median dorsal line of the body. The Myriapods, in short, represent the third land invasion of the Arthropods, and their respiratory apparatus, in spite of resemblances to that of Peripatus and the tracheate Arachnida, has been formed independently and quite contrary to the old adage "Nature never repeats herself".

The Insects constituted a fourth wave of immigration, undertaken not, however, by the Entomostraca with bodies made up of a number of segments varying from type to type, but by the Malacostraca or higher Crustaceans, which include Wood-lice at one end of the scale and Crayfish at the other, and mounts up through miniature freshwater Shrimps and marine Shrimps to arrive finally at the Crabs. These Crustaceans are innumerable, but all of them have twenty-one body-segments. The Wood-lice and some related forms reached the land without losing any of the characters of the Isopod Crustaceans, and small tubes, elementary short tracheæ, develop on the respiratory feet borne on the abdomen. The related Asellidæ migrated to the fresh water without undergoing any important modification, and there are in subterranean waters certain other forms, manifestly marine in origin, since species of the same genera still exist in the sea. In the same way the freshwater Shrimps (Gammarus) belonging to the Amphipod group, Palaomonetes, Palaomonella, and Caridina, which are almost Shrimps, and Telphusa, which are Crabs, all penetrated into fresh waters, and certain Crabs, of the genus Birgus, and Gecarcinidæ, which are Decapods, even became terrestrial. But these are only individual immigrations, so to speak, of relatively recent date, like the forms of the creatures which accomplished them. Unquestionably such migrations are still taking place. They have altered nothing in the general economy of Nature. 
It was otherwise with the immigration responsible for the Insects, whose rôle, in our days, is so important. For them a new conquest was in store-the conquest of the air. Until their appearance the only living organisms that had mounted up into the air were the spores of Cryptogamous plants, the pollen grains of Conifers, and perhaps the cysts of the Infusorians, all borne along by the wind, and they were nothing but dust. At first the only living organisms creeping about in the moss were peculiar creatures like Acantherpestes, Palcocampa, and Euphorberia. These creatures had some of the characters of Peripatus, but were more varied in form and often carried dorsal appendages, some of which have been interpreted as branchiæ. Doubtless they were the sole prey that the primitive Scorpions could secure. The Myriapods themselves, although rapid in their course, adhered strictly to the surfaces over which they ran, and contributed a very slight modification to the manifestations of life. With the appearance of the Insects a great change takes place. All over the world creatures with elongated limbs and very vivacious movements, begin to multiply. New locomotor organs, their wings, carry them into the air, and with a single flight they cover notable distances. Before their coming, scarcely any sounds could have been heard on earth but the whistling of the wind, the rustling of branches stirred in its passage, the fall of the cones from the trees, above which must often have arisen the roar of the tempest, and of rivers in spate, the booming of the waves whipped into fury, the crash of thunder, the explosions of volcanoes, or the subterranean rumblings heralding earthquakes. Then came the first humming of rapidly beating wings, and the strident voices of Cicadas, Grasshoppers, and Crickets, great and small, singing, on the threshold of the dark forests, the feast of the sun. The Insects in their countless hordes carried everywhere a new animation. They swarmed on the plants, devouring their leaves, boring into the bark, draining the sap, sipping the nectar from the flowers, and causing the appearance of bizarre swellings and galls on the surface of stems and leaves where they had pierced them ; but also fertilizing the flowers and manufacturing wax, honey, and silk; and, if they sometimes became troublesome pests, like the Flies, or active propagators of disease, like all those Insects which stab in order to draw blood, they became on 
account of their fecundity an inexhaustible source of food for many other animals. The appearance of Insects therefore was an event of first-rate importance in Nature, and deserves to be closely studied.

There is no doubt whatever that these creatures are derived from the higher Crustaceans, in which the number of segments was fixed at twenty-one. In the insects themselves this number is slightly reduced. At most it is nineteen in the larvæ of the primitive forms. It may diminish owing to the suppression or transformation of the last segments of the body, but it is never increased. Five pairs of appendages surround the mouth, as in all Crustaceans, ${ }^{1}$ and this number remains constant. Furthermore, the mandibules and the maxillæ are bifurcated like the claws of the Crustaceans and exhibit on a base formed by two articulations, an inner branch, the endopodite, and an outer branch, the exopodite, generally transformed into a tactile organ, the palp. Beyond these appendages, in most Decapod Crustaceans, come three other pairs, more or less locomotor in function, assisting also in the grasping of food, the maxillipeds. Finally there are five pairs of walking legs and then the abdominal appendages. The three pairs of maxillipeds have become the thoracic legs of Insects; all the others have disappeared, except at the posterior extremity of the abdomen, where there are often free appendages called cerci, and others utilized in the formation of the external genital apparatus. The Machilidæ, Lepismidæ, Campodea, Japyx, and some of the Staphylinidæ, ${ }^{2}$ are the only ones possessing true abdominal legs, which are repeated in the Machilidæ on almost all of the abdominal segments, whereas among the Lepismidæ they are confined to the last segments, and in the other cases to the first. Everywhere else the abdomen is devoid of appendages, but, on the other hand, bears as many lateral respiratory orifices as it does segments. It is difficult to say whether there is any connexion here between the two facts, as in the case of Scorpions. In any case, the maxillipeds have regained their locomotor functions and suffice for their fulfilment. The three segments that bear them constitute the thorax, and of these three segments the last two are provided with wings. It is not very probable that these wings were

1 These are the antenna, the labrum, the mandibules, the maxilla, and the inferior labium resulting from the fusion of two maxilla.

2 Spirachta eurymedusa. 
formed complete and unrelated to the parts already existing in the original Crustaceans. There is general agrcement that they were primitively respiratory organs. This, therefore, is the question we have to determine: is there any respiratory organ among the Decapod Crustaceans that can possibly be compared with the wings of the Insects? Such an organ actually exists. We saw that the second segment of the leg of these creatures bears an articulated branch like the foot itself, known as an exopodite. The first segment likewise carries an appendage, the epipodite, but this appendage is not articulated and has the form of a lanceolate plate. It rises from below the carapace in an upward direction, and usually bears branchial filaments. It is therefore a respiratory organ. Let us suppose that the carapace, the protecting shutter of the branchiæ, disappears with the branchiæ, and thus leaves the epipodite exposed; and let us assume that the segment of the leg that bears the epipodite grows and becomes one with the wall of the body; then the epipodite, mobile, and to some extent already directed backward, will be carried back against the dorsal surface, just where wings are situated. It is exceedingly likely, therefore, that these organs were originally respiratory accessories of the feet-epipodites-which became wings by a change of function when the carapace disappeared. The "beating" of these accessories probably had no other object in the first place than to renew the air around the Insect and to assist its respiration, which, on account of the aerial tracheæ, had become very intense. Hence the wing is no new organ, but a pre-existing one adapted to another function. Without this organ, Insect-flight would never have been achieved; it could be regarded, therefore, as a preadaptation for flight, and this simple deduction suffices to indicate how vague, inaccurate, and elastic the word is, and how capable therefore of giving rise to false interpretations.

We have thus seen how the creation of the Insect was evolved. The earliest, Neuroptera and Hymenoptera, were represented in the Devonian Period. Even in the Silurian deposits something very like a wing of Hemiptera has been found. In any case the Carboniferous Period witnessed the appearance of huge Ephemeridæ, of Libellulæ seventy centimetres in span, of gigantic Phasmidæ, precursors of the Termites, the Cicada, Fulgoridæ, and the existing Hemiptera, in which the body 
possesses at birth practically every character of its permanent form except the wings and remains active while these are forming, instead of passing through that crisis of immobility and renovation constituting the metamorphosis of the more recent forms.

The prairies and forests also became full of life. But, at the same time, another phenomenon of the greatest importance occurred - the invasion of the land surface by the Vertebrates. The starting-point in this great line of organic evolution, naturally enough was the Fish; two things were necessary for its progress. Firstly, an important modification of the respiratory apparatus, to protect it from the dangers that might result from variations in the hygrometric condition of the air, and secondly, the transformation of the fins into feet capable of treading dry land. We cannot say which particular fossil Fish manifest the first stages in the development of lungs, though certain of the existing forms may perhaps give us some idea of what took place. These are older types, such as Polypterus and Protopterus of the African rivers, Lepidosiven of America, and Neoceratodus of Australia, or relatively modern forms like the Siluridæ of the genera Heterobranchus, and Saccobranchus inhabiting the Nile. All these freshwater Fish live in large rivers subject to floods, which make the water extremely muddy, and their respiration is greatly hindered during the period when the water is polluted, so that they are obliged to have a continual current of blood passing rapidly through their branchiæ in order to keep them active. The branchiæ are therefore more abundantly nourished. Their epidermis develops more rapidly and ends by bearing branching processes constituting supplementary branchiæ. These arborescent growths are highly developed in certain Fish of the Siluridan order, the Heterobranchs and the Clarias, and they are contained in a pouch-like expansion of the branchial cavity. Unquestionably the external branchiæ observed in the early stages of Polypterus, and which, at all events, are represented in the Ganoids, correspond to these arborescent processes. They are very apparent in the young of the Dipnoid order. Moreover, the expansion of the branchial cavity of the Heterobranchs into the pouch-form in turn corresponds in its vascular details to the pair of long pouches attached to the branchial cavity in those other Siluridæ, the 
Saccobranchs and Amphipnous. The organs we call lungs in the Dipnoid Fish differ in no way from these pouches in their vascular qualities. They are themselves exactly equivalent to the lungs of the Batrachian, which are provided in their early stages, and sometimes throughout their whole life, with external branchire. There is certainly no genealogical relationship between the Fish of the Silurid family and the Batrachians; it has not even been definitely established that the latter are directly descended from the Dipnoi. If, however, we admit a principle which has been so frequently demonstrated, namely the same mechanisms acting on organisms of the same fundamental constitution produce the same effects, then the arrangements we have just compared permit us to assume that the Batrachians owe their external branchize and their lungs to the fact that their ancestors had for a long time lived in waters frequently polluted, i.e. in swamps or muddy rivers, as the Dipnoi certainly did. The principle just invoked, moreover, is the same that has brought about those resemblances, due to causes other than heredity, which are found among different animals, and which have recently been called phenomena of convergence-a term far less exact than Isidore Geoffroy SaintHilaire's expression parallelism.

Thenceforth the Vertebrates were provided with an apparatus permitting them to brave the danger of desiccation, and to breathe in the open air, but they could not move over the ground by means of their fins; they needed feet. How did feet develop from fins, which they most certainly replaced? For can it be doubted that the amphibious Batrachians are descended from Fish, and form the link uniting them with the first definitely terrestrial Vertebrates, the Reptiles? Here we remain in the dark, but still we must know the reason why. There are some Fish which walk with the aid of their fins, but, unfortunately, these Fish are very different from the primitive forms, and their comparatively recent attempts at walking are far from perfect. Indeed, their fins are so little adapted to walking that Anabas, which has special arrangements in its branchial chamber permitting it to live for a certain time in the open air, prefers, when climbing trees, to use the spines of its operculum and the ray's of its caudal fin rather than its pectoral fins. However, the Pteriophthalmidæ, which live more out of water than in it, do 
walk by means of their pectoral fins, which present, so far as this goes, no special modifications of the normal organ. The Red Gurnet and Red Mullet walk on the sand by means of three of the anterior rays of their pectoral fins, which have become free and move like fingers. Frog-fish and analogous fishes also make use of their pectoral fins for walking on sand, but here we find a curious phenomenon of parallelism ; the portion of the pectoral fins corresponding to the secondary rays is attached as though it were a hand to a kind of arm supported by two primary rays resembling the radius and the ulna, and which themselves are mobile, and move on an unpaired element resembling a humerus. There is, be it understood, no genealogical connexion between the pseudo arm of the Frogfish and the anterior leg of the Batrachians, but the fact that a similar development could have taken place so much later at the expense of a fin already highly modified shows that it might have taken place also at the expense of primitive fins under the influence of the same mechanical conditions.

Unfortunately, the Dipnoan fishes, so closely related to the Batrachians in many ways, have only left us representatives, either in living or fossil form, in which the fin-skeleton is an axis consisting of pieces placed end to end. They remain fairly simple in Protopterus and Lepidosiren, but in Ceratodus they bear a double pennate series of multi-articulate rays. From these facts we cannot draw any inferences as to the origin of feet. We may feel fairly certain, however, that they are derived from fins. Indeed, all the Fish and all the higher Vertebrates are born with their limbs. Only the Batrachians are born without them, and do not acquire then for a long time. Their feet are formed slowly, in a very special way, and no longer as accessories of the muscular segments or myotomes of the body of the embryo, as in the case of all the other Vertebrates, but as developments of small internal, isolated buds. The anterior feet remain for a long time concealed under the skin in Frogs, Toads, and other tailless Batrachians. This delay in the appearance of the limbs can be explained if we assume that it corresponds to a period in which the fins that the Batrachians took from their ancestors, the Fish, are reabsorbed, after being normally formed, in order to be replaced by feet. As required by tachygenesis, to the normal period in which the fins became gradually transformed into feet without ceasing to 
function there must have followed a period in which the originally scattered elements which brought about this transformation were placed in reserve, and began to develop into feet only at the moment ripe for the reabsorption of the fin. Subsequently the developmental stages of the fin destined to disappear were still further economized by tachygenesis, and the feet developed directly, but slowly, without first passing through a fin stage. This would account for everything, but we recognize without difficulty that the discovery of the slightest intermediate link between a fin and a foot would be infinitely preferable to our hypothesis, plausible as it may be.

Thus the development of feet is late and sudden. But as the embryogenetic acceleration continues its task, their formation by dormant buds in the manner of the Batrachians is gradually abandoned; they develop earlier and earlier and finally revert to the primitive method of fin-development by the formation of two buds on two consecutive muscular segments of the embryo. This reversion, paradoxical as it may seem, had already taken place in Reptiles. It doubtless results from the fact that these muscular segments of the forming embryo, which contributed in the course of their development to the structure of the fins, each also furnished cells for the dormant buds, at the expense of which the feet are destined to form and replace the fins. Gradually these cells, instead of detaching themselves from the muscular segments in order to become one with the dormant bud, remain attached to the embryonic muscular segments and are directly assembled in order to form the foot. The time required for the formation of the dormant bud is thus, in its turn, economized and nothing remains to indicate the transformation that the fins have undergone in order to become feet.

Once formed in the manner proper to the Batrachians, the feet preserve the same fundamental structure among all the walking Vertebrates. They vary among themselves only in the degree of proximity to the body of the distal extremities of the humerus and fenur again brought to move in vertical planes, and in the reduction of the radius and fibula as well as the number of digits.

With the acquisition of feet, the adult Batrachians possess all that they need in order to live out of water, but it is otherwise with the young, which are so frail that the parents are 
obliged to return to their earlier habitat, the water, in order to spawn. Indeed, this is a general rule resulting from the fundamental embryogenetic law, according to which the young pass through the same stages of development as their ancestors. As the latter were originally aquatic, they ought to have offspring which begin with an aquatic stage, and then progress more or less rapidly towards a terrestrial existence. We may, indeed, consider it a law that when an animal has changed its environment it returns for a long time after to its original enviromment in order to reproduce itself. Thus the Land-crabs return to the water in vast hordes to spawn there, while the Seals leave the water to give birth to their young on land. Such reversion, nevertheless, ceases in the end; the Whales, for instance, give birth to their young in the water.

The necessity for a periodical return to the water would have inevitably retained the Batrachians, which are poor walkers, close to the shores, and would have interfered with the peopling of land. Fortunately, tachygenesis removed the obstacle. Its action has been exercised in different ways. The Cœcilians, Batrachians without tails or limbs, which live below ground by burrowing in the earth like the worms they so closely resemble, lay their eggs in their subterranean galleries without returning to the water. None the less, in their embryonic stage the young have enormous racquet-shaped or ramified branchiæe, completely enveloping them, which serve them for respiration as well as for protection, and are finally absorbed before birth. The young terrestrial Salamanders have almost completed their metamorphosis when they are born in the water, and the closely related black Salamanders of the Southern European mountains no longer return to the water to lay their eggs, but are now viviparous. Under favourable conditions, viviparity can be induced in the land Salamanders themselves. The young Pipa is likewise hatched at an advanced stage of development, in the hollow pustules on the back of the male, where the eggs have been lodged, the male remaining in the water during the period of incubation. Certain Anura (Leptodactylus ocellatus and L. mystacinus, Paludicola gracilis, Pseudophryne australis and $P$. briboni) lay their eggs out of the water, whither the young are brought by heavy rains after they are hatched. The Chiromantis and Phyllomedusa attach their eggs, enveloped in a glairy substance to the underside of the 
leaves of water-side trees on which they live. The young are hatched within this sticky envelope, which the rains soak and carry away into the stream below, together with the young Batrachians inside. A Tree-frog of the Antilies, Hylodes martinicensis, goes even further than this; it also attaches its eggs to the undersides of the leaves on the trees it inlabits, but the young are born in their permanent form. The same is true of Rana opisthodon and Hyla nebulosa. These are still but tentative experiments, so to speak, in passing from an aquatic or amphibian life to the life of the open air. Moreover, these experiments, favoured by the large size of the eggs, very rich in reserve substances, are relatively recent, since the tailless Batrachians of the Frog type date back no farther than the Tertiary Period, and there were Reptiles definitely terrestrial in their habitat at the end of the Primary. In Tertiary times the Batrachians renewed, this time without complete success, the happy attempt of more remote times, to become dwellers in the free air. However, the success of the earlier efforts had been assured by a new phenomenon: nutritive material had become accumulated within the egg, which finally became of considerable size. Thus the embryo, finding within the egg all the nutriment necessary, and not being compelled to expend any of its energy in the search for food, employed it in multiplying its structural cells. Hence its development was considerably accelerated. The phases of development corresponding to the aquatic life were gradually curtailed, finally becoming mere indications. Since the limbs remained unused they were superseded in growth by the viscera and nervous system, and the external form of the embryo was thus temporarily modified, the more so as it was obliged to expand temporarily above the vitelline substance, which had become tremendously enlarged, and to take on the appearance of a plate formed of three superimposed layers, corresponding to the ectoderm, the mesoderm, and the endoderm. Furthermore, those portions of the embryo destined to disappear before birth have been constituted by some of the cells born of the segmentation of the nucleus and of the vital plasma of the egg, which have spread around the spherical yoke mass and gradually enveloped it, producing the blastoderm, which consists of cells that retain their primitive aspects and merely fulfil a digestive function. This was probably due to the fact that the first cells formed were early 
sufficient in number to become differentiated and to constitute the essential parts of the embryo. As the nuclear substance and the vital plasma of the egg were not yet exhausted, the cells formed last remained outside the embryo, so to speak, and merely served to help in nutrition. The egg itself was formed in the same way; the oldest elements within the ovary or those best adapted for nourishing themselves alone developed and nourished themselves at the expense of the others.

The embryo naturally took its food from the region immediately beneath it, the vitellus or yolk. It gradually assimilated its substance, and consequently sank down into it. Thereafter the extra embryonic blastoderm gradually spread up and closed over the embryo, whilst it contracted below, thus forming an envelope which is the less mysterious in origin inasmuch as it also forms for identical reasons and in the same way around the embryos of insects. This is the ammion. The sac becomes filled with liquid, and henceforth the embryo is protected against all risk of desiccation. Respiration is accomplished in a fashion that is somewhat roundabout, but therefore all the more interesting. Minute renal ducts early appear in the mesoderm and empty the products of their secretion into a pocket or receptacle which is nothing more nor less than the embryonic bladder. This sac has no external opening. Hence it retains the products of secretion which it receives, and becomes so greatly distended as to nearly line the amnion itself, while a close network of vessels is formed in the thickness of its walls; this is the allantois. ${ }^{1}$ As this membrane is extremely rich in vessels, is separated only from the outer air by the thin containing membrane of the amnion, and presents a large surface, it is admirably fitted to assure respiration for the embryo all the time that the lungs are not in communication with the outer air. Here we have a new example of those changes of function resulting from the accidental concurrence of circumstances to which Dohrn, as we have already pointed out, so justly called attention. Protected against desiccation, abundantly supplied with nourishment, and breathing adequately, the embryo is now developing under favourable conditions, and the process is

1 From ả $\lambda \lambda \hat{a} s$ sausage, so-called because at first it has the form of a closed tube recalling that of a sausage. 
accelerated. It passes rapidly through the patrogenetic phases of its evolution that had as their end the hereditary formation of organs such as the branclize, which it now has no need to develop and can resorb as soon as they appear. Before leaving its egg-shell the cmbryo can await the acquisition of sufficient vigour to enable it to seek its own nourishment and to win victory over those untoward chances to which existence in the open air might expose it. The mother is no longer obliged to return to the water in order to obey the hereditary instinct of an aquatic organism which still exercises influence upon her progeny. Independence of a humid environment, together with an air-breathing mode of life, is finally acquired for the Vertebrates. It is the life that will be led by Reptiles, Birds, and Mammals, and which will make them masters of the world.

Since the respiratory system was at first feeble, and the arrangement of the circulatory system a survival of the time when breathing was done by gills, the internal combustion in the body of the Vertebrate was not capable of producing a body-heat that could defy the variations in the external temperature, for the oxygen with which the blood plasma was only very incompletely saturated did not suffice to supply the organs with all they could have consumed. The creature lived in a state of dependence on these conditions. Its internal temperature, which regulated its activity, varied according to that outside. When the latter fell below or rose above certain limits the vital functions either decreased or ceased altogether. The animal's vitality thus became intermittent. This is the case with Reptiles. However, in their own way, and by different methods, both Birds and Mammals succeeded in bringing their lungs to a high degree of perfection, and in completely separating in the heart and circulatory system the blood charged with carbon dioxide from the blood saturated with oxygen, thus assuring a full supply of oxygen to the structural cells and organs, to whose existence and functioning it is essential. This functioning, if it consumes energy, develops a proportionate quantity of heat, both the energy and the heat resulting from the combustion of foodstuffs. Moreover, the heat developed is retained within the organism once it has become warm, by the layers of air imprisoned betwcen the feathers of birds and in the fur of Mammals. Certainly neither feathers nor hairs were instituted for such a purpose; these tegumentary growths 
were probably formed as a result of the stimulus which perpetual contact with the air exercised upon the skin, and which brought about, especially above the richly vascular papillæ of the skin, the rapid multiplication of the epidermic cells which quickly dried up and accumulated outside the area where they had multiplied. In this way there developed a whole group of structures, with no particular object, but accidentally adapted to protect the animal against loss of heat. This protective apparatus, which has played the same part among the Birds and the Mammals, owes its origin in these two cases to entirely different circumstances. Birds, as we shall see later, are only a specialized form of Reptile, itself evolved from the Batrachians, whereas Mammals are directly evolved from the Batrachians. Their evolution was parallel with that of Reptiles, whereas the Bird, in a sense, was the ultimate achievement of the evolution of the Reptile. The Batrachians have a skin particularly rich in sensitive organs and glands of all sorts. These glands have totally disappeared in Reptiles, except in limited areas of the body, such as the edge of the thigh in Lizards. The sensitive organs are equally few and far between. Birds, like Reptiles, have a dry skin, and their tactile organs are collected in definite regions of the body. Their feathers develop like little thorns at the top of dermal papillæ that then become invaginated in the skin. In the Mammals, on the contrary, the skin remains moist or softened by numerous glands, the sudoriparous glands producing sweat, and the sebaceous glands producing a liquid which lubricates the hair and renders the skin oily. The hairs themselves are modifications of a part of the sensitive organs of the Batrachians. The bulb is often surrounded by a nervous ring, turning them into tactile organs of great sensibility. Instead of being formed like feathers, at the head of the papilla, they arise from a deep epidermal bud which is buried in the dermis or true skin and there, so to speak, indents the pilary bulb. Certain skin-glands specialize in the secretion of milk, and have given rise to the mamme which furnish the young with their first food. The disappearance of the slin-glands has made lactation impossible in Birds, whereas it has become characteristic of Mammals.

Thus the nature of their skin might seem to accentuate the differences which separate Reptiles and Birds from Mammals. 
On the contrary, it has brought them closer together, in that in both it contributes to their protection against chilling, since it preserves a constant internal temperature in spite of the variations in the external air ; that is to say, it renders them warm-blooded animals endowed with a new independence of external environment, and capable of resisting its modifications, thus enabling them to achieve the highest organic development of all living creatures. This achievement was reached, however, by two different paths, not directly, but by a combination of circumstances nowise working towards that end.

When the organisms of the warm-bloorled Vertebrates became accustomed to a constant temperature, this temperature had to be artificially assured to the embryo, which being inactive, could not itself produce it. This was achieved passively in Mammals and actively in Birds, which would thus seem in this respect to have made a definite advance at some given moment. Those mammals which to-day are least removed from the ancestral forms, the Monotremata, represented by the two genera Ornithorhynchus and Echidna, lay their eggs in a sort of nest resenubling a Bird's, and sit on them in the same way. In the Marsupials, which come next in the order of evolution, the eggs are no longer deposited. They remain small and are retained in the womb of the mother, where they develop without, as a rule, being in any way linked with its walls. At birth the young are very small, and their limbs are poorly developed. They are placed by the mother in the ventral pouch, which most Marsupials possess, and which contains the mammæ, and here they develop. In other Mammals the egg, detached early from the ovary, passes into the uterus before it has exceeded in size the tenth of a millimetre. It then contains only a very small amount of reserve material. This, however, does not approximate it to the small eggs of Fish, or even of Batrachians. It is not a primitively small egg, but an egg which has reverted to a small size, and which has hereditarily preserved the method of development imposed upon large eggs by the enormous size of their yolk. The reason for this mode of development, quite obvious in the case of the large eggs, no longer obtains here, and would be unintelligible and absurd if we did not know that the primitive Mammals were oviparous and laid large eggs, 
like the Reptiles and Birds. The small eggs of the present Mammals produce a yolk-sac, an amnion, and an allantois like those of the Birds, and these organs, which under Mammalian conditions cannot be accounted for without recourse to heredity, are utilized in a new manner. It is at their expense, and with the more or less active assistance of the womb, that a placenta is formed, by means of which the young Mammal can obtain from the blood of its mother the nutritive substances not found in the egg. When the organism suddenly abandons the womb, as a result of the nother's accouchement, these substances go on accumulating in the parent's blood, where they are no longer required. It is then that the glands of the skin intervene and eliminate them. Those on the ventral surface, stimulated by the incessant friction or the suction of the young over which the mother is lying in order to keep them warm, grow larger and finally become the milk-producing mammæ that for a long period will furnish the only food of the newly-born. Probably these glands were first differentiated as a consequence of the twin acts of laying and brooding in the oviparous Mammals, whose young simply licked the walls of the ventral cavity in which the egg was still incubated. Subsequently these differentiated glands became localized in the ventral pocket where the Marsupials carry their young. In the placental Mammals they were eventually multiplied in two symmetrical lines. Both their number and the position occupied were gradually brought into relation with the size of the litter and the habitual posture of the mother, in conformity with Lamarck's principle that use and disuse influences the development of the organs independently of natural selection. Dogs, Cats, and Pigs, in spite of the differences separating them, have numerous mammæ, because of the equally large size of their litters; the Horse family, Ruminants, and Monkeys, which produce but one or two at a time, have only two or four mammic. In fleet Mammals, these mammæare concealed between the posterior limbs in such a manner that the young are hidden and protected, while being suckled, by the body of the mother, who stands erect while it suckles. Animals which use their arms in climbing, like the Nonkeys and Sloths, or to hook themselves on to resting-places, like the Bats, or which raise the anterior region of the body out of the water in order to feed their young, like the Sirenians, have the mammæ 
placed on the breast. The position and number of the mamme is thus seen to be independent of both diet and internal organization, and simply depends on the degree of fecundity and the posture. Heredity can intervene here as elsewhere and seem to interfere with the conclusions that should follow the application of these principles. But in reality it confirms them when we discover that the supposed disharmony is actually a concordance with primitive conditions of existence now abandoned. The gait of the Ant-eaters, which progress by supporting themselves on the edge of their feet or the back of their toes, indicates clearly that these animals, though to-day they burrow, were originally climbers, and for this reason. opposed the palms of their hands. On the other hand, the length of their nails and their reproduction organization show that in spite of the tremendous difference in the form of their heads, they are related with the tree-Sloths; they have preserved as a fact their pectoral mammæ. Elephants also have pectoral mammæ, and their past, once revealed, should explain the reason for this arrangement characteristic of climbing animals, which our knowledge of their present habits does not suggest as a primitive condition, though the crossing of their radius and ulna lends confirmation to it.

We may thus sum up all that has just been said about the origin of the land Vertebrates:-

They are descended from the Batrachians, whose eggs. became very large owing to the considerable accumulation of this nutritive substance. The volume of these substances caused the formation within the egg of a blastoderm over and above the very limited portion of it destined to form the embryo. The abundance of nutritive material permitted that intensive embryogenetic acceleration which had already suppressed the ancestral fins of the Batrachians to progress an additional step, in consequence of which the imperfect respiratory apparatus of the aquatic young gradually became. transitory, then simply suggested, to disappear completely before the birth of the embryo. Thus, within the egg, the embryo passed through its entire series of metamorphoses. under the protection of an amnion and an allantois-of purely physiological origin, as we have seen. Henceforth the egg could be deposited in the open air, protected as it was by a solid shell. This stage of evolution, independently of the fate reserved 
for the skin, is common to Reptiles, Birds, and to the ancestral Mammals represented to-day only by Monotremata.

While this evolutionary stage is maintained among the dry-skinned Reptiles and their descendants the Birds, a regression takes place in the viviparous Mammals. The egg ceases to accumulate abundant nutritive substances, but reverts to complete segmentation, which these substances would hinder. Heredity, nevertheless, conserves in the embryo the method of development it acquired by reason of their former abundance although that method has lost its original purpose. The enveloping membranes then change their function, and, while continuing to act as a protecting organ for the embryo, also form a placenta that serves as the link between mother and embryo. New causes now intervene, however, in the formation of this placenta; first, the irritation which two vital membranes of different nature produce upon each other when they are perpetually in contact, and secondly, the exchange of various substances that takes place between these two membranes or through their walls, since it is impossible that the embryo should draw certain substances from its mother without giving others in return. Did the case actually present itself, we might see here an explanation of the supposed influence which the first male exerts on the later conceptions of the mother, a process called tclegony. Thus it is not the first male but his first offspring, who would be responsible for influencing the mother. Nor must it be forgotten, moreover, that immature eggs confronted with spermatozoa frequently assimilate them, so that strictly speaking the spermatozoa may thus be added to those substances capable of influencing the egg's final evolution.

Since the mammæ arise as a result of the conservation of the excretory functions of the skin, there are plenty of reasons to account for a parallel evolution of the Mammals and Reptiles, and for their having started to evolve at the same time; and to suggest that Mammals, at least the oviparous ones, must be very early in origin. The case is otherwise with Birds. They derive from a Reptilian type already highly specialized, and also form a class whose homogeneity is in marked contrast with the variety exhibited by Mammals. Putting aside the development of feathers, a phenomenon of a purely external order, the ancestor of the Bird must have 
first become a hopping creature, whose feathers, developed quite independently, perhaps even before it acquired that aptitude for hopping, later permitted fight. The only Reptiles which have been preserved to us-we shall see why later (p. 276)-are those whose method of progression was of the humblest order. During the course of the Secondary Period, however, certain Reptiles acquired dimensions of which even Whales scarcely give us an idea, and nearly all had developed modes of locomotion analogous to those of existing Mammals. While many of them had bodies still sunken low on the legs and trailed on the ground, like Crocodiles and Lizards, others had straightened their limbs in such a way as to permit the body to be carried high, dog-fashion, and a number of others stood almost erect on their hind legs, like the Kangaroo. It is among these last that we ought to look for the ancestor of the Birds. This ancestor would have already to possess the characters common to all: he must stand erect with the sole of his foot straightened on his toes, five in number at first, and his three median metatarsals, supporting the upright sole of his foot, must unite in a single rod. The fibula would be rudimentary, and united with the tibia at either extremity. Now there exists to-day a Mammal whose hind feet display most of these characteristics. This is the Jerboa, or leaping Mammal par excellence. The union of the metatarsals is seen also in Ruminants, the fleetest of the Mammals, whose method of progression is nothing but a series of bounds. The Bird, then, must be descended from a leaping and probably arboreal Reptile. The a posteriori verification of this conclusion is provided by those Birds which have lost the faculty of leaping, like Auks and Penguins, and which are essentially swimmers and walkers, or the Parrots, which, instead of hopping from branch to branch like Sparrows, hoist themselves up using their hook-shaped beaks in the process. In both these quite different cases, with nothing in common but the abandonment of the leaping habit, the metatarsus is shortened and broadened, and the three bones which united to form it are tending to become isolated again.

From this vantage point we might be tempted to look for the primitive Bird among those present-day birds unable to fly: the African Ostriches, the South American Nandus, the Indian Cassowaries, the Australian Emus, the New Zealand 
Apteryx. Their distribution seems to bear witness to their antiquity, but a number of facts render this hypothesis doubtful. We know from Archaopteryx, which has left fossil remains in the Jurassic limestone of Solenhofen, that the ancestor of the Birds preserved the long tail of the Reptiles; that the jaws, although invested with a horny plate, were not elongated into a genuine beak, and that when this elongation took place it did not at first cause the disappearance of the teeth with which the jaws had been provided, since these occur also in the birds of the Cretaceous Period, still inserted in separate alveolæ, in such forms as Archceopteryx, Ichthyornis, and Apatornis; or arranged in a common groove in Hesperomis, Enaliomis, and Baptomis, which seems to presage their approaching disappearance. It is scarcely probable that Archceopteryx was capable of sustained flight. Its fore limbs were still actually legs, whose four toes, provided with nails, were definitely separated. The furcula was U-shaped, as in birds of prey, but this form was not necessarily connected with flight. In any case, the keel of the breast-bone was weak, and the long tail, incapable of serving as a rudder, was rather in the nature of a cumbersome ornament. Nevertheless, the feathers on these anterior limbs and on the tail were already clearly characteristic of the wing and tail feathers of flying birds, so that they were actually prepared for flight.

This faculty was well developed in Ichthyornis of the Clialk formations, whose tail was already reduced to a rump and the keel of whose breast-bone was very prominent. But Hesperornis, although more highly evolved, could no longer fly, which is enough to render suspect the antiquity of the loss of this faculty, and leads us to ask whether we were correct in including in one order, i.e. the Ratitæ, all those large Birds without a keeled breastbone and incapable of flight. It is quite likely that the Ostriches are the only members of this order which represent a prinitive group, by reason of their large wings, their almost normal digits, and their united pubes; but they represent a much modified form, since their feet have but two toes. The Nandus, with their large wings and their united ischia, would be typical of a second group coming nearer to existing Birds. Epyornis, Dinomis, the Cassowaries, and Apteryx with open pelvis and small wings-indeed, wings in miniature, for they are so constructed as to deserve in every respect the name of wings- 
would be degenerate Birds which had lost the faculty of flight as a result of long habitations of regions where no enemy was to be encountered-like the Dodo, which is only a big pigeon, the Penguin and the Auk, related to the Diver. Having abundant food and living in complete security, they acquired considerable proportions, and idly gave up all effort at flight, since flight had become for the time being unnecessary. This renunciation, resulting from the absence of any struggle for existence, proved fatal to them when Man invaded their domain and they could no longer flee from him.

The Ichthyosauridie were viviparous; Seps, Slow-worms, Hydrophis, Vipers, and other Reptiles have acquired this character, and there is no a priori reason why certain Bircls should have developed it. Perhaps the size of their eggs made a prolonged sojourn in the oviduct difficult, and their limeproducing aptitude evidenced in the compact texture of their osseous tissue, the thickness of the protecting shell of the egg, and the precocity of its formation, were all obstacles to the achievement of viviparity. Be that as it may, the Birds remained oviparous, and all their energy was directed to the construction of nests in which they could lay and sit on their eggs and shelter and warm their young. Their inaptitude for viviparity must be very great, since it has reduced the Cuckoo and the Cow-Bunting or Molobrus, a sort of American Starling, to the expedient of confiding the incubation of their eggs and the rearing of their young to other Birds, in consequence of the disparity between the egg-laying season and the seasonal migration.

We have now passed in review the conditions in which the principal types, branches, and classes of the Animal Kingdom arose. At the outset, and dominating even the existing evolution of individuals, there is one property fundamental to all living substance-the congregation together in small masses which multiply by division and are capable of association among themselves. The arrangement of these masses or cells is at first regulated by purely mechanical conditions: immobility and mobility determined respectively two main structural types, the branched and the segmented. One of the main divisions of the segmented type, the Annelid Worms, with plastic body, thereupon 
lent itself to a series of modifications due to the immobility which followed on a parasitic life or rendered necessary by attitudinal alterations, themselves due to chemical phenomena such as the secretion of lime or fatty substances, or to a physiological phenomenon-the great development of the nervous system, followed by tachygenesis. Thus arose such specializations as Flat Worms, Echinoderms, Molluscs, and Vertebrates. The initial vertebrate forms, becoming degraded as a result of their early fixation, constituted that peculiar branch of the Animal Kingdom, the Tunicates. In all the varied circumstances under which these animal modifications arose, the organism, far from succumbing to unfavourable conditions of existence, defended itself with success. It became the artisan of its new organization, and, so to speak, created itself anew by continuous efforts that could only be crowned with success under conditions of absolute security. Natural selection and the struggle for existence, as Darwin understood these principles, had nothing to do with the creation of the great organic types. Animals did, indeed, struggle for their existence, but against the unfavourable conditions of their environment and by reacting upon themselves, without having to fear competition. They played an active part in their transformations. How, indeed, could we suppose that animals endowed with sense organs for receiving sensations, with nervecentres for their appreciation and reflexion to the periphery in order to set the muscles and glands in motion, could remain passive in the presence of incessant stimuli coming from without?

It was only later, when the chief differentiations into type had already taken place, that competition made its appearance on the over-populated sea-shores. Its first consequence was not combat but flight - toward the open sea and the ocean depths, the fresh waters, and terra firma. The urge toward the land was especially productive of transformations. In so far as the animal remained aquatic, the local multiplication of epidermal cells were produced externally as easily as internally, and gave rise to superficial prominent appendages utilized in respiration. From the time the animal organism became terrestrial this multiplication was able to give rise only to internal tegumentary appendages - the tracheal sacs of the Arachnida and the tracher of the Myriafods and Insects. Lungs took the place 
of the gills in the Vertebrates. In order that these transformations should produce their full effect, it was necessary for the eggs to become transformed, for embryogenetic acceleration to intervene, and for the organs resulting from a reciprocal adaptation of mother and embryo to manifest themselves. It is thus impossible to contain the history of organic evolution in any one of those simple formulas so dear to certain philosophers-creation by the word, astral insemination, preformation, use or disuse of parts, the continuity of the germ plasm, natural selection, mutations, and so forth. In reality all that goes to make up the energy, motion, and substance of the world has taken part in its turn in the evolution of life, and its organic forms are the result of the unceasing action on them of these different forces whose mobility only is translated by evolution.

Organisms themselves are capable of active intervention in their own modification. When new organs appeared as a result of the rapid multiplication or specialization of the elements of a certain category, they might at first remain unused, but favourable circumstances permitted the organism to take advantage of them. The use to which it turned them would then direct their subsequent modifications towards some definite end. They would become more and more capable of fulfilling the part that devolved upon them, and would adapt themselves better and better to their function. In their turn they might react on and modify the organs with which they were connected. This is the history of the feathers of the Bird and of the webbed feet of walking Vertebrates which once more became aquatic. Feathers were at first merely an epidermal investiture, consisting of long prominent papillæ of the skin, probably ramifying in all directions, as the down of young birds would seem to indicate. The tegumentary papillæ then became imbricated, like the false scales of Serpents, and consequently they tended to flatten, while at the same time their mutual overlapping must have interfered with the multiplication of the epidermal cells on the ventral and dorsal surfaces. This multiplication then became confined to the rim of the papillæ, and brought about the quasi-symmetrical arrangement of the branches hereditarily preserved after the initial papilla was drawn back under the skin. Thus was constituted the disc-shaped tegumentary appendage, made up 
of barbs sustained by a solid axis, which we call the feather. There were feathers on the fore-limbs of those Reptiles which stood erect on their hind legs built for leaping, and these only needed a certain amount of elongation to support the Reptile in the air and transform it into a Bird. But once the faculty of flight was acquired, the front limbs were modified in their turn, no longer by accident, but by the actual use made of them by the newly achieved bird. To give a greater solidity to the wing during flight the two largest digits were closely pressed against each other. These toes, still quite independent in Archeopteryx, and almost so in the Ostrich, became united and gave the anterior limb the definitive character of a wing. In the same way, in order to assure the free movement of the wing-elevating muscles attached to them, the dorsal vertebræ were united, while the increasing volume of the muscles which lowered the wings brought about the formation between them of a prominent ridge attached to the sternum, called the keel. A kind of epidermal accident has thus affected all the rest of the organism, thanks to the animal's own activity, and determined the direction of its evolution.

Analogous influences were exerted upon the organization of the limbs by the web developed between the toes of walking Vertebrates which had reverted to an aquatic habitat, but the origin of this web was not accidental, as in the case of the feather. No trace of it exists in any true terrestrial forms. On the other hand, it is observed in all quadrupeds, no matter to what group they belong, which inhabit marshes or water. It is almost universal in the tetrapod Batrachians and occurs again in Crocodiles and marsh or river Tortoises; it is so characteristic of water Birds that they are called web-footed Birds; it appears in Mammals, and, in an entirely independent manner, in the Monotreme Ornithorynchus, the Desmans, which are insectivorous placental Mammals, in Myopotamus, Hydromys and the Beavers, which are Rodents, and in the Martens, Otters, and Seals, which are Carnivores. The fact that a similar conformation appears in animals so different, whose only common condition of existence is their water habitat, and which is absent in all those which do not share this habitat, clearly indicates that identity in mode of life is the primary cause for the development of the web. Indeed, we can readily understand that contact with the wet ground would soften the skin of the 
toes, and that even the slight resistance of the ground on which they press would make the skin stretch laterally so as to form a web. Thus the web is no accidental product here; it is linked with a mode of life which the animal only accentuates when it takes to swimming. The movements necessitated by swimming have the same consequences everywhere. The better to utilize its strength, the animal immobilizes the bones of its limbs, and the pull on them of the muscles attached to the body during the action of paddling, shortens the bones, while the resistance of the water flattens them, and the web then envelopes all the flat bones immobilized in relation to each other and consequently brought closer together to form a mutual support. Thus the entire foot is transformed into a swimming paddle. This transformation, like the development of the web itself, takes place in the most varied groups: first in the Sauropterygians, ${ }^{1}$ the Ichthyopterygians, ${ }^{2}$ and certain Mosasaurians-large Reptiles of the Secondary Period-then in marine chelonians. Still later, after having been merely rudimentary in the hind limbs of the Seals, it appears in Halitherium, Zeuglodon, the Sirenians (Dugongs, Manatees), and the Cetaceans. It is so clearly the mechanical conditions of swimming that determine this foot-formation, that anong the Birds the Penguin's wing, also transformed into a swimming organ, though it preserves all the essential characters found in the skeleton of a bird's wing, is modified in the same direction and transformed in the same fashion into a swimming paddle. The same limb has thus been successively a foot, a wing, and a swimming organ.

A parallel series of facts, similarly linked together, leads to the development of flight in the climbing quadrupeds. When, in climbing, they cling to the trunk or branches of a tree, the skin becomes laterally flattened and thrust back on the base of the limbs; hence a kind of membranous parachute is formed, which can be observed indifferently among Marsupials such as Petaurus, Rodents like Pteromys and Anomalurus, Insectivora like Galeopithecus, Lemurs like Microcebes, and culminates in the wing of the Bats. A striking instance of this kind of arrangement is seen in certain specifically climbing Lizards of the Gecko family, which cling closely

1 Plesiosaurus and related genera.

2 Ichthyosaurus and related genera. 
to the trunk of the tree. In Uroplatus of Madagascar ${ }^{1}$ the skin runs back along the whole length of the head, trunk, limbs, and tail, which is flattened into the shape of a trowel. An analogous bordering of skin spreads out considerably in Ptychozoon of the Malay Archipelago, ${ }^{2}$ and extends web-fashion between the digits of the feet. This brings us to the remarkable case of the Flying-Dragon of the Sunda Islands, in which the skin at the sides forms a kind of a parachute supported by bony rays attached to the ribs. It is probable that analogous conditions gave rise to the wing of the Pterodactyls and the other Pterosaurians of the Secondary Period. This wing resembles that of the Bat in its mode of formation, but instead of being supported by the four outer digits, the pollex remaining free, as with the Bat, it is supported only along the length of its anterior border by a single outer digit which is greatly elongated.

Though it may be true that in certain cases we can explain the intimate adaptation of animal organs to the functions they carried out by supposing that these organs were formed with no particular end in view, and that those animals, thus enabled to lead a certain kind of life forbidden to others not thus provided, profited by these organs to live an existence for which they found themselves in some measure pre-adapted, the facts we have just been enumerating show us clearly enough that this hypothetical pre-adaptation can give us only an incomplete view of the truth. Moreover, the word pre-adaptation itself suggests the notion that animals have been formed in advance to live in a predestined manner, and comes dangerously near to reviving the old doctrine of determinism.

By the very fact that it is alive, an organism cannot be considered to be passive. If it is subject to the influence of light, heat, humidity, dryness, the regular return of day and night, the periodicity of the seasons, in a word to everything that is called external environment; this influence must also react profoundly on its internal environment, which thus becomes a powerful agent of modification. Every living cell by the very fact that it feeds, every muscular element that contracts, every gland cell that secretes, and every neuron that undergoes or elaborates a stimulus, pours into this interior environment some substance capable of acting upon the cells with which it 
comes in contact, even though they may be separated from it.

The wonderfully energetic action exercised by minute doses of what are known as internal secretions, is only a particular instance of this general phenomenon. The activity of an organ does not modify that organ alone; it may react on the whole organism, as in the well-known instance of the maturation of the ovum. It can determine modifications in other organs, and become the cause of unexpected variations in characters, and herein, perhaps, lies the secret of one part at least of those sudden variations pointed out by Charles Naudin in I865, upon which was based a doctrine subsequently credited to De Vries. It is the collaboration by means of their excretions of all these structural elements in the formation of the internal environment, partly with the aid of the nervous system, and partly in independence of it, which establishes the solidarity characteristic of higher individualities. Every modification in the chemical constituents of one of these elements may have its echo in others, and, as Armand Gautier has shown, can even modify the forms of living beings; so much so that, at some future date, morphology may be entirely bound up with the chemistry, still so mysterious in many respects, of the albuminoid compounds, diastases, and numerous other substances, to which, for lack of better knowledge, we now give the vague names toxins, hormones, etc.

On the other hand, every time that two organisms enter into permanent relations with each other they gradually modify each other by reason of these very relations; this is what I described in $\mathrm{I}^{8} 8 \mathrm{I}^{1}$ as the reciprocal adaptation of organisms. A parasite is modified by its sojourn inside its host; but to an equal extent it modifies the body in which it lives. Allmann in I87 I ${ }^{2}$ had already called attention to the fact that the larvæ of the Pycnogonida, which lodge as parasites in Hydroids, give to the host merids that nourish them the aspect of reproductory merids, and I myself wrote in regard to this subject: "When the growing reproductive organ attracts to itself the nutritive fluids, is it not acting in the same way as a parasite which turns to its own profit a part of the digestive activity of the polyp? "? In fact the presence of the parasite often excludes all develop- 
ment of the genital organs, causing what Giard has called parasitic castration. But this is not a matter of castration alone. The appearance of the host may be modified to such an extent that it appears to constitute a new species, as Jean Perez showed in the case of the stylopized Andrena. These are all specific instances of a general phenomenon which, when considered in its amplitude, ends by including within its own circumference all the results of the struggle for existence and natural selection. The present distribution and arrangement of fauna and flora presupposes, in fact, a reciprocal adaptation of organisms such that, without too much endangering each other, they can live side by side. We shall have to apply this principle in the course of our chapters on life during the various geological periods.

Once these various organic types had been fully and securely established, sea and land became rapidly populated. The struggle for existence became more and more bitter, and if it created nothing new, it did at least determine what could live and what must die, assure the conservation and the development of the most vital forms, and cause those gaps among living organisms that mark off one species from the other. This is what we shall find did actually happen when we come to study the great geological periods. 


\section{PART III}

\section{TOWARDS THE HUMAN FORM}





\section{CHAPTER I}

\section{Life in the Primari Period}

$\mathrm{T}$

HE remains of plants and animals of former times, preserved in strata, deposited, abandoned, covered again, and undermined in turn by the sea or given over first to the eroding action and then to the deposition of new layers of mud by fresh water, form a series too incomplete for it to be possible to reconstruct, from these resources alone, the world's primeval aspect. Some of these remains - and it will appear strange that they should be so few-have remained to some extent enigmatical, or rather have left the palæontologists uncertain as to their true nature; but the very rarity of such doubts clearly demonstrates that the bounds set as the result of the study of nature to-day have never been broken, that at all times the same laws have presided over the evolution of life, and that the considerations enabling us to relate existing forms retain their full value for the past. They imply an order in the appearance of organic types that determines for each series which forms must have appeared the first; they fix the position of those that have disappeared, and even enable us to classify as necessary evolutionary links certain forms that would be perplexing if we had no such considerations before our minds. It is interesting, therefore, to compare the indications of theory with the evidence palæontologists have hitherto obtained.

So far as plants are concerned, investigations from the Silurian deposits onwards yield remarkable agreement between theory and fact. The earlier strata also certainly contained organisms. Theory indicates Algæ as the first living earthly organisms; if we ever succeed in creating life artificially, experiment will no doubt solve the problem; but palæontology provides no precise information as to the nature of the earliest organisms. The oldest sedimentary deposits have undergone in fact profound transformation. Certain layers 
may exceed I0,000 metres in thickness, but these have been violently folded and eroded. All that remains to-day is that portion of these colossal folds directed inwards into the earth's surface where the heat generated lateral pressure at the time of the folding, and the resistance of the still older formations beneath to penetration by the edges of the folds, was so intense that all the matter deposited by the waters became dissolved or molten, and was regrouped in crystalline mineral formation; quartz, felspar, pyroxene, mica, and amphiboles, whose association first produced the mica-schists, then gneiss, and leptynites whose primitive stratification is still discernible, and finally, the granites, amphibolites, and unstratified porphyry, in which occur isolated minerals such as garnets, tourmalines, emeralds, and other hard stones. We could not expect to find in deposits so completely metamorphosed, as the geologists say, the remains of delicate primitive Algæ. However, in Finland, the oldest of these formations, the Archean, contains carbonized matter and specks of a special kind of lime called cipolin. We may feel pretty sure that lime and organic matter found in sedimentary deposits are all of organic origin. Hence there must have been living organisms even at that remote epoch, which was long known as the Azoic, because it was supposed to correspond to an era in which the first consolidation of the earth's crust took place, when life did not yet exist. A Scandinavian naturalist, J. J. Sederholm, has even found in it the remains of organisms, but they are so ambiguous that some have regarded them as plants, others as Echinoderms.

Furthermore, the existence of living organisms on the earth during the Archæan Period is rendered highly probable by the discovery of a variety of fossils in the Algonkian strata which follow next, and are essentially formed of mica-schists, and for a long time were also regarded as azoic. No plants have been discovered here, nor yet in the Cambrian Deposits which initiated the series belonging to the Primary Epoch, and which at times attain a thickness of 3,000 metres. However, it should be remembered that at Shunga, in the Government of Olonetz, and at Snojärvi, in Finland, there are intercalated between the layers of Algonkian schists beds of dense coal, presenting here and there a metallic lustre, which are richer in carbon than anthracite and often attain a depth of two metres. 
Inostranzeff has given them the name of shungite. They may result from vegetable fossils more lighly altered than those which formed coal measures.

During the Silurian Period Algæ of the Siphoneæ family at last appear, and others that recall the large Laminaria of to-day. With these are associated remains that would seem already to be divided up into the three classes of vascular Cryptogams: Horse-tails (Annularia), Ferns (Sphenophyllum), and Club-mosses (Sigillaria). The presence of Siphoneæ is of especial interest. These Algæ, which still exist, may grow to a large size, remain spheroidal (Codiaceæ, such as Grivanella), or branch out like the higher plants, the branches recalling leaves and even forming whorls (Dasycladeacæ, Palceporella, Rhabdoporella, Vermiporella). Despite this, they do not show the cellular structure so general in organisms that are no longer microscopic. The body, enclosed within a wall of cellulose, supported by an irregular network of threads of the same substance, consists only of an amorphous protoplasmic mass within which are scattered numerous nuclei. In view of this we may ask whether the cellular structure of almost all the present animals and plants is not a secondary development, resulting from an equal distribution of an originally continuous protoplasmic mass between the nuclei which contain the substances regulating nutrition, such as chromatin. In the cellular Algæ we pass, by finely graduated transitions, from organisms reduced to a minute sphere (Protococcus), or to a single cell (Desmidiaceæ, Diatomaceæ) to filamentous Algæ (Confervæ), Algæ spread out in undivided lamellæ (Ulva), dentated or serrated (Fucus), and others in which we can already discern a pediculate portion simulating a root, and a free, more or less cylindrical part analogous to a leaf-bearing stem (Cystocira, Macrocystis, etc.). Rudimentary leaves already begin to be characteristic of cellular terrestrial plants of the class Muscineæ, in which gradual differentiations can be traced from Hepaticæ, such as Riccia or Marchantia up to Mosses. Thus, leaves which in the higher plants are so individualized that we can say that such plants are really an assemblage of leaves arising one from the other, whose concrescent parts have formed the branches and the stem (p. Ioo), have only acquired this individuality, like the cells, as a secondary development. Just as the intimate structure of 
plants results from the multiplication of a single initial cell, the ovum, so their general form is actually achieved by the successive multiplications of leaves, beginning with two, or even one.

Bernard Renaud discovered the presence in coal-seams of monocellular Micrococci, already attacking the cellulose, as the Bacillus amylobacter does to-day. On account of their fragility the Algæ, Hepaticæ, and Mosses have rarely been preserved in a fossil state, so that the forms by which vascular Cryptogams (Horse-tails, Club-mosses, Ferns), the first plants with roots, detached themselves from the Algæ or the Mosses, is still hidden from our knowledge. From that point, however, all is clear-everything happened in conformity with the conditions indicated by the law of tachygenesis. Grand'Eury has established the formation of veritable ovules evolving into seeds in plants-Pteridosperms, which are Gymnosperms in this respect, though still Ferns so far as their leaves are concerned. The Gymnosperms (Cordaiteæ, Conifers, Gnetacex, Cycads) associated with the vascular Cryptogams are the only terrestrial vegetable forms of the Primary and the Triassic Periods. In the Jurassic certain questionable Angiosperm forms alone are known, and it is not until well into the Cretaceous that we see such plants definitely flourishing. While the Conifers among the Gymnosperms were multiplying vigorously, Dicotyledons were abundant, but they were chiefly represented by small-flowered plants, generally unisexual and with the flower arranged in catkins something after the style of the cones of the Conifers. These were Poplars, Willows, Birches, Myrica with male flowers often reduced to one or two stamens, Beeches, Oaks, Walnuts, Figs, Bread-fruit, Credneria, Plane-trees, Liquid-ambars, and Maples, to which were added a few flowering plants: Ivy, Dogberry-tree, Laurel, Saxifrage, etc. To these small-flowering Dicotyledons were already added a few Gamopetalous plants, such as the Viburnum and Oleander.

Next to the Dicotyledons with small unisexual flowers, the oldest plants must be those in which the flower-parts, still very numerous, have retained the helicoidal arrangement of the Conifers and in which the sepals are often transformed gradually into petals and the petals into stamens. These are the Magnoliaceæ, the Nympheaceæ, Cacti, Ranuculaceæ, Rosaceæ, 
Papaveraceæ, Berberidacex, etc. It is rather astonishing that there are not more of these plants among the fossils of the Secondary Period, but we shall find other lacunie in the Animal Kingdom that indicate quite clearly the paucity of the available evidence. From the beginning of Tertiary times, all the present-day plant-types can be traced. Their distribution, however, is different, and we have seen how important is the study of their geographical distribution to our knowledge of climate in different parts of the earth. We need not go over this again.

In the preceding pages (p. Iog) we have given our reasons for considering the Monocotyledons as being derived from Dicotyledons living in marshy soil, and which owe to their ordinary habitat in regions of this nature, their thick parallel-veined leaves, their long underground stems, or their bulbs, and the peculiar structure of their aerial stem, which resembles that of the vascular Cryptogams, whose stem is likewise often developed on the underground stems or rhizomes. Van Tieghem has established, moreover, that the Graminaceæ at least, which appeared rather late, are Dicotyledons in which one of the cotyledons has been suppressed. They must have appeared after the Dicotyledons; but it is impossible to establish the exact date of the appearance of either. In any case they became sharply differentiated only at the time when the Dicotyledons were already numerous in the Cretaceous deposits, and since the Dicotyledons probably go back as far as the Jurassic, the appearance of the Monocotyledons in the course of the Cretaceous is in no way astonishing.

Theory and fact are, therefore, in perfect agreement. Moreover, as the laws of tachygenesis apply equally well to the Animal as to the Vegetable Kingdom, we may have confidence in the inductions we are going to draw from it as regards the first of these kingdoms.

Theory demands for animals as logical an order of evolution as for plants, but their variety is much greater. The unicellular animal organisms called Protozoa, which constitute the first step in animal organization, ought to have appeared first. But we can hardly expect to find any traces of these delicate organisms, as e.g. Rhizopods, with their diffluent protoplasm incessantly changing form, either by sending out delicate ramifications that often anastomose their network into still 
finer divisions, or by contracting in such a manner as to fray out from their surface lobes of varying depths, as in the case of the Amœbæ; Infusoria of definite form, motile on account of their one, two, or more long, fine flagella, or, thanks to the waving of vibratile cilia, arranged either as a uniform fleece or along regular belts; or Sporozoa, living a parasitic life in the bodies of other organisms. Of all these generally microscopic organisms only the Rhizopods, the most delicate, have left behind any traces. Amongst them are the Foraminifera, which secrete a sort of calcareous covering that is often exceedingly elegant; and the Radiolaria, which secrete silica that is distributed throughout their substance in delicate disjointed bodies of varied form constant for each species, or is united in a kind of skeleton which often has the appearance of a ball of lace stuck all over with needles. Cayeux has found spicules of Radiolarians in the phtanites of the Algonkian strata of Lamballe (Côtes-du-Nord). As beds of lime are already found in these layers, one might imagine that skeletons of Foraminifera had been incorporated in them. But the earliest Foraminifera definitely identified date back only to the Cambrian Period, and it is worthy of note, as confirming the stability of the simplest living forms, that these are Orbuline and Globigerine, whose analogues still float on the surface of our seas to-day in considerable numbers, and when they sink to the bottom form a Globigerina ooze very much like that which resulted in our white chalk.

Ramified animals, as we have seen, are divided into three distinct series parallelly evolved, whose starting-point was from certain initial forms that can be described schematically as ovoid vase-shaped organisms fixed at the base and differing among themselves in the make-up of their walls, ${ }^{1}$ and which we propose to call Spongomerids, Hydromerids, and Bryomerids.

Embryogeny alone could have told us how a Spongemerid becomes transformed into a Sponge; but unfortunately the Hexactinellidæ, the sponges that go furthest back into remote times, are not sufficiently well known from this point of view, though their life-history would be particularly instructive. The most beautiful of the Sponges, they have continued through 
all the geological periods and are still plentiful in the depths of the Atlantic and in the less profound regions of the Phillipine and Japanese waters where they attain a considerable size. The exactly rectangular arrangement of the six branches of the large spicules, constituting the essential part of the skeleton, gives it the appearance of elegant opaline lace. They are generally vase-shaped, with the upper opening protected by a kind of operculum formed of siliceous tissue with delicate meshes. Within the fugitive living tissue enveloping the skeleton are regularly arranged delicate thimble-shaped sacs whose walls are covered with large cells each bearing a vibratile flagellum arising from the bottom of a funnel. These are the active elements, the choanocytes found in all Sponges, and which so exactly reproduce the form of the remarkable Infusoria of the Choanoflagellate order that James Clarke classed Sponges as simple associations or colonies of these Infusoria. ${ }^{1}$ It is not impossible that the earliest Sponges were gradually formed by an association of this kind, in which diverse elements were afterwards differentiated. As a matter of fact, the Choanoflagellates frequently form both ramified and compact colonies, ${ }^{2}$ and one of the last has even been called Protospongia.

The ovoid sacs of the Hexactinellidæ are found also in the Hexaceratinæ, which also have six-branched spicules made of spongin, the elastic and flexible substance seen in the fibres of toilet Sponges. These sacs were the origin of the flagellate chambers of other Sponges. They are always connected with a system of tubes which bring to them the water that has been attracted by their flagella, and which then passes into the efferent cavities opening on the outside by means of large orifices, the oscula. To the Hexactinellidæ must be added, somewhat later, Sponges with calcareous spicules, belonging to the Pharetronid family, ${ }^{3}$ and then the Stony Sponges with spicules united by a siliceous glaze, the Lithistidæ, ${ }^{4}$ and finally the sponges with fundamentally fourbranched spicules (Tetractinellidæ) or with spicules in the form of a pin (Monactinellidæ). From the last are derived fibrous sponges without spicules, employed for domestic purposes. But the organization of Sponges has remained

\section{LXIV.}

2 Salpingaca, Codosiga, Codonocladium, etc.

${ }^{3}$ From the Trias onward. ${ }^{4}$ In the Jurassic. 
fundamentally the same from the very beginning; it has been modified only in the details of its canalization.

At this point we are confronted with problematical organisms, Oldhamia, not found later than the Cambrian; the Graptolites, innumerable in the Silurian Period, but extinguished in the Devonian in the ramified forms called Dictyonema; Pleurodictyum, confined to the Devonian, and many others that have been attributed somewhat hazardously to the Hydromedusæ, to Corals, or to Bryozoa.

The fossil Oldhamia are fine ramified imprints radiating from a centre (Oldhamia radiata), or diverging from the top of a broken line (Oldhamia antiqua). They have been classed both as Algæ and as Hydroids, and it has even been thought that they simply represent the trail of Worms. The fossil known as Oldhamia radiata, according to this notion, came from a tubicolous Worm living in the mud, which must have placed the anterior part of its body in turn all round its hole. And Oldhamia antiqua marked the track of the Worm which, as it crawled over the mud, must have frequently changed its direction, hesitating at each change and inclining the anterior part of its body at different angles before deciding on its new path. These changes of route would occur at such regular intervals on this hypothesis as to be quite astonishing. We know, too, the tracks of Annelids, in the Cambrian, at first taken for Algæ, and called Eophyton; they were broad and strictly rectilinear. Apart from their radiated form, not a single character justifies us in interpreting Oldhamia as Hydroids, and it is difficult to see in them merely ripples on the surface of the Cambrian mud-another explanation proposed. In short, there is no really plausible hypothesis which we can adopt.

The Graptolites lasted much longer; they lived through two geologic periods and in such great numbers that they have ornamented the entire surface of certain slates. They consist of minute chambers with narrow openings" arranged in close formation in a single plane extending the whole length of a hollow stem. These chambers may appear on one side of the stem only (Monograptus), or on both (Diplograptus, Phyllograptus, Climacograptus); the stem may be rectilinear as in the preceding genera, curved in the forms of hooks (Rastrites), double and branched in the form of a printer's 
"bracket" (Didymograptus), in three (Cyrtograptus), or four (Tetragraptus), or in a large number of radiating branches (Dichograptus), curved in the shape of an " $\mathrm{S}$ " and bearing branches along its whole length (Canograptus), twisted in the form of a helix (Monogruptus turriculatus), or, finally, arranged in the form of a net (Dictyonema). The general view is that these are all hydroid polyps. Allmann, however, pointed out that the opening of the chambers was too small to allow a polyp with tentacles to pass through, and he also called attention to the fact that in the Plumularice there are two kinds of chambers, one large, inhabited by polyps, the other smaller, sheltering only fishing filaments, the dactylomerids, which can emit protoplasmic filaments from their surface, capable of capturing prey and digesting them, and consequently of feeding themselves. He noticed also that at first the colonies of the Plumularias were formed exclusively of these small chambers with their fishing filaments, and he was therefore fully justified in considering the Graptolites as Hydroids which had persisted in this state although adult. An important discovery made by R. Ruedemann, however, has altered the whole question. It was formerly believed that the stems so abundantly found in the Silurian schists were free, and they were classified in as many different species as forms discovered. In reality stems presenting very different characters were attached to a soft body formed generally of a kind of central globe surrounded by a crown of smaller globes between or under which the stems with their chambers were attached. This body has been regarded as a mere floating organ, but this would greatly diminish the importance of so large an organ, which would seem moreover to have been provided with a mouth. It seems more likely that this was the real organism comparable in structure to a Medusa or Cydippe, which both have long tentacles, and that the stems with their chambers are really, as Allmann thought, fishing filaments, nematophores or dactyomerids invested with a rigid coating instead of being free and flexible. How were the helicoidal Graptolites, whose axes are connected by an intermediary network, attached to the central organism? That question has not been answered.

The study of existing hydroid polyps is very instructive. We have already seen how they gave rise to the large bell-shaped 
Medusæ, which were bordered at their opening by a membranous ring or velum, and how by embryogenetic acceleration they gave rise to the large Medusæ, umbrella-shaped, without this velum-Pelagia, Rhizostomata, etc. All these Medusæ have four planes of symmetry, and we can connect with them certain internal impressions with the same kind of symmetry, called Medisites and Laotira, found in the Cambrian. The relationship of Brooksella with the Medusæ is less evident.

However, the hydroid polyps possess another interest for us.

It was formerly believed that all calcareous polyparies were made by organisms similar to those that build up the coral branches. Only two groups were recognized. The polyparies, formed of tubes divided into storeys by horizontal plates - the tabulate polyparies-and the drugose polyparies, so called because of their coarser appearance. During the famous voyage of the Challenger, a member of the expedition named Moseley showed that among the smooth group there were polyparies whose bases were constructed by organisms called Alcyonarians, ${ }^{1}$ akin to the coral-builders, but that the others, as Dana and Louis Agassiz liad recognized, were the work of Polyps of the Hydroid group. I myself have shown ${ }^{2}$ how the series of Hydroids with smooth, calcareous tabulate branches, which Moseley classed together as Hydrocorallia, and which comprises Spinipora, Millepora, Allopora, Stylaster, Cryptohelia, etc., leads directly through special groups analogous to those that have produced the Medusæ, to the present-day Polyps which build reefs, and to the ordinary Sea-anemones, thus forming together the order of Hexacorallia; and I have pointed out how the embryogenetical researches of Lacaze Duthiers on these Polyps, and those of Marion on the Alcyonarians, force us to the conclusion that, in spite of their eight tentacles, the Alcyonarians were only Hexacorallia modified by embryogenetic acceleration. Now the Hexacorallia did not make their appearance before the Triassic of the Secondary Period, so that it is not very likely that Heliolites and Plasmopora of the Silurian, and Cladochonus and Syringopora of the Carboniferous, could have been Alcyonarians. They are far more likely to have represented special types of hydrocorallines, 
and the same can be said of the other forms included by various writers among the Tabulata. ${ }^{1}$ On the other hand, the Hexacorallia are noted for the definiteness of the chambers of their polypary and the regular arrangement into radiate systems of the septa dividing them, and all these characters can be logically deduced from the theory classing them with Hydrocorallia.

Nothing like this is found among the Tetracorallia of the Primary Period which have septa and chambers of a very rudimentary character. Some fixed Medusæ exist, e.g. the Lucernarians and others, and the large Medusæ constituting the Acelephæ class, also begin here in the form of fixed Scyphistoma. Since certain Hydractinias, and all the Hydrocorallia, which are real hydroid polyps, secrete lime abundantly, there is nothing improbable in the assumption that organisms comparable with Lucernaria and the Scyphistoma were able to do the same, and we should therefore regard as kindred animals the Tetracorallia which constructed around the continents of the Devonian and Carboniferous ages the vast coral reefs which afterwards became marble. Theoretically, these Tetracorallia should have appeared before the Hexacorallia.

Pleurodictyum problematicum of the Devonian Epoch, which looks like a deep funnel, with walls formed of elliptical particles united by transverse twigs, at the bottom of which is found a kind of a Serpula bent back upon itself, more nearly resembles a Bryozoan like the Adeona of the present day, which is likewise funnel-shaped, than a hydroid. It would, however, be imprudent to go too fast when certain forms intermediate between the Hydrocorallia and the Bryozoa are under discussion. The latter are easily recognized from the Silurian onwards. They have persisted in large numbers up to the present day without ever playing an important part, or showing the least tendency towards a higher evolution. We shall therefore pass them over like the Sponges.

We now come to the Artiozoa, which began simultaneously in two kinds of segmented animal organisms, the Arthropods, which have preserved their primitive structure almost intact, and have not attained a high development, and the Worms, which are also segmented but display great plasticity. WVe

1 Favosites, Alveolites, Trachypora, Aulopora of the Devonian: Chatetes, Michelinia of the Carboniferous. 
have previously enumerated their various metamorphoses, and presaged their great future.

The evolution of the Arthropods can be outlined very simply. We have already called attention to Peripatus, that ambiguous creature tossed from Worms back to Arthropods, which even to-day still appears to be distributed along the edge of the old Gondwana continent. All the segments of its body are alike, except three: the first, bearing the tactile appendages comparable to antennæ; the second, bearing the mouth; and the third a pair of appendages directed towards the mouth, and provided with claws that serve as mandibles, incorporated with the cephalic region through the formation of a kind of lip rising behind them and united to the corners of the mouth, thus enclosing them in a kind of buccal cavity. Similarly among the Arthropods, the locomotor appendages are successively put to the use of mastication in varying numbers and different ways. The first stages in this adaptation are still unknown, but the Algonkian, which has already revealed so many traces of the Arthropods, may perhaps some day give us the desired information.

In the Cambrian Period we find ourselves in the presence of fairly advanced adaptations. In one group the five (Eurypteridæ) or six first feet (Limulus) differ but little from the locomotor appendages, or, at times, even preserve this character, but they surround the mouth and from the base arises a laminated process which assists in mastication. The first pair in Pterygotus resembled pincers, and this creature during the Devonian Period acquired a length of two and a half metres. ${ }^{1}$ This first pair resembled the appendages of Eurypterus, and in both these genera the fifth pair, very large and flattened, have become a swimming organ. In Limulus, which already existed in Silurian times, and to-day are to be found in Mouccan and Japanese waters and along the two sides of the Isthmus of Panama, the first five pairs of legs terminate as pincers, the first being smaller than the others, and the extremity of the last pair is furnished with complicated appendages that, however, hardly modify their appearance. All the segments provided with appendages are united in a large cuirass bearing the eyes, which, strictly speaking, might be considered as a kind 
of head. These organisms are grouped together under the name Merostomata, signifying that the limbs encircle the mouth. It is worthy of note that in this group, so homogeneous in appearance, Eurypterus and Pterygotus lasted but a short while, whereas Limulus has persisted almost unchanged throughout twenty million years.

Side by side with these organisms lived the Trilobites, in which the first pair of appendages had already been transformed into antennie, while the five other pairs preserved the regular structure of the Merostomata, from which there is no reason to separate them. Arising from the abdominal articulations were very small feet surmounted by branchiæ, so fragile and delicate that for a long time they remained unobserved. It is puzzling to see how such heavy organisms could make use of them. They lived on the sand and could no doubt descend to great depths, for some species are blind. Others, on the contrary (Aiglina), had enormous eyes. Two longitudinal grooves running along the carapace, demarcated a median area, the glabella, which they separated from the gene, or cheeks, on either side of which were placed the eyes, and these grooves extended the whole length of the abdomen, whose terminal articulations were sometimes united in a pygidium appendant to the carapace (Bronteus, Agnostus). The body was thus divided into three longitudinal belts, hence the name of Trilobite. Embryos of Trilobites have been recovered, those of the Cambrian genus Sao in particular, and it has been established that after the carapace and the last segment had been formed, the others were formed one by one in front of the terminal segment, so that the method of segment formation nowadays common to Arthropods, Annelid Worms, and Vertebrates dates back at least twenty million years. That is equivalent to saying that it has never varied, any more than the mechanical conditions which determined it.

In Primary Times the Trilobites were distributed throughout all the seas. They were especially numerous during the Silurian and Devonian Periods, but in the Carboniferous were represented only by Prœtidæ, themselves reduced to two genera, Prectus and Phillipsia, somewhat resembling the Cambrian Paradoxides, the oldest Trilobites known. Trilobites present a large variety of forms. Not only can we distinguish littoral and deep sea species, but also, as one might say, local 
species and genera, permitting the delimitation of zoological provinces even in the Cambrian Period. At that time the species and even the genera of the Northern sea inlets were distinct from those of the Tethys; and the Circum-pacific Ocean also had its own species. Sao, Conicephalus heberti and C. levyi, and Paradoxides mediterraneus were unknown along the coasts of the North Atlantic Continent, where Olemus was common. During the Acadian Period the first Asaphidx appeared in the Pacific. Thence they spread towards the waters of the future Europe, which they did not actually reach until the Ordovician Epoch. Dicellocephalus was characteristic of the region of the Circum-pacific Ocean, which extended from the western shores of America to Australia, but Olenus was absent. During the Silurian Period certain Trilobites acquired the faculty of rolling themselves up into a ball, as the Woodlouse and Glomeris do to-day. Their genera and species multiplied, but remained characteristic of distinct zones. The existence of such zones, however, does not imply a difference of climate, for the calcareous deposits did not change in character. The floating Graptolites remained cosmopolitan, and coral banks continued to form in the northern as in the equatorial regions; therefore, the temperature must have remained high everywhere. Nevertheless after the Ordovician Period the Trilobites enable us to distinguish clearly the Northern European, American, and Bohemian regions. The two first tend to become merged during the Gothlandian Period, on account of exchanges taking place between these regions, particularly between America and Europe, by way of the Arctic Ocean. In the Devonian Epoch this communication disappeared, and the American and European fauna once more became distinct. The American fauna extended from the United States to South America and the southern parts of Africa, while the European extended over the rest of the world.

The Trilobites lose all importance in the Carboniferous Period. These strange organisms approximated to Crustaceans in the possession of antennæ; but Crustaceans have two pairs and their buccal appendages have definitely become mandibles, jaws, and maxillæ. As in the Trilobites, five pairs of appendages, or six as in Limulus, if we count the peduncle of the eyes in the higher Crustaceans, are employed either as tactile organs, or for prehension and the trituration of food. 
The constant number of these appendages leads us to believe that the Crustaceans may very well be descended from the Trilobites. They must have diverged very early, however, for in the Cambrian Epoch true Crustacea cxist already, with large membranous appendages serving both for swimming and breathing, like those of our present $A$ pus, which still resembles the Trilobite in some respects, or our Branchipus, Artemia, and the Estheridæ. ${ }^{1}$ There are also Crustaceans related to Cypris, commonly known as Water Lice, and frequently used in pisciculture to feed the fry. These have received the name of Ostracods, ${ }^{2}$ because of their bivalve carapace resembling the sliell of the Lamellibranch Molluscs. These two orders were thenceforth reinforced by the appearance of new genera, which in some cases displaced the older genera and in others lived alongside them. From the Silurian Period onwards the Ostracods were replaced by the Cirripedes, represented to-day by Balanidæe or acorn-shells, shaped like sharp-edged truncated pyramids, with which the rocks bristle at low-tide, and Barnacles which suspend themselves by long periuncles to floating wood or to the keels of ships. For a long time there was considerable hesitation as to the place these organisms should occupy; they are born in nauplius form (p. I24), a character common to all lower Crustaceans, and are later transformed by the acquisition of a bivalve shell and six pairs of bifurcated abdominal legs, into little organisms so closely resembling Ostracods that they have been called cypridian larvæ. This stage implies a relationship not with the present Ostracods, but with some still unknown preCambrian Ostracod. The cypridian larva attaches itself, by means of a sucker in its antennæ, to some solid submerged body, and it is only then, while undergoing an important change in attitude, that it finally acquires the characters of a Cirripede.

Myriapods ${ }^{3}$ and Insects have also been discovered in the Silurian strata. This is important. We have seen that Myriapods are derived from the early entomostracan Crustaceans, and Insects from the higher Crustaceans, or Malacostraca. Hence the existence of Myriapods and Insects

1 Hymnenocaris, Protocaris.

2 Isoxys, Leperdilia, Primilia.

3 Archidesmus. 
in the Silurian presupposes the existence at some earlier epoch, either the Lower Silurian or the Cambrian, of Crustaceans belonging to these two orders. They have not been found. Yet such gaps occur in all groups; indeed, a group sometimes appears to flourish in one epoch and then to vanish, only to reappear later on in very much the same forms, and occasionally to persist even till the present day. It is evident that these disappearances and reappearances are only apparent. When they are not merely the result of our own imperfect investigations they simply hide from us migrations that have taken place owing to some alteration either in the composition of the water, its depth, the nature of the deposits at the bottom, or the direction of the currents, and so forth. Such phenomena are neither uncommon nor in any way mysterious. Only a few years ago a series of hard winters in the bay of Saint-Vaastla-Hougue, rendered famous by the researches of Henri Milne-Edwards, de Quatrefages, Claparède, Grube, and many others, caused the disappearance of the Comatulids and Asterina, which lived there in great numbers, and brought in exchange various northern species, hitherto unknown in these latitudes. The old fauna has not even yet been restored. This represents on a small scale what often happened during the great geological periods.

Why did the Trilobites disappear? We saw that the existence of Myriapods and Insects at the close of the Primary implied the presence in the seas of that epoch of higher Crustaceans whose fossil remains do not become numerous till we get into the Secondary. With their very complete buccal armature, their stout appendages, adapted in some cases to walking and in others to swimming, these creatures should have been able to supplant the Trilobites easily, either by preying upon them or simply by competing with them for food. In Victor Hugo's words, "Ceci devait tuer cela." 1 Thus the mere demonstration of the existence of a group of animals at some definite epoch can be extraordinarily suggestive.

Significant facts of this kind are not lacking. Two genera of Scorpions have been found in the Silurian (p. I6g). This is not at all surprising, since Scorpions are very closely related 
to the primitive Merostomata and especially to Limulus. But Scorpions are essentially carnivorous and confine their depredations to other terrestrial Arthropods. It is certain, therefore, that other terrestrial Arthropods cxisted during the Silurian Epoch, and this is confirmed by the discovery of the wing of a bug, ${ }^{1}$ in these same layers. Bugs are Insects already far removed from primitive forms. 'Though their metamorphoses are still reduced to the appearance of wings, the mouth-parts are highly modified; the mandibles and maxillæ have been elongated into pointed probes and the inferior labium has become a case in which these stylets are enclosed. A very long time must have elapsed for these primitive parts that still retained notable features of their early condition as legs, to be modified to this extent, and during this period Insects with powerful mandibles-Neuroptera and Orthoptera, at least-must have multiplied greatly. We know but few examples of them, and this is due to the fact that very little of the continental formations of the Silurian period has come down to us.

It is not absolutely impossible that Insects should have existed already in Cambrian times; nevertheless, their class seems to have made little progress during the Devonian, for we still find only Neuroptera and Hemiptera. It is not until the Carboniferous that we see a real blossoming of this class. A luxuriant vegetation of Club-mosses, Horse-tails, Ferns, Conifers, Cycads, and Cordaites then clothed the land. Some Club-mosses and Horse-tails attained the dignity of trees, possibly equal in size to our most beautiful Conifers. The atmosphere was hot without the heat being excessive; the temperature was high but uniform, and the sunlight filtered through a humid and misty atmosphere-a phase through which the planet Venus is probably passing at present. These are conditions thoroughly favourable for Insects, which were then represented chiefly by Neuroptera such as the Ephemeridæ, Dragon-flies, and Perlidæ, or by Orthoptera such as Phasmidæ, Cockroaches, Locusts even, or again by Hemiptera ${ }^{2}$ related to our large Fulgoridæ, Cicadas, and Bugs. The clear differentiation of orders with which we recognize to-day had not yet been achieved. Transitional forms, notably between the

1 Protocimex siluricus.

2 Dictyocicada, Eugereon, Fulgorina, Mecynostoma, Phtanocoris. 
Neuroptera and Orthoptera, existed; for instance, Protophasma dumasi had the body of Phasma and the four large flat wings of the Neuroptera, whereas Phasmas to-day are wingless or have very small anterior wings and posterior wings folded fan-wise. This last character, which is nowadays common to all Orthoptera, was lacking in their ancestors, whose posterior wings, scarcely larger than the anterior, remained flat when at rest. Finally, in certain forms traces have been recognized, or claimed as recognizable, of a pair of wings on the prothorax, which is innocent of wings in present-day forms. This confirms the opinion previously expressed that the wings were at first epipodites, or dependences of the legs, since each of the segments provided with legs could also be provided with wings. But the most astonishing thing about the Insects of the Carboniferous Period, which have been studied so carefully by Charles Brongniart, is the size to which they attained. Titanophasma fayoli achieved a length of twenty-eight centimetres; certain Dragon-flies had a wing-span of seventy centimetres, and the wings of a species of Ephemeridæ of the genus Meganeura measure no less than thirty-three centimetres in length. This great size was a characteristic no doubt of certain species only, though very large Phasmids, Cyphocrana, for instance, and very large Scarabs, Dynastes and Goliath, still live in hot countries. But the fact merits no less attention on that account. To-day the life of Insects is short ; it hardly exceeds a year except for those larvæ which live sheltered under the ground like those of the Cockchafer or Cicada, or in tree-trunks like those of the Stag-beetle and large Capricorn-beetle, or in waters that do not freeze, like those of our large Dragon-flies. These larvæ live three or four years. There is an instance of a Cicada in the United States ${ }^{1}$ which will live underground for as many as seventeen years. It is so largely a question of shelter that longevity increases considerably in adult Insects living in social groups, and having arrived at the building of common homes, such as Termites, social Wasps, Bees, and Ants. This leads us to conclude that brevity of life in Insects has been caused by the annual variations of temperature, which brought periodically excessive cold in winter or excessive rains in summer. These 
variations did not exist in the Primary times. They only began to be clearly marked, and even then in moderate fashion, in the Polar regions, towards the close of the Secondary; hence there is no reason why the longevity of the larvæ and adult Insects of that time should not have been much greater than it is to-day and have permitted them to attain a greater size.

Insects to-day grow only during their larval stage during which they shed their skins three or four times, corresponding to as many epoclis of sudden growth. At the end of this stage they shed their skins yet once more. Immediately after this last sloughing, short, oval sheatlıs, the rudiments of the wings, are seen attached to their meso- and metathorax. After this sloughing they either preserve their activity, as in the case of the Neuroptera, Orthoptera, and Hemiptera, the only orders represented in Primary times, or lose the power of moving their cephalic and thoracic appendages, as in the case of the more recent Coleoptera, Hymenoptera, Lepidoptera, and Diptera. The first group undergoes an incomplete metamorphosis, and the form of the body is fixed from birth ; the second has a complete metamorphosis, and the larvæ vary according to the mode of life. They may be agile and slender, plump, ${ }^{1}$ and provided with thoracic legs only, ${ }^{2}$ or provided with thoracic legs and false abdominal ones ${ }^{3}$; without legs, ${ }^{4}$ or without legs and without a differentiated head. ${ }^{5}$ The different phases of their existence are not always so clearly distinguished as this would indicate. In the aquatic larvæ of the Ephemeridæ, which carry on the back of each abdominal articulation a pair of scales singularly like rudimentary wings, the first signs of wings appear after the first or second, and grow larger with each successive moult. It is the same with the Termites, which are, morphologically, inferior Insects. Hence we may conclude not only that primitive Insects had no sudden metamorphoses, but that the growth of their wings was distributed through the various phases of their life, and that their evolution was continuous like that of other animal organisms. The winged Insects of the present day do not grow any further, but lay their eggs

1 Campodeiform larvæ.

${ }^{3}$ Eruciform larvæ or Caterpillars.

s Acephalate larvæ.
2 Melolonthoid larvæ.

4 Helminthoid larvæ. 
and die; but our Ephemeridæ, which inherited the earliest forms achieved, after having attained their permanent form, do not fly away until they have freed themselves of a light envelope, which actually constitutes a final moult. IVe may therefore ask whether the primitive Insects, arrived at their adult form, were not still capable of growth and moulting. In that case we must grant either that the wings were still formed of living cells-whereas there is no living substance in the wings of our present insects except in the muscles attached to the base in order to move them-or else that the wings fell off spontaneously, as is the case with Termites, where their falling is prepared in advance by the formation of a ruptureline at their base, but that they could be subsequently reformed at each reproductive period. This would bring the Insects thoroughly into line with the general rule. Is it not singular that they should have only a few weeks to live after they have attained maturity? Many other animal organisms-the lowly Worms, ${ }^{1}$ Fishes, ${ }^{2}$ and many Birds-display brilliant colours or splendid ornaments during the mating season. Sometimes the eyes enlarge, the organs of locomotion are perfected, the creature becomes more agile, and all the distinguishing marks of this season constitute their bridal apparel. It is just in characters of this kind that the adult Insects differ from their larvæ. Is not the definitive stage just the mating apparel that the insect of to-day only puts on once, but which their ancestors displayed at each period of reproduction? We are justified in asking this question since the larger Crustaceans can reproduce themselves several times. The duration of life in an adult Insect can be prolonged, moreover, if certain precautions be taken. Labitte has kept the beetle, Blaps, alive for more than eight years.

We need say little of the Worms which have left evident traces (Nereites, Arenicolites, Scolithus, etc.) in the tracks of their bodies imprinted on sand, or mud, in the holes where they lived, or else material remains such as mandibles. Among these there are still Eunicidæ and Amphinomæ, which attain a great size, as much as two metres in length and four centimetres in width. It is also possible that the

1 Syllids (Autolytus, Myrianis, etc.), Nereids (Neveis cultrifera), Phyllodocids, Cirratulids.

2 Macropods of China, Sticklebacks, Minnows. 
passage of large Worms may be responsible for tracks such as those that have been grouped as Bilobites, and that have been attributed occasionally to Trilobites. To the Worms nust be linked other animal organisms, the Brachiopods, which were long taken for Molluscs, but are still isolated. Morse has given a very interesting explanation of these organisms, which has inspired his theory of cephalization. He draws attention to the fact that in the majority of segmented organisms the part nearest the mouth undergoes greater development proportionately than the posterior region, which tends to diminish and disappear. Among the Nerostomata and Trilobites, the body ends in a point; that of the Scorpions has shrunk to a post-abdomen bearing the poison-sting. In the majority of the Batrachians, Reptiles, and Mammals, the viscera are so much concentrated in the anterior or at least medial region that the posterior part of the body becomes a tail behind the anus, which tail is sometimes used for prehension, but may disappear altogether when not used. This phenomenon is easily explained on Lamarck's principle. In the anterior region of the body are assembled together not only the mouth but the sense organs. This portion initiates the movements which drag the rest of the body, and the posterior region can but follow. The anterior region therefore is generally the active region par excellence, and the one which, according to the principle we have just invoked, ought to attain the maximum development, while the inactive part is atrophied. That is the reason why the number of body segments in the Arthropods and the higher Worms tends to be reduced to a fixed, indispensable minimum. If, however, the posterior region of the body does become active, after this reduction has taken place, the segments will not increase in number, but they will be very large. The higher Crustaceans which swim, like Squilla or the Crayfish, by striking the water with a suddenly flexed abdomen, have this part powerfully developed, while in the Crabs, essentially walking creatures, the abdomen is atrophied. In the same way Fishes, Cetaceans and Sirenians, which swim by striking the water laterally with their tail, possess broad tails. The marine tubicolous Worms, which bury themselves in the mud, live under conditions which favour the marked development of the anterior part of their body at the expense of the posterior 
region, which is deprived of all contact with the exterior environment. Hence their heads developed those voluminous plumes covered with vibratile cilia which by their movements draw towards the organisms both food particles and water charged with oxygenated air. On account of these plumes, Lamarck called all these worms Cephalobranchs.

Brachiopods enclosed between the two valves of their shell obtain food in exactly the same way. Their mouth lies between two respiratory plumes that are either twisted spirally ${ }^{1}$ or like a screw ${ }^{2}$ or variously convoluted before being rolled. It is to these plumes that the Brachiopods, now under consideration, owe their name. In studying the embryogeny of the Lingulæ, which existed already in the Cambrian Epoch, and have scarcely been modified since that distant period, Morse was struck by the resemblance between these young organisms and Serpula. The two valves of the shell develop in a region of the organism's body corresponding to the collar of Serpula. He was thus led to consider the Brachiopods as cephalized Annelids. Embryogeny, moreover, leaves no doubt but that these organisms are derived from Annelid Worms with a reduced number of segments. Their resemblance to bivalve Molluscs is entirely superficial. The valves of their shell are dorsal and ventral, instead of left and right, like those of the Molluscs, and their texture is totally different. Their internal structure has nothing in common with that of Molluscs. On the other hand, the Brachiopod clearly approximates in internal structure to one or two segments (Rhynchonella) of the Annelid Worm that have become individualized.

This said, we can distinguish two main types of Brachiopods : Firstly, the Inarticulata, in which the valves of the shell, with their somewhat horny consistency, are independent of each other; secondly, the Avticulata, in which the two strongly calcified valves are united with each other by a real hinge. It is muscles that open the shell, and not a mere ligament which springs back as in the bivalvular Molluscs or Lamellibranchs. Furthermore, the shell of a dead Brachiopod is obstinately closed, whereas that of a Lamellibranch gapes. The Lingulæ live in the sand, where they bury their long, mobile peduncle, which represents, according to Morse, the

1 Terebratulidæ.

2 Rhynchcnellidæ such as Spirifer, etc. 
body of the primitive Annelid. Articulate Brachiopods attach themselves permanently to the rocks by the extremity of this peduncle, and indeed a very large number of both nonarticulate and articulate species glue themselves to the rocks by means of one of their valves. The Inarticulate Brachiopods have a complete digestive tube open at both ends. In the Rhynchonellidx, of which there are living specimens as of Lingulidx, the body is apparently composed of two body-segments, and ends in a cœcum. Among other articulated Brachiopods, the digestive apparatus is reduced to a sac which is prolonged as a thin filament directed toward the hinge. According to the theory of cephalization, these arrangements would clearly indicate an organism undergoing reduction.

It may be asked how creatures so simply organized, and destined for a life of immobility, were able to multiply as they did during the Primary Period, and become so abundant and varied that they furnish geologists with precise stratigraphic evidence. The non-articulated group is dominant in the Cambrian, and is there associated with the Strophomenidæ and the Pentameridæ, but after the Silurian numerous families, including the Rhynchonellidæ, are added to the former group, and the latter undoubtedly also existed in the Cambrian. Among the new forms we must cite Productus, with a much rounded lower valve, which during the Carboniferous Period attained one decimetre in diameter. The families, gencra and species, continue to multiply during the Devonian Period, and it is then that the Terebratulidæ, which still inhabit our present waters, make their appearance. The Carboniferous, in turn, is even richer, and it is only during the course of the Secondary Period that the decline begins and continues to become more pronounced down to the present dlay, when the Brachiopods play an insignificant part. They could not have prospered so well during the Primary Period unless the plankton, their only possible source of food, had then offered abundant supplies for which there was little competition. The Primary, therefore, must have been the epoch of microscopic floating Algr, Protozoa, and minute embryos.

This abundance of the plankton in the seas was equally necessary for the evolution of the Crinoids, all of which are fixed Echinoderms, living entirely on the small particles directed 
to their mouths by the currents set up by the vibratile cilia on their branchial groove. Theory indicates that this branch must have begun with more or less spheroidal forms, derived from some short worm rolled up in such a manner as to describe a complete corkscrew turn. The Cystids, limited to Primary times, seem to correspond to this earliest phase in the evolution of the Echinoderms. We have seen how embryogeny thereafter yields an initial radiate form, originally without arms, from which it is easy to derive all the other classes. The Cystids antedate the embryonic form in question; they seem to have been affected by all manner of external influences, from which they were unable to escape, owing to their fixed position. This fixation has brought with it changes in form that were calculated to render the initial type unrecognizable. These varied both according to the age at which the embryo became fixed and to the conditions of fixation. An average embryo is generally fixed by means of its anterior extremity; but these particular embryos were weighed down by the lime in their tissues and sank upon the ground, to which, therefore, they could attach any part of their body whatsoever. Once this fixation was accomplished, the embryo must have effected a rotational metamorphosis, like all fixed embryos, with the object of placing mouth and anus as far as possible from the point of fixation. This metamorphosis was achieved by the Cirripedes among Arthropods and by the Crinoids among existing Echinoderms, as well as by the Tunicates, and it completely altered the shape of their bodies. The Cystids evidently underwent this rotation, since mouth, anus, and genital orifice are usually grouped together at the opposite pole to the point of fixation. Such a change could not have occurred without profoundly altering the initial type, and this, no doubt, is the reason why these organisms appear to be so aberrant. How they obtained their food, fixed as they were with scarcely any mechanism for directing alimentary or respiratory currents to their mouths, remains a problem, in spite of the richness of the surrounding waters in plankton. It may be that their digestive tubes were highly ciliated or that they fell back on a symbiosis with green Algæ.

From the Silurian onwards other classes of Echinoderms are already cliaracterized, and represented by numerous 
individuals; these primary forms, however, were very unlike those of the present day and sometimes not so clearly differentiated. For instance, there were Star-fish with the madreporic plate situated on the ventral side of the body, as in the Ophiuroids. In the Sea-urchins, the ambulacral areas were very narrow and furnished with enormous spines, as they still are in our present Sea-urchins known as Cidaris; these areas were sometimes almost linear and sinuous. The inter-ambulacral plates were numerous and arranged in mosaic, ${ }^{1}$ instead of merely forming two alternate rows in each radial area. Nevertheless true Cidaris appear in the Carboniferous and even Diademæ with their long spikes, hollow and fragile, similar to those of the Mediterranean species, which have their ambulacral areas already broadened, and bearing ambulacral pores arranged in groups of three pairs. The Crinoids have comparatively short arms; their calyx comprises three rings of plates; five radial, bearing the arms; five lasal, placed below and alternating with the latter; and sub-basal plates, occasionally but three in number, connecting the ring of basals with the stem. The last of these rings of plates and often the penultimate ring are absent in existing Crinoids. Such are the salient characters of the early Echinoiderm fauna.

We sketched on page I35 the probable descent of the Molluscs. The Gasteropods and the Cephalopods may have evolved simultaneously. The first preserved a broad ventral sole, probably provided with lateral lobes utilized for swimming; in the second the ventral sole diminished until it was reduced to the region around the mouth. Both must originally have had straight shells, which later on developed a spiral form in the swimming species and a corkscrew form among the Gasteropods which had reverted to the crawling habit. Palæontology confirms these deductions, which in turn throw light on certain palæontological problems. If the Gasteropods were really descended from the Chitons, and if their shell was derived from the dorsal plates of the latter, the shell of the oldest forms should be formed of triangular plates juxtaposed from top to bottom. The shell of the Comularia fulfils this condition. That of the subsequent forms ought

1 Melonites, Lepidocentrus, Cystocidaris, Bothriocidaris. 
to be continuous but straight. This decides the place that Hyolites and Tentaculites should occupy, which, if this deduction is not followed, are sometimes classified among the Annelid Worms. The phase of spiral formation is represented by Bellerophon. All these forms are Cambrian, and with them we must include the helicoidal forms of the Diotocardiac Gastropods, whose primitive characters we have already described, as well as Eumphalus, and the Pleurotomarice. These last persist to the present day in the deep-sea fauna. From the Silurian onwards may be added such forms as Trochus, also diotocardiac, Patella, transitional forms representing the first Monocardiacs with shells entirely open, 1 the carnivorous Purple-Fish, whose shell is channelled at the opening in order to permit the passage of a siphon destined to bring the water into the branchial cavity. The Turbos, differing from Trochus in the thickness of its calcareous operculum, and Capulus with its small, hood-shaped, scarcely pointed shell, appear in the Devonian. The Carboniferous witnesses the arrival of the "Worm-shell", which attaches its shell to foreign bodies, and the first true Snails and other pulmonata Gasteropod, such as the Pupæ. Seeing that the lake deposits and river drift of the Carboniferous are so incomparably better known than those of the preceding periods, it is conceivable that the pulmonate type had been achieved much earlier.

The straight-shelled Cephalopods are represented by the Orthoceratidæ. The Cephalopods retained their swimming habits, and when their shell became rolled it simply formed a spiral and remained symmetrical. Both types, at the latest, existed in the Silurian. It was not until the Cretaceous that certain Ammonites, which probably became crawling organisms for reasons we have already given (p. I37), acquired the helicoidal form, and thus constituted the Turrilite family. The straight-shelled and related forms enable us, moreover, to divine the causes that determined the special characters of Cephalopod shells. These shells are divided internally into successive chambers by calcareous septa, concave near the shell orifice, and either attached to its walls in a gradual manner so as to preserve their curvature-a characteristic of the most ancient forms, constituting the group of Nautilidæ

1 Littorinidæ, Scalaridæ, Pyramidellidæ. 
or else folded in such a way that the line of junction of the septum and the shell forms a line broken only at its point of origin, ${ }^{1}$ or a wavy line whose curves increase in number and consequently decrease in size-the lines traced thus becoming more and more complicated as the Jurassic period advances; these complicated lines of junction are characteristic of Ammonites. The septa are traversed throughout by a tube, the siphuncle, which among the still existing Nautilidx, congregating in large numbers below the surface of our warm seas, becomes attached to the top of the shell which is perforated there by a slit; whereas in the inner shell of the Spirulidæ, partitioned like that of the Ammonites but with smooth walls like those of the Nautilidx, the siphuncle goes through the last partition and terminates in a small ovoid sac, the ovisac, which is attached to the top of the shell by a ligament, the prosiphon.

From the head of the Nautilus spread a number of discs, bearing very mobile vermiform tentacles that give these organisms a most characteristic appearance; they have four branchiæ. The head of Spirula, on the contrary, is formed like that of the Calamary and the Cuttle fish; and has only two branchiæ. Munier-Chalmas, who discovered these differences between the terminations of the siphons among these creatures, has shown that Spirula resembles the Ammonites in this respect. From this he concluded that the latter, like the Spirulæ, were dibranchiate Molluscs with ten tentacles to their heads, whereas the large Cephalopods with smooth septa should be grouped with the Nautilus.

The Cephalopods, with straight and partitioned shells, of Primary times have, however, a much larger siphuncle than the true Nautilidæ (Orthoceras). It is sometimes lateral (Cyrtoceras), sometimes central, and the septa themselves may be lateral (Ascoceras). We must conclude, therefore, that the siphuncle was at first an integral part of the body, and that in Orthoceres, whose straight shell can exceed two metres in length, it is nothing but the integument of the upper portion of the body, originally fixed to the shell but detached on account of the weight of the latter, since the animal, as has been said, swims with its ventral side uppermost.

1 Goniatites, with siphon near the convex wall of the shell. Clymenia with siphon on the opposite wall. 
It must have been a sort of a tail whose formation would be mechanically conditioned by the weight of the shell hanging in the water. Once formed, this siphuncle would be hereditarily preserved in the later spiral forms. This implies that the part of the Mollusc's body containing the viscera mounts up within the shell step by step as it grows, and secretes behind it, at each stage, a partition isolating it from the empty part of the shell. The siphuncle remains pressed against the outer wall of the shell in the Goniatites ; it is internal in the Clymeniæ, a group which lasted but a short time. The same theory that accounts for the origin of the Cephalopod Molluscs finds a natural extension here. We shall probably never know exactly how Orthoceras was formed, but it is impossible to doubt its genealogical relationship with the other shelled Cephalopods.

From the Silurian Period the septa begin to become sinuous in Goniatites of the genera Anarcestes and Agoniatites. These continue to grow more complicated, each series being characterized by the relative proportions of height. width, and length of the chambers, particularly of the last, which is necessarily moulded upon the body of the mollusc. Von Mosjisowicz, En. Kayser, Fr. Frich, Émile Haug, etc., have been able to follow the gradual evolution of the diverse series of Ammonites, thus contributing important evidence to demonstrate the theory of evolution.

From the general point of view, at this stage, there is little to be said about the Lamellibranch Molluscs. They began in the Lower Cambrian, which indicates that the symmetrical Diotocardiac Gasteropods, which evolved into Bellerophon, must have already existed during the Pre-Cambrian Period. Not until the Silurian, however, do their species become sufficiently numerous to enable us to follow the successive stages of their evolution. As theory indicates, the oldest forms have a long hinge with a very simple articulation; these form the group of "Palæochonchæ". ${ }^{1}$ Then come the genera in which the very long hinge has numerous small close-set teeth, Cucullella, Leda, etc. ; and, following them, species which suspend themselves by a byssus, and whose shell becomes broadened near the base on account of its own weight, of which the muscles

1 Cardiola, Conocardium, Dualina, Lunulocardium, Pracardium, Slava, Vlasta, etc. 
are consequently unequal : these are the Aviculida from which the Monomyaria are derived, forms with a single valveretractor muscle, represented in the Devonian by the Pectens. By the side of these are found Lamellibranchs of the normal type: Anodontopsis, Paracyclus, Amita, etc., reminiscent, to a certain extent, of the forms found in our fresh waters.

Vertebrates have not yet been encountered in the Cambrian; but they are represented in the Silurian and the Devonian by Fishes, and also in the Carboniferous by Batrachians, and finally by true Reptiles. This succession would seem to indicate that we have arrived at the point when the evolution of the Vertebrates begins. We know that they must have started in a form analogous to Amphioxus. The nature of the tissues of Amphioxus does not readily lend itself to fossilization, but we have found fossilized Medusæ, whose tissues are even softer, and we must not give up all hope of also discovering fossil ancestors of the Vertebrates. After Amphioxus, the simplest Fishes-simplest because the vertebral column consists only of the embryonic dorsal chordare the Marsipobranchii, of which the Lampreys are typical. Mounting up from these, the evolution of fishes follows a logical order. In my Traité de Zoologie, Iojo3, I began their history by calling attention to the modelling they had undergone by the pressure of the surrounding water, occasioned chiefly by the sudden movements of their tails in swimming, and to the fact that the number as well as the position of their dorsal fins was due to the tearing of an originally continuous dorsal fin by the currents that were thus formed on the creature's sides. $^{1}$ Frédéric Houssay has been able to demonstrate this by interesting experiments. He showed that the first stage in the development of a fish's shape is that taken by a cylindrical linen sack filled with a soft paste, when it is drawn horizontally through water or held horizontally in a vase full of water and opposite an aperture through which the water flows out. This form is that described as "la veine inversée", because it results from the pressure exercised by runnels of water flowing swiftly into the place of the water running out. But if we can thus account for the normal shape of Fish, the explanation does not stand for the special forms they some- 
times take. These, too, however, result from the reactions of a liquid on an organism in the act of swimming, reactions which modify the branchial region in particular. From this point of view three types of Fishes can be distinguished: Marsipobranchs, Elasmobranchs, and Ctenobranchs. The Marsipobranchs are represented to-day by three genera only: the Bdellostomas, Myxines, and the Lampreys. The Elasmobranchs include numerous genera belonging to the Sharks, Rays, and Chimæroids ; the Ctenobranchs comprise all the rest. In the Marsipobranchs the branchial system consists of two almost symmetrical series of sacs placed behind the head, independent of one another, and each communicating directly or indirectly, by means of afferent and efferent ducts, with the cesophagus and the exterior respectively. A kind of cartilaginous grille supports each sac. In the Flasmobranchs these gill-sacs become flattened, unite with one another, and become indistinguishable from the ducts in such a way that each sac communicates with the cesophagus by one slit and with the exterior by another. Cartilaginous arches, from which numerous rays branch out, support the thick partitions resulting from the union of the walls of the gillsacs. In the Ctenobranchs the partitions are reduced to the supporting and now osseous arches, to the dependent rays, and to the highly vascular tissues which clothe the arch and the rays it supports, while leaving these rays completely independent. The Bdellostomas have as many as fourteen branchial sacs, and their embryos show indications of many more; the Lampreys have seven on each side and Myxine has only six, opening to the outside by a single duct. Seven branchial slits are observed also in Sharks of the genus Heptanchus; Hexanchus and Chalmydoselachus have but six, while five is the number characteristic of all the others, as well as of Rays and the Chimæroids. Finally in the Ctenobranchs there are generally four branchial arches, rarely less, and the rudiments of a fifth. This simple enumeration will suffice to show that the branchial region constantly diminishes as the type of Fish becomes more advanced.

We have pointed out (p. I30) that the cause of this shortening was the resistance offered by the water to the progression of the animal propelled forward by the movements of its tail. As is always the case, some Fishes have resisted this 
transformative action and have come down to us unchanged, whereas others have been obedient to it and have become modified. This action, moreover, has been exercised equally on the trunk, properly so called; gradually the purcly muscular and impulsive part of the body constituting the tail increased at its expense, whilst at the same time the currents it produced forced forward the pelvic fins, which were primitively situated at a distance from the pectoral, until they were placed underneath and in front of the pectoral fins and articulated with the branchial skeleton itself. This, as we have seen, is the characteristic of the swimming Fishes par excellence, the fishes of the open sea.

The Marsipobranchs must therefore be considered the oldest of all Fishes. They show no tendency to secrete lime and their skin is absolutely denuded of any solid product. However, in the buccal cavity, where it is naturally subjected to incessant friction, the epidermis of its papillæ, in Lampreys, takes on a horny consistency, and produces short pointed spines, broad-based and conical in shape, which play the part of teeth, but which are only the antecedents of teeth and are known as odontoids. The epidermis of the Elasmobranchs, on the contrary, becomes calcified all over, but in such a way that it becomes a sort of a mosaic of small thick scales, circumscribed by linear intervals where the epidermis remains flexible. This epidermal structure extends to the mouth as well, and is identical with that of the dental enamel of all the other vertebrates. In certain parts this calcification continues below the epidermis to the superficial portion of the dermis, to which the living cells that have produced it send fine prolongations without themselves penetrating it. Solid plates are thus formed, more or less covered by enamel, and sometimes with sockets carrying spurs, as, for example, in the armature of the Rays. These plates and sockets, formed of calcareous incrustations and traversed by fine vessels, have the same structure as dental ivory, and, as they are covered with enamel, the teeth of the terrestrial vertebrates must be regarded as the last remnants of the defensive armour of the Elasmobranch Fishes, finally localized on the jaw.

The Elasmobranchs have no bones. Their vertebræ, it is true, may become calcified, but this calcification, which takes place in various ways, does not modify their internal 
structure. The vertebræ are still cartilage impregnated with lime. This is also the case with the earlier Ctenobranch Fishes, whose direct descendants are the present-day Sturgeons. With them, however, calcification is, so to speak, more deep-seated. Abandoning the epidermis, so as to reach the dermis, the process of calcification invades the region of the star-shaped dermal cells, which then constitute the osseous corpuscles. The superficial parts of the dermis, richer in lime and more compact in texture, form at first over each osseous plate a brilliant glaze, to which the name ganoin has been given. Fishes having such scales were called by Louis Agassiz Ganoids. At first they preserved a cartilaginous skeleton, and resembled the Elasmobranchs in the peculiar shape of the tail, the extremity of which curves up. Underneath this erect part the caudal fin develops into a triangular blade, which gives the tail the appearance of being divided into two unequal lobes. On account of this dissymmetry in their tails, Sharks and Ganoids are called heterocercal. Franz Eilhard Schulze, Professor at the University of Berlin, has shown that this arrangement aided the Elasmobranchs, which have no swim-bladder, to rise in the water. It persists as a simple inherited character among such of the Ganoids as possess it, and tends to disappear in Amia of the North American rivers, which are Ganoids in all other respects. In the other Fish described as homocercal, the caudal fin terminates either in a regular convex curve or is emarginated into a fork having two equal branches.

Ossification of the skeleton has already begun in the higher Ganoids, and it is definitely osseous in the homocercal Fish or Teleostei. Here the tegumentary skeleton goes deeper even than in the Ganoids, and the fish is protected by plates of bony tissue pure and simple, contained in the dermis itself. These are the true scales. They unite in the region of the head, and form more or less extensive plates which closely fit the cartilaginous cranium, but are still easily detachable in the Salmon and the Pike, for example, but in later forms become incrusted in the cartilage, uniting with the bones of the cranial basis, and constituting, in the higher Vertebrates, the bones of the cranial vault known as the membrane-bones. Their frontal and parietal bones, and their 
temporal and occipital scales, like their tecth, are a heritage from the Fishes.

The preceding considerations retrace in a gencral way the genealogy of Fishes, and indicatc the order of their appearance. Not a single species is known in the Cambrian, and what we know of the Silurian is evidently incomplete. In the Devonian, however, there is a singular form, Palcospondylus gunnii, which, if it does not belong to the Marsipobranchs, belongs to a still more primitive type. Analogous forms must have existed in Silurian times, but they are unknown. On the other hand, in the Upper Silurian of England, the Island of Axel, Podolia, Galicia, Ludlow, and various other places, there are strange creatures which we can only consider as Fishes, but which do not seem to fit into any existing series. Their shape was flat, and they bore a superficial resemblance to the Trilobites, especially on account of the shield-like form of their head. Their large ventral mouth, elongated into a transverse slit, had no jaws, but their cephalic cuirass was protected by real bones, containing bone-cells. They initiated the series of Ostracodermous Fishes devoid of lateral fins. Among them were Cephalaspis and Auchenaspis, associated with Pteraspis, whose trunk and tail were covered with lozenge-shaped scales, and with various other genera. ${ }^{1}$ To these are to be added similar fishes which, however, were provided with a pair of paddleshaped fins, also covered with polygonal bony plates, ${ }^{2}$ and of these certain forms may have existed from Silurian times on the east coast of the Baltic. At the same time other forms appeared, with occasionally globular heads, ${ }^{3}$ strongly armourplated with polygonal bony articulated plates, which gave them a very distinctive appearance. ${ }^{4}$

The fins of Pterichthys are already highly specialized organs. Since many of the Selachians, even during the Carboniferous period, ${ }^{5}$ and of which there are representations to-day, ${ }^{6}$ have very primitive fins conforming almost to the genealogical indications furnished by embryogeny, it must be assumed

1 Ateleaspis, Birkenia, Cyathaspis, Lanarkia, Thelodus, etc.

2 Asterolepis, Bothriolepis, Pteriichthys.

3 Coccosteus.

- Dinichthys, Heterosteus, Homosteus, Titanichthys.

5 The Pleuracanthidæ especially.

- Chlamydoselachus of the Japanese waters. 
that these armoured fishes are more recent than the Elasmobranchs, and that we shall have to look in the older strata for connecting links between the two groups.

It has been considered surprising that these primitive Fishes had heads so heavily armoured, and that they should have resembled Trilobites; it has even been suggested that they are descended from them. They were found, however, in the Old Red Sandstone, which in some places attains a thickness of six thousand metres, and which was deposited as mere sand. In this sand there lived, together with numerous Trilobites, Pterygotus, Eurypterus, and other large Merostomata which they hunted, probably by digging in the sand. This common way of life would naturally produce resemblances in external form between the preying fishes and their victims, and would lead to a considerable development of the solid plates on the head of the former in accordance with what we have said before about the action of friction and shocks upon the development of the skeletal parts.

Ctenobranch Fishes also appear in the Devonian; they are heterocercal Ganoids, naturally: ${ }^{1}$ Crossopterygians, ${ }^{2}$ still represented in the rivers of Africa by the two closely related genera Polypterts and Calamoichthys, whose pectoral and pelvic fins, distant from one another, have the form of big scaly stumps fringed with a membrane supported by rays and Dipnoi whose fins are supported by an axis with numerous articulations, bearing rays arranged almost symmetrically on each side, as in the present Ceratodus of Australia.

The armoured Fishes disappeared at the same time as the majority of the Merostomata and Trilobites, during the Anthracolithic or Carboniferous Period, when the coal beds were formed. The Elasmobranchs of this period, however, have left numerous remains, especially the Pleuracanthidxe, whose cartilaginous skeleton was packed with calcareous corpuscles and therefore fossilized perfectly. They have furnished us with exact information on the organization of primitive Elasmobranchs, and I myself have pointed out ${ }^{3}$ how easy it was to derive from the structure of their fins those of the Dipnoi, such as Ceratodus, whose rays are arranged like the barbs of a feather 
on each side of an axial ray. This arrangement distantly resembles that of the rays in a branchial arch, and led the celebrated anatomist Gegenbaur to the audacious supposition that one of the arches of the fish's gills had become modified both in form and function until it developed into a fin. Unquestionably an organ can change both its function and its. form, but there must be some reason for this change. We might perhaps admit the possibility of such a change in the anterior fins close to the branchial cavity, but how could it happen in connexion with the posterior fins, which are far removed from this cavity? and what should we say of the unpaired fins, whose structure so closely rescmbles that of the paired fins that Tristichopterus appears to carry on its back a third fin similar to the pectoral fins? The embryogeny of the Elasmobranchs agrees with comparative anatomy in showing that the fins were at first represented by four longitudinal folds of the body wall extending along its whole length, one dorsal, one ventral, and two lateral, the last two forming what is called the patagium, and the two former the diphycercal fin, which only exists in Marsipobranchs. Each segment of the body still furnished these fins, in the course of their development, with the same number of rays, muscles, nerves, and blood vessels. At first continuous, the folds were subsequently broken (p. 227) at the places that bore the force of the backwash set up by the quick flexions of the tail to the right and left in swimming. It has been suggested that the apparent absence of the lateral fins in certain Ostracoderms is due to the fact that these flattened Fishes have preserved their patagium or developed it again, as the Rays and the Torpedo-fish, which live the same kind of life, have done to a certain extent-more in appearance than reality.

We now come to the beginning of the Carboniferous Era. The gradual perfecting of their organism has made the Fishes the dreaded enemies of the Gigantostraca and the Trilobites, on whom their relatively greater size has destined them to prey-and whom they have probably caused to disappear on that account. So the Fishes now prepare to invade the land. Many of them had already penetrated into fresh waters, and, apparently, taken to their new surroundings, 
for, apart from the Sturgeon, which goes thither only to lay its eggs, it is here that the last representatives of the oldest orders of Ctenobranchs are to be found: the Ganoids represented by the Lepidosteus and Amia in North America; the Crossopterygians localized in the rivers of Africa; the Dipnoi represented by Protopterus in Africa, Lepidosiven in America, Ceratodus in Australia. These last, as we have seen, are by now very well adapted for leaving the fresh water and venturing on land. We have already explained the mechanism by which they acquired the organs that were to prepare them to live outside the water (p. I73). The pioneers of the conquest of the land were very modest indeed. Their skin was covered with delicate scales; their cartilaginous cranium was protected by a bony covering like that of the Fishes; between the parietals was an open space which, if we may judge by the existing conditions in Lampreys and certain Lizards, must have been occupied by a single dorsal eye whose nerve was connected with the epiphysis of the brain or pineal gland, and which has become an eye for gauging temperature, a sort of a thermal eye, rather than an optic one: a circle of bony pieces fixed to the sclerotic surrounded the pupil. There were only four digits to all the limbs: these creatures resembled Salamanders. In the Carboniferous of Bohemia, Ireland, and Ohio we already find Keraterpeton, whose ventral surface was covered with scales and whose head bore two small horns. The European species, Kereterpeton crassum, attained a length of thirty centimetres, of which the tail occupied twenty. Urocordylus came near it. In the Permian lakes of the district of Autun the larvæ of Branchiosaurus developed with external brancheæ, and Albert Gaudry has described them under the name Protriton petrolei. We have been able to study their growth from the time when they were sixteen millimetres long to the adult stage, when they never exceeded sixty-four millimetres. They were small Salamanders, with minute scales covering their entire bodies. The vertebri of these creatures consisted only of a notochord surrounded by a bony pellicle. It was the same with the Dolichosomatidæ, which, although they preserved their external gills, had already lost their limbs and elongated their body until they had one hundred and fifty vertebræ to the length of one metre. 
Whenever the limbs of an animal are missing or are not used for locomotion, the body elongates thus and the segments multiply. This proposition is as true of Arthropods and Worms as of Vertebrates in which the number of body segments is indicated by that of the intercalated vertebre. Like other biological propositions, it is capable of being interpreted in two contradictory ways, both of which may be correct under different circumstances: Firstly, the body if it elongates sufficiently for undulatory movements to satisfy all the needs of locomotion, renders the limbs useless, and they become atrophied through lack of use ; secondly, if the limbs become too short to lean on the ground, or give the body sufficient speed, the body itself will take an active part in locomotion. The increase in its activity means a greater intensity in the phenomena of nutrition, which by tachygenesis may already manifest itself during the period of multiplication of the body segments. The number of these segments then increases, and the body itself becomes more and more capable of providing for the animal's peregrinations. The first interpretation would seem to fit the case of primitive animal organisms, in which an indefinite multiplication of the body parts is a sign of their reciprocal independence and a mark of inferiority. That can be admitted for the Myriapods, such as Geophilus, with their elongated bodies, and for errant Annelids such as Myrianidæ, Phyllodocidæ, Nereidæ, Eunicidæ or even Nais, etc. The second interpretation, on the other hand, especially fits the Vertebrates, in whom the number of body segments early became limited and in whom locomotion was accomplished very early by the aid of limbs whose original insufficiency we cannot admit. The aquatic Vertebrates, in which the undulatory movements of the body clearly play a preponderating part in locomotion, have especially good reasons for neglecting to use their limbs when moving, and it has been proved precisely in the case of existing species which live under special conditions that this atrophy of the limbs coincides with a multiplication of the body segments. This is clear in the case of the Proteidæ of the Adelsberg cave, in Carniola, in which the fore-limbs have only three digits and the hind-legs two. They preserve their gills all their life and, by tachygenesis, are born with the four legs of the adult. ${ }^{1}$ This is shown even better in the lacertine

1 Marie de Chauvin, Zeitschrift f. wissenschaftliche Zoologie, Bd. xxxviii, 1883, p. 671 , and Nature, vol. 1x, p. 389. 
Sirenidæ, which also preserve their three pair of branchiæ, and have only two short front legs with three or four toes. These are unciuestionably former terrestrial Salamanders, in other words quadrupeds that have again become aquatic. In fact they indicate the normal metamorphosis of the forms destined to become terrestrial by losing the branchiæ which they possessed at birth. These gills are subsequently regenerated. The atrophy of the hind-legs can be attributed to the lengthening of the tail, which in an animal of seventy centimetres has a length of about twenty-five centimetres. The Amphiumæ, whose body is elongated, but whose tail, on the contrary, is short, preserve their hindlegs as well as the others.

An analogous phenomenon, even more striking, is produced in other Batrachians which have no legs and live underground like worms. They constitute the group of Cæciliidæ. About forty species are known, distributed over India, Malaysia, tropical Africa, the Seychelles, South America, and Panama, that is to say, in regions which were all part of the continent of Gondwana in Carboniferous times. These animals were originally aquatic, because their embryos, while still in the egg, acquire magnificent branchiæ. Their general characters resemble those of the Stegocephala of that epoch. Certain species have even preserved the scales concealed in the segmented folds of their skin. ${ }^{1}$ We may therefore ask whether these vermiform Batrachians are not genealogically related with the Dolichosoma.

The other stegocephalous Batrachians belong to higher types. Their vertebral centra are at first formed of four pairs of elements, the upper ones bearing the arches which surround the spinal cord. They are therefore called temnospondylous. The four pairs are already reduced to three in the vertebræ of the trunk in Archegosaurus, Actinodon, and Euchirosaurus, where only the caudal vertebræ preserve the primitive composition. The Batrachians become siereospondylous when all the parts are united in one single bone in the form of an hourglass, with concave bases. They generally have scales only on the ventral surface of the body, thus betraying the influence of friction on the development of the solid parts of the integument.

1 Ichthyophis, Hypogeophis, Dermophis, Cacilia, Rhinatrema, Geotrypetes, Crytopsophis, Gymnophis, Herpele. 
Many genera of Stegocephala are known, all belonging to the Permian epoch. They were not very large, the largest, S.phenosaurus, being about two metres in lengtli, Archegosaurus de Decken of the Permian of Germany measuring a nietre and a half, Chelydosaurus of the Permian of Bohemia about one metre, and Actinodon of the Permian of Autun, which has been so completely reconstructed by Albert Gaudry, a little less. Euchirosaurus of the same region was a related form. All these organisms had the general appearance of small Crocodiles or large Lizards, but it has been established that the young of Archegosaurus had branchial arches. The scales on the belly of Chelygosaurus formed about forty bands " enchevron", very regularly and elegantly arranged, while the belly of Actinodon was equally well protected. Some species such as Dinorophus multicinctus of Texas had a carapace like that of the Chelonians united to the vertebral skcleton, and for that reason Cope called them Batrachian-armadillos. The Stereospondyles are represented by analogous forms, Loxomma of the upper Carboniferous of England and the Permian of Bohemia. They really constitute an outpost which continued into the Trias, when the structure of their teeth, characterized by sinuous folds, has earned for them the name of I-abyrinthodonta. The Stegocephala, Temno- and Stereospondyles seem to have belonged to the fauna of the North Atlantic continents.

Even at this epoch, however, the true Reptiles had already appeared, whose embryos no longer had anything but useless rudiments of gills, and alone were born with a special apparatus for aerial respiration. This advance seems to have been made during the lower Permian period; it seems to have been first achieved in America by Eryops, whose skull alone was six decimetres long and four decimetres wide, and by Cricotus, which was almost four metres long. The bodies of the vertebræ were still made up of three pairs of separate parts in Eryops, while in Cricotus the neural arches were united with posterior elements called interventrals, and the basiventrals were united to each other, a condition which also occurred in the former genus. This last character marks the line of separation between the first Reptiles and the last Batrachian Stegocephala. The transition between the two groups is thus practically imperceptible. ${ }^{1}$

1 In the early Batrachians and in the embryos of the present forms during the early phas s of their development, the vertebræ are composed of two 
The Microsaurians were Stereospondyles; they had dermal scales, dorsal as well as ventral, arranged on the belly like those of Stegocephala; their pelvis, largely cartilaginous, had only two osseous discs widely separated from each other. They have also been classed among the Batrachian Stegocephala, but they have feet with five digits and mobile chevron-bones on their caudal vertebræ, and iliac bones which are articulated to two vertebræ instead of one. These characteristics are common to the Reptiles, and in the absence of embryogenetic data we can only make purely conventional distinctions between these primitive groups. The Hylonomes of the Carboniferous of Nova Scotia, their near relative Hyloplesion of the Upper Permian of Bohemia, which was only a decimetre in length, Seleyia, only four centimetres long, and Melanerpeton and Orthocosta were all kindred forms. In Petrobates the ventral armour showed a striking resemblance to the abdominal ribs which we shall find in the Rhynchocephala, and which also exist in Crocodiles.

The Rhynchocephala, sprung from the Microsaurians, are probably the stock whence all the other Reptiles diverged. Their biconcave, stereospondylous vertebræ are separated by spaces, and bear caudal chevron-bones; the quadrate bone is fixed; they have abdominal ribs formed of disjointed parts arranged in chevrons as though, by a process analogous to that already encountered in fishes, the ventral dermal bones were only embedded in the wall of the abdomen, and did not show any superficial dermal ossification. Their teeth are planted in the sharp edge of the jaws and have no alveoli. A pelvis similar to that of the Microsaurians still persists in Palaohatteria of the Permian sandstones of Saxony, and the Protorosaurians of the magnesian limestone of Thuringia. These were lizards of about one and a half metres long, and they lead up to the true Rhynchocephala with their completely ossified pelvis; among which are to be included Callibrachion, reconstructed by Boule and Glangeaud, and Sauravus costei, described

anterior dorsal parts, the basi-dorsals; two ventral anterior parts, the basiventrals; two dorsal posterior parts, the inter-dorsals; two ventral posterior parts, the inter-ventrals. Those animals are by general agreement regarded as Batrachians in which these parts have remained distinct, at least in the caudal region, and those in which the inter-ventrals are missing, since the half of each vertebra is simply tripartite. Those forms in which the half-vertebræ are likewise tripartite and the inter-dorsal is missing are classed as Reptiles. This is the case with Eryops and Cricotus. 
later by Thévenin; the last-named comes from the Upper Carboniferous of Blanzy. A Rhynchocephala, protected by special laws, still lives in New Zealand, the Sphenodon punctatum or Hatteria punctata.

Up to this point all this world of the early Reptiles is a modest one, even in comparison with living forms. But the struggle for life during the Primary Period did not stop here. The way was being prepared for the appearances of monster Reptiles of unknown origin, forming a new order-the Theriodonts. Pareirasaurus appears suddenly and simultaneously in the neighbourhood of the Dwina in Russia and at the Cape of Good Hope. By what unknown route did such heavy and massive beings make their way from one of these regions to the other, the first being a part of the NorthAtlantic Continent and the second of the Gondwana continent, separated, at least since the Devonian Period, by an uninterrupted tropical sea? Must we put still further back, to the Silurian, in fact, the origin of Reptiles? To this problem no solution has yet been found.

Life was already prodigiously developed on the earth when the Primary Epoch closed. But throughout its manifestations there was but a faint foreshadowing of what would follow; monotony prevailed in the sea as on the land, where, through the warm northern mists, the already much-softened profiles of the eroded Huronian and Caledonian mountains stood out against the sky, whilst in more southern latitudes the young Hercynian chain showed, under an equatorial sun, jagged summits at an even greater altitude than the peaks of our Pyrenees and Alps.

Everywhere the sea waves buffeted the reefs built by polyps, whose indeterminate shapes could not compare with the brilliant garland of living gens encircling our Polynesian islands and tropical continents. Sponges, which scatter with splashes of gold, lapis, malachite, and scarlet the rocks of our seas to-day, transforming them in to palettes of glowing colours, were then elegant but without colour. On the reefs, in the sand and in the mud huge Pterygotus, Eurypterus, Limula, and Trilobites went where they would without fear almost undisturbed, but from Silurian times onwards were less bold and learned to roll themselves into balls at the slightest alarm. Worms of all kinds, forms, and colours undulated 
among the reefs and under the smallest rocks. The fairest ornaments of the sea, they were also the habitual food of all those creatures such as Merostomata and Trilobites, which contented themselves with small game.

The Echinoderms and the Molluscs had not yet attained their final form, for they had scarcely yet recovered from their efforts to save their lives under the hazardous conditions through which they had had to pass. Endowed with only feeble powers of locomotion, the Echinoderms multiplied in situ, the Cystids and Blastoids growing like buds of stone whereever they could attach themselves. A few Encrinites outspread vigorous blossoms on the rocks, and Starfish lived on them when Molluscs were not sufficiently plentiful ; Melonites heaped their purple globes one upon the other in great banks along the sea shores. The Turbos and Aviculæ, the Nautili, the Pleurotomarias, and the Trochi, had shells almost entirely of shining mother-of-pearl, which was to change later into porcelain, but they had not yet acquired those glowing hues nor those shapes so capricious in appearance-though in reality strictly and wonderfully geometrical-nor yet that ornamentation of such fantastic design, which, under the form of cones, pyramids, sailing barks with twisted and horned prows, delights our eyes to-day. Feeding entirely on such small fry as Diatoms, Radiolaria, Infusoria, and the larvæ which were flung as the small change of life into each wave, the early gasteropod Molluscs still floated under water, where they were easily captured by Sharks, against which their only weapon of defence in the struggle for existence was their prodigious fecundity. Although strange fishes were decimating the swarming worlds of Trilobites at the bottom of the sea, none of those species were in existence which infest it to-day in swift-moving, unnumbered shoals.

On the land a mantle of green had spread wherever the soil was sufficiently moist, but there was no turf, for our green grass is composed of Gramina, which it required many centuries to elaborate. The soil belonged entirely to Hepaticæ, Mosses, the humblest of the creeping Lycopods, and herbaceous ferns, among which the horse-tails uplifted their ringed stems, on which, at regular intervals, grew circlets of slender branches. Above these sorry prairies arose serried ranks of straight-branched fragile trees-Calamites and 
Lepidodendrons - a vegetation typical of damp soils. Abundant water, in fact, was essential to the fecundation of these plants, as their antherozoids could move only in drops of rain or dew. The place they occupied in relation to the higher plants might be compared with that of the Batrachians in relation to the land Vertebrates. They were ill adapted to grow on mountain slopes. However, tachygencsis gradually suppressed their complicated method of reproduction; the microspores became pollen grains ${ }^{1}$ and acquired the power of fertilization; thus the wind sufficed to carry them to the ovules. Thenceforward the Cordates were enabled to cover the ground with a forest of reeds, and Conifers were enabled to climb the mountain-sides, whilst Cycads spread out their great plumes in the sheltered valleys to be borne away on the wings of the tempests. Wherever roots could penetrate the soil became clothed with a vegetation that was extraordinarily luxuriant in Carboniferous times, but so fragile that the wind often stripped its branches, broke its stems, and tore the plants up by the roots. The remains of such as grew in marshy regions or along the borders of lakes have accumulated in situ. Protected by drift brought down by floods, or by the mud spread over them by the waters, these beds of fallen vegetation have been preserved to us. Plants that grew on the valleyslopes, far from the sea, as in the Central Plateau, were carried along by torrents to the freshwater lakes, which they gradually choked up. We can still identify the successive layers thus formed by floods at the height of each inundation. Still others were carried as débris by the great rivers down to the sea, as the Mississippi still carries it at the present day. And as this went on through century after century, in the course of which the configuration of the earth scarcely changed and the rivers kept to their old beds, vast accumulations of trunks, branches, leaves, and even herbs formed, thus creating the coal seams which feed our modern industries.

But while all this preparation for the mad activity that devours us to-day was slowly taking place, nature itself was silent and stern. Not a single flower lightened with the fresh colours of its petals the sombre green monotony, scarcely even varied in shade, of the vegetation, for, as there were no seasons, 
it was the same all the year round. This vegetation grew in rank profusion, without pause or pity, with undiminished vigour throughout the year. Under a warmer sun in a moist atmosphere, with an almost constant temperature, the production of vegetable matter, at any given time, must have been much greater than in our own day, when regular cold and dry intervals interrupt its growth. This is one reason why the coal beds remained so extensive and so intact, although, as Bernard Renaud has shown, cellulose-destroying microbes had already begun their work of disintegration upon the cellulose of which the solid plant tissues are composed in the manner of our existing Bacillus amylobacter. But it was not only its green uniformity that made this luxuriant vegetation seem so mournful. No living creatures were to be seen crawling among the mosses and on the trees but millipeds hunted by scorpions, indeterminate-looking spiders, spiritless Insects, such as white Ants, Cockroaches, and Phasmids scurrying to shelter. In such a world slow-moving armoured Salamanders must have looked like giants. The air was practically uninhabited. The swiftest of its denizens were May-flies, Ant-lions, and Dragon-flies. There were neither Bees, Butterflies, nor Birds. No voice sang of the joy of living, or sent its love-calls or even its cries of terror into the moisture-laden air. There was no intelligence present to be scared by volcanic eruptions, by the flash of lightning, or the rumbling of earthquakes. Life was manifestly experimenting. It was not to blossom till the period which we shall now enter. 


\section{CHAPTER II}

\section{LifE in SECONDARY TIMES}

IN Secondary Times life blossomed in every direction. During the Carboniferous Period the whole of Europe had been slowly but profoundly transformed by the hercynian folding along two main lines of direction : one running northwest to south-east, the other south-west to north-east, crossing each other at a sharp angle in the Central Plateau. Analogous movements took place in the north of Africa, the Altai region, the north of China, the Rocky Mountains, Bolivia, and the basin of the Amazon. In all these areas the once deep valleys where deposits accumulated up to the Dinantian Period were heaved up, and the mountains thus formed have been called the Hercynian Chain.

At the beginning of Secondary Times, during the Triassic, volcanic eruptions caused by these uprisings were still taking place in the Tyrol, the Pyrenees, Spain, Portugal, Morocco, all around the Pacific, especially in British Columbia, where the débris of volcanic eruption is found over a vast area, the strata often being four thousand metres thick, and in New Caledonia, New Zealand, etc. But in time everything became calm once more and until the beginning of the upheaval of the Pyrenees-that is to say, for at least four million years-tranquillity reigned almost undisturbed on the earth. No doubt the surface did not remain absolutely stationary. As it has always done and is still doing to-day, even on our coasts, it rose or sank slowly in different places, so that the sea invaded a certain number of coasts in the north and east of Africa, for instance, and formed gulfs in the region of the Jura and the Alps, penetrating even to the heart of the low-lying portions of the continents, which it inundated with shallow expanses of water, temporarily isolating Scandinavia and Finland from the rest of Russia during the Jurassic. These 
oscillatory movements of land surface levels were accentuated to such a degree during the Cretaceous Period that a deep fold, invaded by the sea, was produced right across Europe, then consisting of a series of archipelagoes, from east to west, and across the North American continent from north to south, cutting it in two, and also across Africa, whose western portion, now projecting into the Atlantic Ocean, was thus cut off from the rest of the continent. It was then that the shifting and derangement of strata took place known as the dislocation of the chalk. Elsewhere, however, the sea retreated, leaving behind it lagoons which dried up and left evidence of their presence in deposits of salt, while the summits emerging from the water formed islands and temporary archipelagoes. New communication was thus established between the different seas and former communication was cut off. The faunas hitherto separated became mixed in some districts and in others was isolated in groups and thus forced to follow individual lines of evolution. Hence a greater variety of marine species resulted, and many southern species were carried north by currents passing through the new straits, whereas northern species penetrated to the south, so that we cannot arbitrarily assume persistent variations of the mean temperature from the presence of such species in given waters. Such changes, however, were of minor importance and in no way disturbed the universal calm.

In every respect the transition from the Primary to the dawn of the new era was effected gradually. Throughout the Triassic Period the vegetation did not differ, except in details of genera and species, from that of the Primary; nor would it seem at a first glance, at least, judging by our information at present, to have been greatly modified during the subsequent Jurassic Period. It is probable, however, that it was during this era that the fertile female leaves, which rentained open in the Gymnosperms, in certain instances coiled up and closed around their ovules in order to protect them : a decisive step forward was thus taken in the Vegetable Kingdom-Angiosperms had been evolved. At all events, they were abundant and varied from the beginning of the Cretaceous, and the families that made their appearance first were precisely those that we should expect to do so according to the theory enunciated on p. Io6. Dicotyledons were greatly in the majority, and 
among them the first to appear, as we should cxpect, were those having catkins: Poplar, Willow, Birch, Beach, Oak, Walnut, Myrica, and their near relatives the Plane-trees and Liquidambers; then the Maple, Eucalyptus, and Laurel, with numerous stamens having traces of ramifications, and Myrtacex with ramified stamens. With them there were certain plants with isomeric flowers and even inferior ovaries, such as Ivy and Dogberry-tree, and gamopetalous plants like Viburnum and Oleander. The Monocotyledons were already represented by several families having large flowers: Liliacex, Alismaceæ, Pandanus, Palms, and even Aroidex. It must not be forgotten that, once they had become differentiated from the isomeric Dicotyledons, the Monocotyledons must have developed parallel with them and even rapidly, for they could no longer modify themselves except in details.

Everything indicates a very mild climate during this period. Seasons did alternate in the regions around the Poles (p. 5I), but everywhere else the temperature remained practically uniform. There were no annual periods of frost capable of holding up vital processes, no seasons of torpor or death, and even in the polar regions, although Palms were absent, the Bread-fruit tree, nowadays confined to the tropics, was growing in Greenland. On the western coast there was a succession of three distinct and very rich floras, testifying to a gradual cooling, for the tropical Cycads gradually disappeared, and Dicotyledonous plants became more and more important. The Tethys-the great Mesogean Sea of Douvillé and the Central Mediterranean of Neumayer-warmed by a two-fold inflow of waters from the torrid zone, kept its two coasts at an almost constant temperature considerably higher than that of the Côte d'Azur. The two arms of this sea which enclosed the North Atlantic continent ensured it a mild climate, and the other continents were equally well endowed-all were enveloped in a sort of Gulf Stream. The Madrepores built up coral reefs all along the coasts right up to Scottish latitudes. The Madrepores of this epoch were very like those of our own day, and were Hexacorallia closely related to the builders of the fringing reefs of the Red Sea and of New Caledonia, the barrier-reefs of the north-west of Australia and the Fijian archipelago, and the atolls, those remarkable ringshaped islands of the Pacific. Now we know that the 
polyps cease building in waters whose temperature falls below $25^{\prime \prime}$ C. So abundant are their remains that they constitute huge calcareous formations, providing the name for the Coralline division of the Jurassic.

The Oolitic limestone, which plays so large a part in the strata of this epoch, is simply a precipitate of the calcareous granular dust, formed from broken-off pieces of polyparies after they have been battered about in the waves, which collects round débris of one sort or another. In its fossilized form it has given the name to one of the two main subdivisions of the Jurassic.

In the seas encircled by these coral-builders a whole world of new invertebrates found a home. Elegant Radiolaria ${ }^{1}$ floated in the water, and the rocks blossomed with every sort of siliceous and calcareous Sponge, ${ }^{2}$ with Polyps, and with Crinoids so closely resembling plants that they are called Sea-Lilies when they attach themselves by a stalk to the seabottom and look like living flowers, and marine Palms when they spread out at the summit of their fifty-foot stems great plumes that looked exactly like the leaves of date-palms, as the Pentacrinoids do that still exist as green meadows in the waters off Rochefort.

It was at this time that some of these Sea-Palms detached themselves from their stems, and gave rise to new free forms like our modern five-armed Eudiocrimus, which lives in the depths of the Pacific and the Atlantic; to Comatula, which has ten tentacles like rose-coloured feathers and swims in a leisurely fashion by undulating them alternately; and to Actinometra, an inhabitant of the warm seas, whose ten primitive arms have an indefinite number of ramified branches. Over these reefs, gay and glowing as those of whose incomparable beauty Saville Kent has written, countless Molluscs dragged shells which displayed an infinite variety of new forms. For, in addition to the surbased forms and those with rounded openings there were Scalaria and Turitellidæ with long shells and corkscrew turns, Naticæ and others with rounded and polished shells, large Strombidæ with long scooped-out orifices, many forms of carnivorous Gasteropods with shells either notched or drawn out into a tube, Cerithium, Fusella, etc.

1 Spumellaria and Nassularia.

2 Hexactinellidæ, Tetractinellidæ, Lithistideæ, Monactinellidæ, Pharetronids and other calcareous Sponges. 
It was at this time, too, that the hermaphrodite Gasteropods greatly increased-and terrestrial Snails and Slugs, the future freshwater Limneæ and Physæ, the Bullæ, first of the series of marine Molluscs in whom we can follow the gradual loss of the shell, and Acteons, the least modified of the Opisthobranchs, themselves probably the forebears of the open-sea Pteropods, which fly in water by the aid of two large wings dependent from their feet as butterflies fly in the air.

The bivalve Molluscs were not behind the Gasteropods in progress. During the Jurassic period the majority of the varieties existing to-day were added to those we have already come to know. But there were others as well. We have nothing in our seas that can be compared to Diceras, whose two cow-horned valves, joined at their base, faced each other ; to Requienia, in which only one of the horns persisted, the other being reduced to a simple operculum, closing the orifice of the first ; to the Rudistæ, whose large valve exhibits a form and texture so disconcerting that it has suggested the possibility that they are really operculated polyparies like Calceola sandalina of the Devonian strata. They are considered to-day to bc related to simple existing bivalves like the Chamidæ, which has one of its thick valves attached to rocks, as in the case of Oysters, and the other one free. The powerful hinge uniting the two valves in fact resembles that which unites the two valves of the Rudistr. Among living Lamellibranchs, the only variety having a valve by which the creature attaches itself, developed in a way recalling the Rudistæ, are the $\mathbb{E}$ theriidæ, found only in the rapids of Central African rivers. Dr. Anthony believes that the exaggerated development of this valve is due to the continuous action of the violent currents to which it has been subjected. He surmises that the Rudistæ lived in waters in which they were violently buffeted by the waves. Like the coral reefs they replaced in many localities, they formed a defensive bulwark for the continental masses.

Throughout the Cretaceous Period the Madrepores were gradually retreating southwards as though the temperature were progressively falling. The polar regions then enjoyed a relatively temperate climate, but the south of France and southern Europe still retained their tropical 
climate, as we can tell by the presence at certain points of lateritic minerals, which can be formed only under the action of intense solar radiation. Douvillé has discovered Orbitolites-large circular Foraminifera---which only inhabit warm seas abounding in lime, wherever there are reefs of Rudista. They presage the imminent arrival of the Nummulites which will play so great a part in the seas of the Eogene period.

We cannot help being struck by the modifications produced in the habits of animals during Jurassic times. In the preceding period almost all the Gasteropods had shells with entire openings; these organisms lived exclusively upon vegetable food, and the pulmonate Molluscs which also have shells with entire openings, and which had invaded both land and fresh water, are likewise almost exclusively vegetarian. The carnivorous Gasteropods, the opening of whose shell is either notched or drawn out into a tube, did not make their appearance until the Secondary Period. This correspondence between the diet and the shell aperture is not due simply to chance. The carnivorous Molluscs are led to their prey by the sense of smell. As soon as a dead body falls into the water it is surrounded on all sides by Nassæ. Now the olfactory organ of the Gasteropods, the osphradium or false gill, is situated in the branchial cavity near the true gill. A tube or siphon, formed by a prolongation of the fleshy top of the branchial chamber, conducts the water into this chamber, and on to both the osphradium and the branchix, whose functions are thus regulated. This siphon fits either into the notch or the canal of the opening of the shell, and we can see that its gradual elongation was due to the efforts of the mollusc to induct the maximum quantity of odoriferous effluvia within its reach.

Was it the great number of these preying molluscs that drove certain of the Lamellibranchs to adopt the life of the recluse? Their senses are so rudimentary that they can hardly be credited with sufficient intelligence to carry out a deliberate intention. It is, however, undeniable that during the Primary Period those Lamellibranchs living on the surface of the ground and crawling by means of a foot, somewhat similar to that of the Gasteropods, or suspended by a byssus, were in the majority. Whereas, in the course of the Secondary those Lamelli- 
branchs increased that buried themselves in sand, mud, or even limestone, and that remained in communication with the exterior only by means of two long tubes, the siphons, situated in the posterior part of the body, of which one distributed the water on to the branchiæ, which then passed it on to the mouth, while the other ejected the water from which the oxygen and food particles had been assimilated, and which carried with it the excreta.

This change of labit, which, indeed, furnishes us with food for reflection, is not limited to the Lamellibranchs, for it also occurs in the Sea-urchins. The Sea-urchins of Primary times, without any predilection in choosing their direction, crawled among the Algæ or on rocks. The shell of the more recent species was divided into ten areas and bore numerous spines. These characteristics have been preserved, but there were others as well-burrowing species, covered all over with fine spikes, which dug their way in the sand in a definite direction. In these species, continually pressed against the covering earth, the shell is flattened around the mouth and forms a true ventral surface; the ambulacra on this side have taken on an entirely different appearance from those of the dorsal side, and henceforth their tube-feet alone play a part in locomotion. As the excreta are now no longer easily evacuated through the top of the shell, buried as it is in the earth, the anus changes its position from the top to the neighbourhood of the ventral face, thus characterizing a posterior region of the body opposed to that which the sea-urchin carries in front when it is burrowing. Thus a very definite bilateral symmetry (pp. I27 and I49) is superposed on the primitive radial symmetry. The mouth at first remained situated in the middle of the creature's ventral aspect and conserved the jaws of the primitive Seaurchin, though somewhat diminished in size-an example of which is provided by the Clypeastridæe. Later the mouth moved almost to the anterior edge of the ventral surface; the posterior lip advanced, spoon-fashion, in such wise as to be capable of being dug into the muddy sand, and of shovelling it into the sea-urchin's mouth. The useless jaws disappeared. An example is seen in the Spatangidæ. During the Secondary era we find all the stages of transition between the ordinary Sea-urchin and this type, and they are so numerous in certain geological layers that they have served to characterize 
them. The burrowing Sea-urchins actually swallow the mud, and this mode of nourishing themselves is a factor in their choice of habitat. But, we may ask, is not this in itself a result of their search for security?

Among the Lamellibranchs Cardium digs up the soil as if seeking food in it, and may serve as a starting-point which will explain the formation of siphons in organisms such as Solen, the Razor-shell, which only moves upward and downward in a vertical burrow and feeds on floating particles carried thither by the water without any search on the part of the Razorshell. It is impossible to see anything in its underground habitat beyond the desire for security. This is quite evident in the case of the Pholadidie, which perforate the limestone they cannot possibly eat, and in that of Teredo, which lives in wood. If these animals were thus led to live in seclusion, we may suppose that those among the congeners of their ancestors which did not adopt this way of life were destroyed. This would be a consequence of that struggle for existence, in which only those organisms survived that were able to avoid it, either involuntarily or of set purpose.

This motley crowd of Invertebrates was dominated by innumerable swimming Molluscs, first among whom we see the Ammonites riding the waves and seated as one might say in their shells, spirally twisted like the horns of Jupiter Ammon, and divided into chambers, whose origin and increasing complexity during the entire Jurassic Period we have already described. What purpose can have been served by this complexity, which was never produced in the Nautili? If we admit the assimilation, postulated by Munier-Chalmas, of the straight-partitioned Cephalopoda with the Nautili, and of those having folded partitions with the Spirulæ, certain observations become unavoidable. The first of these must have had at least two pairs of branchiæ and the second only one, possibly because of a shortening of the body, which was in communication with the outside world only by its anterior extremity, and which thus underwent a kind of cephalization. ${ }^{1}$ Under these conditions the mantle, increasing its surface by folding, was able to take the place of the second pair of absent branchix. The folds would become more complicated as the Cephalopod became more active and its potential size 
greater-certain Ammonites approached a metre in diameter. They evidently kept either close to the surface or at moderate depths, and we thus understand how it was possible for the transformations to come about that they underwent during the Cretaceous Period. The last convolution of the shell is at first detached from the others as if it hung in the water below the remainder of the shell and served as a ludion; then it described an upward C-shaped curve, as though the creature's mouth, at first directed downwards, were subsequently upturned. This change in the orientation of the mouth is perhaps only apparent; we may, in fact, admit that the shell, having originally opened upwards as in other Ammonites, was now oriented in such a way as to keep the mouth as far as possible in the same direction, whenever there occurred any displacement of the centre of gravity, due to the growth of the Mollusc and of the air-filled chambers of the shell, such as would upset the balance struck between the animal and its shell. Having once begun, this uncoiling continues, and ends in the complete unwinding of the shell from its point of formation. Thus we pass from the type of Scaphites and Crioceras to that of Pictetia. The shell of the last is C-shaped, and the upper hook is coiled spirally. In Hamites the convolutions are no longer spiral, but formed of parts bent at right angles one over the other. Finally, in Baculites the straight portion is so long in proportion to the coiled part that we might think it a reversion to the Orthoceratidæ. The actual organization of the Ammonite, moreover, undergoes a kind of degeneration. The folds of the mantle, which follow the sinuosities of the lines of suture, become so simplified as to resemble Ceratites of the Trias, or even Goniatites of the Primary. It was thus, no doubt, that the transition was gradually effected to the form of the little Spirulæ of the present epoch, with its interior unwound shell and simple septa.

The Turrilites, which are twisted corkscrew fashion instead of being coiled in a flat spiral, and which are consequently dissymmetrical, could not have been produced if the organism had remained either floating or swimming in some homogeneous environment like water. The torsion the shells have undergone must be due to the same causes as those which affected the Gasteropoda, and indicates the existence of a group of crawling Ammonites. 
Why did these splendid creatures disappear? For long ages they had ruled the sea. Their shells have been preserved in such great numbers that all their variations can be followed, and their genealogical tree be worked out so completely that the history of this group may be considered as an irrefutable demonstration of the modification of living forms. Iet puissant and plastic as they were, they became extinct. Are we to think that the Ammonites needed such specialized food that at some given moment it was not forthcoming ? Had this been so Palreontology would have given us at least some indication of the facts, and we have none. Is it conceivable that some new carnivorous marine animal of greater activity multiplied and caused such a carnage among the Ammonites that they were annihilated? We shall see later that this was not impossible. Side by side with this solution, however, the manifest simplification of form and the profound alterations in certain of them suggest some modifications in the environment in which these beautiful molluscs prospered and elaborated their structure until it proved insufficiently plastic to survive the new conditions. As they were sea-animals, this change can only have consisted in a lowering of the temperature, for the sudden extinction of an organic type in unvarying surroundings is thoroughly improbable.

The only Molluscs which disappeared together with the Ammonites were the Belemnites, which were also dibranchiate Cephalopods and very numerous. Their conical shell, short, straight, and partitioned, terminated in front in a kind of a large spoon-shaped shield, concave towards the base, and behind in a calcareous point with the form and dimensions of a cigar. Such perfect imprints have been found that all the soft parts of the body are easily recognizable. The ink-sac has been so well preserved that if its contents are crushed and mixed with water it can still be utilized to make a washdrawing. These organisms were close kin of our Squid. They must have been more active swimmers than the Ammonites enclosed within their shells, and they could thus easily prey on them. However, the most important part in the wiping out of both was probably played by the Fishes.

This was the period when bony Fishes had been evolved, and were added to those whose skeleton was still cartilaginous. These newcomers undoubtedly sprung from the ganoid Fishes 
which multiplied so rapidly during the Jurassic Period, were limited during that period to the Leptolepididæ, but afterwards became very varied. The majority at first, as we should expect, had pectoral and pelvic fins far apart like those of the Sharks and Ganoids, and fifteen families can be enumerated, many of them specialized. Among them were families which still thrive, such as the Scopelidæ, now pelagic and resembling the Salmon; Clupeidæ, closely related to our Sardines and Herrings ; ${ }^{1}$ the deep-water Halosauridæ; Osteoglossidæ, and even Murenidæ, which have lost their fins. ${ }^{2}$ Fishes with pelvic fins close to the pectoral also made their appearance in the form of the Berycidæ, representatives of which still exist.

It is thus an already quite important fauna, consisting of agile Fishes, whose very moderate size enabled them to find their way everywhere; hence they must have made life very difficult for the Ammonites; not only pursuing them, but competing with them for food. This must be taken into consideration if an explanation of the disappearance of the great swimming molluscs is sought. Those that lived under special conditions-for instance, the Cretaceous C-shaped Ammonites, which lived suspended in mid-water far from the surface, persisted much longer than the others, because the zone they inhabited was relatively poor in large-sized prey and little frequented by Fishes.

Let us now turn our eyes to the land. The sombre and monotonous vegetation of the Primary Period still persisted, for the most part, during the Triassic and Jurassic, but in the Cretaceous the virgin countryside was brightened by many a different shade of young foliage and brilliant flowers. The trees we know to-day uplifted their capriciously branched trunks somewhat shyly at first among the severely regular stems and arms of the primitive conifers; but they ended by driving them out of the plains, and Poplars, Willows, Birches, Beaches, Oaks, Walnuts, Plane-trees, and Maples, the first branches of the theoretical genealogical tree we set up a few pages earlier, crowded into their place. The surface of the earth became covered with vast forests in which there grew also Figs, Bread-fruit trees, and other unisexual flowering Urticeæ. Holly, Ivy, and different members of the Cornaceæ family sprang up in their shelter, and even some gamopetalous

1 Diplomistus, Scombroclupea.

2 Urenchelys. 
forms such as Viburnum and Oleander. And if we cannot add to this list a long series of brilliant flowers, it is because beautiful flowers hardly ever grow on big trees, and because the delicate stalks of shrubs and herbaceous plants which do bear them are ill-adapted to fossilization.

All this new vegetation naturally had its echo in the graceful and active world of Insects living in its midst. Apart from certain Hemiptera, which stuck a sharp probe into the young branches and sucked their juices, the Primary Period had scarcely known any Insects but those which lived on solid food crushed by their powerful buccal armament. But the new prairies, with their blossoms, and the woodlands with their tender foliage, offered the restless Insects a thousand new occasions for the exercise of their activity. Honeyed drops collected on the leaves, nectar formed within the depths of the corolla of the blossoms. This was dainty and almost ambrosial food for aerial denizens. Cutting mandibles and jaws armed with powerful pincers were of no use for imbibing such exquisite fare, and they had to be elongated, softened, refined, and partially atrophied, transformed into the lamina which support the bee's flexible tongue, the proboscis of the butterfly, or the suction tube of flies. Thus to the clumsy insects of Primary times was added a host of delicate, swift-flying creatures often eclipsing in brilliance the very flowers they plundered. The earth is at last decked in such fairy colours as we admire in the tropics. The time has come when its surface at least teems with living things, and the air is peopled. The conditions of Primary times so eminently favourable for this world of tiny creatures to-day so fragile, continued into Secondary times. Nowhere did the temperature drop sufficiently to destroy at one fell blow all the Insects of any particular region. Like the higher organisms they died one by one, and the duration of their lives was cut short only by accidents. This full span of life permitted them to observe, to acquire experience, and to profit by what they had learned. One generation overlapped another. Parents lived to see and know their progeny, could live among them, care for them, and feed them as long as they were unable to feed themselves; or, at least, place them in such conditions as would provide them with the means of subsistence close at hand until they were old enough to go farther afield and seek it for themselves. 
The older generations, moreover, had time to educate their young, and these being perpetually in contact with their parents, imitated their actions, and thus were initiated into life, profiting from the acquired experience which in this way became transmitted from generation to generation.

Their activity was limited at first to a few simple actions, partly in the nature of those constituting what botanists have long called tactism, and therefore unconscious acts. As the organism perfected itself, these acts were replaced by others, more or less conscious; but the repetition of the same acts, stimulated by the same circumstances, caused them to become automatic, like those associated with habit or performed unconsciously in sleep, those which are simply the result of tactism, and those which Claude Bernard has called reflex actions, and which we ourselves perform without the intervention of our will and unregistered by our consciousness. Thus we blink our eyes when a ray of light suddenly strikes them, make a defensive movement if our face is menaced by a blow, and contract our muscles in walking and swimming. In these conditions the minute brain of the Insects, constantly stimulated by the same influences, and set working by the performance of the same actions, gradually acquired an appropriate organization which was transmitted by heredity, so that the slightest external stimulus thereafter sufficed to set going a whole series of actions marvellously linked together, succeeding each other in a given order, even when the specific purpose they were intended to serve had been suppressed. This was the elaboration of what is called instinct. ${ }^{1}$

Certainly the theory put forward above supposes an initial intelligence analogous to that to be observed at the present day at work side by side with automatism in Birds, which live with their young in conditions not unlike those which prevailed in the Cretaceous Period when Insects lived with their larvæ; and it may come as a surprise that such fragile creatures should be credited with similar intelligence. Such

1 I developed this theory of instincts in 1881 in a textbook called Anatomie et physiologie animales, written for the Philosophical Course of the Lycées. Almost at the same time, although somewhat later, the same theory was elaborated in England by G. J. Romanes in his volume on Animal Intelligence, for the French translation of which I wrote a preface (1883). Then we were both brought to a standstill by the difficulty of explaining the transmission of instincts from one generation of Insects to the other, since two generations are not contemporaneous. 
intelligence, however, exists and functions to-day in the very manner we have just indicated in all the social Insects-White Ants, Wasps, Humble-bees, Bees, and Ants, and we must necessarily bow to the facts. Darwin made a masterly study of what we call instinct in birds, where the word designates an assemblage of unconscious and more or less conscious faculties. He demonstrated that in the same group of Birds, Molobrus, for instance, a kind of American Starling, we can follow all the stages in the development of an instinct identical with that of the Cuckoo which deposits its eggs in the nests of other birds. It is the same with the social insect, and especially in Ants, where we can see the social instinct, the constructive instinct, and the instinct prompting a provision for both larvæ and adult, as well as many another, occurring in different species and genera under forms which are easily graded from the most primitive to the most complex manifestations of instinctive behaviour. From this we must conclude that in Insects, as in Birds, instincts are not innate, and were not bestowed upon the creature once for all, without possibility of variation, but were gradually perfected in just so much as the insect modified itself, and that this apparent innateness is nothing but heredity. The same gradation of instinct can be observed in Insects which live solitarily. We know that all insects are not equally endowed in this respect. Those which have preserved the primitive forms and mode of development (Archineuroptera, Orthoptera, Hemiptera) have generally remained at the very bottom of the scale so far as instincts are concerned. Insects with crushing mandibles and a complete metamorphosis (Euneuroptera, Coleoptera) are somewhat better endowed without there being any connexion between this fact and their method of evolution, for the Lepidoptera and Diptera are as poorly endowed as the Archineuroptera, whereas the White Ants of the Neuroptera group are almost equal to the most remarkable Hymenoptera. Their social species, it is true, appeared only during the Secondary Epoch.

In the order of Hymenoptera, both in the solitary and the social forms, the instincts exhibited can be arranged in a definite series and their progressive evolution followed from species to species, be it in connexion with the building of nests, the provisioning of the young, or the manner of killing the prey, right up to the manifestation of those other instincts that have 
been so beautifully observed and have inspired such eloquent writing on the part of that great naturalist, the recluse of Sérignan, J. H. Fabre. ${ }^{1}$ In those species which feed on swect liquids, whereas they nourish their young on animal prey, we can even trace the transformation from a carnivorous diet, at first common to larvæ and adults, to a sugar diet, originally limited to the adults as in various Wasps, and then extended to the larvæ as well, as in the case of Bees and Ants. It is obvious then that instincts have been evolved, though any explanation of such evolution is brought up against a difficulty which seemed insurmountable to Darwin, Romanes, and myself, which set Fabre against the doctrine of evolution, and whose solution I myself only guessed at much later. ${ }^{2}$ This explanation lies simply in the fact that the Hymenoptera, aniong all insects able to live on liquid food, are those in whom the mouth-parts have the most varied aptitude, so much so that we find among them all the transitional stages between a mouth adapted almost entirely for crushing and one essentially constructed for licking, so to speak, like that of the Bee. Hence they were able to profit more greatly than the Lepidoptera and Diptera by the particularly favourable conditions prevailing in the calm, warm Secondary Period. The advent of winter seasons caused the disappearance of all those insects whose individual evolution took longer than a year, and which had not learned to shelter their larvæ or themselves against the rigours of the periodic cold season. Among thuse individuals whose evolution took less than a year, only those survived whose development happened to take place during the summer. In this way the seasonal rhythm of Insect reproduction became established. This rhythm had as a result the isolation of one generation from another. While the brevity of life cut out experience, the seasonal rhythm did away with education. The insect brain, however, was already sufficiently organized to make most of the reproductive acts automatic. Heredity preserved what has been acquired in this way, but the winters prevented all possibility of modifications, and in this way the instincts that had become fixed took on that guise of mystery that deterred for so long any attempt at explanation. As soon as the veil of mystery is withdrawn, we arrive at the apparent paradox that the very fixity of Insect 
instincts is in itself an unexpected argument in favour of the theory of evolution, and of the mutability of living forms.

Contemporary with this development of Insects, such small creatures, the evolution of the terrestrial Vertebrates took a sudden step forward. During the Triassic Period the Stegocephalan Batrachians were still represented by temnospondy lous ${ }^{\mathbf{1}}$ and stereospondylous ${ }^{2}$ forms. Among the latter, the Mastodonsaurus of the Trias of Germany and England attained a gigantic size; the skull alone was one metre long. The last representatives of this group, which did not survive the Trias, appears to have been Labyrinthodon of the county of Warwick and its South African counterpart Rhylidosteus. Thenceforward, the forms which were to persist came closer to those of to-day. A small Batrachian something like a salamander, Hyoloobatrachus, is found in the Wealden clay. The anurous Batrachians began to appear in the Jurassic with Palceobatrachus, but the large Batrachians, such as the more or less armoured species, had had their day. The world was to belong to the true Reptiles whose skin was so dry as to become scaly and in whom the skull was articulated with the vertebral column by a single condyle, whose branchial arches were atrophied before birth without ever being used, so that the animal could breathe only in the open air.

At the time of their appearance the world was empty of large animals. Vast horizons were opened to their activity. We can hardly admit that the struggle for existence or natural selection played any considerable part in the evolution of those that did exist. This evolution was in two directions. The first large Reptilian fauna that appeared on earth is known to-day chiefly by the fossils found at Elgin in Scotland, in the Permian of Bohemia, Thuringia, and Autun, in the Karroo formations of South Africa belonging to the early part of the Triassic Period, and in the North American deposits of the same age. These Reptiles seem to have disappeared toward the middle of this period. We have no precise indication of their origin, but they appear, however, to approximate to the Stegocephalan Batrachians. Pareiasaurus, which appeared, as we have scen, towards the close of the Carboniferous Period,

1 Eupelor, Brachiops, and in India, Gondreanasaurus.

2 Trematosaurus, Capitosaurus, Metopias in the Trias of Germany: Diadetognathus, Pachygonia, Gonioglyptus. 
had the aspect of a Frog as large as an $\mathrm{Ox}$, and had a short tail. These Reptiles attained a length of two and half metres. Their membranous skull was entirely covered with bony dermal plates, leaving a hole for the parietal eye. These plates were rugose as if they had been hewn, and in Elginia, a related form, had peculiar spiny processes. The teeth were small and uniform, with several serrated points, arranged in series, and arose from both jaws and the palate. The limbs, short and squat, each terminated in five digits, whereas the Stegocephala never have more than four. The skull articulated with the vertebral column by a single condyle, as in the case of the Reptiles, whereas Batrachians have two. The lower jaw, made up of several parts, was attached to the skull by a quadrate bone united to it. The shoulder girdle comprised a scapula, a united coracoid and precoracoid, and a cleithrum. These characters are clearly Reptilian, but in the shoulder we already observe some features which appear later in Mammals. The coracoid bones are united with the scapula in the manner of the coracoid process of the Mammals and the scapula is provided with a spine characteristic of these animals. These characters are accentuated in the pelvic girdle, constructed on exactly the same plan as in Mammals, and which articulates with two or three vertebræ constituting a sacrum. Pareiasaums and Elginia form the first group of Theromorpha, the Pareiasaurians.

In a second group, the Theriodonta or animals with mammalian teeth, the bony envelope of the skull remains incomplete as among the other Theromorpha. In these animals however, some very remarkable modifications are produced in the dentition. The teeth no longer serve merely to hold the prey ; they also grind the food-the Reptile uses then, as later on the Mammals used theirs; nor is the number very different. We can already classify them as incisors, canines, and molars. The dental formula of Lycosaurus, for example $\left(\mathrm{i}_{3}^{\frac{4}{3}} \mathrm{c}_{1}^{1} \mathrm{~m}_{\frac{5}{5}}\right)$, might be applied to the mammalian Marsupials. That of Gomphognathus (i $\frac{3}{3} \mathrm{c} \frac{1}{1} \mathrm{~m} \frac{1}{1} \frac{2}{2}$ ) differs only in having more molars.

The molars, however, retain their reptilian character. They have but one tubercle and one root, except perhaps those of Tritylodon, which have two, and consist merely in one broadened tooth, whereas the molars of the Mammals are formed by the union of several teeth. Also, side by side with 
resemblances that are sometimes more remarkable still, we find certain differences that are no less striking. Tritylodon had long incisors deeply imbedded in the jaws and of perennial growth, no canines, but in their place a gap, as in Rodents. The molars of Trivachiodon were multituberculate. There were likewise no canines in the continuous tooth-series of Stereorachis of the Permian of France, nor in Empedias molaris of Texas, which had palatal and vomerine teeth. Clepsydrops, Dimetrodon, and Nanosaurus of Texas, on the other hand, sometimes had more than two canines in each jaw, which never happens in Mammals. Thus for these reptiles we have no typical dental formula fixed by heredity, as for the placental Mammals, from which it would be possible to deduce all later formulæ by simple reductions. The dental matrix was altered in shape under the pressure of the teeth according to the use to which the teeth were put. Naturally, the muscles of the lower jaw were also modified according to the use the animal made of it, and this entailed a corresponding modification of the facial region to which the muscles were attached. A zygomatic arch was constituted, recalling that of Mammals, but somewhat differently composed. The chewing habit adopted by the Theromorpha suffices to explain the resemblances the skull presents to that of the Mammals. A certain identity in gait likewise explains the form of their scapula and the construction of their pelvis. There is nothing to prove that we are here in the presence of the ancestors of Mammals.

In the Triassic, indeed, there were already small Mammals, Marsupials like Dromatherium of the Carolinas, and Microconodon.

Certain Theromorpha, particularly Cynognathus, had all the ways of our Carnivora, but were much larger. Their skull was sixty centimetres long. They captured their prey and carried it away in their jaws like our Tiger. The head in consequence had to be firmly fixed. We also see the single condyle of Pareiasaurus becoming broadened and kidney-shaped, ${ }^{1}$ and finally assuming the two-fold shape seen in Mammals. ${ }^{2}$ At the same time the cervical region was shortened. It had only six vertebræ, whereas the dorsal region had twenty-nine. The existence of such carnivores also supposes the contem- 
poraneous existence of herbirorous reptiles, or at least reptiles which fed on insects, molluscs, and other small prey. We are thus far from having any knowledge of the food habits of the terrestrial vertebrate fauna of the Trias.

Perhaps we should see herbivorous vertebrates in Anomodontia, represented by several genera distributed from Elgin in Scotland to the Cape. The dentition of these animals is reduced to two tusks in Dicynodon, recalling those of the Walrus; these canines are short and conical in Gordonia and Geikia of Elgin, and can be present or absent in individual cases in Cistecephalus, suggesting that they are characteristic of the male sex. This would lead us to assume that Oudenodon, which had no tusks at all, was merely the female of Dicynodon. The jaws of this animal, whose skull can attain a length of two decimetres, elongate beyond the tusks and were probably covered by a beak analogous to that of the Chelonians, which, as a matter of fact, were already represented in the Triassic Epoch by several genera. ${ }^{1}$

The Rhynchocephala were represented by Telerpeton.

Finally, the series of Theromorpha terminates in the Placodonts, terrestrial animals which had again become marine and lived on molluscs whose shells they crushed with the aid of two or three scissor-like teeth on the intermaxilliary, and three to five rounded upper molars and some flattened teeth borne by the palate and the posterior part of the mandible, arranged like paving-stones. A number of varieties of Crocodiles completed the Triassic reptilian fauna.

Rhynchocephala, Crocodilians, and Chelonians all became more and more diversified in detail throughout the Jurassic and Cretaceous-two periods most clearly marked with the impress of new ages. The heavy Theromorpha disappeared, but whilst vegetation of marvellous variety flourished, the development of Reptiles positively luxuriated. They had no competitors on land; the earth was theirs, and the constancy of the temperature was particularly favourable to them. No danger menaced the more powerful; they grew slowly like the Crocodiles of our times, but the length of their peaceful lives was such that some of them were forty metres long. Given that their rate of growth approximated to that of Crocodiles, this would

1 Chelzyöon, Arctosaurus, Psammochelys. 
imply that they had a longevity of five or six centuries. If some retained the squat form, others were slim and elongated. Gradually many of them abandoned the recumbent posture of their ancestors, to which present-day Reptiles are condemned-we shall see why later.

Using the muscles coupling the limbs to the trunk in a new fashion, the extremities of the humerus and tibia were brought back towards it in such a manner that the arms and thighs, instead of moving in horizontal planes like those of the Lizards, moved in vertical planes like those of the running Mammals. Hence the abdomen no longer trailed on the ground. The same muscular effort exerted on the limbs-now become elongated lever arms-forced the extremity much further forward; thus the Reptile no longer crawled, but walked, ran, and even jumped.

Then, assuming an even prouder attitude, the animal raised itself up on its hind legs, which grew very large, whereas the fore limbs, being scarcely used, either shortened or became transformed. This was the preparation for the bird form-the form that would very soon venture into and take possession of the air. A certain remarkable anatomical arrangement that was to be retained in the future is to be observed already. Cavities filled with air, no doubt in communication with the lungs, made their appearance either in the vertebræ of the large Dinosaurian Reptiles, ${ }^{1}$ or in the long bones, while at the same time the structure and method of using the limbs were already approximating to that of Birds. That it was merely necessary for these Reptiles to make a demand on their muscles for those muscles to bring about such modifications is in no way surprising. A large Australian Lizard of our present day fauna, King's Chlamydosaimus, is still capable of assuming this erect attitude, which is its posture for defence.

A first attempt at the conquest of the air is thus foreshadowed, but it was only partially successful. Not until their prey became scarce and the ground a dangerous place for them were Reptiles obliged to hunt in the air, and then only after having been put to tree-climbing in their efforts to find food in security. A further indication of such insecurity on the ground surface lies in the fact that other Reptiles, whose ancestors had taken great pains to leave the water and invade the land, returned to the seas, and, while retaining their

1 Brontosaurus, Coclurus, Anchisaurus, Compsognathus. 
reptilian organization, resumed the life of Fishes in order to hunt them and dispute with them the easy prey presented by the indolent Ammonites found in every sea.

In the course of passing through the different stages just enumerated, Reptiles naturally developed new characters, used by naturalists to distinguish each group leading the same kind of life. At first the pelvis remained very similar to that of the Crocodiles. Below the iliac bones the two pubes formed a $\mathrm{V}$ with the apex directed forward, and the two ischia a V with the apex directed backward. The Reptile could only stand erect under exceptional circumstances, but it could be either plantigrade or digitigrade, that is to say, it could walk on the entire sole of its feet or only on the toes, the sole being raised up off the ground. The Sauropoda exemplify the first, and the Theropoda, with extremely elongated bodies, and the Ceratopsidæ with the ponderous form of our Rhinoceros, exemplify the second condition.

In another series the hind-quarters gradually assume a greater development than the fore-quarters, and it is likely that the animal was able to stand erect. The thigh muscles consequently become larger, and the pubic bones to which they were attached acquire a greater surface, and, above all, present, as in birds, both an anterior and a long posterior branch (post-pubis) for the insertion of the muscles that erect the body; the pelvis remains open in front as with Birds. These features characterize the Orthopods. Those orthopod Reptiles which continued to walk on all four feet and remained plantigrade form the sub-group of Stegosaurians; those whose fore limbs are so small that the animal could no longer have supported itself upon them, and must have held itself erect on its hind legs in the manner of a Kangaroo, form the suborder Ornithopods. All these animals together form the subclass of Dinosaurs or giant Saurians comprising the biggest and strangest terrestrial creatures that ever lived.

Sauropods had the aspect of huge Serpents with an elephant's body stuck midway of their length. At the end of a long neck they carried a remarkably small head, which in Brontosaurus excelsus, ${ }^{1}$ an animal thirty metres in length, was no bigger than the fourth cervical vertebra of a neck made up of thirteen. Contemporaneous with it in the Wyoming strata was Atlantosaurus

1 Of the Upper Jurassic. 
immanis, which was nearly sixty metres in length. Morocaurus grandis, on the contrary, was half the size of Brontosaurus, and had only four sacral vertebræ instead of five. Another of their contemporaries in Colorado, the celebrated Diplodocus longus, completely reconstructed by Professor Holland, and a magnificent cast of which was given by Carnegie to the Muséum d'Histoire Naturelle in Paris, measured 26 metres in length. Its head, not so small as that of Brontosaurus, had somewhat the aspect of a horse ; its lower jaws were provided, in the front only, with long incisor-like teeth, each accompanied inside by a row of replacing teeth.

The form of the teeth in all these large Reptiles shows them to have been herbivorous. If the connexion, previously pointed out, between the multiplication of the vertebræ and the part taken by the trunk in locomotion be recalled: if to this we add that the caudal vertebræ of Diplodocus was provided with bones arranged chevron fashion, and each having two symmetrical horizontal rafter-like supports, indicating that this tail must have been planted on the ground and used for propulsion-then we are led to the conclusion that the Sauropodians lived in dense jungle, through which they had to thread their way by separating the growth with movements of their long necks and then pushing into and through it by the leverage of their tails, their limbs permitting them to raise themselves off the ground where the tangle of branches was thickest. The shape and small size of their feet excludes the notion, sometimes advanced, that they were marsh animals, and the position of the nostrils, on and not at the extremity of the muzzle, a character common to Sauropodians and aquatic animals, is even better explained by the use they made of their heads in forcing the branches apart. This action alone would mechanically push the nostrils back, the more so because if they had been situated at the end of the snout they would have been constantly torn and blocked by thorns.

Ail the large Reptiles above mentioned belong to the Upper Jurassic, but analogous animals must have been living much earlier, from the Lower Trias, in fact. In the sandstones of Fozières near Lodève, which date back to that period, and in those of Connecticut, imprints of pentadactyl feet with a separated pollex actually have been observed. These cannot have been made by Stegocephala, in whom four digits is a constant 
feature of the feet. Again, a tridactyl foot has left tracks so much like those of a Bird that Hitchcock, when he discovered the first of them in Connecticut, called them Ornithichnites, i.e. bird imprints. There were certainly no Birds at the beginning of the Secondary Period. It is therefore impossible to attribute these foot-prints, some of which are four decirnetres long, to other than the Theropods, at least provisionally. Pentadactyl four-footed imprints, of which the fore tracks were distinctly smaller than the hind, have also been found. They were made by animals of various sizes, but manifestly of the same species-as if the young had lived with their parents. The steps taken by these larger beasts sometimes equalled a span of two metres. The persistence of these tracks up to the time when new strata were deposited over them, seems to confirm the assumption that these animals were not very numerous, and that the struggle for life was consequently not very active in those regions where their footprints have been discovered. To this unknown animal, which has thus imprinted its footsteps in the sand, the name of Brontozoum giganteum ${ }^{1}$ has been given. Brontozoum has left in the sand imprints of its tail, as well as of its feet.

The Theropods had pointed, hooked teeth; they were carnivorous Reptiles moving in the same manner as Kangaroos. The elevation of the body to an erect position on the hind legs was evidently the result of a habit that had gradually modified the size of the muscles and their points of attachment, modifications which reacted on the bones and on the size of the limbs. This habit is easily explained in the case of carnivora living in thick low bush, and which are obliged to raise their heads above it in order to reconnoitre, watch their prey, and retreat to a place of safety at need. Such a habit had already no doubt begun to be imposed on the Sauropodians, whose hindquarters were better developed than the fore-limbs; later it was associated with the further habit of leaping. The posterior limbs, still almost plantigrade in Anchisaurus of Connecticut, become gradually digitigrade. Thereafter the smallest toes, which cease to touch the ground, become rudimentary. Zanclodon of the Upper Trias of Würtemburg, which was three metres in length, and analogous forms in

1 Brontozoum means "thunder-animal". We have already met with Brontosaurus or "thunder-lizard". 
France, England, South Africa, and India have five digits to each limb. The Megalosauria which flourished from the Trias to the Upper Cretaceous in France, England, Colorado, and India are slightly larger and have only four toes on their hind feet. Hallopus victor of Colorado did not exceed one metre in length ; its extremely short front limbs had only four digits, its hind limbs three, the first being absent and the fifth represented by a short metatarsal. Ceratosantus of the same region, which exceeded five metres in length and bore a horn on its nose, also had but three toes on its hind legs, but all three metatarsals were united-a condition we shall see produced later on in leaping and swift-footed animals. The Allosaurians of North America possessed but three digits on all their feet. Finally the hind legs of the small Compsognathus longipes of the Jurassic of Bavaria were veritable bird legs whose three existing metatarsals were united not only to each other, but also to the distal series of the bones of the tarsus; the proximal series being likewise adherent, without being united to the tibia, to which was joined a rudimentary fibula. In spite of this the pelvis remained typically reptilian, and had behind it a long tail. Sharply pointed teeth extended the whole length of the jaws. Many Theropods (Colurus, Hallopus, etc.) had hollow bones presenting holes in their surfaces into which air sacs dependent from the lungs were inserted, as with the birds, from which these creatures were still far removed by the form of their pelvis.

The pelvis of the Orthopods, on the contrary, approximated sufficiently closely to that of the Birds for Huxley to propose for them the name of Ornithoscelidæ. This form of pelvis does not necessarily correspond to a permanently erect attitude; it implies no more than a great development of the posterior members relatively to the fore-limbs, and the possibility of erecting the body on them. The Reptiles grouped together in the sub-order of Stegosaurians were still almost plantigrade. Those of the genus Scelidosaurus, however, have only four digits on each foot, while in Stegosaurians there remain but three on the posterior feet. The Scelidosaurians slightly exceeded four metres in length; they lived at the time of the Lower Jurassic (Lias) of Lyme Regis. Analogous forms are also found in the English Wealden (Hylnosaurus polyacanthus). The Stegosaurians of the Upper Jurassic of Wyoming and Colorado 
approach ten metres in length. These Stegosaurians were strange beasts. The disproportion between their anterior and posterior limbs caused considerable convexity in the back when they went on all four feet, and along the line of this curve in Scelidosaurus was arranged a double row of projecting bony plates, which became unique on the greatly elongated tail. The dorsal plates of the Stegosaurians formed but a single row, but they were of great size, triangular, and erected vertically, with the apices in the air, the largest of them being almost a metre in height. This row of plates divided into a double series on the tail, which thus carried two rows of spines sixty centimetres in length.

The digitigrade type became highly accentuated and constant in the Ornithopods, which habitually held themselves erect on their hind-quarters. Their long bones were hollow and in communication with the air sacs like those of Birds. We have already met with this character in the Theropods, which had also adopted the biped attitude. This attitude implies a greater expenditure of muscular effort in the posterior body-region than the quadruped attitude. On the other hand, the development of the air sacs adds considerably to the respiratory power of the lungs. In the case of both Theropods and Orthopods it is not impossible that the possibility of acquiring their new method of locomotion, endowing them particularly with an aptitude for running and leaping, was due to this increase of respiratory activity. We find in Ornithopods a series of forms analogous to those of the Theropods. Camptosaurus of the Lower Jurassic and of the lowest layers of the English Cretaceous (Wealden) had five fingers and four toes. Hypsilophodon from the same localities had only four fingers and four toes. The northern Iguanodon, of the Neocomian of Belgium and Germany, had only four digits on its fore-legs and three on its hinder, the pollex having been transformed into a formidable spur. Hadrosaurus and Trachodon of the same regions closely resembled them, except that the mouth was prolonged into a sort of edentate duck-bill. At the back of this bill were several rows of small teeth, forming one functional row, followed interiorally by numerous rows of replacing teeth, the total number being two thousand.

The best known of all these Reptiles are the Iguanodons, so named because their herbivorous teeth resembled those of 
the large American Lizards called Iguanas. They flourished in the time of the Upper Cretaceous of England, Belgium, and Germany. An early species, Iguanodon mantelli, was found in England, and measured only five or six metres in length. The complete skeletons of thirty individuals of another species, Iguanodon bernissarti, were found together at Bernissart between Mons and Tournay in Belgium, close to the French frontier, at the bottom of a mine-shaft two hundred metres below the present sea-level. They were discovered in an excavation in the Carboniferous earths filled in by Wealden clay, on the surface of which were still to be seen the imprints of their feet, indicating that the hind-legs only were placed on the ground. As no tracks made by the tail have ever been found, it is to be assumed that it was held far above the ground and was used to balance the Reptile. The Iguanodons were certainly herbivorous; they had no teeth in the fore-part of the mouth, the lips probably being covered with a horny envelope. Their attitude indicates, moreover, that they did not browse on grass, but ate the leaves of trees, whose trunks they seized between their powerful hands, as did Megatherium at a later date.

The last representative of this group was Ornithomimus of the Upper Cretaceous of Colorado, all four of whose limbs were tridactyl, and in whom the proximal end of the third metatarsal, set deep between the second and the fourth, was partially united with them, as it is in young Birds. They were very large animals, but unfortunately all we know of them is their limbs.

All the Dinosaurs that we have briefly passed in review were marked by a family resemblance. They had a long neck, a long tail, and a trunk generally not exceeding the neck in length. The head was nearly always small, or even diminutive-so much so that the brain was sometimes less in volume than the lumbar portion of the spinal cord. They must have formed two parallel series, the one carnivorous and the other herbivorous, each beginning as a plantigrade species with a closed pelvis and no post-pubis, and closing with an erect species having a post-pubis. Having regard to the latest discoveries, this is probably the order in which we shall have to set up their genealogical classification. For if it be easy to understand that animals feeding on the same kind of food should gradually assume the series of attitudes just described, it is hard to see 
why a different form of pelvis should correspond with two different dietaries. Unfortunately the series of carnivores is still very incomplete, and is represented only by digitigrade Theropods in which a post-pubis is absent.

The monstrous Ceratopsidæ, of which we have still to speak, present a complete contrast with the Reptiles we have described. Their neck and tail were of medium size. The trunk was powerful, and the four limbsalmost equal, each with five digits, all of which were planted on the ground. It had the massive appearance of a Rhinoceros, but of a rhinoceros whose gigantic dimensions exceeded six metres in length and two or three metres in height in the rear. Its head was perhaps one of the strangest things in the whole animal kingdom. It terminated in front in a sort of beak like that of a Bird of prey, which did not prevent the jaws from being provided with two-rooted teeth implanted in alveoli, and dilated in the rear into a great thick, osseous funnelshaped mantle, which covered the neck and reached almost to the shoulders. This formidable head, two ${ }^{1}$ or three ${ }^{2}$ metres in length, carried three powerful horns, one on the nose and two others above the eyes. Other members of the Ceratopsid group, Nodosaurus, for instance, were still further protected by a bony, dermal armour-plating. These monsters lived during the Cretaceous Period in North America, notably in Wyoming. Only a single genus is known in Europe, Cratcomus, whose presence Depéret discovered in Hérault. They were herbivorous like the Titanosaurians, Iguanodons, and Trachosaurians, which may have been their contemporaries and were even more colossal. All these herbivora must have lived in comparative peace. Their great enemies were the Megalosaurians and Lalaps, huge carnivorous leaping Theropods of swift movements, against whom they confidently opposed those terrible weapons, their beaks and horns, and their impenetrable cephalic shield.

Whence did these extraordinary and gigantic beings come which peopled the land in Secondary times? Doubtless the land Vertebrates had already tentatively appeared by the close of the Primary Period. Reptiles of the Trias, with varied dentition, although still earth-crawlers, had attained large dimensions, and some of them are distantly linked to the large Stegocephalous Batrachians, to which also belong the Rhynchocephalic Reptiles. These creatures, though still of moderate

1 Triceratops flabellatus.

2 Triceralops prorsus. 
dimensions, seem to have been the ancestors of the Dinosaurs, to which they passed on various peculiarities of skull-formation, and particularly the construction of the palatal vault. But if the physiological mechanism is clearly apparent that has turned crawling Reptiles into Reptiles that walk and leap, and if it has been possible to reconstruct at great intervals some of the steps in this evolution, the series of stages covered is broken nevertheless by enormous gaps. We can see that any such reconstruction will be difficult. Many of these cryptogenous beasts appear almost simultaneously at parts of the globe so widely separated from one another that we find some difficulty in admitting that any means of communication existed easy enough to allow such heavy animals, probably sedentary in their habits, to cover such great distances. Forms that vary but slightly from the Triassic genera, Zanclodon and the Megalosaurians, for example, are found in Europe and the United States, which both formed part of the North Atlantic continent, and also in the southern parts of Africa and in India, which at that time formed part of the Gondwana continent. Morosaurus, Colurus, Stegosaurus, Camptosaurus, Triceratops, and Hadrosaurus are represented sometimes by different species in Europe and the United States, that is to say, at the two extremities of the North Atlantic Continent, during the Jurassic and Cretaceous Periods. Although these periods lasted long enough to admit of the lengthiest journeys into the interior of a single continent, this wide distribution remains remarkable, and it is incredible, in any case, that such migrations took place between Gondwana and the North Atlantic Continent. We must admit, therefore, that similar forms may have arisen separately, which confirms the view that constant natural forces acting upon organisms which at first differed but little from one another, as the early Batrachians must have done, have independently produced analogous organic series in widely separated regions of the globe. That is equivalent to saying that the same causes acting in similar conditions always produce the same effects. This is an elementary truth well worth remembering in the domain of natural science, where the idea of capricious and independent creations reigned for so long. The parallel evolution of the herbivorous and carnivorous Dinosaurs shows, moreover, how weak was the principle of the correlation of forms and the subordination of characters upon 
which Cuvier based his essentially finalistic comparative anatomy.

We have now studied the wonderful evolution of the land Reptiles. But they did not limit their activity to the invasion of the land. They also acquired wings, probably as a result of the folds of skin similar to those we have already mentioned (p. I3o), which formed upon the flanks of trec-climbing varieties in the Secondary Epoch. Unfortunately the transitional forms are unknown. The wing of the Pterosaurians was always constructed on the same plan. At the back a large membrane ran along the whole length of the sides as far as the end of the tail, and in front spread to the exterior edge of the digits of the forelimbs, which had become three times as long as the body. Contrary to all that took place in the preceding cases, the enormous head was sometimes one-third as long as the body (Pterodactylus crassirostris). It was perpendicularly articulated with the neck and its bones united as in Birds, an arrangement which seems to indicate a relation between this condition and rapid aerial locomotion. "The jaws carried sharply pointed teeth (Pteranodon), and were sometimes replaced by a sort of horned beak, of which the termination of the jaws in a point in Ramphorhyncus may be considered an indication. The oldest known remains of a Pterosaurian go back to the Lias of Lyme Regis. This forerunner (Dimorphodon macronyx) of the Pterosaurians had a slender tail six decimetres in length, and the body was almost the same length. Ornithocheirus of the English Wealden also had a long tail terminating in a kind of membranous rudder; the teeth were pointed, widely spaced, and inclined forward. On the other hand, their contemporaries, the Pterodactyls, had short tails; their size fluctuated between that of a Crow and that of a Sparrow. The giant among Pterosaurians was Pteranodon, which spanned six metres and whose dimensions far exceeded those of our largest Condors. It flourished in Kansas during the middle Cretaceous Epoch. They were Insect-eaters ; their long pointed beak did not permit them to tear their prey. Like Bats, they could not rest on the ground in order to capture small animals, or they would have been unable to take flight again. This also applies to all Pterosaurians, which in order to rest were obliged to suspend themselves from the branches of trees by means either of the normal four fingers of the hand, or by the feet. They had then merely to 
open ont their wings as they fell, in order to start flying again. The size of Pteranodon indicates that insects must have increased greatly during the Cretaceous Period. The existence of Dimorphodon in the Lias proves that numerous flying Insects must have already existed. But we have still to discover what use Ramphorhyncus and the Pterodactyls made of their teeth, which were too long for such minute prey. This seems to imply that Birds already existed, and that Archaopteryx was perhaps not the most perfect of them.

We come at last to those Reptiles which invaded the water during the Secondary Period. This return to a former environment need not unduly astonish us, since Crocodiles have never abandoned the neighbourhood of rivers. Since the time of the Trias there had been marine Reptiles whose legs, by a contrary process from that which took place in Dinosaurians, were shortened and broadened. The digital phalanges were often multiplied and the feet finally transformed into paddles which could only have been used for swimming. They belonged to two types : in one, the Plesiosaurians, also called Hydrosaurians or Sauropterygians, the head was small and the neck elongated, as in the Dinosaurs, but the tail was very short; in the other, that of the Ichthyosaurians or Ichthyopterygians, the head, on the contrary, was large, the neck very short, the tail long but flattened, which, like a fish's tail, gave the animal the greatest possible impetus in swimming. To these differences in aspect two quite different modes of life must have corresponded. The Plesiosaurians, swimming only by means of their lateral paddles, helped perhaps by the undulations of their long, swan-like necks, probably lived on the surface, and must have been able to dive quite easily, but confined themselves to shallow waters, where they probed and dug the mud in the manner of geese and swans. The Ichthyosaurians, on the contrary, lived like real Fishes, and only came to the surface in order to breathe, as our Porpoises do. Swimming not only with their paddles but also by the aid of their tails, they would be met with the same resistance by the water as are Fishes. Hence their neck would be shortened and they would acquire the same shape as the Fishes. In the fine palæontological gallery of the Paris Museum, there may be seen an example, acquired by the Société des Amis du Museum, preserved with its integument held together by small scales. 
Apart from the paired fins, it had a median fin on its back, and its tail terminated in a fin divided into two unequal lobes. That part of the vertebral column corresponding with this fin clescribed a sharp downward curve in the opposite direction to that of heterocercal fishes. We saw (p. 230) that this tail was an organ of levitation to bring them to the surface; that of the Ichthyosaurians, on the contrary, was a diving organ. Lightened by the air in its lungs, the Ichthyosaurian was naturally borne to the surface, and had to exert effort in order to descend.

Up to the present no transition of form has been found between the Ichthyopterygians and terrestrial Reptiles, unless it be Mixosaums of the Trias, in which the radius and ulna are still elongated and separated by a slight longitudinal interval. The teeth, very numerous in Ichthyosaurians, became very small in the Ophthalmosaurian of the English Jurassic and Cretaceous. They have quite disappeared in Baptanodon of the Upper Jurassic of Wyoming, as they have done in our Baleen-Whales.

The Plesiosaurians are less isolated. They are linked with Reptiles which, like themselves, had biconcave vertebræ, and present an upper temporal fossa and ventral ribs, while their limbs, still differing little from those of land Reptiles, are, however, already adapted for swimming. These are the Nothosaurians, primitive forms in which the notochord is preserved in the centum of the vertebræ. Mesosaums, the initial type of this group, is found in the Triassic sandstones of the Karroo in the south of Africa and in those of Sao Paulo in Brazil. They had only nine cervical vertebræ, and did not exceed three decimetres in length. Lariosaurus attained a length of one metre, and preserved its palatal teeth. Its neck consisted of twenty vertebræ and its tail of forty, although these were very short. Nothosaurus grew to a length of three metres and had sixteen cervical vertebrie. Other forms have been found in the Muschelkalk, near Magdeburg. In the Plesiosaurians, properly so-called, which lived between the Lower Triassic and the Jurassic, the neck was still more elongated, and possessed as many as from twenty-eight to forty vertebræ. The neck was longer yet in the Elasmosaurians, in which the number of the vertebræ varied between thirty-five and seventytwo. On the other hand, the tail was extremely short. The Elasmosaurians differed especially from the Plesiosaurians in the 
details of their shoulder-girdle, whose scapulæ were joined ventrally instead of remaining separate as in Plesiosaurians. Elasmosaurus of the Upper Cretaceous of Kansas had a neck about seven metres long, to a total length of fifteen metres. Pliosaurus, which was ten metres long and whose bones are found in the Kimmeridge clay, probably swam under water more habitually than the other species. Its cervical vertebre, twenty in number, were, in fact, flattened as if they had been compressed by the resistance of the water. They were creatures of terrible aspect, armed with formidable teeth, some of which were three decimetres in length, and would not have found on the coasts prey worthy of such a powerful maxillary apparatus. The limbs of all these Plesiosaurians were less modified than those of the Ichthyosaurians. They never had more than five digits, whereas the Ichthyosaurians sometimes had six owing to the division of one of them. The number of phalanges only was notably augmented. The humerus, radius, and ulna, as well as the corresponding bones of the hindlimb, remained considerably more elongated than the carpus, tarsus, and digits.

While the Ichthyosaurians and Plesiosaurians, which had sprung from the lower forms of Reptiles, disappeared from the seas of the Upper Cretaceous, other Saurians became aquatic and even marine ; but they were quite differently characterized. They seem at first to have appeared in the southern seas. Their dentition clearly indicates their relationship with the Lacertilians. The Plesiosaurians had cach tooth implanted in an alveolus, while those of the Ichthyosaurian were aligned in grooves, not divided into alveoli. Those of the new aquatic Reptiles, the Pythonomorphs, were simply welded to the maxillaries as in numerous Lacertilians. But the form of these teeth was varied, and this gave the palæontologist Dollo some indications as to the nature of their food. The powerful dentition of Mosasaurus indicates that they doubtless attacked either less well-armed Mosasaurians or marine Chelonians. The thin curved teeth and weak jaws of Plioplatecarpus would hardly have allowed it to attack any but medium-sized molluscs such as the Belemnitellæ. Globidens with its rounded teeth and weak jaws probably fed on sea-urchins. This is no mere hypothesis; their prey has sometimes been found fossilized along with them. ${ }^{1}$ These animals already existed 
in the Lower Cretaceous. When they became aquatic their body elongated, like that of the Snake, the limbs, however, retaining the essential characters of land Reptiles, except that they had shrunk. Their bones became shorter and flatter, and the whole limb thus became a swimming blade. The oldest of these was Dolichosaurus of the English Lower Cretaceous, which was only one metre in length. The rami of their mandibles were united. They had supplementary articulating apophyses on their vertebræ, like Snakes. Acteosaurus of Istria was similarly endowed, whereas in Plioplatecarpus of the Upper Cretaceous of Holland these apophyses were absent. In the Mosasaurians the resemblance to Snakes was accentuated by the substitution for the mandibular symphysis of a ligament permitting the separation of the two rami of the lower jaw. The Mosasaurians, whose name means the Lizard of the Meuse, were able to attain a length of six or seven metres, the average length of a Boa or Python. In the Museum at Brussels, there are beautiful complete specimens of Clidastes, which was still longer and more slender. They have been found in Europe and in North America, that is to say on the coasts of the former North Atlantic Continent. Platecarpus and Liodon, however, have an even larger area of distribution. Their bones have been collected from North America and Europe to New Zealand. Liodon haumuriensis of this region attained a length of thirty-five metres. On account of the distensibility of its lower jaw and the specially articulated apophyses of their vertebræ, the Mosasaurians have been regarded as the ancestors of Snakes. Yet though the presence of two posterior rudimentary feet in pythons may prove that the Ophidians are descended from animals with feet and that these feet gradually disappeared in the Scincoidians, from the Skinks to the Slow-worms through the intermediate form Seps, we are still unable to tell how the order of Ophidians arose.

The Chelonia date back to the Triassic, where they are represented by the genera Chelyzoon, Arctosaurus, Psammochelys, and Progomochely's, which seem to bear some relation to the Rhynchocephala and Crocodilians. Possibly they had a common ancestor with the Theropoda in Primary Times. Hans Gadow has attempted to reconstruct the first Chelonian by attributing to it the more general and apparently primitive 
characters known in fossil and living forms. He supposes that in this imaginary animal each of the body segments except those of the anterior half of the neck and posterior half of the tail, carried a transverse series of dermal bones, covered by horny shields whose relative position and dimensions were subsequently modified by the manner of growth of the trunk, which took place by a rapid diminution of the parts nearest the neck and tail.

The order of Chelonians attained its maximum development toward the end of the Secondary Epoch. The extant types are but a remnant of those existing in Secondary times. It is probable that the normally web-footed varieties inhabiting the marshes were the ancestors of terrestrial forms whose mode of progression is still reminiscent of a lind of swimming action on resistant ground, and that marine Turtles, with their feet transformed into paddles, were likewise derived from them, the feet having gone through a modification analogous to that which we have already noticed in Plesiosaurs and Ichthyosaurs, and on whose significance we have already insisted. ${ }^{1}$

At the close of the Secondary Period, those prodigious Reptiles whose history we have just narrated disappeared as completely as the Ammonites had disappeared from the sea. To what are we to attribute the world-wide extinction of such puissant animals, whose vitality was manifested by their extraordinary longevity? We can scarcely believe that organic types, like individuals, grow old and die. This oft-repeated proposition has no other value than as a figure of speech. So long as a given species has representatives capable of reproducing their kind, and sufficiently numerous to carry on the process, that species is no more likely to disappear spontaneously than the type to which it belongs. Of course it is within the bounds of possibility that some extraordinary modification in environment may induce sterility in all the individuals of the same organic group, but for this to come about the modification must be so general that no species escapes it, and so sudden as to make any adaptation out of the question. Both suppositions are equally unlikely, and hence we are led to conclude that things came to pass in those days very much as they do to-day, when species do not disappear unless wiped out by their enemies

x Cf. pp. 193, 272. 
or by some scourge operating in the regions in which they live. Thus we must seek to discover what agency was capable of destroying the most gigantic animals that ever dwelt on this earth.

From the beginning of the Secondary era two types of Vertebrates had slowly and sparsely multiplied-Birds and Mammals-which we have hardly had occasion to mention. The oldest of the Birds, Archaopteryx lithographica, is known by two forms only, discovered in the lithographic limestone of Solenhofen of the Oolitic Period. Birds do not reappear till four genera are found in the Chalk-Enaliornis of England, Hesperomis, Ichthyomis, and Apatomis of Kansas, in North America. All these Birds are still very strange. Archaoptery: $x$ had short jaws rounded at the end instead of being pointed and elongated like those of the majority of present Birds, and furnished with teeth. The anterior limbs had wing-feathers, but the four toes terminating them were free and provided with almost normal claws; the tail was long and reptilian and composed of twenty-two vertebræ, each bearing a pair of long tail feathers-a most encumbering appendage for flight, and had it not been for its feathers Archceopteryx would undoubtedly have been classed among the Reptiles. Thus is the reptilian origin of Birds clearly indicated.

The Cretaceous forms had more distinct birdlike characters. The beak was clearly characterized and the body ended in a rump of normal form instead of in a long tail. Enaliornis and Hesperornis had rudimentary wings, or none at all, and no keel on the breast-bone. The vertebræ of Enaliomis were mostly biconcave like those of the primitive Reptiles; while those of Hesperomis were concave on the terminal aspect, convex on the other. In both these genera the teeth were situated in a simple groove and not enclosed in alveoli, a fact that has led to their classification together under the name Odontolcæ. In Ichthyormis and Apatornis the teeth were implanted in alveoli and accompanied by replacing teeth (Odontormæ). The wings and the keel on the breast-bone were well developed. It is evident that these Birds, despite their alveolar teeth, were more primitive than Hesperormis, whose wings had disappeared and whose teeth, placed in a simple maxillary groove, were on the road to disappearance. This fact alone would indicate that rumped Birds were already old in the Cretaceous Period, seeing that 
they had had time to modify themselves; and, since we find practically all the types of the present day at the beginning of the Tertiary, it is extremely probable that they had already been achieved in the Cretaceous, and that owing to one of those peculiar chances so frequent in palæontology, we are acquainted only with the abnormal types of this epoch.

The Mammals had evolved side by side with the Birds. In the Trias they were already represented by the genera Dromatherium and Microconodon. To these were added during the Jurassic, many Marsupials with special dentition, ${ }^{1}$ and during the Cretaceous further new genera of the same type, together with Plagiaulax, provided with teeth of a new type. None of these appear to be of great importance in the fauna of the time at the outset, nor is it till the seasons become marked that they become more considerable. By the end of the Cretaceous Period, however, the seasonal cycle is accentuated. Birds and Mammals were not affected by this modification in the climate which, as we saw, reacted so profoundly on the Insects. Their blood was at a constant temperature, and they maintained the same activity all through the year. And since Birds sit on their eggs and Mammals are viviparous, the young of both were able to avoid, like the full grown creatures, the vicissitudes inseparable from variations in the temperature. With Reptiles, however, it is quite otherwise.

All existing Reptiles have a body-heat which changes according to external variations in temperature. An excess of heat or cold benumbs and can kill them, and they take no care of their progeny, which are more exposed than themselves to extremes of heat and cold. There is no reason for believing that it was otherwise with the great Reptiles of the past. The minute size of their brains indicates that they were extremely unintelligent creatures, and their organization was no higher than that, for instance, of their contemporary the Crocodile. As in the Crocodile, the arterial and venous blood was probably mingled. But even if they had been more perfect in this respect they would have been little better off. Inner heat is a function of activity, and the unintelligent Reptiles

1 The Triconodonts: Amphilistes, Phascolotherium, Triconodon; and the Trituberculates: Amblotherium, Dryolestes, Amphitherium of the Jurassic; and Pedromdys, Dielphops, and Crinolestes of the Cretaceous. 
of the Secondary Period could only move their huge bodies with some difficulty. Moreover, in the higher organisms, the body-heat is preserved by the layer of air which feathers or fur keep at a constant temperature. A shorn rabbit soon dies. The large Reptiles of the Secondary Period had no such protection, and the heat produced in their bodies by respiratory processes would be dissipated, not only by the surface of the trunk, but also by the long neck and enormous tail. So long as the external temperature remained warm and fairly constant they did not suffer from these imperfections, and the Birds and Mammals had no advantage over them. It was otherwise when extremes in temperature became greater. Their lives would be punctuated by more or less lengthy periods of torpor, during which they would be at the mercy of animals having a constant body temperature, such as Mammals and Birds, which could maintain the same activity at all times. Thus the Reptiles became an easy prey. Indeed, it was inevitable that they should disappear before the increasing number of their rivals. The composition of present day reptilian fauna furnishes a powerful argument in favour of this explanation. The flower of the reptilian class has disappeared; none but a few species of Crocodiles have survived-species that hide in water and are further protected by solid armour; or Chelonians that, enclosed in a carapace, are almost impossible to extract ; together with Lizards set low on their legs, and Snakes with none at all, which are therefore able to hide themselves in holes and the interstices of rocks inaccessible to the majority of preying animals; or those endowed with special means of protection, such as the green colour of Dendrophis, the Tree-snake, the faculty the Chameleon possesses for changing its colour, or weapons as treacherous as they are formidable, such as the venom of Helodermes among Lizards, and, above all, the poison of snakes. All those Reptiles which were not able to dissimulate their presence or to defend themselves by treachery, have disappeared: the existing class consists only of those which escaped in the struggle for existence.

Apart from a few Scincoid Lizards such as the Slow-worm, and several Snakes like Vipers and the marine Snake or Hydrophis, the Reptiles of the present epoch lay eggs. The Ichthyosaurians, and perhaps Compsognathus, were viviparous, but there is no evidence that this method of reproduction, 
consisting simply in the hatching of ordinary eggs inside the oviducts, and depending often on more or less temporary external conditions---was more widespread among Reptiles in the past than it is to-day. It is true that we have not up to the present discovered fossilized eggs of these large animals which, however, like Crocodiles' eggs, must have been protected by a very strong shell. Be this as it may, the young, like the eggs, were equally exposed to the teeth of Nammals small enough and alert enough to escape all pursuit with ease, or to the beaks of Birds whose wings would carry them out of danger by capture.

With regard to cerebral development, Mammals and Birds were already gifted in a very different degree from the colossal brutes of the reptilian class. They were clever enough to save themselves in time from the least menace on the part of these creatures. Just as their nervous system, taken as a whole, has given to Vertebrates supremacy over the other animals, so the improvement in the brain was to give the warm-blooded Vertebrates supremacy over the Vertebrates whose blood had a variable temperature. With Tertiary times, intelligence, which had already built up instinct in insects, though it has subsequently become frozen in their tiny brains, was to reappear on the scene and gradually expand till, by its possession, Man should become master of the world. 


\section{CHAPTER III}

\section{Life in Tertiary Times}

THE rising up of the Pyrenean, Alpine, and Himalayan contours. The seasons became more marked. The torrid, temperate, and frigid zones were on their way to their present limits, though the polar regions were throughout favoured with a temperate climate. Plants took on the forms in which they still appear to-day. New Protozoa, the Nummulites with lenticular shells, round like coins, invaded the seas in such quantities that the first half of the Tertiary has been called the "nummulitic period". They make their first appearance in the Pyrenees, Istria, and Egypt, in layers where we still find a few survivors of the large Mosasaurian and Dinosaurian Reptiles, whereas in these same layers in Patagonia we see the oldest known placental Mammals appearing for the first time and in considerable numbers.

At the opening of the Eogene, which corresponds to the first half of the Tertiary, western Europe and North America were joined by a strip of land which probably comprised Scotland, Ireland, Cornwall, Brittany, the Central Plateau, the Iberian Meseta, and the eastern coasts of North America, and which was here and there broken up into archipelagoes. From time to time communication between Europe and America was sundered, notably in the middle of the Neogene, and was again established for a time toward the end of the same period, after which it was completely broken, and the North-Atlantic continent was formed.

The Sino-Siberian continent remained isolated. It was probably the home of the even-toed Mammals which, on several occasions, suddenly appeared in Europe during the Lutetian and Ludian Periods, for Anoplotherium already existed in Asia at that time. The Afro-Brazilian continent 
still persisted: Tree-coneys, and Orycteropus which is to-day localized in the south of Africa, also lived in that part of Patagonia where the Carolozittelide and Pythrotherium are perhaps somewhat analogous to the precursors of Elephants discovered in the Fayum deposits in Egypt. This continent included Madagascar, whose fauna presents curious affinities with that of South America, and its northern edge was then prolonged as far as the Antilles, as is indicated by the resemblances between the fauna of this island and the Mediterranean fauna of that epoch.

The Australo-Indo-Madagascan continent was then splitting up. But while Australia became definitely isolated so that its fauna is still one of Marsupials, India and Madagascar remained united, which explains the existence of Lemurs in both these regions. The Tethys Sea still extended between the North Atlantic and Sino-Siberian continents on the one hand, and the Afro-Brazilian, Indo-Madagascan, and Australian on the other. It cut the American continent in two at the Isthmus of Panama. From the region now occupied by that part of the Atlantic Ocean extending from the Caribbean Sea to the Franco-Spanish coasts, it thrust a narrow, fluctuating channel into the sea which lay between Europe and the NorthAtlantic continent, and so outlined the North Atlantic coast.

The physical relation then existing between Europe and North America and between South America and the African continent suffices to explain the simultaneous invasion of the two Americas by the placental Mammals, and makes it unnecessary to assume a problematic Pacific continent.

A shallow expanse of water covered the Paris basin, the basin of Mayence, and its southern prolongation, the valley of the Rhine, and the region of eastern Europe between the North Sea and the Caspian, and skirting the eastern foot of the Urals it separated Europe from Asia. It abandoned these countries after the beginning of the Neogene Epoch, but continued to submerge Aquitania and the coasts of Portugal. The region once occupied by the Tethys, for the most part, was now above water. There were still, however, some low-lying areas which the sea alternately invaded and abandoned and which corresponded to the south of Spain and to that portion of the Mediterranean which washes its coasts as far as Provence. The water extended over the 
site of the Alps and reached the basin of Vienna, the Baltic area, etc., and sometimes leaving only a few narrow channels, until the time when the Mediterranean was to take its present form.

During the Neogene Period, the European and the SinoSiberian continents united, never again to separate, so that the Mammals of Asia easily passed over to Europe, and it was moreover through Asia that African animals migrated into Europe. North America and Asia were still in communication by way of Spitzbergen and Greenland, but an arm of the sea separated Europe from the Arctic continent. North and South America were separated; the latter ceased thenceforth to be united to Africa, and Madagascar became isolated from India and Australia. The hypothetical Pacific continent seems to have disappeared under the water. Summing up these data we find that there was now an Arctic Ocean separated from the Atlantic by the continent which included North America, Spitzbergen, and Greenland, and which was connected to Asia; and that the present Atlantic, Pacific, and Indian oceans were now definitely constituted.

During the Eogene Period, the alternate rising and sinking of the land surface allowed the passage of ocean currents, flowing sometimes from the Arctic and sometimes from tropical seas, and this brought about a more or less durable fall or rise of temperature along the coasts, although the mean remained relatively high. The oldest known flora of this Period, the Gelinden, ${ }^{1}$ contains Willows, Cupuliferæ, ${ }^{2}$ Ranunculace ${ }^{3}$ Laurinaceæ, Celastrinaceæ, Menispermaceæ, etc., which still recall the Cretaceous flora. A little later ${ }^{4}$ the petrifying spring of Sezanne encrusted the flowers, leaves and fruits of plants which are found to-day, some in temperate and others in tropical regions, and still later a definitely tropical flora flourished in the Isle of Wight. ${ }^{5}$ The climate must therefore have become hot again. The tropical flora was maintained still later ${ }^{6}$ in the sandstone formations at Sabalites in the region of Maine and in the south of England. ${ }^{7}$ At the end of the Tertiary Era ${ }^{8}$ the mean temperature of

1 Lower Thanetian.

3 Dewalquea.

5 Lutetian.

7 Lattorfian.
2 Dryophyllum.

- Upper Thanetian.

- Auversian.

8 Neogene. 
the Arctic region was still about $\mathrm{I}^{\circ} \mathrm{C}$., according to Oswald Heer. At Spitzbergen there grew side by side with Osmundas, Horsetails and Taxodiums-Poplars, Plane-trees, Walnuts, Elms, Hazels, Hamamelidacer, Alders, Magnolias, Lime-trees, Viburnum, Catalpas, etc., and to these were added in Greenland, Willows, Birches, Myrica, Beeches, Maples, Holly, Ash, Hawthorns, Plum-trees, Black Alder, Rhubarb, Ivy, Cornacer, and even the Grape-vine. The relative lowering of the temperature during the Cretaceous Period, however, is sharply indicated by the absence of Palms. from these regions. Fewer species appeared even in Europe.

Although these questions have been discussed before (pp. 2S, 5I), from another point of view, it was necessary to recall the facts here in greater detail to render intelligible the relation they bear to the various fauna that succeed one another. The Nummulites appear to be a transformation of an older genus of Foraminifera, the still extant Operculina, to which should be related the Assilinas with their less complete spirals. The Nummulites are so numerous in that it has been possible to use them to determine the lines of the sea-coast, and on account of their widespread distribution they have furnished us with the best method of studying the deposits of this age and their development. The different types of our present Invertebrates were already determined, and though their species, dating like coins the age of the various strata, have a great interest for geologists; though it is often possible to follow their transformations through a series of layers (as in the case of certain Cerithidr) and to bring thereby supplementary, but not indispensable support to the doctrine of evolution; yet they are only of secondary importance from the point of view that we are considering here. What we seek are the causes which lead to the formation of the principle organic types, and the laws that have determined their evolution. We cannot enter here into a discussion of the infinitely varied accidents-often, indeed, quite beyond our ken-that have determined the characteristics of species.

Among the Vertebrates we saw different types of Fishes, Batrachians, and Reptiles appear, evolve, and very often disappear. From the Cretaceous up to the time when they appear to be almost as varied as they are at the present day, 
the evolution of Birds is wrapped in impenetrable mystery. This evolution must have been rapid, because although Birds are descended from a highly specialized branch of the Reptiles, they differ among themselves only in characters that are really secondary. Already at the end of the Cretaceous era some had lost their wings and the keel of their breast-bone, and being more completely affected by this retrograde cvolution than those of our present-day birds unable to fly, cannot be considered as their ancestors. This alone suffices to render suspect the natural character of the order of Ratites. Since, however, it is characterized by this inability to fly, it is the only order which has raised hopes of providing some indication of the ancestral form of Birds. Unfortunately, the faculty of flying can be lost as well as acquired; and it is often difficult to distinguish retrogressive from initial forms. The earliest known Tertiary Birds are Gastornis, Diatryma, Dasornis, and Remiornis, all Eocene. There is no reason for placing the one that lived in France during the Tertiary Period-Gastormis-at the head of their geneaological tree. Some naturalists make it a Goose, some a Bustard of the size of an Ostrich and unable to fly. The others: Diatryma of New Mexico, Dasornis of the I.ondon clay, and Remiomis of the neighbourhood of Rheims, are all incompletely known. Only a metatarsal of the first, skull fragments of the second, and some fragmentary bones of the third have been discovered. It is too little to warrant us in drawing inferences as to the structure of primitive Birds.

In the Miocene strata at Santa Cruz in Patagonia, Dr. Ameghino dug up a whole series of Birds, which have been grouped by Morenco and Mercerat under the denomination of Stereornithes. But this grouping would seem to be entirely artificial. Of its constituent genera, Mesembriornis seems to be akin to the Nandus which still abound in South America; Dryornis was a bird of prey related to the Condor; Dicholophus resembled the Cariama; Phororhachos, with its enormous skull, its upper mandible terminating in a strong hook and the lower bent up over it, remains enigmatic.

The Ostriches may perhaps be nearer to the initial type than any of these fossil Birds. The digits of their wings approximate more closely to the ordinary digital type than those of all other Birds; and they present a pubic symphysis, in 
which they are more backward than the Orthopod Dinosauridæ. They have, however, lost three of the toes of their feet, showing that the type had already experienced important modifications. They are present in the Miocene of Samos.

The Nandus also lived in the Miocene, but in South America. As in the ostriches, the pelvis was closed, though in their case by union of the ischia, whereas it was the pubic bones that were united in the ostrich : the foot terminated in three toes, the wing digits had already the conformation found in flying birds, and they were still further removed from the ostriches by the structure and position of the vocal organ or syrinx. It is probable that they did not even belong to the same series.

The Cassowary group is represented in the Pliocene by the genus Hypselornis. These birds have scarcely any wings, but the skeleton of this minute wing with its two united digits is that of degenerate Birds which have lost the ability to fly.

After the Ratites, the present-day birds presenting the most primitive characters are the Tinamous of tropical America. They are characterized by the union of the vomer with the palatine bone, a condition already indicated in the Emu and Apteryx, by the articulation of the quadrate with the skull by a single condyle, the absence of union in the ilium and ischium, and the independence of all the caudal vertebræ. But they are not known in the fossil state. In the Miocene we find every type of Bird already represented, as the fine work of Alphonse Milne Edwards on the fauna of Saint-Gérandle-Puy in the department of the Allier have shown. Nothing enlightens us as to their past, so that interest becomes concentrated on Mammals, whose wonderful and gradual expansion during the Tertiary Period constitutes one of the most brilliant chapters of Natural History.

Mammals had lived side by side with Reptiles from Triassic times, but during four million years they occupied a modest position, effaced by their small size. As with Birds, they only became important when the day of the Reptiles was over, but their progress, instead of being made in regard to detail, fundamentally modified their organization and was slower than that of the Birds. Accordingly, we can follow it step by step. We must not imagine, however, that this evolution 
took place in such a manner that we can pass consecutively from primitive to modern forms, each fossil genus furnishing us with a link in the chain binding them together. A great many series remain outside this chain. They are like the branches of independent genealogical trees, forming a veritable forest when seen from above, but in which it is extremely difficult to recognize the trees, and, on these trees, the branches to which present-day forms should be attached.

The small Mammalian forms that appeared in the Trias (Tritylodon) are encountered again with their multituberculate molars and complete coracoid in the form of Neoplagiaulax, Polymastodon, Ptilodon, and Chirox, in the Nummulitic deposits of New Mexico. ${ }^{1}$ The Ornithorhynchus and the Echidna are their present representatives. The horny tooth of Ornithorhyncus is, in fact, preceded by a rudimentary indication of a multituberculate tooth. These Mammals, confined to New Guinea, Australia, ${ }^{2}$ and New Zealand, even in some cases to Australia alone, ${ }^{3}$ are still oviparous, and it is probable that the multituberculate forms also were oviparous. These Mammals, which form the sub-class Monotremata or Prototheria, are removed only from Reptiles by their hairy skin richly provided with glands, some of which are already lactigenous; their mode of reproduction, the structure of the shoulder-girdle comprising two clavicles united into a sort of fork, with a coracoid and a precoracoid bone on each side, like that of the Lizards, and their marsupial bones, the last renunants of abdominal ribs, are distinctly reptilian.

With the exception of the Theriodontia, the Reptiles were chiefly modified in the direction of locomotion, for they retained their simple teeth, with a cutting edge in plant-eaters and sharp points in flesh-eaters. The Mammals, on the contrary, evolved in three directions-gestation, dentition, and locomotion. Further, their flexible skin, permanently moist, and rich in glands, but also in the sensitive cells to which even hairs are only, as it were, annexed, constituted a source of multiple excitation, which explains in some measure the rapid development made by their cerebral apparatus.

From the point of view of gestation the present viviparous

1 In the San Juan Valley (Puerco and Torrejon beds).

2 Proechidna and Echidna.

3 Ornithorhynchus. 
Mammals exhibit two stages, of which one is certainly primitive and has led to the other. In the first the young develop within the body of the mother in a special pocket, the womb, formed at the expense of the oviducts and which simply served to shelter them. They are born in an early stage of development, and at once deposited in an external sub-ventral pocket called the marsupium, containing mammæe to which the young immediately attach themselves. These Mammals form the sub-class Marsupialia, Didelphia, or Metatheria. They have retained the epi-pubic bones of the Monotremes, but the shoulder-girdle is singularly simplified. It is reduced to clavicles and to scapulæ, with which are united in the form of an apophysis all that remains of the atrophied coracoids. The two clavicles are never united into a furcula. The posterior angle of the mandible is turned inward.

The other Mammals form the sub-class Placentalia, Monodelphia, or Eutheria. The embryonic envelope of the young and the maternal womb here enter into intimate union, through the medium of highly vascular villi produced by the embryo, which penetrate the uterine wall, to form, in conjunction with it, the placenta, thus permitting the easy filtration of the nutritive elements in the mother's blood into the blood of the fœtus. In the Eutherians the marsupial bones have vanished, and the angle of the mandible is never inflected. The placenta can be discoid (shaped like a cake), zonary (shaped like a muff), bell-shaped, diffuse, or cotyledonary. The same form of placenta characterizes an entire order.

If, however, we attempt classification according to placenta form, the Primates find themselves somewhat singularly grouped with the Insectivora and the Rodent; Elephants, and the herbivorous Hyrax with the Carnivora, and Lemurs with the Pachydermata, while the order of Edentata would be broken up, for Orycteropus and the Armadillos have a zonary placenta like Hyrax, the Ant-eater's is bell-shaped, and the Pangolin's diffuse. The contact area of the allantois and the chorion that furnishes the placental villi, is small in the Insectivora and employed in its entirety in their formation. It is extensive in the Primates where the villi are restricted to a part of its surface only. There is here a considerable difference, though it is not impossible that the one arrangement may have developed from the other. In the other zoological 
series it is highly probable that the placenta was at first discoidal, then became zonary, and finally diffuse or cotyledonary. To the Insectivora with discoidal placentas succecded the Carnivora with zonary placentas, and here the evolution was arrested. The Rodents correspond to the initial condition in the herbivorous animals, Elephants and Hyrax to the second stage; Pachydermata and Ruminants to the last. In support of this way of looking at it, it may be pointed out that the young of animals with a discoidal or zonary placenta are born incapable of feeding themselves or of walking, and that the Herbivora which have a diffuse or cotyledonary placenta are born in a fairly advanced state of development, and are capable of walking and running. It is in these animals, moreover, that the limbs are most highly differentiated. The Metatheria are confined to-day to South America and Australia, land-areas which were united only during the existence of the Gondwana continent, and we must consequently put their origin back to that period. At one time, however, they were cosmopolitan. The Eutheria appeared later, probably outside the regions to which the Metatheria have been driven back to-day - at any rate, outside Australiawhere the Metatherians constituted the entire Mammalian fauna prior to the European occupation.

In common with Reptiles the primitive Mammals had uniform teeth, and four limbs constructed on the same plan each ending in five digits. Living under the same conditions they would necessarily have evolved in analogous fashion if these conditions actually counted in their evolution. Like the Theropod Reptiles of the Triassic Period, all Mammals masticated their food, and their teeth were appropriated in the same way to the various functions that this habit requires; they were divided into cutting teeth or incisors, tearing teeth or canines, grinding teeth or molars. Fxcept that the molars, instead of remaining simple and being modified only by a broadening of the crown, as in nearly all the Theropods, were made up like those of the Ceratopsidæ, by the union of several teeth, whose roots generally remained separate but whose crowns became one. Efforts have been made to determine the number of the teeth thus united from the number of tubercles possessed by the crown, and the following adage has even been formulated: tot numeramus 
dentes quot tuberculia. ${ }^{1}$ But if in that stage of their development, when they consist entirely of enamel, teeth can become united by their crowns, in the later stages it is the number of dental bulbs, and hence the roots that have remained free, that will indicate the number of teeth united. This union often occurs in an accidental manner in the simple teeth of the Cetacea, and is also evident in the molars of certain Marsupials, such as the Thylacine. It may happen, however, that a compound tooth appears to have but one root, as in the outer incisor, always marked by a notch, of the Giraffes and the Okapi. This incisor results from the union, throughout their extent, of two teeth, one of which is reduced almost to its crown. Considerable prudence must therefore be exercised in enumerating the teeth that have entered into the composition of a molar, but the fact that they have been thus produced by union cannot be contested, and establishes an important distinction between the Theropod Reptiles and Mammals.

The molars of living Marsupials do not all appear simultaneously. After the first dentition is established, the last cheek-tooth falls out and is replaced by another behind which new molars are formed. In the placental Mammals all the teeth of the first dentition are replaced by others, followed by the eruption of new molars. These are the molars properly so-called. The cheek-teeth replaced are called pre-molars. As teeth are modified with the change of diet, the marsupials can be divided, according to the form of their teeth, into orders corresponding exactly to those adopted for the placental animals, as follow: the Creophagi corresponding to the Carnivora, the Entomophagi to the Insectivora, the Rhizophagi to the Rodents, the Poephagi or Grass-eaters to the Herbivora. This correspondence does not imply, however, that the form and the number of the teeth correspond for each group with what may be observed in placental animals. In the Creophagi there are four or five pairs of incisors in the upper jaw, whereas in ordinary Mammals there are never more than three at the most; hence Richard Owen called the first Polyprotodontia. On the other hand, the Carpophagi and the Poephagi have but a single pair of incisors in the lower jaw and generally three pairs in the upper, and these Owen grouped as Diprotodontia.

1 There are as many teeth as there are tubercles. 
An identity of diet has occasionally produced in Marsupials and Placental Mammals some astonishing resemblances in detail over and above the general resemblances just enumerated. Diprotodon, for example, which lived in Australia at the beginning of the present era, was about as large as a Rhinoceros and had a dentition almost identical with that of the Rodents. Its upper jaw, having no canines, became elongated into a snout bearing two enormous incisors separated from the molars by a wide space, and concealed immediately behind these large incisors were smaller ones similar to those of a Rabbit, except that instead of one there were two, one behind the other.

The limbs underwent slight modifications only, and in a particular direction. The anterior limbs, being frequently used for prehension, retained their five digits; but the hind legs, in species belonging to numerous genera living on insects or fruits, have the second and third toes united and are relatively slender. This arrangement recalls that to be observed in the Kingfisher, Hornbill, and other syndactylous Birds, and is due to the same cause. These Marsupials live on trees whose branches they are obliged to seize, and therefore the longest digit plays the principal rôle; the others press against it, unite with it, and partially atrophy. This arrangement is preserved and exaggerated in the jumping Kangaroos, whose median digit is very large, the hallux absent, and the other digits astonishingly slender and joined together by skin. Nothing in the Kangaroo's present mode of life demands such an arrangement. But it is at once explained if we regard these animals as descendants of climbing Marsupials, a supposition confirmed by the existence of arboreal Kangaroos, the Dendrolagi. The Marsupials are, moreover, far removed from the Placentals with regard to their place in the scheme of Nature. From the beginning of the Tertiary Epoch, the Placental Mammals, being endowed with a method of reproduction far superior to that of the Marsupials, have everywhere had the advantage of them, have multiplied very rapidly, and adapted themselves to the most varied conditions of life; and, living in security and amid plenty, they have frequently been able to increase their size from one generation to another. They thus played the same part that the Reptiles filled in the Secondary Epoch, without attaining to their dimensions, 
except in the water, but surpassing them greatly in both agility and intelligence. Like the Reptiles, some are carnivorous, others herbivorous. The carnivores are plantigrade or digitigrade, without presenting any great modifications in limb; the herbivorous types not only raised themselves upon their digits, but succeeded in achieving what the Reptiles never did, a stance on the end of the distal phalange, around which a nail developed so as to form a hoof ; they now became " unguligrade" and constituted the order of Ungulata. As the Reptiles had done before them, they took possession of the air and of the water. We saw before (p. I93) how climbing Mammals of many orders acquired a parachute, and how they led up to the Bat, which has wings constructed on the type of the Pterosaurs of the Secondary era, but more highly perfected, since four of its digits instead of one are employed in supporting the flying-membrane. Indeed, this seems to have been achieved twice, that is to say, by two distinct types of Mammals, for the large fruit-eating tailless Pteropus of warm countries is very different from the ordinary Bat, which is insectivorous and has a long tail incorporated in the wing membrane.

Twice, also, have placental Mammals managed to acquire the freedom of the ocean, as did the Ichthyosaurians, which they resemble but surpass in the perfection of their adaptations. Thus we find Herbivorous Mammals constituting the order of Sirenidia, which preserved the mobility of their elbow, and Carnivorous Mammals the order of Cetacea, which preserved only the mobility of the shoulder. In both cases the hind limbs disappeared, and the tail became a very powerful motor organ. The Sirenidians have pectoral mammæ and rise half out of the water to suckle their young; the Cetaceans, by a sudden muscular contraction, ejaculate their milk into the mouths of their young, which do not suck : their mammæ are inguinal. Possibly a third type presents this same adaptation to an aquatic life. Seals are Carnivora of an advanced type which have preserved their four limbs in a form less removed from the ordinary foot than the natatory paddles of the Sirendia and the Cetacea, modelled on those of the Ichthyosaurians. However, in the Eogene Period there lived in Alabama and New Zealand a huge aquatic Mammal, the Zeuglodon, which sometimes attained a length of thirty 
metres, like our Baleen Whales and Cachalots. It had no hind limbs and its tail was probably pointed, not flat like that of the Cetacea, and it had molar teeth with two roots, singularly recalling those of Seals, whereas in Cetacea all the tecth are alike and have but one root.

We have now to see how these diverse forms were grouped during the successive periods of the Tertiary Epoch.

The laws determining modification of limbs are simple and precise. Confining our attention to the exterior aspects, we may say that, whatever diet was adopted, every series began by forms in which the feet rested entirely on the ground, consequently known as plantigrade. Then the foot gradually became raised so that the toes alone were on the ground; in these conditions the shortest toes soon ceased to touch the ground; being unused, they tended to disappear: but this disappearance occurred much earlier in a hind- than in a fore-limb. The anterior limb was often put to various uses, whereas the hind-limb was always more specialized for the locomotor function: it was the main instrument of propulsion in other types besides Mammals. So much so that the following rule may be formulated: The hind-legs of lanit quadrupeds, more especially ittilized for propulsion, are both more highly developed and more modified than the fore-legs. In general the contrary is true for aquatic Vertebrates, for as the tail plays a considerable part in propulsion, the unused posterior limbs are either reduced (sub-brachian Fishes, Ichthyosaurians) or disappear (Sirenia, Cetacea, Siren among the Batrachians, Sirens, Eels, etc.).

The limbs of the Carnivora undergo no important modifications. The plantigrade forms are numerous and preserve the digits on all four legs. In the digitigrade forms, the Dog and Cat have only four digits on their hind and five on their fore feet. Hyenas have only four digits on all four feet. In the Herbivora, modification extends much further. The digits of the Carnivora, utilized more or less for seizing and holding prey, terminate in claws. It is the same with Insectivora, whose feet remain pentadactyl. In the Rodents, on the contrary, the number of toes is often reduced to four or even three, and the structure of the tridactyl hind foot of the Jerboa, with its united metatarsals, recalls the foot of a Bird. Certain Rodents (Cavy or Cabiai) have the extremities 
of the toes provided with nails resembling a hoof. They would thus appear to have led up to the Ungulates, which arrived eventually at walking only on the extremities of their toes, and in whose limbs the highest degree of reduction of the digits is attained. The arrangement of the carpal and tarsal bones is subjected to the most remarkable modifications. These bones are disposed in two rows. In the carpus the first row comprises three bones: one of them, the scaphoid, articulating with the radius, is also called the radiale, and another, the cuneiform or pyramidal, articulating with the ulna, is therefore sometimes called the ulnare. Between the two there is intercalated the intermedium or semilunar bone. The bones of the second row are placed exactly in front of them: the radial supports the trapezium and the trapezoid; the intermedium the os magnum, and the pyramidal the uncinatum or unciform bone, which itself results from the union of the fourth and fifth bone of this row. Each of these bones supports one digit only, with the exception of the unciform bone, which is double and supports two. Thus the bones of the digits and those of the carpus are disposed as tar as the bones of the forearn in longitudinal series, in which each bone unites only with the one preceding and the one following, and is free laterally. This serial arrangement in the carpus is not particularly inconvenient and has perhaps some advantages for animals with a heavy tread, in whom the foot plants the whole extent of its inferior aspect on the ground and is thus unembarrassed by irregularities. On the other hand, it exposes fleet-footed animals to the risk of dislocations, since at each bound they land sudrlenly upon the end of the toe, which is the only part of the foot to touch the ground. This arrangement is already modified in the hind foot in the oldest plantigrade forms. There the tibiale and intermedium are united to form the astragalus, which articulates with the tihia; the fibulare or peroneal, which follows the fibula, develops particularly in the rear, and forms the calianeum or heel-bone; a special bone, the nuvicular, represents the os centrale of the Batrachians, and a free bone, the pisiform, is perhaps the remnant of a sixth digit that has always remained rudimentary. In front of the bones of the first row are arranged the five bones of the second, of which three, the cuneiform bones, remain free and two are united to form the cuboid. The serial arrangement appears only after these 
last, each cuneiform supporting one toe and the cuboid two. This serial arrangement is characteristic of a group of mammals which did not survive the Eocene Period, and to which Cope gave the name of Condylarthra. Their principal representatives are mainly, if not exclusively, American: Periptychus, still plantigrade, and Phenacodus, semi-digitigrade, about the size of a large sheep. Among the large Ungulates, all of them Eocene, this seriation had already become modified ; they were still semi-plantigrade, and consequently provided with all five toes. Cope grouped them together as Amblypoda. In their feet, the bones of the second row of the carpus slightly override the first, and the metacarpals alternate with them regularly in such a way as to support themselves between two of them and thus maintain their union.

Representatives of this order particularly well distributed in North America are Pantolambda, Coryphodon, Loxolophodon with a skull more than a metre in length, and Dinoceras, about the size of a Hippopotamus, powerfully armed, like the others, with horns and canines, of which we shall speak later. The short feet still have four to five toes, all of which rest on the ground in Mceritherium and Palcomastodon, in various precursors of the Elephants, and in the Elephants themselves. These have all been grouped together in the order of Barypoda, in which the dentition undergoes considerable reduction. We see, finally, a gradual diminution in the number of toes, coinciding with important modifications in dentition in the heavy animals, with serially arranged tarsus or carpus, as in those Condylarthra that Burmeister has included in the order of Toxodontia. Homalodontherium and Prototypotherium are still pentadactyle, but there are only four digits in the hind feet of Typotherium, and this reduction has also taken place in the fore feet of Toxodon. Finally, in Hyrax, an animal of the size of a Rabbit, our present-day representative of the whole order, there are only three digits in the hind and four in the front foot. This brings us to those orders in which the straightening of the foot having reached the maximum, the animal only rests the extremity of its longest digit upon the ground.

If the third digit is sufficiently longer than the others, it supports the whole weight of the body. Ungulates with feet so constructed are called Perissodactyla. If the third and 
fourth digits are almost equal they share the task of supporting the body and become almost exactly alike. The foot then assumes the cleft form characteristic of the Artiodactyla. In both cases the lateral toes tend to disappear thiough lack of use and all the stages in this retrogression can be followed. In the order of Perissodactyla, where the foot is reduced to a single toe, as in Horses, this reduction and disappearance takes place only after the bones of the carpus and the tarsus have gone on for some time being displaced in order to afford mutual support, piling up over one another and articulating one on the other. They may unite, but do not disappear. It is otherwise with the Artiodactyla. Here the reduction was produced in a first series of forms, while the carpus and tarsus were still seriated. The bones of the carpus and the corresponding bones of the tarsus are either reduced or disappear, and both hind and fore feet have preserved their frailty. This is what Woldemar Kowalevsky, brother of the famous embryogenist, called non-adaptive reduction. The Artiodactyla that underwent it all disappear from Miocene times onwards : they were Dichobune and Hyopotamus, provided with four digits; Anoplotherium, an aquatic animal which had only two to the fore limbs, with a third much reduced digit to each hind limb; and Xiphodon, more graceful than our gazelle, which had only two toes on all four feet, and whose molars were the first to show the Ruminant tendency, although Xiphodon must not be considered as their ancestor. To these must be added Anthracotherium, Charopotamus, and Hyotherium, related both to the Wild Boar and the Peccary, and particularly Entelodon, large as a Rhinoceros. In the persisting forms which have led in one direction to the Pig and in another to the Ruminants, the heads of the third and fourth metacarpals have been broadened as though crushed under the animal's weight. They have encroached upon the carpals supporting the lateral toes, and thus assured the preservation of these last. When the reduction in the number of toes begins only after this modification has taken place, W. Kowalevsky describes it as adaptive reduction. This is the condition in the Hippopotamus, Wild Boar, Peccary, and the other existing Pigs. The metacarpals and metatarsals in these animals are never united, nor were they united in prinitive Ruminants. The latter series begins with Oreodon, 
a form probably originating in the Condylarthra, related to Pantolestes, and which still possesses, besides a complete dentition, five digits on the fore feet and four on the hind feet; the pollex is already very small and the four persisting digits are all equal in size. Oreolton was closely related to the ancestors of the Camel, whose first representatives are Leplotragulus of the Eocene of North America, which still had four digits on its fore limbs, and lateral metatarsals without toes on the hind. The Pccbrotherium of the Oligocene of America had only two toes and two rudimentary metacarpals in the fore limbs. The metacarpals and the metatarsals are united into a single cammon-bone in Protolabis and Procamelus of the Miocene. This same union has come about in another and quite independent series of Ruminants. In these initial forms there are four complete digits on each foot, only two of which touch the ground; in Dorcatherium and Hypertragulus, both of which are Miocene, there is no union between the metacarpals. Union is present, however, in Gelocus, aiso Miocene, so far as the metatarsals are concerned, and also in Hycmoschus, still living in Western Africa. There is union in both in Tragulus of the Pliocene. In all other Ruminants the metacarpals and metatarsals are respectively united to form a cannon-bone. In Cervidæ and Bovidæ there are still two lateral toes, but the metacarpals and metatarsals are more or less incomplete and reduced often to a simple splint. In the Ovidæ there is no longer any trace of lateral toes, and they are absent also in Giraffes, Sivatherium, Samotherium of the Miocene in Samos, Helladotherium and the Okapis, although these forms are less highly evolved than the Cervidæ so far as the horns are concerned. Here the feet are completely consolidated and no longer comprise any useless parts. If the animal had not in the beginning immobilized its metacarpals and metatarsalsor practically done so-by a deliberate act which became habitual, their union, itself a proof of such immobilization, could not have taken place. The part played by the animal in the modification of its own organism is thus clearly apparent.

The Perissodactyla present digital reductions parallel to those of the Artiodactyla. They had a common ancestor in the five-toed Phenacodus, with seriated carpals and tarsals. 
This seriation is preserved in the Titanotheridæ of North America (Lambdotherizm, Palaosyops, and Diplacodon of the Eocene), which, with Titanotherium, attained in the Miocene to the size of an Elephant. These animals had four digits on the front and three on the hind feet, and bore on their noses a pair of large protuberances, which doubtless supported horns analogous to those of the Rhinoceros. The Macrauchenia and the Proterotheridæ had only three digits to each foot. They lived in South America and constituted a series which immediately followed on to the Condylarthra. In another series the carpal and tarsal bones had ceased to be seriated. This series begins in the Eocene with Hyracotherium, an animal about the size of a Fox, which appeared in America, and there evolved into Pachynolophus and Propalacotherium, represented in America by Orohippus, Eohippus of Wasatsch, and Epiphippus of Uriste, which had four digits on the fore and three on the hind limbs. The Lophiodontidæ of Europe and of the American Eocene (Lophiodon. Heptodon, Helaletes), the Tapiridie, which differ from them in the character of their molars (Systemodon, Hyrachyus, Tapiravus, of America, and Protapirus and Tapirus of Europe), all had four digits in front and three behind. But in Palcotherium and Paloplotherium of the Eocene of Europe, many species of which have left their remains in the gypsum of Montmartre, the number of digits on all four feet had already decreased to three, all of which rested on the ground. These animals had the gait of Llamas; their radius and their fibula were complete, and they had a rudimentary fifth metatarsal. Similarly the Rhinoceros, which has survived to our own times, appears first in the Eocene of Wyoming and the Uinta formations as the genus Amynodon, with few exceptions (Acerotherium, Diceratherium) as a tridactyle animal.

The reduction of the toes was continued in the series of Equidæ, whose molars are marked by a median longitudinal crest. The three toes in this series are still almost equal and touch the ground in Mesohippus of the American Oligocene, whose fibula has begun to be reduced. The median toe becomes prominent in the American Miohippus, which migrated into Europe in the Miocene, where it constituted the genus Anchitherium in the Middle Miocene of France and Germany. This predominance is accentuated, and the lateral toes cease 
to touch the ground in the Anerican Merychippus and Hippotherium, as also in the European Hipparion of the Upper Miocene. Finally, in Protohippus and the Pliohppus, only one functional toe remains. These last reached South America, and then produced Hippidium and the true Horses, which gradually spread over both hemispheres, but died out in South America.

In all these animals, when the foot could no longer make any rotatory movement in relation to the leg, the muscles attached to the fibula, which determine these rotatory movements, were no longer used, but atrophied, as the doctrine of Lamarck prognosticates, and brought about the gradual atrophy of the fibula to which they were attached. For the same reason the radius of the fore leg which corresponds to the fibula became completely united with the ulna.

To sum up, the same tendencies are at work in the evolution of the limbs both of Mammals and Reptiles. In both classes the terrestrial animal succeeded in penetrating into other environments open to its activity - the water, from which its ancestors formerly came, and the air, from which its weight would seem to exclude it, and it arrived at progression in both these media by analogous procedures. On land its evolution, apart from a few special adaptations, such as that permitting underground or arboreal life, for instance, was dominated by two needs-to see as far and to run as fast as possible--which induced them to erect themselves on their limbs. In both cases the intervention of the animal's own volition, with a view to attaining a desired end, is evident. The resulting modifications were not linked with any particular diet; therefore the modification of the teeth do not strictly follow those of the limbs.

The oldest placental Mammals possessed what is called a complete dentition, that is to say, forty-four teeth-eleven to each half of the jaw (three incisors, one canine, four premolars and three molars). This dentition is seen at the beginning of the series in the herbivores, the insectivores, and the carnivores. It is occasionally reduced, but never increased, except where elements of the molars become dissociated, as in Cetacea. It must therefore be considered as the primitive dentition of the placental Mammals, and its generality leads us to think that all these animals descend from the same initial type, one 
that probably existed during the Cretaceous Period, but which has not as yet been found.

Both cutting-edged incisors and sharply-pointed canines had only one root and are but little removed from Reptilian teeth. They are teeth that cut or tear, and by these actions stinulate the dental gern that produced them and maintains them in activity. Hence their growth was continuous, especially in the case of animals which attack hard substances like wood. This phenomenon had been already produced once before in the case of the Marsupial Diprotodon (p. 29I). It occurred again in Eocene times in Tillondontia, in whom the first and second incisor (Psittacotherium) or the second only (Estonyx) Tillotherium, or even the third (Stylinodon), underwent great development; the others became smaller again or disappeared (Tillotherium). In Rodents the second incisor is highly developed, while the first and third attenuate or disappear. In Hares, Rabbits, and analogous forms the upper jaw of each side has two incisors, one large and the other small, situated one behind the other. In other Rodents the small incisor disappears. Tuxodontia also had incisors very unequally developed (Nesodon) or even reduced to two pairs (Toxudon). The same phenomenon is produced in the series leading up to the Proboscidea, which, in addition to a trunk, possess enormous incisors constituting tusks.

Thanks to the discoveries made in the Fayum, in Egypt, twenty years ago, we can here follow this transformation step by step, and determine the exact causes which have produced these tusks and have led by way of repercussion to the development of the trunk. In this region there lived about the middle of the Eocene period Mcritherium, of the dimensions of a Tapir, whose second pair of incisors had taken a considerable development in each jaw. The large incisors of one jaw came into contact at the extremity with those of the other, and this reciprocal pressure tended to bring them into the position of a prolongation of the jaws. The other incisors and the upper canines were rudimentary; they had already disappeared from the lower jaw. The Moritherium must have possassed either a long mobile upper lip, like that of the Rhinoceros, or a short trunk like that of the Tapir. A little later on there lived in the same region the Palcomastodon, which had only two enormous incisors in each jaw and no 
canines at all. Its lower incisors, having become almost horizontal, were no longer worn away at the edge with use, and consequently became greatly elongated. The upper incisors clearly tended to become parallel with themone step more and we arrive at the condition in Tetrabelodon and the Mastodons, which had four large horizontal incisors, two upper and two lower. All these animals had trunks; that of the Mastodon rested on its tusks and consequently could not be curled around an object like the trunk of an Elephant, and could only seize things by the terminal lobe. We can therefore see the mechanism at work in the production of this singular appendage. It was at first a simple, mobile, and prehensile lip like that of the Rhinoceros. As fast as the incisors grew, the elforts of the animal to continue to seize with his upper lip the food that lay beyond their extremities was bound to lead to the gradual elongation of the lip, which was constantly being cxtended beyond the incisors, transformed into tusks, and thus grew to a great size, constituting the trunk-prehensile only at its extremity-of the Mastodons. From these animals, by the disappearance of the upper incisors, was derived the huge Dinotherium, and by the disappearance of the lower incisors the Elephants. In the Dinotherium the lower tusks, at first bent downwards by the upper ones, eventually grew vertically, the animal using them in the manner of picks. In the Elephants, the upper incisors are widely separated, leaving an empty space between. In both cases the trunk, having become free, can be either raised or lowered at the animal's will, and serves him for the most varied purposes.

The animals above described balanced the great development of the incisors by losing their canines. In the Dinoceratide, on the other hand, it was the canines of the upper jaw that became large. They are very long, and flattened like sword blades, in Dinoceras, and curved back in a semi-circle in Loxolophodon. This pronounced development of the upper canines was balanced by the disappearance of the incisors of the same jaw. This may be compared with the disappearance of the upper incisors in the Chevrotains, where the male is provided with a pair of enormous canines, whereas the incisors disappear, so that this disappearance of incisors in the upper jaw would seem to be covered by a general law. This 
disappearance once achieved in the Chevrotains, it would be preserved by heredity in other ruminants, such as the Cervidæ, where the males still have a canine.

The molars, being employed in the trituration of food, naturally become modified according to the use that the animal makes of them, and end by being more specially adapted to the consistency of the food than either the incisors or the canines. The primitive number of seven-four premolars and three molars - may be reduced, but they never disappear in animals which masticate their food. Arising from the union of several teeth, such as the purely prehensile teeth of the Reptile, in the first place they naturally had a crown with a broad and mamillated surface, especially as this crown might already present, in Reptiles, certain surface complications, such as we noticed in Theriodontia. These surface bosses or tubercles may be joined in such a way as to form ridges transversal to the direction of the jaw (Mastodonts, Tapirs, etc.), or longitudinal crests (Carnivora). On the basis of these data, a first approximation of the essential facts may be condensed into some such formula as this:-

As generation succeeds generation, the modifications in the teeth occur as though the adults transmitted to their descendants the forms that have been acquired in the course of their lifetime through use and attrition.

According to the degree in which a Mammal adopts an increasingly carnivorous diet, the molars of the lower jaw meet those of the upper jaw scissor-fashion, and become sharpened by the shearing away of the upper edge of their crown. Thus we see the transition from the tuberculate molars of the Bear to the exclusively scissor-edged molars of the Cat. On the other hand, when Mammals live on vegetable food, generally hard, the crowns of the opposing molars in the two jaws become planed down and present a large grinding surface striped with bands of enamel. It is in this fashion that the molars of Mastodons, with their protruding transverse ridges, became the flat-crowned teeth of the Elephants, in which the enamel is arranged in lozenge-form (Loxodon or African Elephant), or in flattened ellipses (Elephas or the Asiatic Elephant). In the same way the tuberculate bossed teeth of Palceotherium and Anchitherimn are replaced by the flat-surfaced teeth of Horses in which the enamel bands with an apparently capricious 
contour outline the base of the primitive tubercles. The tuberculate teeth of the Rhinoceros have a flattened crown but an elongated body, and thus evolved, as Boule has pointed out, into the smooth, elongated teeth of Elasmotherium. In Rodents we can follow all the transitions between the bossed teeth of the Marmot and the rasp-like teeth of the Cabiai, Beavers, Dormice, etc. The omnivorous cleft-footed Mammals, of which our Wild Boar is typical, have retained the mamillated teeth of Anthracotherium, and Waldemar Kowalevsky has created for them the sub-order Bunodontia. These teeth are replaced in the herbivorous forms, which he called Selenodontia, by teeth with a flat crown, formed by juxtaposed crescents which represent the bases of the worn-down tubercles of the Bunodontia. But as attrition always causes the disappearance of the enanel on the surface of the teeth, and as enamel is produced here in the ordinary way, it is evident that there is no question here of inherited attrition. In reality the dental germ takes the form determined by the pressure transmitted to it, according to the use the animal makes of its teeth while they are growing. Constant pressure of upper and lower teeth one against the other must bring about a flattening of the surface of the dental germ, and, as a result, must cause it to produce a flat tooth which looks like a worn tooth, with its tubercles reduced down to their bases, these also looking like worn tubercles. The same obtains for the lateral compressions in the teeth of Carnivora.

The influence of the increasing development of certain teeth on neighbouring teeth, already pointed out in connexion with incisors and canines, is again encountered in the molars of the Carnivora. Here the molars that do the most work are those situated in the neighbourhood of the attachment of the masticatory muscles to the jaw. They grow and develop that cutting edge which has earned them the distinctive name of carnassials. They are already clearly characterized in Dogs, some of which still have forty-four teeth. In the Carnivorous group the other molars decrease in the front as well as at the back of the carnassial teeth, and finally disappear one by one in measure as we pass from the Dog to the Civet, Marten, and Cat families. Thus their number decreases from seven to two (Machcerodus).

The reduction of the number of teeth is due, however, 
to other causes besides the disproportionate growth of certain individuals. Among the herbivorous animals the Ruminants are the first examples of this. These animals, as we have seen, appear to be derived from Oreodon of Oliogocene times, which already had the molars of Ruminants but five digits, of which one was very small on the front feet and was absent in the hind ones. They appear to be descended from the Condylarthra (Pantolestes), and were followed by Ccenotherium, which still had a complete dentition, though a wide space known as the gap or diastema, in which the canine occupied a variable position, had been produced between the incisors and the molars. In their successors the lower jaw preserved the complete dentition, in spite of this gap, except that the canine was placed against the incisors, whose form it took, and the first premolar, with a greatly reduced root, united with it, so that it appeared to be hollowed out on its cutting edge in the Giraffidæ (Giraffe, Okapi). Thus apparently there were only six molars in all, and that is the number that persists in the other Ruminants. Things were far more complicated in the upper jaw. There the dentition was still probably complete in Leptotragulus and Proebrotherium of the North American Eocene; but in the Camels the middle incisors disappeared, and the laterals, canines, and first premolars, set very wide apart, took the form of sharp, curvedback hooks. There are only two premolars in the upper jaw and one in the lower, and in Halomeniscus and Eschatius there is actually only one in each. As for the other Ruminants, those forms with hollow horns have neither incisors nor canines in the upper jaw. It may indeed be asked why the incisors of Ruminants have disappeared while they remained in Horses, which also browse on grass. Aristotle had already pointed out, and after him Cuvier, that Ruminants with horns had no canines, but both made use of this coincidence as an argument in favour of finalism, on the grounds that animals which could defend themselves with their teeth had no need for horns, and vice versa. The correlation pointed out by Aristotle is not, however, strictly accurate, nor is it an explanation. Is it possible that the calcium employed in the formation of the bony portion of the horns has been used up at the expense of the teeth? Triceratops, the only Reptile with real horns, had no teeth in the anterior portion of its jaws, which were 
transformed into a kind of beak. Dinoceras, lacking upper incisors, was armed with three pairs of horns analogous to those of the Rhinoceros, whose upper incisors have also disappeared. These teeth were also very small or altogether missing in Titanotherium, the most pronouncedly horned form of Perissodactyl; but the reduction of the nuniber of teeth begins in their series with the appearance of horns. The canines are already weak in Hyracodon of the White River Oligocene, and disappear from the upper jaw of the first Rhinoceroses, which have no horns (Aceratherium), and retain only two pair of incisors in the upper and one pair in the lower jaw. They migrated to the former continent and arrived in India during the Upper Miocene, and disappeared in the Pliocene. During this Period the American Rhinoceros (Diceratherium) acquired symmetrical horns; the true Rhinoceros has only one nedian horn or two placed one behind the other. These already existed in Europe during the Middle Miocene (Sansans), where their most highly modified representatives presented neither incisors nor canines. This is also the case in the African Rhinoceros (Atelodus), in the Rhinoceros of Pikermi (Ateloduspachygnathus), and the Rhinoceros Tichorhinus (Calodonta), the contemporary of man. The molars themselves were reduced to five, and had bands of enamel extraordinarily folded in the gigantic Elasmotherium of Siberia, which had a head a metre long, and an enormous horn on its forehead.

From what we have seen above it follows that it is no more possible to affirn in the lineage of the Rhinoceros than in that of the Ruminants that the reduction in the number and dimensions of the teeth present, particularly in the upper jaw, can be due to the development of horns. Nevertheless, we are dealing with such a remarkable coincidence that we have the right to ask whether some fundamental relationship does not exist between these two phenomena, connected with some competition for the valuable lime salts to which both teeth and horns must have recourse in their development.

The oldest horned Ruminants date back to the Oligocene Period, and from that time forward were liberally provided in that respect. These were species of Protoceras of the White River in America. They had then four well-developed digits in front, but two only and a lateral splint behind, large canines, and ten pairs of horns in the male, reduced to two in the female. 
The upper incisors were absent. Following them, in the Miocene, is Proceroulus, in which the horns were not shed and as a rule were simply bifurcated. During the same period, however, they acquired a circle of "pearls" separating the deciduous part from a long persistent peduncle in Dicroceras of the Miocene. In the Upper Miocene the peduncle became shortened and almost the whole of the horn became deciduous in Cervulus, still extant in India. Thus we come to the Roebuck, which dates from the Upper Miocene. The Giraffidæ (Helladotherium, Sivatherium) appear at the same time. At this time also the Antelope, in which a horny casing covers a bony axis, with hollow spaces in it, becomes distinct from the Deer, and thus opened the series of Ruminants with hollow horns, in whom canines have disappeared. Hence the Aristotelian idea of a "balance", as G. Saint-Hilaire would say, between the defensive organs. Arsincetherium of Fayum, which will be discussed later, supplies the gravest objection to such a conception.

It is not easy to explain how the teeth could become simplified and disappear in those animals which are grouped together in the class Edentata. This is, however, no isolated instance. The Ornithorhynchus and the Echidna replaced the multituberculated teeth of their ancestors in the Secondary period by horny ones, except where they lost them altogether. The teeth of the Sirenia and Cetacea, like those of the Edentata, are simplified, multiple, and at last completely atrophied. A general problem thus arises. In the Eocene of Patagonia Ameghino discovered fossil Mammals whose molars were simplified and had become cylindrical, but which still possessed their complete canine and incisor sets. Lestodon and Megalonyx of the same period still retained one canine. They may be considered the ancestors of the living Sloths, which live in trees and feed exclusively on such leaves as they can pull off with a minimum of effort and which they then only need to masticate. We may here invoke the consequences of disuse. The gigantic Megatherium likewise, in spite of its great size, which sometimes equalled that of the Rhinoceros, had numerous affinities with the Sloth. Instead of climbing trees to get their leaves, they pulled them down; but they walked only on the outer sides of their feet, as the Sloths are compelled to do when on the ground because of the length of their nails. If they are 
descended from Megatherium, to whose diet they have remained faithful, there is no reason why their dentition should have been modified. Ant-eaters have the same way of walking, and their pectoral mamma indicate that they are descended from tree-climbing animals, and the structure of the reproductive apparatus makes it clear that these tree-climbers were Sloths. But they have changed their dict: they live on Insects, and their extraordinarily long vermiform tongues are all they need to take hold of their food, which docs not have to be masticated. Lack of usage can explain the total disappearance of the teeth, the form of the tongue, and the elongation of the head and jaws.

In the skin of Mylodon, related to Megatherium, and which has not long disappeared from South America, there were numerous ossicles. These ossicles formed a complete carapace in Glyptodon, whose back was hemispherical and nearly two metres in diamieter. The head still resembled that of the Megatherium, but the feet rested flat on the ground. It is quite likely that the Armadillos of to-day, which can be traced back to the Tertiary (Eutatus, with a carapace formed entirely of mobile strips, and Dasypus), are related to them in some degree; but in their case the jaws are elongated, and this coincides with a multiplication of teeth, which in the great Armadillos are twenty-six in the upper half-jaw and twenty-four in the lower, a total of one hundred in all.

Orcteropius and the Pangolins of the Old World seem to form a special group in which we observe the same abortion of the teeth. They date back to the Miocene.

And here we encounter a new difficulty. Among the fossils of the Eocene beds of Montmartre, Cuvier found a bifid phalange with a nail which he attributed to a very large Pangolin, the only animal except the Mole that possessed a similar character. This hypothetical Edentate received from Lartet the name of Macrotherium, and some time after a head attributed to a kind of Horse was named Chalicotherium. Subsequently, however, an unexpected discovery in the beds of Sansans proved conclusively to Filhol that Macrotherium and Chalicotherium were one and the same animal. Related forms were dug up in the Eocene deposits of North America, and completely reconstructed by Professor Holland (Moropus, Eomoropus, and Pernatherium). They had the general 
appearance of a horse walking on its fetlock-joints, and were, indeed, almost plantigrade. They had only three toes on their feet, terminating in enormous nails. How, we may now ask, did they lose their lateral toes? Were they descended from climbing or hurrowing animals? We do not know.

All Edentata are characterized by the remarkable development of the skeletal system, which presents a curious contrast to the abortion of the teeth. The same contrast is manifested in Ornithorhyncus and the Echidna. Can we, therefore, suppose that this enrichment of the skeleton by the lime salts was accomplished at the expense of the dental system, thus rendered comparatively inert?

This massivity of the skeleton coincides in the Sirenians with an analogous reduction of the teeth. The Eocene Prorastomus, indeed, had almost too many, since in addition to the normal number of incisors and canines it had eight molars instead of seven in each half-jaw. Halitherium, likewise Eocene, which had preserved the rudimentary femur of its hind limb, had already lost two incisors and the supplementary molar. Only the male Dugong has functional incisors, and four of its six molars are rudimentary, while in the Sea-Cow the two incisors remain concealed under a horny plate, but the number of molars of each half-jaw increases, as in the armadillos, and reaches eleven altogether, of which six only are functional. Finally, in the adult Rhytina, the teeth have been replaced by horny plates, as in Ornithorhyncus, These great animals had already been exterminated by 1768 , twenty-five years after their discovery.

The dentition of the Cetacea has undergone similar vicissitudes. No fossil forms are known that present a dentition like that of the primitive placental Mammals. Zeuglodon seems to approximate rather to the Seals. From the very begiuning, as the jaws elongated, the molars seem to have become dissociated and to have returned to the conical form seen in Reptiles. Only the Miocene Squalodon shows a differentiation of the teeth into incisors, canines, and molars. At that time, however, there already existed Dolphins whose teeth were all of the same pattern; Cachalots which had none except in the lower jaw, and species of Hyperoüdon which had only one pair of teeth at the free end of the mandible; as well as a large number of Balænoptera, or even of Whales 
like the Greenland whale, which no longer had teeth but horny baleen plates. We know that while Porpoises and the Grampus live on fish, Dolphins, Sperm-whales, and Hyperoödon live chiefly on soft cuttle-fish, and Balcen-whales on all kinds of small creatures. Such diet, giving the tecth no work, would account for their disappearance, since there would be no stimulation of the formative bulb.

A number of works, pre-eminent among which are those of the American palæontologist, H. F. Osborn (xc, xci, and xcii), have made us remarkably well acquainted with the fauna whose remains were carried down by large rivers during the Eocene Period and deposited in the valleys of the Rocky Mountains. The deposits thus formed are of different ages, and Osborn divides them into four successive groups; in the first, comprising the deposits of Puerco and Torrejon in the basin of the San Juan of New Mexico, ${ }^{1}$ were found Neoplagiaulax and Polymastodon, inherited from the Triassic period, Insectivora, ${ }^{2}$ Creodonta, Tæniodontia, Condylarthra, and Amblypoda. Some of the animals of this first phase have also been found in France, ${ }^{3}$ others in Patagonia. ${ }^{4}$ From the second phase onward, at Wasatch, there are added to these primitive groups Rodents, genuine Perissodactyla, and already-interesting to observe-Primates.

During this second phase there are no longer any forms common to both North and South America, which were at that time probably separated, but numerous species appear in Europe. They become rare during the third phase, which corresponds to the whole of the Meso-Nummulitic, ${ }^{5}$ a period that witnessed the disappearance of the Condylarthra and the appearance of families indigenous to the New World, to which they are restricted, such as the Oreodontidæ, herbivorous animals with an even number of digits, which lasted until the end of the Tertiary, and the Titanotheridæ, represented by the gigantic Titanotherium or Brontotherium. Huge monsters were also produced among the Amblypoda.

1 These deposits are of the Eonummulitic Epoch (Montian, Thanetian, Londinian).

2 Miochlonus, Oxyacodus, Wortmannia, Onychodectes, Triiosodon, Oxyclonus, Loxolophus.

3 They belong to the fauna of Torrejon: Neoplagiaulax, Proviverridæ, Arctocyonidæ, Mesonychidæ, Phenacodus.

1 Trigonolestes, Helohyus, Parahyus.

- Fauna of Puerco. 
Among the Perissodactyla, which were more numerous than the Artiodactyla, Hyrachyus began the line which led to the Rhinoceros, and Orohippus that which led to the Horse.

In the fourth phase, corresponding to the Neo-Nummulitic, ${ }^{1}$ nuinerous types, notably marsupials, ${ }^{2}$ became common to North America and Europe, but the two Americas remain completely separated. Side by side with the Marsupials, Peratherium, the Creodonts are still represented by Hyanodon. The true Carnivores likewise made their appearance with Cynodictis, which appears also in France, and to which Filhol has related all the other Carnivora. Perissodactyla, Protapirus, presaged the coming of the Tapirs, and Mesohippus formed a new link in the genealogy of the Horses; later on they were associated with Miohippus. ${ }^{3}$ Finally, among the Artiodactyla, common to the old and new Worlds, we find Elotherium, Anthracotherium, and Hyopotamus.

The basin of Paris and of the south of England was not, at this epoch, equally rich in Mammals. Nevertheless, after the Thanetian, we find the following: in the tufa of la Fère, Arctocyon, a large plantigrade Creodont whose name signifies bear-dog; in the sandy beds of Cernay discovered by Victor Lemoine, and belonging to the Upper Thanetian and the Sparnacian, in the conglomerate of Meudon and Vaugirard: Neoplagiaulax, Hyanodictis, and Arctocyon, Lemurs of the genus Plesiadapis, and lying above other Creodonts, ${ }^{\mathbf{4}}$ Coryphodun, as in America, and Lophiodon, the precursors of the Tapirs. At this same level of the Sparnacian, moreover, the sands of Ay and the London clay have yielded. Hyanodictis and Pachynoluphus, the latter constituting an advance in the direction of the Tapirs. To these genera must be added, among others, in the Lutetian or the coarse lirnestone of Gentilly, Passy, and Nanterre, the first Palcotherium, and Pigs of the genera Dichobune and Cebochorus. Then come the famous Ludian gypsum formations of Montmartre, where Cuvier made the discoveries that laid the foundations of palæontology. Here were discovered Peratherimm, also known

1 Lutetian, Auversian, Bartonian, Ludian (in the order of their age).

2 The Oligocene or Tongrian comprises, in the order of their antiquity, the Lattorfian, the Rupelian, and the Chattian.

3 Besides Ronzotherium, which belongs to the Rhinocerotidæ, there are Entolodon, Protapinus, Paratapirus, Cadurcotherium, Titanomys.

4 Pachyhyana, Palaonictis. 
in America, Cynohycenodon, Creodonta with teeth similar to those of the Cynhyænas, Cynodictis, Palaotherium, Anoplotherium, Xiphodon, and among Lemurs Adapis, all of which since Cuvier's time have been quoted in the most elementary textbooks. The earliest Bat, the true Vespertilio, also made its appearance. This fauna is almost exactly reproduced in the Lattorfian limestone of Brie, and in the Rupelian sands of la Ferté-Aleps appears the first European representative of the Rhinoceros group, Acerotherium, still without a nasal horn. An analogous fauna is found at Ronzon in Velay, but here we must also draw attention, along with the Conotherium, intermediate between Anoplotherium and the Ruminants, to the first true Ruminant, Gelocus.

Analogous animals lived in the Quercy district, where the waters have hollowed out in the limestone plateaux extensive caverns, whose walls have been covered with a layer of phosphorite, and into which all sorts of bone fragments have been carried. These bones, studied by Filhol, belong to the second half of the Meso-nummulitic and the commencement of the Neo-nummulitic. Finally, during the Chattian period, are seen the precursors of the Shrew-mice (Amplisorex, Sorex), the Moles (Myogale), Otters (Potumotherium), Cats (Eusmilus), Beavers (Stenofiber), and hornless Ruminants (Dremotherium, Amphitragulus).

While Mammals were thus evolving in the different portions of what had been the North Atlantic continent, evolution was proceeding along entirely different lines in those parts of Anerica and South Africa, which resulted from the dismemberment of the old Gondwana continent. In the Montian Epoch Dinosaurs still survived in these regions. There were also numerous Allotheria, ${ }^{1}$ Marsupials already analogous to our Opossum, Edentata foreshadowing Megatherium, Orycteropodidæ which still live in South Africa, Sloths and Armadillos which have remained exclusively South American, Insectivora, ${ }^{2}$ Typotheria, Amblypoda, many of them allied to Lophiodon, ${ }^{3}$ the precursors of the Proboscidea nowadays localized in Asia and Africa, Phenacodon already existing in North America, the Hyracoidea analogous to the Hyracidæ, whose representatives are now confined to Asia and Africa,

1 Plagiaulacidx, Polydolopydx, Promyzopidx, Odontomysopidæ.

2 Spalacotheridx.

3 Carolozittelia, Paulogervaisia. 
Palæotheridæ and other Perissodactyla as well as Lemurs now no longer seen except in India, South Africa, and Madagascar. This fauna, known as the Notostylops fauna, is followed by two others preserved in the clays mixed with volcanic ash which are found in the neighbourhood of the gulf of Saint-Georges. To the preceding Mammalian groups we must add other later precursors of the Proboscidians, such as Promerytherium and Pyrotherium, large animals studied by Albert Gaudry, whose molars with transverse ridges recall those of Rodents and Elephants, and whose lower jaw carries two long almost horizontal incisors. In this collection there is no trace of the Bats, Creodonta, Carnivora, and Artiodactyla, all of which already existed in North America, but, on the other hand, it includes Sparassodontia, Edentata, Typotherium, and Toxodontia which specifically belong to it, while its Perissodactyla are of a particular type. They were represented by Macrauchenia, so named because of its long neck, and by forms which approximated to the Equidæ, but were quite different from those of North America.

This curious South American fauna is less astonishing than that discovered twenty years ago in the Fayum of Egypt, and belonging to the Middle Eocene. The oldest zone, that of Birket-el-Querun, is still marine, but it already contains Zeuglodon, found also in Alabama and New Zealand, and some related forms, ${ }^{1}$ which supposes a long anterior existence for the aquatic Carnivora like the Seals. The Middle Zone, that of Kasr-el-Sagha, contains, in addition to Crocodiles, Turtles, Snakes, and Cetacea, one of the oldest Sirenidans known, ${ }^{2}$ a mammal whose position is doubtful, Barytherium grani and $M$ critherium lyonsi. In the 300 metres depth of strata comprising the third zone, to whose formation the sea and a large river have contributed, there are entombed innumerable fragments of Mammalian bones.

Three things have rendered the Fayum fauna especially remarkable: first the existence of the monstrous Arsincëtherium, second that of Maritherium, Palaomastodon, and Tetrabelodon, ancestors of the Elephants (p. 300), and third the existence of a group of Monkeys, some of which to-day are exclusively American, while others belong to the Old World. The simultaneous presence of these groups of monkeys 
causes the antiquity of these fundamental groups to recede far back into the past (p. 32I).

The colossal Arsinoëtherimm, larger than a rhinoceros, had the complete dentition of the herbivores. On its nose there rose two enormous bony horns, no doubt clothed in a sheath like those of Oxen, and behind which two smaller horns appeared.

In the Neogene Fpoch the fauna of Europe, Africa, and Asia tended to acquire sufficient homogeneity to permit the whole of the regions in which it is distributed to be called Arctogean. In France the oldest specimens of this fauna are found at Saint-Gérand-le-Puy, in the department of the Allier, and it is also seen at Ulm in Germany, where it belongs to the Aquitanian. Anthracotherium, so frequent during the preceding period, now persisted only in India. It was replaced by Brachyodus, associated with a species of Tapir, ${ }^{1}$ two genera related to the Rhinoceros, ${ }^{2}$ a genus of Pig, ${ }^{3}$ two genera of Ruminants, ${ }^{4}$ and above all with numerous Conotheria. All these types appear to have evolved in the locality in which they were found. The fauna of the sands of the Orléanais, ${ }^{5}$ which is a little older, was enriched by a genus of Chevrotain, Hyomoschus, which still survives. But as these animals are less advanced than the Ruminants with complete cannon-bones, which existed already, they must date back still further. Palcomeryx and Dicrocerus have taken the place of Dremotherium and Amphitragulus. To these autochthonous types we may add the Mastodonts and Dinotherium, which no doubt came from Africa, since their ancestors have been discovered in the Fayum; two new types of Rhinoceros, ${ }^{6}$ two genera of Pigs, ${ }^{7}$ a new Cervulus, ${ }^{8}$ and finally an Anthropoid Ape, sprung, undoubtediy, from the anthropoid genus of the Fayum, Pliopithecus. America, where the Horse type was rapidly evolving, contributed Anchitherium.

At Sansans in Gers, at Grive-Saint-Alban and Saint-Gaudens in France, at Erbiswalden and respectively at Simorre and Montebambili, ${ }^{9}$ the first Felidæ now appear, as well as the Porcupines which came from South America by way of Africa

1 Paratapirus.

3 Palaochoerus.

* Burdigalian.

? Choerotherium, Listriodon.

9 Vindobonian.
2 Aceratherium, Diceratherium.

4 Dremotherium, Amphitragulus.

- Teleoceras, Ceratorhinus.

- Micromeryx. 
(the Afro-Brazilian continent), while Asia and Africa furnished a whole series of Bears, ${ }^{1}$ a new anthropoid, Dryopithecus, a tailed Monkey of the Afro-Asiatic type, Oreopithecus, and Chaticotherium, which had already existed in the Orléanais sands. The Pontian fauna of Pikermi near Athens and that of Mount Léberon near Avignon are celebrated by the researches of Albert Gaudry. It was in connexion with the first of these that this eminent scientist, before Darwin and relying entirely upon his own observations, had the courage to reinstate the theory of evolution abandoned since the days of Lamarck. The Pontian fauna is particularly rich, and Gaudry's poetic mind lent reality to the Lion of Nemea, the Boar of Erymanthus, and the Goat of Amalthea, ${ }^{2}$ whose generic names suffice to indicate how nearly this fauna approached to that of to-day. The Felidæ even surpassed in their evolution the point arrived at by the Lion in a form now extinct, but which must have been redoubtable. This was Machorodus. Its long upper canines, flattened and curved like the blade of a scimitre, pointed, sharp, and notched on the inner surface, must have been terrible weapons. Their development was such that the animal could not bite with its incisors, but tore strips of flesh from its prey with the powerful canines in order to drink the blood of its victims. This costly diet must have led to the creature's rapid disappearance as Antelopes became thinned out. It had only two molars in the upper jaw and three, including one which was rudimentary, in the lower. The Antelopes, preyed upon by Hyæna, ${ }^{3}$ were already divided into numerous genera, probably of African origin: Gazelles, Palceoryx, Palceorcas and Protragelaphus-and they were accompanied by the first Roedeer, ${ }^{4}$ which initiated the series of Ruminants with ramified antlers, and the earliest Sheep (Criotherium). The Giraffe family was represented by many genera. One of these, Helladotherium, which Albert Gaudry dedicated to Greece, was remarkable for the relative shortness of its neck and the absence of horns, and was almost exactly like the Okapi, which differs from it only in the presence of

1 Pseudarctos, Hyenarctos, Ursavus.

2 Tragoceras.

3 Lychyona, Hyanictis, Hyana.

- The African origin of the Roedeer is perhaps a little doubtful ; the lateral metatarsals of these deer are, in fact, atrophied in the same fashion as those of the American Cervidæ, of which only one, the Canadian deer, shows the same kind of atrophy of the lateral metatarsals as the European Cervidæ. 
small horns in the male. Orycteropus, the Hyracidx, and a Rhinoceros (Atelodus) had also come from Africa, but we have seen that the Orycteropidæ already existed in South America throughout the preceding period. The African migration was completed by the arrival of the tailed Monkey, Mesopithecus, which added two genera to the anthropomorphs, Dryopithecus and the Anthropodus. At the same time Hipparion and the Hare crossed from North America to Europe by way of Asia.

The series of Neogene fauna came to an end in France with that of the Pliocene of Montpelier and Pcrpignan. It was not quite so rich in precedent forms as some that had gone before, but it had been reinforced by an African Pig, Potamocharns, a Macacus, and a new type of Mammal, Ruscinomys. A Hippopotamus ${ }^{1}$ had come from Asia, as also some of the present Cervidæ, Axis, and the Fallow Deer, accompanied by another of the genus Polycladus. From Asia, too, came the Raccoons, although they were emigrants from North America and made their way over an isthmus at the site of the present Behring Straits, and no longer by way of the North Atlantic continent already described. Among the Rodents we also observe the Vole.

At the same time a fauna analogous to that of Pikermi existed in Persia. The richest fauna of Asia, however, was that whose elements had been brought to the foot of the Himalayan chain by streams that descended its slopes, and which formed the Siwalik Hills. Machoerodus, in company with smaller Felidæ, Eluropsis and Flurogale, still hunted Strepsiceros, Deer properly so-called, as well as Antelopes, Goats, Bison, and Oxen. Many species of Dinotherium and Mastodons flourished; a Chimpanzee, a Semnopithecus, a Cynocephalus, and a Baboon bear witness to the great variety of Monkeys at this epoch. To this fauna belong also Brahmatherium, Vishmutherium, and later on Sivatherium and Hydaspitherium, all large-horned Giraffes.

South America, now separated from North America, was behind the other continents. In the Lower Neogene Period the Paucituberculata still lived there, as well as Typotherium, along with the Marsupials properly so-called, the Sparassodonts, Toxodonts, and the Amblypods (Astrapotherium), 
but the Chinchillas and Cabiais, among the Rodents, were already specialized, and representatives of the Edentata were the gigantic Megatherium, Mylodon, Megalonyx, the true Armadillos, and true Ant-Eaters. The Perissodactyla belonged to two families, Prototheridæ and Macrauchenidæ. Finally, Ameghino has described under the name Homunculidæ a series of Monkeys in which he chose to see the distant ancestors of all the Monkeys and of Man himself.

In the following period, which is our own, the fauna of South America continued its special evolution, but North American elements had already penetrated it, especially in the basin of Parana belonging to the Upper Neogene. These newcomers were Carnivora of various groups-Bears (Proarctotherium), Dogs (Amphicyon), Raccoons, and, right at the end of the period, a Ruminant (Microtragulus).

Man himself was now on the point of making his appearance. 


\section{CHAPTER IV}

\section{The HuMaN Form}

WHILE the Mammals we have just described nere specializing in various ways of life, to which they closely restricted themselves, certain among them, whose exalted destiny nothing as yet suggested, continued to adapt themselves to a most varied diet, to life on the ground, or up in the trees that offered them such safe refuge, employing their limbs in running, leaping, climbing, and grasping, according to their will and the needs of the moment, thus providing the maximum stimulus for their cerebral system, and provoking its development by the activity imposed on it. In striking contrast to this continuous elaboration of the brain, the limbs and the various organs retained their initial indeterminate character and their almost prinitive forms. These mammals have been grouped together in the order of Primates. Their common characteristic was the opposability of the inner digit on each of the four limbs, which allowed them to take hold of and feel objects in a variety of ways, and thus to gather new and precise information, which, in its turn, contributed to the evolution of the brain. There these impressions were combined with those received by the other senses, and provoked more and more frequently the exercise of deliberate volition.

This order to-day comprises Lemurs and Monkeys. The Lemurs live in India, Equatorial Africa, and more especially in Madagascar, where they are numerous and varied. The Monkeys form two large groups, the Platyrrhina, with separated nostrils and thirty-six teeth, except in the case of Marmosets, and the Catarrhina with a narrow nasal septum and only thirty-two teeth distributed according to the same formula as the human teeth. The first belong to the New World, the second to Africa and Asia; in Europe they are represented only by the Magot or Barbary Ape, localized in a district near Gibraltar. Among the largest members of the Monkey tribe of the Old World, the Gibbons of India, the 
Orang-Outangs of the Sunda Islands, the Chimpanzees, and the Gorillas of Central Africa have lost their tails, and the absence of this appendage accentuates their resemblance to Man. They are called Anthropomorphous Apes, i.e. apes shaped like Man.

At the beginning of the Eocene Period there lived in America numerous species of Lemurs (Hyopsodus), which lacked only one pair of incisors to conform to the complete dental formula of the early placental Mammals, with its four molars and three premolars. We may perhaps even consider Pelycodus of the Wasatch, which did conform to the complete dental formula, to be Lemurs. But we may say that true Primates in this period are characterized by a reduction of their incisors to two pairs, which persisted throughout the whole series. Animals of the Upper Eocene with an analogous dental formula-Adapis-have been found in the basin of Paris; but Cuvier, who was the first to describe them, had only seen their skulls, and took them for Pachydermata. Further, the angle of the lower jaw is slightly curved inward, as in the Marsupials. Adapis is therefore very near to the primitive placental Mammals, and we are thus led to admit that the Primates evolved on parallel lines to the other placental Mammals, without mingling with them The Lemurs form a highly diversified group, as witness the long muzzles and straight, pointed ears, giving them a special physiognomy which has earned them the description of Fox-faced Monkeys, the multiple mammæ and varied dentition sometimes including only one pair of lower incisors (Propithecus, Tarsius), and sometimes only a single one in the upper jaw (Aye-Aye), which, thus deprived of canines, resembles that of a Rodent-all of which characters go with a retention of the four prehensile hands. Some lemurian forms have given rise to the American Monkeys, which have retained their four primitive premolars. The Lemurs were distributed throughout the world, and it is very likely that somewhere in this varied group the ancestors of both New and Old World Monkeys evade us. For, even though both these ancestors were Lemurs, they need not necessarily have been identical. The New World Monkeys have a maximum of thirty-six teeth, those of the Old World only thirty-two. But these two types differ among themselves, because the New World Monkeys have a milk dentition which always includes 
three premolars in the upper jaw, even when the total number of teeth is only thirty-two, whereas the Old World Monkeys have only two. This is considered to be an argument in favour of the greater antiquity of the American Monkeys.

From the numerical point of view the dentition of Man resembles that of the Old World Monkeys; it differs chiefly in the smaller size of the canines. The reduction in the formula continues as the ascent is made from Lemurs to Man, in whom it rcaches its minimum limit of thirty-two teeth, already attained in the catarrhine Monkeys. We can only seek the cause of this reduction in a character common to all these animals, and the most logical to which we can attribute it is the faculty of prehension acquired by the hand, which thus relieves the jaws of a great deal of the work that had hitherto exclusively devolved upon them. Thenceforth, having no longer to exercise traction in the seizure and removal of objects, and being no longer stretched by this traction-which counted for at least one important factor in their peculiar elongation, and no doubt provoked the special conformation of the herbivorous head-the jaws became shorter and more compact. Thus was the passage effected from the fox-like muzzle of the Lemur tribe to the flat-nosed face of the Monkey. This shortening was not accomplished without some amelioration of the conditions in which they obtained their food, which perhaps explains the thinning of the hair on this almost naked face.

Furthermore, the variety of attitudes necessarily assumed by climbing animals living in trees must have prepared them for the erect position that the large Apes only partially succeeded in accomplishing. These various transformations were early realized. In the Eocene deposits of Patagonia the brothers Ameghino discovered a whole series of Primates which they named Homunculus, Tetraprothomo, Triprothomo, and Diprothomo, meaning respectively miniature man, great-greatgreat-grandfather, great-great-grandfather, and great-grandfather of man. According to them the cradle of mankind was not, as de Quatrefages believed, at the foot of the great Tibetan Highland, where the different human races are still found in proximity, but in South America. Unfortunately, as Marcellin Boule has shown in his brilliant memoir on the Chappelle-auxSaints Man, all the Ameghino Homunculi are still too far removed from Man to be included anywhere in his genealogy. 
In the Eocene layers of Wasatsch in North America Cope discovered in Anaptomorphus the first link in the chain connecting the Lemurs with the Monkeys. Analogous animals first multiplied in North America, only to leave it and migrate towards South America, where they originated the agile and prehensile-tailed Monkeys (the Sajous) inhabiting that region. Lemurs came to Europe about the same time, and, probably on account of the cooling of the temperature, evidently considered that the safest refuge was in their present homes-India, tropical Africa, and Madagascar. Lemurs and Sajous are even found associated in the Eocene deposits of the Fayum, where the former are represented by Parapithecus and the latter by Mcropithecus. But, side by side with these, palæontologists were very much surprised to find an anthropomorphous Ape, Propliopithecus heckeli, not far removed from a Gibbon, and no doubt related to Pithecanthropus erectus, discovered in Java by Dr. Dubois, and certainly the direct ancestor of Pliopithecus, discovered by Lartet in the Miocene of Sansans. Thus the anthropoid Apes, which were supposed to represent the final stage in the evolution of the Monkeys, because they are nearest to Man, are seen to go back to the very beginning of the Tertiary epoch, which removes any unlikelihood of the existence of Man hinself at this time. Hence the Gorillas and the Chimpanzees would only come after the graceful Gibbons, the most Man-like of all the Apes, which are venerated in India, and the grimacing tribes of tailed Monkeys of the old continents would be even more recent; Mesopithecus of Pentelicus, described by Albert Gaudry, is Miocene, so that in admitting our genealogical relationship with the Monkeys we need not include among our ancestors any of those repulsive beings such as Hamadryas, Mandrills with their streaked and variegated heads, or those other dog-headed Monkeys whose grotesque faces we can see in menageries.

On the other hand, we must recognize-however vexatious to our feelings it may be-that the characteristic features of Man's body are not very far removed from those of the Gibbon, and that, as Lamarck has already said, it is easy to explain those characters which are peculiar to him. They are almost all derived from his absolute vertical posture. It is this which has freed the hands from tasks other than prehension and the examination of objects and the construction and manipulation 
of defensive weapons. Thanks to these, the jaws entirely ceased to bite and tear, as they had already ceased to seize, and limited themselves to the mastication of food. On account of this less arduous work, they became shorter and lighter. In the larger Apes the muscles that raise the lower jaw are very powerful, being inserted in the temporal fossa during youth; but, as the animal grows older, they creep gradually up the lateral walls of the skull, as in Carnivora, till they finally meet at the vertex, where they cause the development of a median crest at the point of their attachment. Henceforth this crest prevents any expansion of the skull, whose bones are definitely sutured along the median line. When the muscles attached to it contract they even tend to compress the walls of the skull laterally, and thus to compress, and so arrest the development of, the brain. This is probably one reason why old Monkeys are more capricious, more evilly disposed, and more stupid than young ones. In Man the nuuscles that raise the lower jaw have ceased to migrate in this way. They are inserted in the temporal fossa, like those of the young Monkeys, and their contraction can exercise no pressure upon the brain; on the contrary, they tend to separate the frontal and parietal bones and so to relieve the brain, thus favouring its development. The head is so balanced on the vertebral column that it projects to an equal extent before and behind; and it likewise develops in height, a fact which has important consequences. The frontal development of the skull and the brain naturally bring forward the base of the nose, whereas the retraction of the jaws permits of the nostrils opening freely above them-hence, the nasal salient so characteristic of Man. The same retraction gives freedom of movement to the lips, now no longer strained forward over projecting teeth, and it becomes possible for them to smile. As the skull grows in height, it dominates the ears, already immobile in Monkeys, and, as it widens at the same time, it brings the eyes, more or less laterally placed in most Mammals, to a frontal position. Thus all the characteristic features of the human face are consequent on the development of the brain, in itself stimulated by the new importance of the hand. In the same way the characteristic features of the Vertebrates have been determined by the predominance assumed by the nervous system, so that the evolution of the 
human form and mental character would appear to have been essentially brought about by the progress of the intelligence. It must have been at a very early date that the development of man's ancestors was orientated in this direction.

Once past the lemurian stage, which in Adapids was still one that had links with the Marsupials, it would appear that the simple erection of the body into the vertical position, without any modification of the structural type, at once opened the way that was to lead rapidly to the human form by the uninterrupted and almost exclusive progress of the organs of intelligence and reason. Elsewhere, limbs, dentition, tegumentary dependencies, and visceral organs themselves were modified in all directions, especially adapting themselves to purely material functions. Here, on the contrary, effort was concentrated in the perfecting of the nervous system and the cerebral apparatus, so that Man, separated at the outset from existing menbers of the Monkey tribe, has no direct relationship with any other Mammal.

Is this to claim on behalf of Man, from a purely material viewpoint, a place apart in nature? Every fact set down in this book leads to a contrary conclusion. Following the example of the geologists, who, refusing to attribute the explanation of the configuration and structure of the globe to unknown causes, have succeeded so brilliantly in explaining all by a unique consideration of the causes yet at work around us, I have sought to establish that laws still regulating life are adequate to explain the formation and evolution of the principal organic types - a problem that seems to me of greater importance than the pursuit of the factors determining variation of species, which is but a fractional part of the main problem.

Thus the human form explains itself like the others. It would seem, indeed, that across the fluent sea of living forms those that set their course towards the human type have left a wake that is wonderfully direct. Sponges, Polyps, Bryozoa, Arthropods, Flat-worms, Star-fish and the world of Echinoderms to which they give rise, Molluscs, Tunicates, Bony Fishes, tailless Batrachians, Reptiles, Birds, hoofed and clawed placental Mammals-all these are off that main track. Moreover, whereas purely mechanical conditions or attitudinal changes have led to the early forms and subsequent 
mutations of other organic types, the structural mutations that led from Invertebrates up to Vertebrates were due to the volume acquired by the nervous system, whose centres, especially the brain, thereupon gradually perfected themselves. It is, above all, in the size and the special arrangement of his brain that Man differs from the other Vertebrates.

That which has raised man above the animals whose structure he retains, and which inspires the horror he feels at the idea of kinship with them, is his consciousness of exceptional mentality. Nevertheless, we must acquiesce in the knowledge that we are made, like the lowliest of living creatures, from a few common substances. The white corpuscles of our blood have retained the structure and amœboid movements of the lowest of the rhizopod Protozoa; the olfactory membrane of our nose, our trachea, and various other of our body cavities are lined with cells provided with vibratile cilia like those of the Infusoria; our nerve-cells have a common external character with those of all other animals; our muscular fibres do not differ essentially from those of other Vertebrates, and even had their counterparts in certain Invertebrata ; our body is divided into segments like the segments of the Worm; our teeth do not differ from the resistant plates which form the dermal skeleton of the Sharks, and of which the teeth of these Fishes are but a modification; the scales of Fish have formed the bones of the vault of their skull-and of our own, as Geoffroy Saint-Hilaire discovered; our sternum and clavicles are allied with the external bony plates of Batrachians. As in them, so in the human embryo are there rudimentary branchial arches, and the Batrachians inherited theirs from the Ctenobranch Fishes. We reproduce our kind by means of cells similar to the reproductive cells of all other living creatures, and the development of our body is modelled on that of the Reptiles, the Birds, and the humblest Mammals.

We must resign ourselves to these affinities. Whatever we may think, we shall never have bodies made of moonbeams like Victor Hugo's sylphs, nor shimmering wings like those outspread by Wells' angel in the course of the "Wonderful Visit" he imprudently paid to our earth. On the other hand, we may take the greater pride in our intelligence since our body has been its work, and because in our evolutionparadoxical as it may appear-mind has ever dominated 
matter. It is our desire to know, to see further and from a greater height, that has made us rise to the completely erect attitude of which we are so proud, and which has incited us to use our liberated hands for the palpation and appreciation of everything they touch, or to fashion raw material into implements exactly suited to a purpose clearly conceived. It is this same desire that has stimulated the evolution of our brain, given to the human countenance its noble aspect, and prepared our lips for language and laughter.

What matters the material-be it living flesh or inert duston which intelligence has been at work, if intelligence has ever and without intermission ennobled that material by its presence? What matter those transformations that the body of Man has had to undergo, if, in a radiant course across the abyss of all living form, Mind has brought it to those heights from which Reason now dominates the world? 


\section{C.ONCLUSION}

STARTING from the origin of matter, we have now arrived at the realization of the human form, linking these two extremes by a continuous chain of facts, solidly riveted by careful arguments based on a small number of principles. Most of these principles were formulated long ago, discussed and then abandoned, because they were first stated in a general form and afterwards discovered to be inadequate. Each, however, had a value of its own, and it was only necessary to give them intelligent co-ordination in order to obtain a rational explanation of Life and its activities.

It is undoubtedly true, as Cuvier ${ }^{1}$ had already insisted in opposition to many of his contemporaries, and as Pasteur has since triumphantly demonstrated, that the spontaneous generation of living beings no longer occurs in Nature; but it has been equally well demonstrated that the sun alone can sustain life on earth, and that if the sun were extinguished life would vanish with it. But this makes it probable that life was born from rays which the sun has lost, ${ }^{2}$ but which we may now actually hope to produce by artificial means, thus opening the door to the realization of the wildest anticipations. It is also true that the variations in plant and animal species are so gradual, or so slight when they are sudden, that we might suppose their forms to be fixed, as the majority of naturalists once believed; yet these variations do nevertheless take place, and, slow though they may be, we can, by expending great care, induce plants to vary from their original condition. But time is needed, and in the days when Cuvier defended the fixity of species, no one considered the shortness of the period during which we have made any observations at all, as compared with one of the geological periods whose history we have been able to reconstruct.

Lamarck attributed the variations of species to habits imposed upon animals by the stimuli of their external

1 Règne animal, 3rd edition, vol. i, p. 9.

2 Cf. p. 70. 
environment. He was right, but only up to a certain point, and this limitation caused his doctrine to be discarded. Darwin admitted that variations were due to all manner of causes, preserved by heredity, and reinforced by natural selection, but there could be no natural selection unless it could exert its influence upon a great number and variety of beings already in existence. Whence did they come? He does not say.

Every conception of this kind-we might make a long list of them-can be defended by arguments drawn from facts, though none can cover all the facts. But all must be allowed a part, though only a part, in the explanation of living forms. As a matter of fact, they have all at some time or other contributed to the determination of forms; and not only these, but many others as well. In addition to the external causes of modification, there are powerful internal causes, often intimately connected with them; for instance, the modifications of muscles and bones by habitual movements provoked by stimuli in the environment, according to the formula of Lamarck. Every structural cell associated in the task of building up an organism, while it contributes to that organism's life, none the less continues to live for its own sake. On the basis of this "indépendance des éléments anatomiques", Claude Bernard founded his entire physiological doctrine. Even this is inadequate when taken literally. Each cell does, in fact, contribute its quota to the construction of the common foundations, in which all share. Thence it draws all the nourishment it requires; into it it empties in return all the residue of its nutrition and the products of its activity. This residue and these products constitute the internal secretions, to which BrownSéquard first called attention, but which, far from being the property of certain glands long regarded as functionless, as we have become accustomed to say, are really the work of all the structural cells. Through the medium of this environment, which they are perpetually modifying, and upon which react all the modifications that they themselves undergo, whether these are due to the action of the external environment itself or to other causes, the cells combined in one and the same organism-even those associated temporarily and accidentally-influence one another, howerer widely separated. An organism, therefore, carries within itself endless causes of modification, which give it sufficient plasticity to enable it 
to adapt itself in a constant manner to its surroundings. Nothing could better illustrate the effects of this distanceaction than such experiments as M. L. Pézard has performed upon Birds, showing that not only their external appearance but their psychology may be changed-by castration, for instance, or genital grafts. ${ }^{1}$ These operations profoundly modified the development of the cock's plumage, and even incited the hen to adopt his crow-a purely psychological effect. It is not surprising, then, that these modifications should react upon the structure of the reproductive cells themselves in order to become functional, which from the time of the repeated segmentation whereby they are able to reconstitute an organism similar to the one from which they came, must recapitulate, in inverse order, the stages through which the latter has passed in order to reach its final form. This is what constitutes heredity. It perpetuates the individual in his progeny. But the substances which accumulate within the individual not only modify him; unfortunately they encumber him, and he ends by succumbing to the burden, after passing through the phase of gradual decay which we call old age.

The regeneration through the reproductive cells of the successive characters of the ancestral organism from which they came, led Etienne Geoffroy Saint-Hilaire to conceive the embryogeny of living forms, both animal and vegetable, as consisting in a rapid epitome of their descent. The increasing rapidity with which the ancestral characters succeed one another in an embryo, unequal though it be for different organs, ensures that these characters are finally telescoped one into another, so to speak, while, at the same time, those which evolve most rapidly by a sort of inter-organic struggle for existence take the place and absorb the nourishment of those that develop more slowly. To this acceleration in the succession of embryogenetic phenomena, resulting from the definitive modification of the adult form, we have given the name of tachygenesis. Thanks to its influence, heredity becomes, by a sort of paradox, a modifying instead of a conservative force. The importance of tachygenesis as a cause of organic transformation cannot be over-estimated. We have seen how it produced the Vertebrate type. But tachygenesis is itself a

1 Le conditionnement physiologique des caractères sexuels secondaires chez les Oiseaux. Thèse de Paris (Sciences), 1918. 
result of something else, and we are far from understanding how it is produced in the first instance.

Embryogeny does not reproduce only ancestral characters. Free embryos, in the course of their development, very frequently modify their mode of life ; they return to the conditions in which these characters were achieved, thus allowing us to discover their causes, so that we are able to emphasize the importance of attitudinal changes in the realization of organic types, whose structure did not appear at first sight to be referable to any causes within the scope of our observation. This conviction led Cuvier to postulate his four immutable structural types, of which, however, only one, the Vertebrata, was clearly delimited by constant and precise characters. For Cuvier's four " embranchements" we have to-day substituted nine: Protozoa, Porifera, Coclenterata, Chitinophora (Arthropoda and Nemathelminthes), Vermes, Echinodermata, Mollusca, Vertebrata, and, related to the last-named by a process of degeneration due to the fixation of their embryos to objects below the surface of the sea, Tunicata. But for each one of these phyla a clear explanation has been given of the characters that distinguish it. It is extremely improbable that deep-sea research will provide us with any new phyla, for it would seem as though those we already know correspond to all the types that are rationally possible. But only four of these phyla have dowered the freshwater or the solid land with a numerous posterity; to wit, the Chitinophora, whose essential types are represented by the Arachnida and Insecta; the Vermes, Mollusca, and Vertebrata. We have already seen how the hermaphroditism of the Vermes and the lacustrine and land Molluscs has raised the question of conditions which determine the production of this or that sex.

It would seem that the males of the lower forms show little aptitude for development, and are relatively weak, and that those of the higher forms show a disposition to squander their food reserves in the production of useless ornaments such as the brilliant plumes of male birds, the decorations of numerous male insects, the mane of the lion, the beard of man, etc., or in organs of defence and attack such as the horns of the various male ruminants, the tusks of elephants, or the enormous mandibles of the stag-beetle. The females, on the contrary, at least in the Animal Kingdom, generally appear to sacrifice 
all unnecessary ornaments-in certain insects, even their wings-to the accumulation of reserves to be utilized as food for their eggs. Under these conditions, we have been led to ask whether the determination of sex is not simply a matter of nutrition, and whether it would not therefore be possible to. produce either sex at will, or, at least, to foretell, at any given time, which one would appear. There is nothing chimerical about such hopes. In certain Bees, the workers, during the egglaying season, prepare special cells for those larvæ which are to develop into males and for those which are to develop into. females; and we know that our common Bee can even transform, during the course of their evolution, the larva designed to. yield a sterile worker into one that will develop into a fertile female, by means of appropriate nourishment. If this result could be generalized, man could obtain control over a. phenomenon which has hitherto seemed to him a profound mystery. If he possessed the power to determine the sex of an organism in its early stages, and knew all the phases through which it must pass, why should he not try to mould it to his will and obtain new forms which he could anticipate in advance, instead of merely exploiting the uncertain caprices of crossbreeding? The infinite number of races of Dogs, Fowls, Pigeons, Rabbits, etc., which have been obtained almost by chance, show how readily species respond to experiments, and, as we have seen, the determination of forms is above all a matter of chemistry. Unfortunately, despite all the advances. made in organic chemistry during the last half-century, despite all its successful work in reconstructing varied and complex substances, especially the albuminoids, the problem of the composition, structure, and possible transformations of substances and their mutual relations has by no means been solved, and we have need of its solution if we wish to make rapid progress in the history of life. The very question of the nature of life may soon be removed to an entirely new sphere. For instance, the microbes which pass through porcelain filters and are only visible to the ultra-microscope are considered to be alive. On the other hand, albuminoid substances. do not pass through these filters, because of the size of their molecules. Hence these molecules approach the limits of visibility. It is questionable whether an "organized" microbe differs very much from a simple chemical compound which, by reason of the size and the small number of its com- 
f

ponent molecules, has abandoned the geometrical shape of ordinary crystals and assumed the forms of granules, straight, curved, and even helicoidal rods which the microbiologists call micrococci, bacilli, bacteria, spirilla, etc. Elementary life, from this point of view, would be nothing more than a form of chemical reaction in which the living molecule, instead of destroying itself by abandoning the debris to substances with which it is in contact, breaks these up for its own profit and increases indefinitely at their expense, not by augmenting its surface volume as the crystals do, but by letting itself be penetrated, and by multiplying itself by the division of its mass in proportion to its growth. Nutrition would thus appear to be the cause of reproduction, which assures mastery of the world to organized beings which multiply by geometrical progression.

The countless variety of flowers which the horticulturists can produce demonstrate that organisms are much more docile than is commonly believed. It can only be the presence within them of some special substances, or even of a single substance, which determines the formation of these varieties, and it is by no means beyond the present power of chemistry to define these substances and produce them synthetically. If man can work successfully along these lines, he will become a creator. Henceforth the whole history of vanished organisms, which palæontology has been so painfully yet brilliantly reconstructing since Professor Marcellin Boule succeeded in rediscovering the entire ancestral series both of the large groups and also of our present species-all this wonderful history of a dimly remote past, whose first pages were deciphered by Cuvier, will then receive experimental confirmation. Undoubtedly the great majority of the genealogies with which we must content ourselves are built up on simple hereditary resemblances. As for the primitive characters whose gradual modification we have observed in our reconstituted series, their causes escape us completely, or can only be imagined by a comparison with those we see about us. In this book we have sought to place the organisms whose story we have recounted in the environment where they evolved by referring, so far as possible, the modifications they have undergone to the conditions of their environment. These modifications result partly from the direct action of physical agents such as heat, 
light, and others connected with electricity, which up till now have been hardly suspected-the currents that traverse the muscles and the nerves, or those involved in the phenomena or radio-activity; but, above all, they depend upon the chemical reactions that take place between the countless products of the activity or decay of structural cells. To isolate these products, to determine their chemical composition, to study the action of each of them on the constituent elements of a given organism, is a piece of experimental work requiring great patience, which will probably never be finished but which will certainly lead to results of the greatest importance if boldly undertaken and methodically planned. It is along these lines that man can hope to complete his conquest of life. This task must naturally have disheartened the savants of the eighteenth century, who could not possibly perceive how to set about it, but who essayed to take the place of the philosophers. A beginning was made by the scientists of the nineteenth century, not without a measure of success; and it has already kindled among those of the twentieth a passionate enthusiasm, which the results already obtained in the domain of biological chemistry must fan to a whiter heat.

In their attempts to fathom the composition of the living cell, biologists discovered first of all that it was surprisingly complex, but of a nature to explain the mystery of life. We have long known that the nucleus is really a complex apparatus notably containing two special globules, the centrosomes, a network of a substance that has great power in fixing carmine chromatin, a network that is transformed at the time of the cell-division into a festooned ribbon composed of a constant number of loops in all the cells of one organism and all the organisms of the same species. These loops are capable of becoming isolated and then forming chromosomes.

The botanists, in their own sphere, have recognized and described the green chlorophyll granules by virtue of which the plant manufactures sugar and exhales oxygen under the action of the sun. They also know the leucoplasts which produce starch. Within recent times discovery has been heaped upon discovery. In 1887 Dr. Raphael Dubois ${ }^{1}$ found within the plasma of cells certain active and special forms to which he gave the name of vacuolides ; Altmann later on called them bioplasts, and to-day

1 R. Dubois, "Les Vacuolides," Comptes rendus de la Société de Biologie, 8 th ser., vol. iv, 1887. 
they are generally designated as mitochondria, a term given them by Benda, while the whole mass is known as the chondriome. But the chondriome itself is not simple, and in analysing it by means of various strains, Dangard has distinguished, at least among the plants, three categories of cells constituting what he calls the vacuome, the plastidime, ${ }^{1}$ and the spherome. These various elements increase in size, change their forms and their manner of grouping, and produce, as Guillermond has shown, various substances. In short they nourish themselves very much in the manner of the beneficent microbes which aid the cell to live instead of destroying it as ordinary microbes do, and they stand in the same relation to the chondriome as the algæ, which live in community, or, as we say, in symbiosis, stand in relation to Radiolarians or to Worms of the genus Convoluta. That is what Portier implied when he called them symbiota. We are thus led back by the circuitous route of symbiosis to the question which we previously raised, of the nature of Life.

The vast horizons which open before us in the future go beyond the old bounds of science. Modern science seeks positive solutions for questions which a short time ago were considered to be outside the domain of observation and experience, and fit only for philosophical speculation. What connexion, for instance, may there be between the motor reactions of Infusoria, simple inevitable reflexes of external stimuli; the vague and blind sensibility of Sponges and Colenterates ; the obscure instinct of Worms ; the remarkably accurate hereditary prescience of the Insect, the free intelligence of the superior animals, and human reason? How is it that some among so many structural cells have been able to make sensibility their exclusive property, and to concentrate into nervous centres without breaking their co-ordination with all the other cells; to receive information from them; to command them by means of a mechanism representing the combined forces of matter, heat, electricity, light, and perhaps other agents between which we now recognize unexpected affinities? 2 How did thought expand in this environment, and acquire the power to embrace unflinchingly the immensity of the cosmos, to face the enigma of the universe and endeavour to resolve it? That is the secret of the future.

1 Comptes rendus de l'Académie des sciences, 1st December, 1919, 9th February and 1st March, 1920.

2 Cf. the excellent book of Jean Perrin, Les Atomes. 


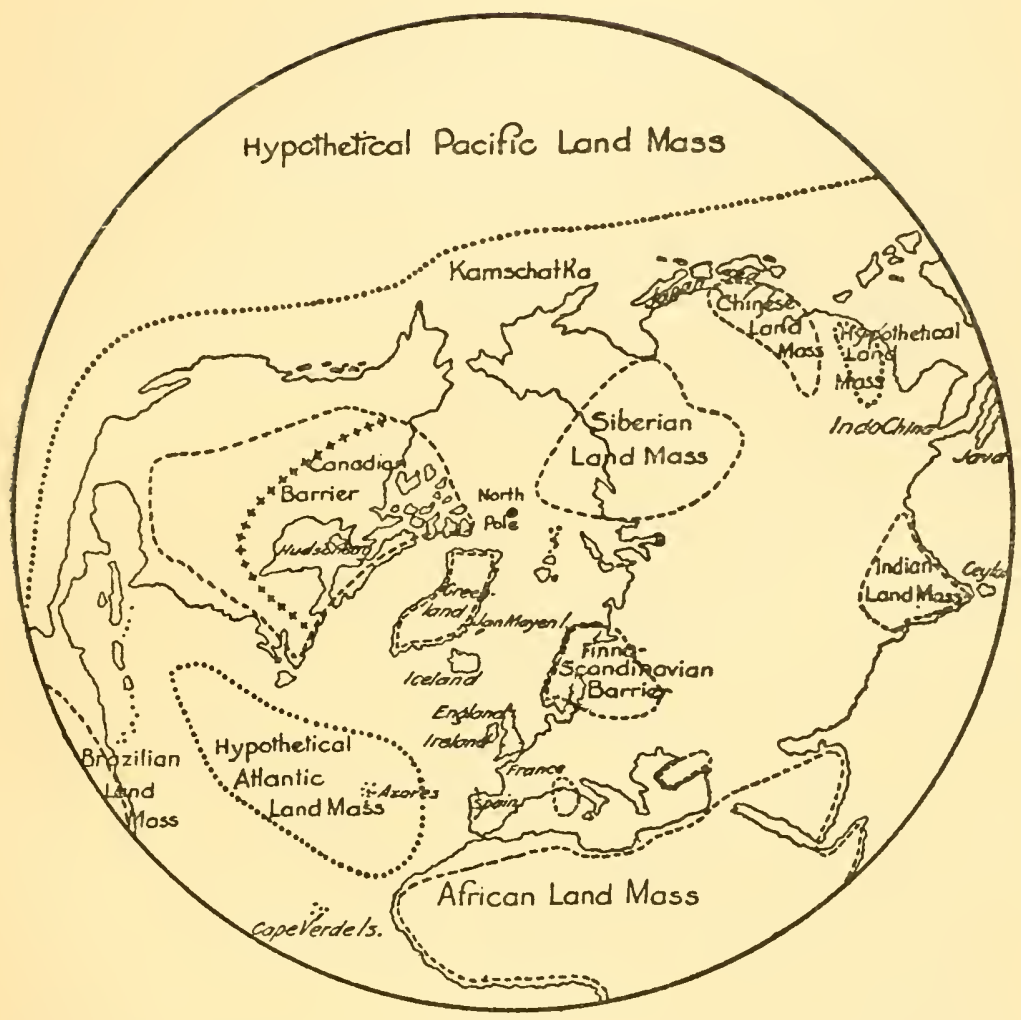

MAP I.-Conformation of Land and Sea in the Northern Hemisphere at the beginning of the Primary Period. 


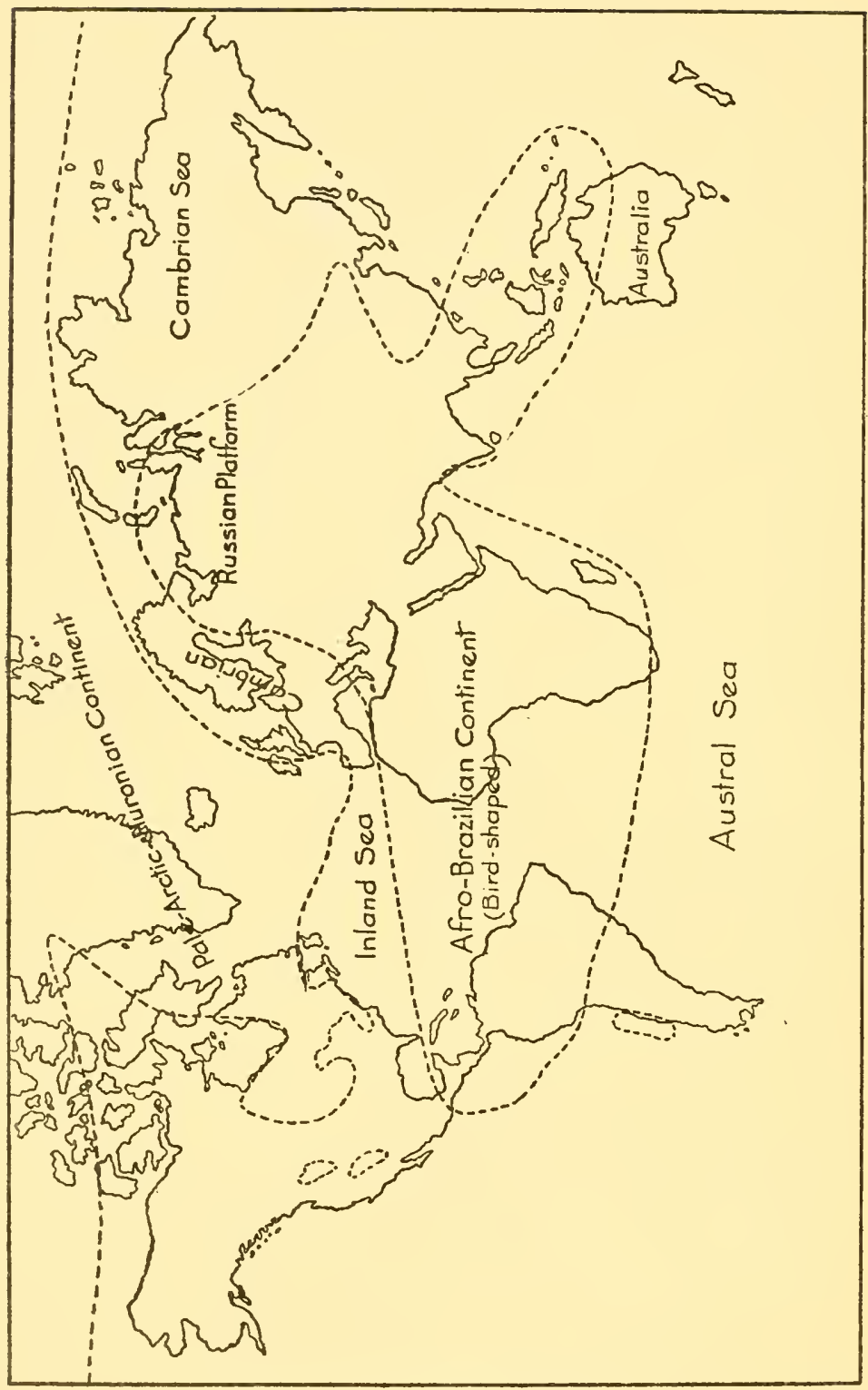

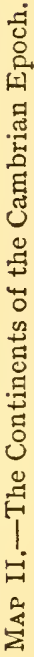




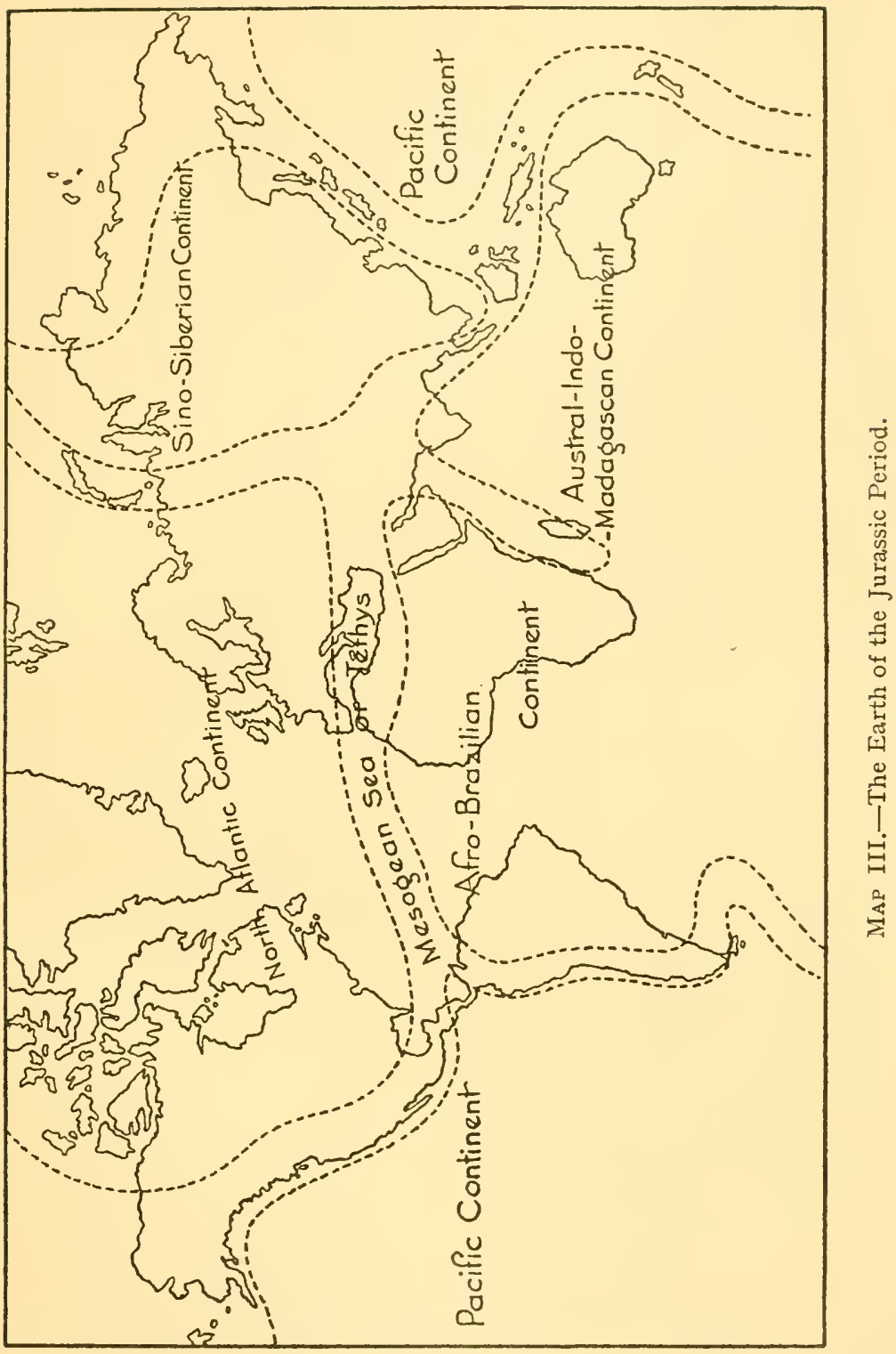




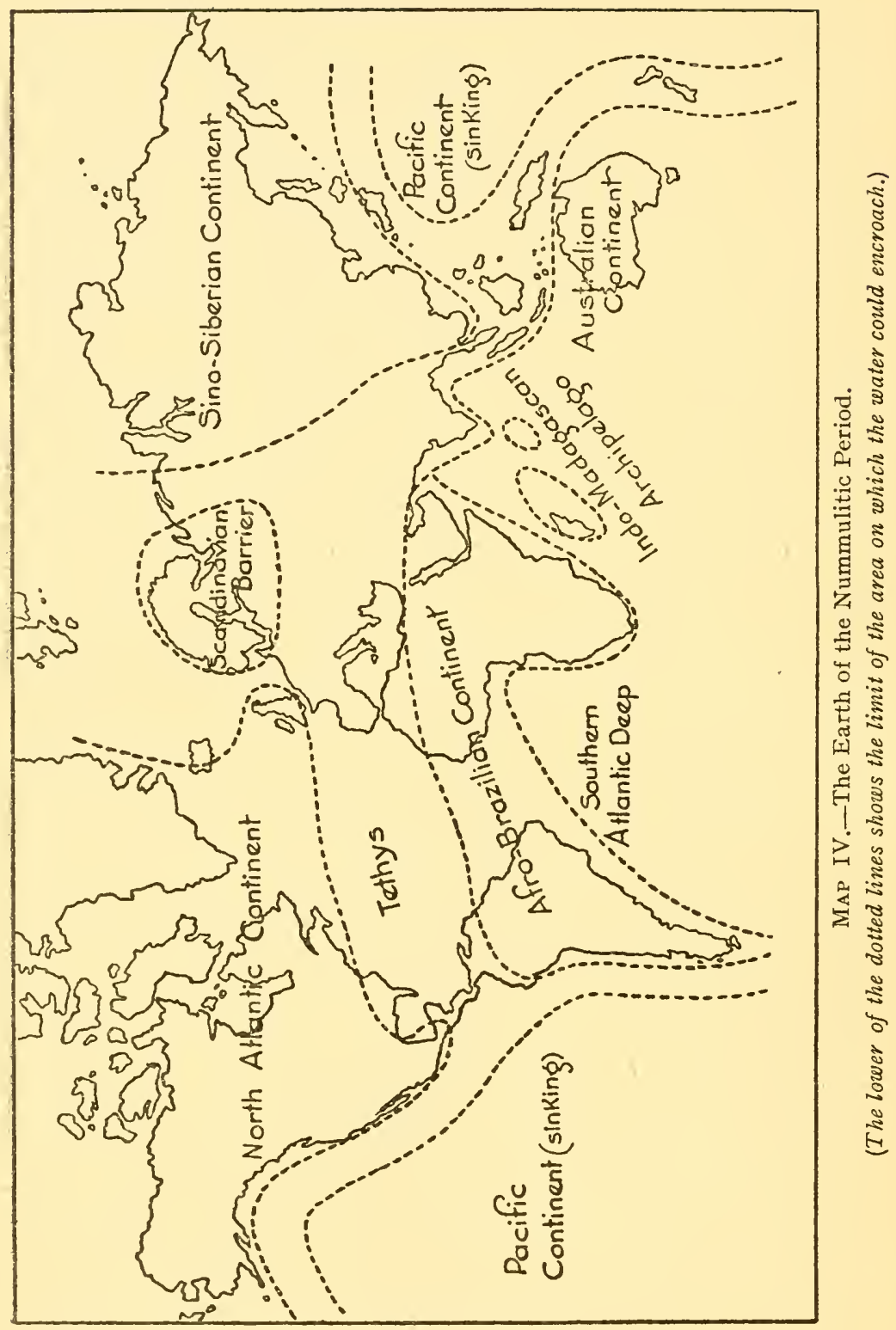




\section{BIBLIOGRAPHY}

Pierre Achalme, Electronique et biologie, 1914 . . . . I

Dr. Gustave Lebon, L'Evolution de la matière, 1915 . . II

A. Berget, La vie et la mort du Globe, 1912 . . . . III

Charles André, Les planètes, 1909 . . . . . . IV

De Lapparent, Traité de géologie, 1st ed., 1883; 3rd ed., 1893 . V

Haug, Traité de géologie, $1908-11$. . . . . . . VI

De Lapparent, Géographie physique, $1896 \quad$ • . . . . VII

Emmanuel de Martonne, Traité de géographie physique, 1905 . VIII

De Launay, La Science géologique. Ses méthodes, ses résultats, ses problèmes, son histoive, 1905 . . . . . IX

Marcellin Boule, Conférences de géologie, 1911 . . . . X

J. Bosler, Le radium, May, 1913 . . . . . . X XI

Lefebvre, Chaleur animale et bioénergétique,1911 . . . . XII

Van Tieghem, Traité de botanique, $\mathbf{1 8 8 4}$. . . . . XIII

Lamarck, La Philosophie zoologique. Histoive naturelle des animaux sans vertèbres. . . . . . .

Haeckel, Histoire de la création des êtres organisés d'après les lois naturelles (Fr. trans., 1874) . . . . .

XIV

XV

XVI et l'origine cosmique de la vie": Comptes rendus de l'Académie des sciences, 4th July, 1910 . . . .

\section{XVII}

Daniel Berthelot, "Les rayons ultra-violets et les actions vitales": Séance solennelle de la Société de pathologie comparée, 12 th December, 1916

XVIII

A. de Gramont, "Sur les spectres stellaires et leur classification" : Annuaire du Bureau des longitudes, 1913

$\mathrm{XIX}$

L. G. Maillard, "Recherches sur le mécanisme naturel des formations albuminoïdes": Presse médicale, 17th

February, 1912.
Bernard Renault, Sur quelques micro-organismies des combustibles fossiles . • . · ·

Ancel and Bouin, " Recherches sur la signification physiologique de la glande interstitielle du testicule des mammifères ": Journal de physiologie et de pathologie générale, vol. vi, p. 1012,1904

Ancel and Bouin, "Recherches sur les fonctions du corps jaune gestatif " : ibid., vol. xii, p. 1, 1910

XXII

Charles Darwin, L'origine des espèces (Fr. trans., 1859) . . .

Charles Darwin, La sélection sexuelle (Fr. trans.) . . .

Weismann, Vorträge über Descendenztheorie, 1902 . . .

Edmond Perrier, Les colonies animales et la formation des

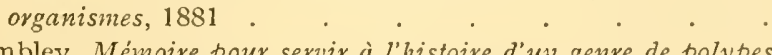

Trembley, Mémoire pour servir à l'histoire d'un genre de polypes d'eau douce à bras en forme de cornes, 1744 
Dr. Alexis Carrel, The Journal of Experimental Medicine, 1911-12

Driesch, "Neue Ergänzerung zur Entwickelungsphysiologie des Echinidenkeimes": Archiv für Entwickelungsmech. d. Organ., vol. xiv, 1902, pp. 500-31; and "Zum Problem der Bilateralität des Echinodermenkeimes": Verhandl. d. Gesellsch. Deutscher Naturforscher u. Aerzte, vol. ii, 1905, pp. 205-6

Bataillon, "La segmentation parthéwogénétique expérimentale chez les oufs de Petromyzon Planeri " : Comptesvendus Ac.Sc., vol. cxxxvii, 1903, pp. 79-80; and Nouveaux essais de parthénogénèse expérimentale chez les vertébrés inférieurs (Rana fusca et Petronyzon Planeri): Arch. f. Entwickelungsmech. d. Organ., vol, xviii, 1903-4, pp. 1-56

T. H. Morgan, "Regeneration in Teleosts" : Archiv. f. Entwickelungsmech. d. Organ., vol. x, 1900; and "Further experiments on the Regeneration of the Tail of Fishes": ibid., vol. xiv, 1902, pp. 539-61

Newmann and Patterson, Biological Bulletin, vol. xvii, 1909, and Journal of Morphology, vol. xxi, 1911; and Miguel Fernandez, Morphologisches Jahrbuch, 1909

P. Marchal, "Recherches sur la biologie et la développement des liyménopteres parasites: La polyembryogénie ou germinogénie." Archives de zoologie expérimentale

XXXIV

Harmer, "On the occurrence of embryonic fusion in Cyclostomatum Polyzoon" : Quarterly Journal of Microscopical Sciences, 1891

Calvet, Contribution d l'histoire naturelle des Bryozoaires marins, 1900 , p. 335

I'ves Delage, L'hérédité

Edmond Perrier et Charles Gravier, "La tachygenése ou accélération embryogénique; son importance dans les modifications des phénomènes embryogéniques; son rôle dans la transformation des organismes." Annales des sciences naturelles, 1902

Blaringhem, Bulletin scientifique $d u$ Nord de la France et de la Belgique, vol. xli, 1907

Dantan, "Le fonctionnement de la glande génitale chez l'Ostrea edulis et la Gryphæa angulata": La protection des bancs naturels: Comptes rendus Ac. Sc., vol. clv, 1912 .

E. Perrier, Expéditions $d u$ Travailleur et $d u$ Talisman. Les Stellérides. . . . . . .

E. Perrier, Expédition du Cap. Horn. Les Stellérides . .

E. Perrier, Traité de zoologie . . . • ·
Arnold Lang, "Versuch einer Erklärung der Asymetrie der Gasteropoden": Vierteljahrschrit der Naturforsch. Gesellschaft, Zurich, 1891

XXXV

XXXVI

XXXVII

\section{XXXVIII}

XXXIX

XL

XLI

XLII

XLIII

XLIV

L. Boutan, "Recherches sur l'anatomie et le développement de la Fissurelle": Archives de zoologie expérimentale, 2nd series, III bis, 1885

A. Robert, "Embryogénie des Troques": Archives de zoologie expérimentale, 3rd series, $\mathrm{x}, 1903$. 
Remy Perrier, "Recherches sur l'appareil rénal des Mollusques Gastéropodes prosobranches": Annales des sciences naturelles, 1889

XLVII

L. Bouvier and H. Fischer, "L'organisation et les affunités des gastéropodes primitifs d'après l'étude anatomique de la Pleurotomaria": Bayrischer Journal der Conchyliologie, vol. iv, 1902 .

Charles Gravier, "Sur lc systeme ncrveux du Nautile": Comptes rendus de l'Acad. des sciences

XLVIII

XLIX

$\mathbf{L}$

Etienne Geoffroy-Saint-Hilaire, Philosophie anatonique, 1808

Carl Seniper, "Die Stammsverwandtschaft der Wirbelthiere und Wirbellosen": Arbeiten aus dem Zool-zootomischen Institut in Wurzburg, vol. ii, 1875, et III, 1\$76-7 .

Balfour, "A preliminary account of the development of Elasmobranch fishes": Q.J. of Miscroscopical Sciences, 1874.

"The Development of Elasmobranch fishes": Journal of Physiology, 1876 . . . . . . .

Annales des sciences naturelles . . . . . . .

Edmond Perrier, Les explorations sous-marines, $1886 \quad$. . LIV

Maupas, "Modes et formes de reproduction des Nématodes" : Archives de zoologie expérimentale, 3 e serie, 1900

Dantan, La sexualite des huitres ${\text { Vejdowsky, System und Morphologie der Oligocheten, } 1884^{\circ} \cdot{ }^{*}}^{*}$ LVII

Edmond Perrier, "Histoire naturelle de la Dero obtusa": Archives de zoologie expérimentale, vol. i, 1871 . . .

MacLeod, "Recherches sur la structure et la signification de l'appareil respiratoire des Arachnides": Archives de biologie, vol. v, 1884

LVIII

LIX

Ed. Lamy, "Recherches anatomiques sur les trachées des Araignées " : Annales des sciences naturelles, 1902

L. X

M. Braun, "Moplatus fimberatus (Schneider) in Gefangenschaft": Voltskow Reise in Ostafrika in den Jahren 1903-5, vol, iii . . . . . . .

\section{XI}

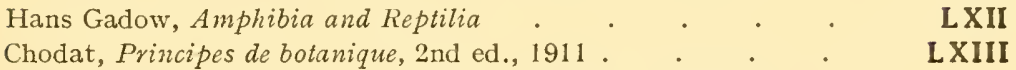

James Clarke, "On the Spongiæ ciliatæ as Infusoriæ": Memoires of the Boston Society of Natural History, vol. i, pt. iii, 1888

Edward Morse, "Cephalization. The Systematic position of Brachiopoda" : Proceedings of the Boston Society of Natural History, vol. $\mathrm{xv}, 1873$

LXIV

LXV

Armand Gautier, "Sur les rapports entre la composition des pigments de la vigne et ses variétés ": Comptes rendus de l'Acad. des sciences

LXVI

Em. Bourquelot and M. Bridel, "Synthèse des glucosides d'alcool à l'aide de l'émulsine er réversibilité des actions fermentaires": Amales de chimie et de physique, 8th series, vol. xxviii, June, 1913

LXVII

Anton Dohrn, Studien über Urgeschichte der Wirbelthiers körper, Mittheilungen aus der Zoologischen Station zu Neapel (1882 to 1902 )

L. Joubin, La vie dans les océans, 1913 . 
Ch. Gravier, Sur les annélides d'eau douce . . . . . $\quad$ L X X

Edmond Perrier, Les Stellérides recueillis dans la mer des Antilles durant les dragages du Blake. . . . . .

Marie Pereyaslawzewa, "Sur le développement embryonnaire des Phrynes." Annales des sciences naturelles, 8th series, vol. xiii

Allmann, A monography of gymnoblastic or tubularian Hydroids, 1871, Royal Society Publication

L X X I

LXXII

L X XIII

J. Perez, "Des effets du parasitisme des Stylops sur les apiaires du genre Andresna." Actes de la Société linnéenne de Bordeaux, vol. xl, 1886 .

F. Le Beddard, A Monograph of the order of Oligochata, 1895 . Giard, "La condition parasitaire" : Bulletin scientifique de la France et de la Belgique

J. Henri Fabre, Souvenirs d'un naturaliste, 10 vol. . . .

Edmond Perrier, "L'instinct": Lecture à la séance annuelle des cinq académies de l'Institut de France.

Holland, The Osteology of the Chalicotherida, 1914 . . .

Henry Filhol, "Mammifères fossiles de Ronzon": Annales des sciences géologiques, xii, 1881 . . . . .

Fiorentino Ameghino, Les formations sédimentaires . . .

Fiorentino Ameghino, "Etudes sur les vertébrés fossiles d'Issel ": Mémoires de la Société géologique, 1888 . .

Fiorentino Ameghino, "Recherches sur les phosphorites du Quercy": Annales des sciences géologiques, vols. vii and viii, 1876-7 .

Ch. Déperet, "L'Evolution des mammifères tertiaires": Comptes rendus de l'Académie des sciences, 1905-6.

Ch. Déperet, "Recherches sur la succession des faunes de vertebres miocenes de la vallée du Rhône": Archives du Musée d'histoire naturelle de Lyon, 1887-92

Albert Gaudry, Les enchainements du monde animal, 1878-83

Cope, Miscellaneous Memoirs: American Naturalist, Proceedings of Philadelphia Academy of Natural History, N.S. Geological Survey, 1877 onwards

G. Cuvier, Recherches sur les ossements fossiles du basin de Paris

Woldemar Kowalewsky, "On the osteology of the Hyopotamodæ": Philosophical Transactions, 1873 . .

H. F. Osborn and J. L. Wortmann, Fossil Mammals of the Wasatch and Wind Rivers. Bulletin of the American Museum of Natural History, 1922 . . . . .

H. F. Osborn and J. L. Wortmann, Fossil Mammals of the Loxer Miocene White River Beds. Ibid., 1894. . .

Scott and Osborn, "The Mammals of the United Formation": Transactions of the American Philosophical Society, 1889

R. Martin, Die Fossilien von Java auf Grund einer Sammlung von Java, 1891-1910

Dollo, "Globideus Fraseri, Mosasaurien mylodonte nouveau " and "L'ethologie de la nutrition chez les Mosasauriens": Archives de Biologie, 1913, vol. xxviii, pp. 618-62.

\section{LXXXVII \\ LXXXVIII}

L XXXIX

$\mathrm{XC}$

XCI

XCII

XCIII

\section{XCIV}

(Note.-This bibliography follows the general order of the chapters without being strictly classificd.) 


\section{INDEX}

Adaptation, 77

Africa , 23-6, 29, 48, 96, 157, 243, 282

Agassiz (Alex.), 148

Agassiz (Louis), 208, 230, 245

Age of the Earth, 31-3

Albuminoids, $63,67,70-2$

Algæ, 78, 96-8

Algonkian, 20, 22

Allantois, 180,185

Allmann, 195, 207

Alps, 17, 19, 26, 29, 30, 47, 49, 52

Alsace, 50

Altai, 17

Ameghino, 285, 316, 319

America, 13, 17, 21-3, 27, 29, 30, 32, $33,46,47,79,210,234,236,243$, $281,282,287,312,315$

Ammonites, 75, 161

Amnion, 180, 185

Ampère, 141

Amphineura, 136

Amphioxus, 79, 92, 125, 134, 142, $143,156,162,167,227$

Angiosperms, 101, 102, 111, 244

Animal Colonies, 126

Animal Heat, 46, 181

Annam, 17

Annelid, 124

Anthony, Dr., 247

Antilles, 74

Apennines, 17

Apalachian Mtns., 16, 24

Arabia, 22

Arachnida, 168, 169

Archæan, 20, 22

Aristotle, 304

Armogony, armogenesis. 93

Arrhenius (Svante), 5, 62

Artiozoa, 209

Arthropods, 123, 124, 130, 147, 209

Artois, 30

Asia, 13, 17, 22, 282, 315

Astronomical Year, 41

Atlantic, 22, 29, 30, 47, 49, 282

Atoms, 3, 4

Attitude, 126 ; ii, v

Attraction, 4

Australia, 13, 17, 24, 26, 28, 29, 47, $157,232,287,289$

Bacteria, 74, 97

Bajocia, 27

Balbiani, 86

Balbiano, 72

Balfour, 141
Baryspliere, 36

Barrande (J. de), 23

Bataillon, 79

Batracians, 46, 175-9, 182, 185, 236, 258

Beaumont (Élic de), 18

Becquerel, 62

Belgium, 25, 26, 4S

Benda, 332

Bernard (Claude), 60, 79, 255, 326

Berthelot (Daniel), 70

Berthelot (Marcellin), 61, 66

Birds, 181, 182, 192, 237, 238, 285, 286

Black Forest, 16, 25

Blainville, 76

Blandet, 44

Blaringhem, 104, 105

Blastoderm, 179

Blastomeres, 79

Blastopore, 115

Blastula, 115

Blavet, 103

Bode, 10

Bohemia, 17, 25

Bonnet (Charles), 76

Bordage, 103

Borneo, 27

Bosler, 44

Boule, 303, 319, 330

Bourquelot, 90

Bouvier, 140

Brachiopods, 219-22

Brazil, 24, 26, 28-30, 48

Bridal apparel, 218

Bridel, 90

Britain (Great) (British Isles), 22, 26, $28,29,48,50,51,53,281$

Brittany, 17, 29-31, 51, 281

Brongniart, 216

Brown-Séquard, 326

Bryozoa, 116

Buffon, 9, 95

Bunsen, 8

Burmeister, 395

Caledonian (chain), 16, 1s, 19, 34, 47. 52,239

Calyx, 102, 107

Cambrian, 20-47

Canada, 21, 23, 24, 26, 46

Cape (the), 26, 28, 46, 47

Carboniferous, $22,4 \mathrm{~s}$

Carbo-hydrates, 63-5, 67

Carnivora, 293, 303, 310 
Carnegie, 264

Carnot, 5

Carpels, 103

Carrel (A.), 79

Carribean Sea, 13, 28

Caspian, 26

Catkin, 102, 160

Cayeux, 204

Cells, 78, 117

Cellulose, 96, 242

Cetaceans, 148, 306, 308

Ceylon, 32

Channel (English), 23

Chatelier (de), 44

Chauvin (M. de), 355

China, 24, 26, 28, 29, 47

Chlorophyll, 67, 68, 97

Chromatin, 85

Claparède, 214

Clarke (J.), 205

Club mosses, 46, 48, 100

Coblentzian, 24

Coelom, 115

Cohn, 62

Comparative Anatomy, 133

Conifers, 45, 46, 111, 202

Cope, 295, 320

Copepods, 39,147

Corals, $20,45,47,50,120,121,148$, $152,208,209,245,246$

Cretaceous, 20, 21, 2S, 51, 244, 255, 278

Croll, 53

Crookes, 4

Crustaceans, 124, 126, 134, 150-5, $162,172,173,212-14$

Cryptogams, 46, 99, 100,102, 110 , $111,201,202$

Cuvier, $31,45,49,61,75,76,96,124$, $140,144,161,271,304,307,310$, $325,328,330$

\section{Dana, 208}

Dangard, 332

Darwin, 76, 131, 144, 190, 255-7, 314,326

Davaul, 103

David (A.), 46

Delage, 90

Demes, 117

Depéret, 269

Determinism, 60

Devonian, 20, 47

Diastases, 65

Dicotyledons, 51, 107, 108, 202, 203, 244,245

Dinantian, 24, 25

Discs (imaginal), 83

Dohrn (A.), 133, 143, 180

Dollo, 274

Douarnenez, 19, 35
Douvillé, $25,75,245,248$

Driesch, 79

Dubois, 320,331

Earthquakes, 35, 36, 40

Echinoderms, 122, 125, 126, 133-5, $147,222,240$

Ecliptic, 41, 54

Ectoderm, 115

Egypt, 300, 312, 320

Electrons, 4

Embryogeny, $77 \mathrm{ff} ., 91-3,114,115$, $123,133,176-81,183,184,204$, 328

Entomostraca, 124

Environment, 76, 84

Eocene, 20

Eogene, 20

Epirogenic (movements), 52

Equinoxes, 42, 43

Erzgebirge, 16

Ether, 3, 36

Europe, 13, 24, 53

Evolution, 75, 83, 314

Fabre (J. H.), 257

Fats, 63, 64

Fernandez (Mique1), 80

Ferns, 45, 46, 99-101, 110, 111, 201

Filhol, 307, 310, 311

Finland, 21, 22, 24, 52, 200, 241

Fischer, 71, 72, 140

Flowers, 102, 103, 107-10

Foraminifera, 26, 112, 204

Foucault, 8

France, 17, 22-6, 30, 31, 50-3

Frasnian, 24

Frauenhofer (lines), 8

Frich (F.), 226

Fuego, Terra del, 17

Fungi, 68, 69, 78, 96-8

Fusulina, 26

Gadow (H.), 275

Gastrula, 115

Gaudechon, 70

Gaudry (A.), 234, 237, 312, 314, 320

Gautier (A.), 66, 88, 195

Gegenbaur, 233

Geikie, 53

Geothermic (degrees), 34

Germany, 22, 24, 49, 53

Germen, 83

Giard, 93, 196

Glacial (climate), 34, 45, 46, 54; (periods), 19, 52, 53; (glaciers), $25,34,46-8,50,52,53$

Glands, 89, 167, 182, 184

Goethe (theory of), 111

Gondwana, 25, 27, 48, 49, 168, 210 , $236,289,311$ 
Gothlandian, 23

Grand'Eury, 101, 202

Gravier, 155

Greenland, 16, 21, 25, 26, 283

Grube, 214

Gymnosperms, 100-2, 110, 111, 202, 244

Haacke, 103

Haeckel, 39, 60, 91, 92

Hariot, 103

Harz, 16

Haug, 75, 226

Heer (O.), 284

Heinrichs, 10

Helium, 9, 32, 71

Helmholtz, 62

Herbivora, 292, 293, 299

Herbst, 80

Hercynian (chain), 16-19, 24, 25, 34, $47,4 \mathrm{~S}, 50,52,239,243$

Heredity, 83-5, 87, 89-92, 104, 126 , $145,160,185,186$

İermaphroditism, 160, 162-5

Himalaya, $17,19,29-30,34,47,52$

Hirn, 5

Histoblasts, 83

Hitchcock, $26 \tilde{j}$

Holland (Professor), 264, 307

Holland, 25

Holothurians, 127, 149, 150

Horns, 304-6, 313

Houssay, 227

Hugo (Victor), 214

Iluronian (chain), 16, 19, 21, 39, 239

Huxley, 60, 66, 266

Hydra, 79, 116-20, 206

Hyponomeutitæ, so

Independent Creations, 75

India, 22, 24-6, 29, 47, 48, 315, 320

Indo-China, 17, 22, 26

Infusoria, 113, 114, 204

Inostranzeff, 201

Insects, 171-4, 213, 215-8, 254-8

Instincts. 255-8, 280

Intelligence, $280,322,323$

Italy, 22, 25, 26, 29

Janssen, 8

Japan, 22, 52, 74

Jehring (von), so

Joly, 59

Jonle, 5

Jurassic, 20

Kayser (E.), 226

Kelvin (Lord), 32, 44, 62

Kent (Saville), 246

Keyserling, 61

King, 262

Kirchoff, 8
IKlein, 103

Korca, 22

Kossel, 71

Kowalevsky (N.), 296, 303

Künckel d'Herculais, 83

Labitte, 218

Lacaze-Duthiers, 208

Lamarck, 31, 59, 95, 131, 134, 144 , $184,219,299,314,320,325$

Lamy, 169

Lang (A.), 137, 138

Laplace, 6,9

Lartet, 307, 320

Lcaves, 99-100

Leibnitz, 76

Lefebvre, 46

Lemoine, 310

Light, 3

Lignier, 110

Limbs, 293-9

Iithosphere, 35

Locomotion, 121-3

Lyell (Sir Charles), 95

MacLeod, 168, 169

Madagascar, 22, 26, 28, 29, 48, 282, 283

Maillard, 71, 72

Malaya, 17, 26

Mammals, 182-6, 192, 259-60, 278, $280-2,286-316$

Mammoth, 4.5, 53

Marchal, 80

Marion, $20 \mathrm{~s}$

Mating (plumage, etc.), 89, 218

Matter, 3, 4

Maupas, 163

Mayer, 5

Mediterianean, 13, 22, 28, 54, 282

Medusæ, 119-20

Mendeleef, 4

Mercerat, 285

Merids, 116, 11S-21

Meseta, 17, 29, 281

Metamorphosis, 15

Mcunier (Stan.), 35

Milne-Edwards, 214, 286

Mimetism, 147

Miocene, 20

Mollısca, 51 , 74, 125, 126, 128, 136-40, $147,156,223,225-7,240,246-50$

Monocotyledons, 51, 109, 110, 245

Mnnlivault (de), 61

Morenco, 285

Morgan (de), 79

Morse, 219, 220, 260

Moseley, 208

Mosjisowicz (von), 75, 226

Mlosses, 98-100, 110, 201

Movement, 4, 5, 40, 45 
Munier-Chalmas, 225, 250

Musset, 59

Myriapods, 213, 214

Naudin (C.), 195

Natural Selection, 76, 190

Nauplii, 124

Nebulum, 6

Nematodes, 163

Nervous System, 140-3, 321

Neumayer, 27, 75, 245

Nutrition, 65

Oken, 60,68

d'Orbigny (A.), 75

Orbit, 41,54

Organic Chemistry, 66

Orogenesis, 19

Osborn (H. F.), 309

Owen, 290

Pacific (ocean, continent), 17, 21, 22, $24,243,245,283$

Pasteur, 59, 61, 325

Patrogony, 92

Perez (J.), 196

Pereyaslawzeva (Marie), 168

Peridot, 35

Permian, 20

Perrin, 332

Petchili, 17

Pézard, 327

Placenta, 184, 288, 289

Plankton, 39

Plasma, 83

Plastids, 78, 112, 117

Pleistocene, 20

Pliocene, 20, 53, 75

Poincaré (H.), 11

Poles, 13, 16, 40, 41, 47, 55

Pollen, 102

Polyps, 116, 121, 208, 239

Portier, 332

Portlandian, 27

Pouchet, 59

Preadaptations, 133, 152, 156, 165 , 173,194

Preyer, 62

Primordial slime, 60

Primates, 288, 317-21

Protoplasm, 60

Quatrefages (de), 118, 214, 319

Radiolaria, 112, 204, 240, 246

Radium, 3, 31, 32

Rayleigh (Lord), 4, 36

Renaud (B.), 202, 242

Reproduction, 65

Reptiles, 131, 186, 187, 237-9, 258, $259,261-75,278-80,299,304$
Respiratory Apparatus, 165-70, 174

Rhizopods, 113

Richter, 62

Riesengebirge, 16

Roche, 36

Rodents, 300, 303, 309, 315

Röntgen rays, 4

Romanes, 255, 257

Ruedemann, 207

Ruminants, 304-6, 311

Russia, 22, 24, 25, 27, 49, 53, 239, 243

Sahara, 24, 25, 28

Saint-Hilaire (Geoffroy), 76, 91, 143, $175,306,323$

Saint-Hilaire (Etienne Geoffroy), 94, 141,327

Saintonge, 19

Salles-Guyon, 62

Savigny, 133

Scandinavia, 16, 21, 22, 24-6, 28, 47, 53

Schulze (F. E.), 230

Schützenberger, 71

Scotland, 16, 25, 26, 28, 281

Secondary (Period), 19, 20, 50 ; III, 2,276

Semper, 78

Serre (A.), 91

Sex, 87, 89, 95, 102-5, 328, 329

Siberia, $16,21,22,24,27-9$

Silesia, 25,26

Silurian, 20, 47

Social (life), 77

Spain, 17, 22, 25, 29, 30, 243

Spawning, 157, 178

Spegazzini, 103

Sponges, 116, 152, 204, 205, 239

Spontaneous Generation, 59, 61

Spores, 62, 70, 99

Stamens, 101, 102, 107, 108

Stratigraphy, 18

Structure (types of), 125, 126, 133, 138,139

Struggle for Existence, 190

Strutt, 32

Sudden Variations, 195

Suess, 23, 25

Sun Spots, 40

Switzerland, 50, 52

Synclines, 16

Tachygenesis, 82, 93, 94, 176, 178, $190,202,235,241,327$

Tactism, 135, 255

Tectonics, 18

Teeth, 259, 260, 289-91, 299-306, $308,309,318,319$

Telegony, 186

Ternary (Compounds), 63

Tertiary, 19, 20

Theromorpha, 259, 260 
Tethys, 25, 27-9, 51, 212, 245, 282

Thévenin, 239

Tieghem (van), 62, 203

Trasciatti, 72

Trembley, $79,116,117$

Triasic, 20, 27, 260, 286

Trilobites, 46, 124, 211-14, 231-33, 240

Tyndall, 5

United States, 16, 23, 27

Vejdowsky, 164

Vermes, 116, 124

Vertebrates, $123,125,126,129,133$, $141-3,145,174,177,181,185$, $227-39,258-80,284$

Violle, 44
Viré, 151

Vitalism, 60

Viviparity, 189

Volcanoes, 17, 243

Volition, 299,318

Vosges, 17, 25, 51

Vries (De), 195

Weismann, 83, 87

W'ertheim, 36

Westphalian deposits, 24

Wings, 171-4, 192, 292

Worms (Annelid), 123, 124, 126, $134-6,140,145,161,163-6,206$, 218,235

Worms (Flat), 159, 164

Zoids, 117 






$-8 \times-8$

$8 \times 18$ 